\title{
CARBON PARTITIONING IN NITROGEN-FIXING ROOT NODULES
}

\author{
Dissertation \\ zur Erlangung des Doktorgrades \\ der Mathematisch-Naturwissenschaftlichen Fakultäten \\ der Georg-August-Universität zu Göttingen
}

vorgelegt von

Maria Schubert, geb. Ramenskaia

aus St. Petersburg, Russland

Göttingen 2002 
D 7

Referent: Prof. Dr. Hans-Walter Heldt

Korreferentin: Prof. Dr. Christiane Gatz

Tag der mündlichen Prüfung: 30.10.2002 


\section{Content}

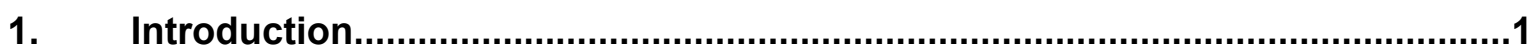

1.1. Degradation of sucrose in sink organs ....................................................... 1

1.1.1. The role of sucrose in the plant cell ........................................................... 1

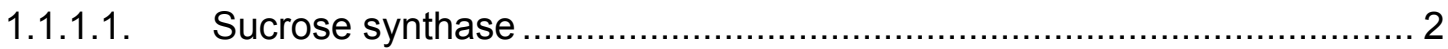

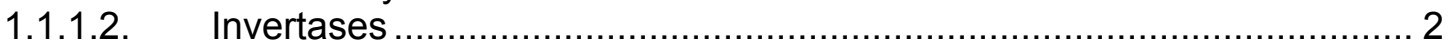

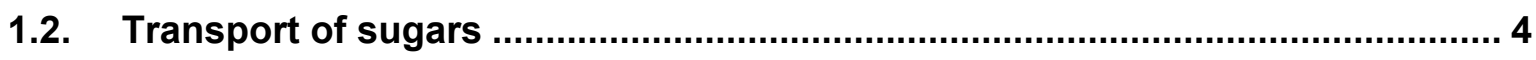

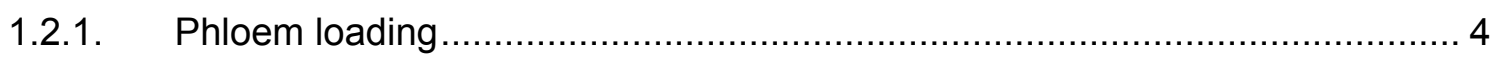

1.2.2. Phloem unloading and post-phloem transport......................................... 5

1.2.2.1. Symplastic sugar transport .................................................................. 5

1.2.2.2. Apoplastic phloem unloading and post-phloem transport....................... 6

1.2.2.3. Sugar transporters in apoplastic sugar transport................................. 7

1.3. The regulation of phloem unloading and sink strength in different systems .. 9

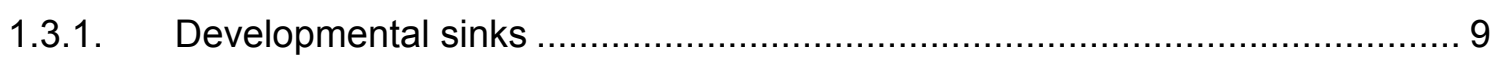

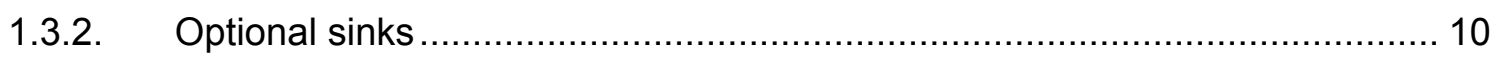

1.4. Nitrogen-fixing root nodule symbioses …..................................................... 10

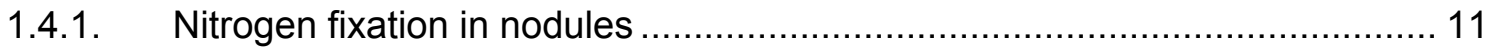

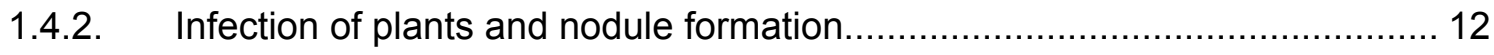

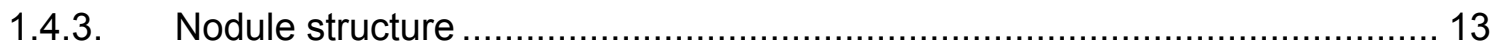

1.4.4. Phylogenetic relationship of root nodule symbioses................................. 15

1.4.5. Carbon sources supplied by the host plant to nitrogen-fixing microsymbionts..

1.4.6. Carbon transport and metabolism in nitrogen-fixing root nodules ............... 17

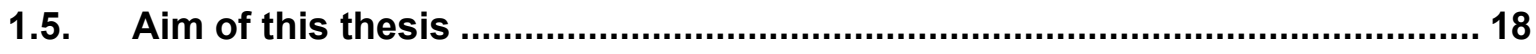

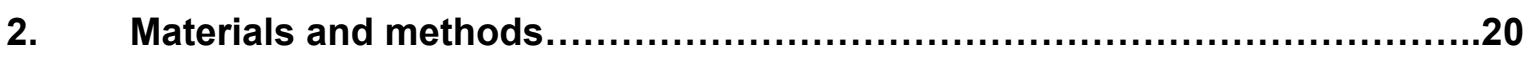

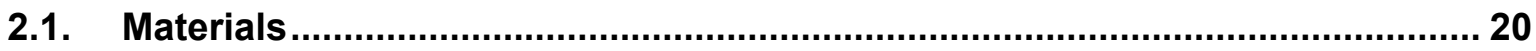

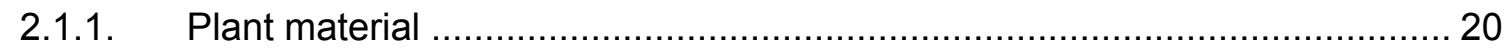

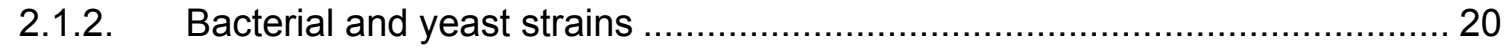

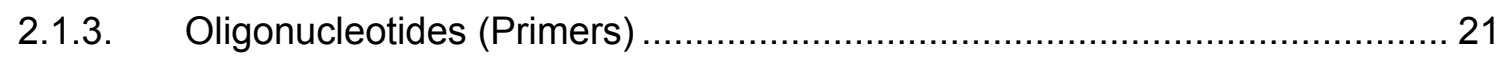

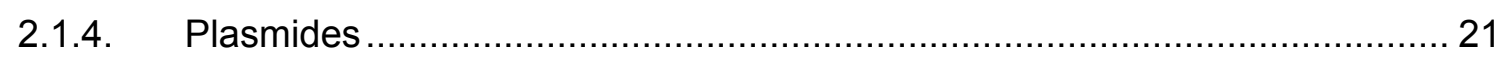

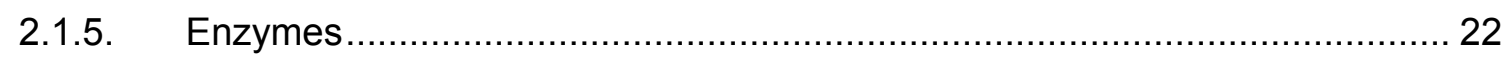

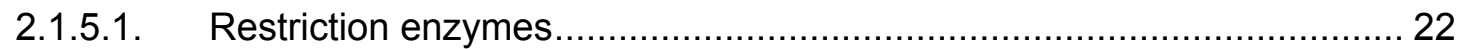

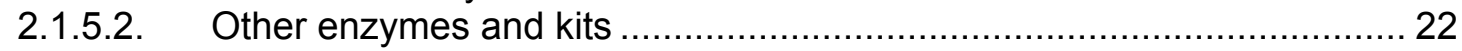

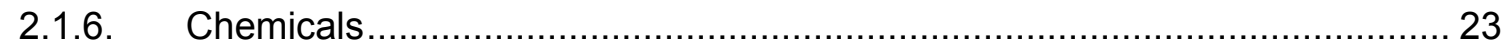




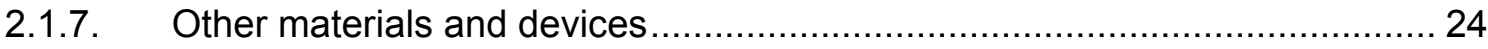

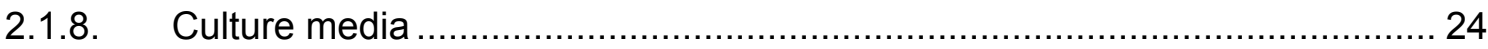

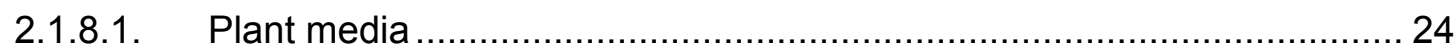

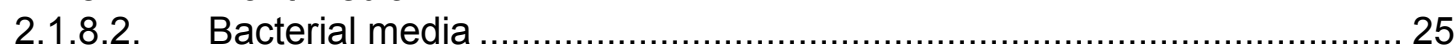

2.1.8.3. Media for Saccharomyces cerevisiae .............................................. 27

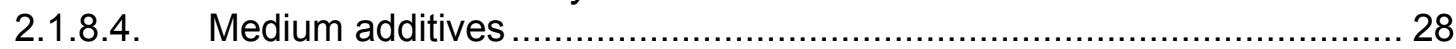

2.2. Plant culture methods and growth conditions .......................................... 28

2.3. RNA isolation from plant tissue

2.3.1. RNA isolation from Medicago truncatula and Datisca glomerata (modified after Burgos et al., 1995) ...................................................................... 29

2.3.2. RNA isolation from Casuarina glauca...................................................... 30

2.4. Isolation of plasmid DNA from bacteria and yeast ......................................... 31

2.4.1. Plasmid mini-preparation protocol „, Triton Boiling“....................................... 31

2.4.2. Mini preparation of bacterial plasmid DNA for the sequence analysis .......... 31

2.4.3. Maxi preparation of bacterial plasmid DNA ….......................................... 32

2.4.4. Preparation of plasmid DNA from yeast ............................................. 32

2.5. Concentration and purification of DNA or RNA solutions .............................. 32

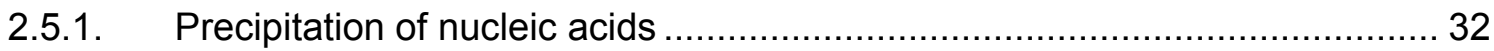

2.5.2. Phenol-chloroform extraction and precipitation of DNA ............................ 33

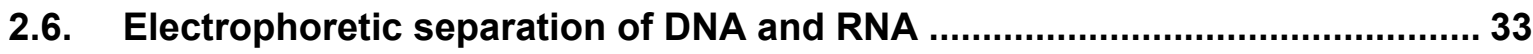

2.6.1. TEA-Agarose gel electrophoresis......................................................... 33

2.6.2. Separation of RNA on agarose gel for Northern blots ................................. 34

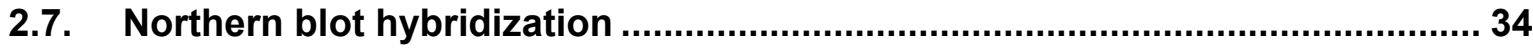

2.7.1. RNA transfer to nylon membranes (Northern blotting) .............................. 34

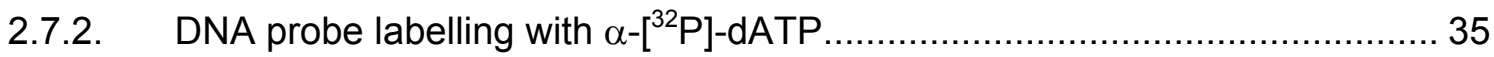

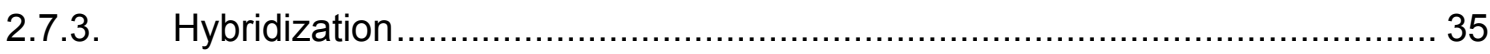

2.8. First strand cDNA synthesis (Reverse transcription) .................................... 36

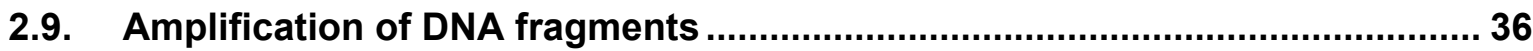

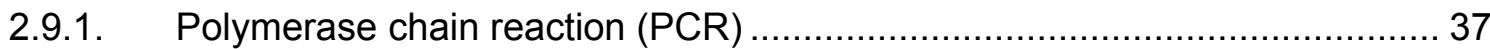

2.9.2. Design of synthetic oligonucleotide primers ............................................ 37

2.10. Rapid amplification of cDNA ends (RACE): 5 '-RACE ................................... 38

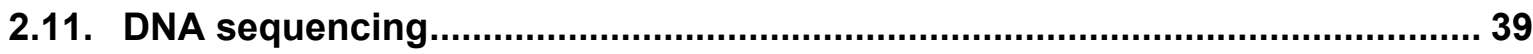

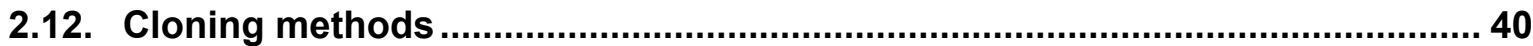

2.12.1. Digestion with restriction enzymes ....................................................... 40

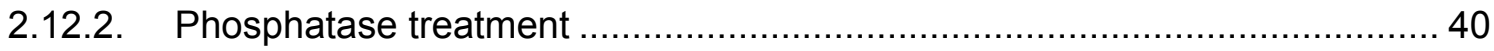

2.12.3. Filling-in of $5^{\prime}$ overhanging ends with Klenow fragment ........................... 41 
2.12.4. Isolation of DNA fragments from agarose gels ...................................... 41

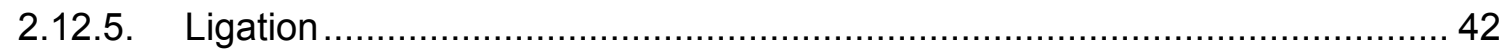

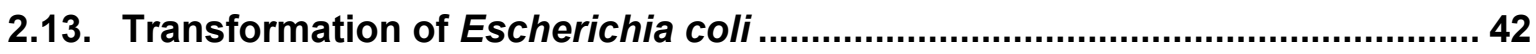

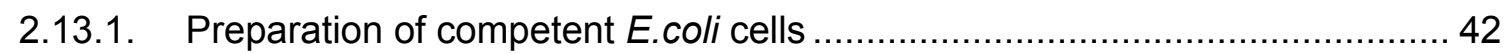

2.13.2. Transformation of competent E.coli cells............................................... 43

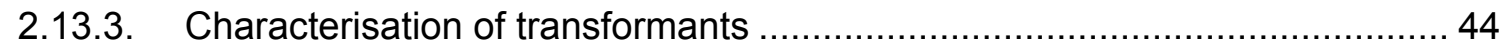

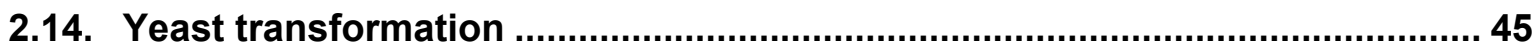

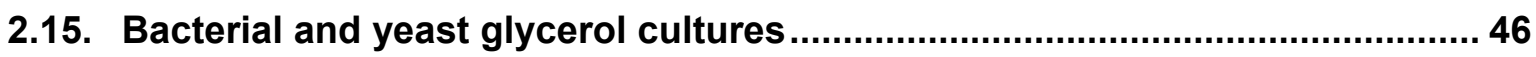

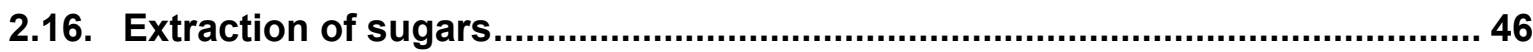

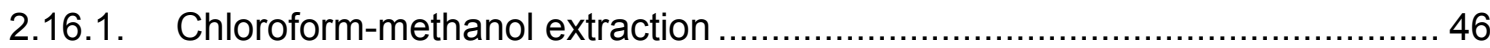

2.16.2. Preparative isolation of unknown sugars / sugar derivates from Datisca ...... 47

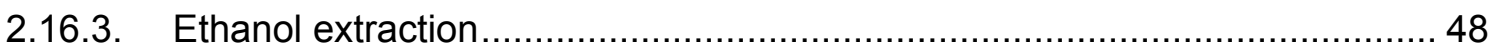

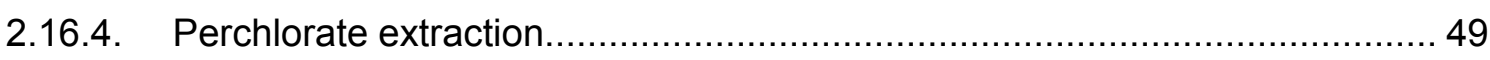

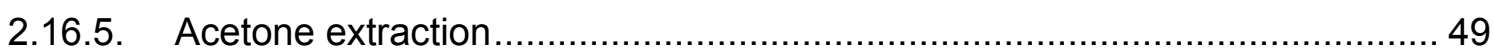

2.17. Sugar analysis by high-performance liquid chromatography (HPLC) ............ 49

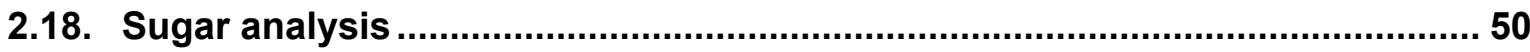

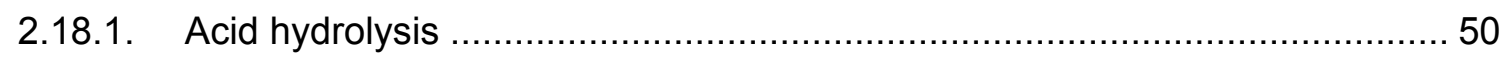

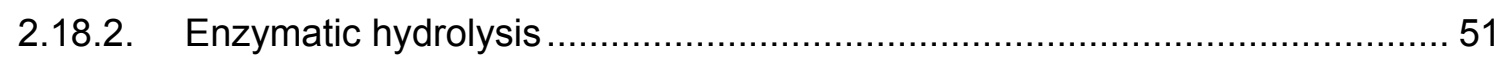

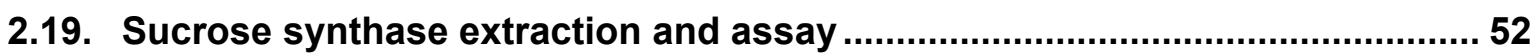

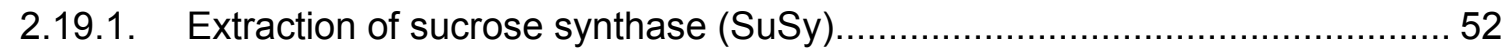

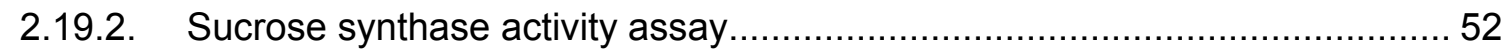

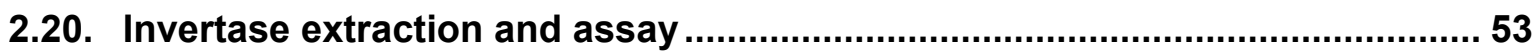

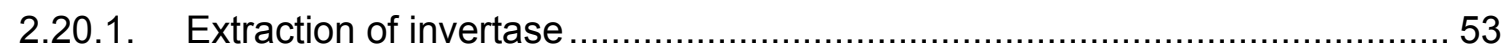

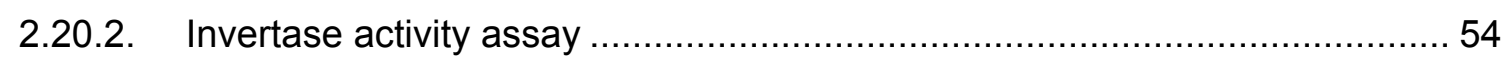

2.21. In situ glucose and acid (apoplastic) invertase activity staining ................... 55

2.22. Total protein isolation from plant material ................................................... 55

2.23. Bradford protein concentration determination .......................................... 56

2.24. Sodiumdodecyl sulfate polyacrylamide gel electrophoresis (SDS-PAGE).... 57

2.24.1. Buffers and solutions for analytic SDS-PAGE ...................................... 58

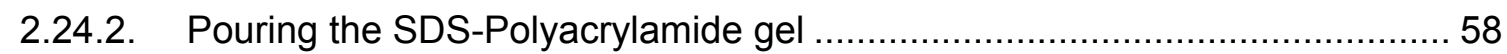

2.24.3. Probe preparation and SDS polyacrylamide gel electrophoresis (SDS-PAGE) 60

2.24.4. Coomassie staining of SDS polyacrylamide gels .................................. 60

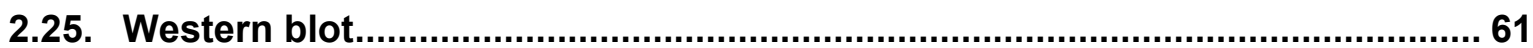




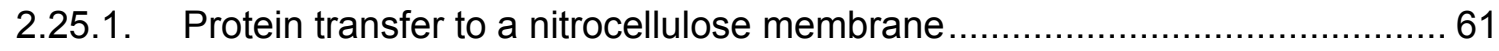

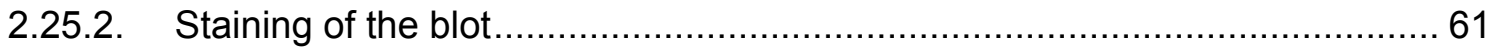

2.25.3. Immunological detection of transferred proteins...................................... 62

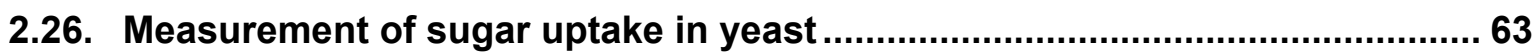

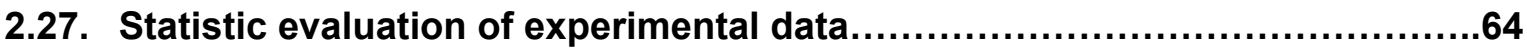

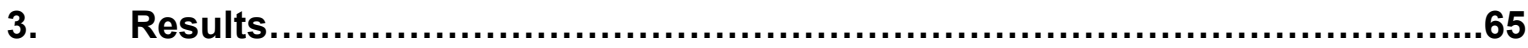

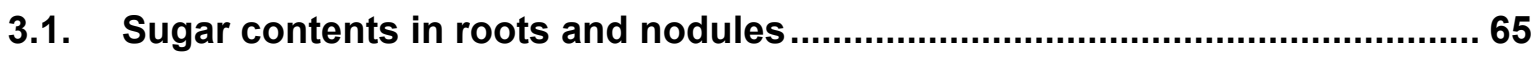

3.1.1. Sugar contents in roots and nodules of Medicago truncatula........................ 65

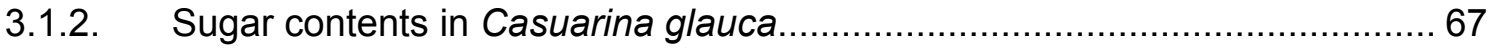

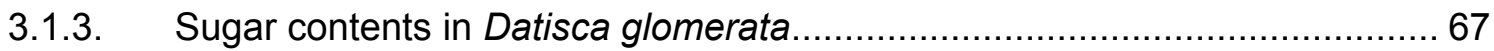

3.1.3.1. Isolation and characterization of two unknown carbohydrates from Datisca glomerata...................................................................... 67

3.1.3.2. Sugar contents in roots, nodules and leaves of Datisca after determination of the molecular mass of the novel sugars .................... 74

3.2. Activities of sucrose cleaving enzymes in roots and root nodules ............... 75

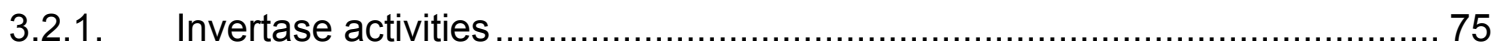

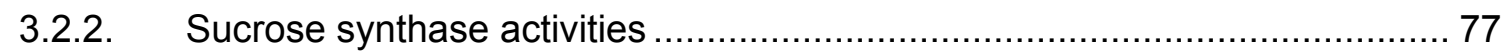

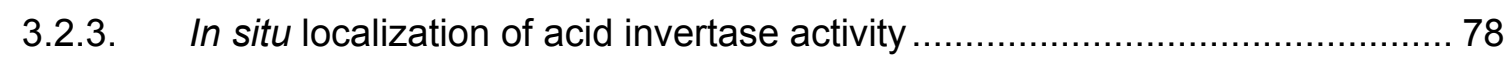

3.2.3.1. In situ localization of glucose in roots and nodules ........................... 79

3.2.3.2. In situ localization of acid invertase in roots and nodules ...................... 79

\subsection{Expression levels of sucrose synthase and sugar transporters in roots and} nodules.

3.3.1. Expression levels of sucrose synthase (RNA gel blot hybridization analysis)82

3.3.2. Levels of sucrose synthase protein (Protein blot analysis) ......................... 83

3.3.3. Expression levels of sugar transporters in roots, nodules and leaves........... 84

3.4. Isolation and characterization of hexose transporter cDNAs ......................... 85

3.4.1. Full size cDNA of the Medicago truncatula hexose transporter (MtHT) ........ 85

3.4.2. Full size cDNA of the Datisca glomerata hexose transporter (DgHT) ........... 88

3.4.3. Protein sequence analysis of DgHT and MtHT ....................................... 91

\subsection{Functional characterization of the hexose transporters by expression in yeast} 94

3.5.1. Construction of shuttle vectors for the heterologous expression of MtHT and

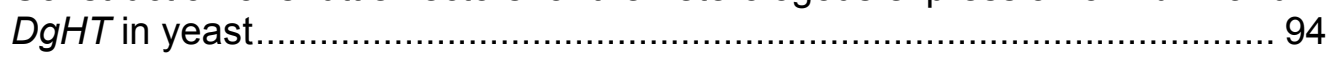

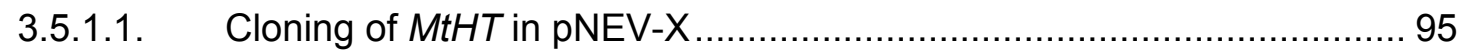

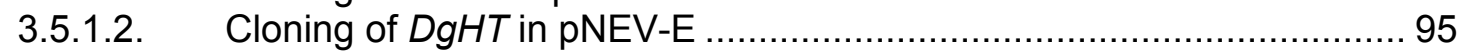

3.5.2. Sugar uptake studies with yeast strains expressing MtHT and DgHT.......... 95

3.5.2.1. Functional characterization of MtHT ................................................ 97

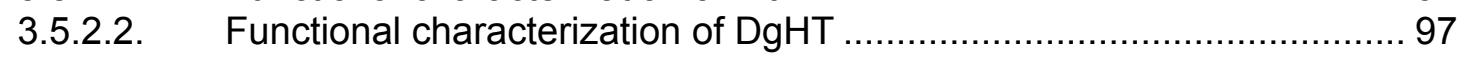


4. Discussion

4.1. Cytological information on putative mechanism of carbon transport in root nodules.

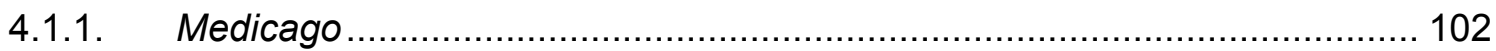

4.1.2. Cytology of roots and nodules of Datisca glomerata ................................. 102

4.1.3. Cytology of roots and nodules of Casuarina glauca ................................. 103

4.2. Expression levels and patterns of hexose transporter genes in roots and

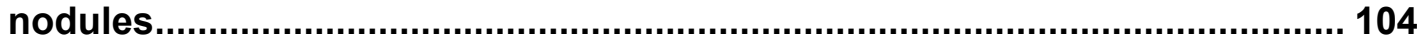

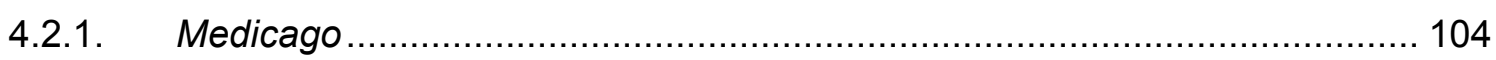

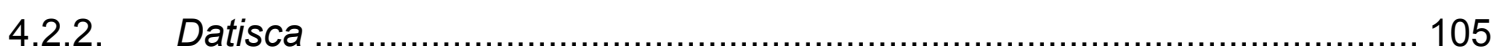

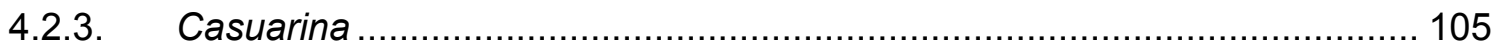

4.3. Activities and localization of sucrose degrading enzymes in roots and

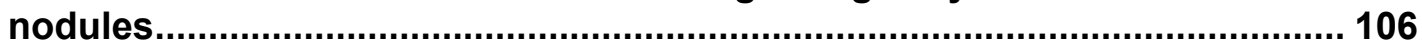

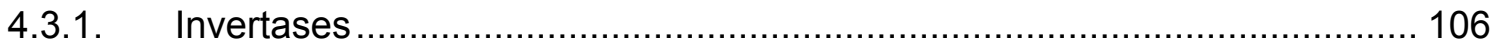

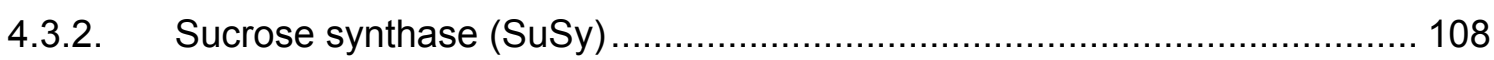

4.4. The Datisca nodule paradox: hexose transporter expression in the absence of apoplastic invertase activity. Could hexoses be the carbon sources for symbiotic Frankia in Datisca nodules? ........................................................ 111

4.5. Hexose transporters from nodules............................................................ 112

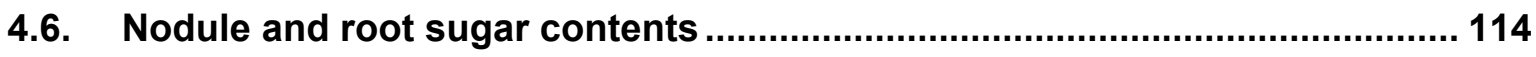

4.6.1. Sucrose, glucose and fructose in nodules and roots ................................ 114

4.6.2. Datisca contains novel non-structural rhamnosyl saccharides................... 116

4.6.2.1. Free rutinose and methylrutinose are found in Datisca sugar extracts 116

4.6.2.2. Possible ways of rutinose and methylrutinose synthesis.................... 117

4.6.2.3. Are rutinose and methylrutinose carbon storage or transport forms?.. 118

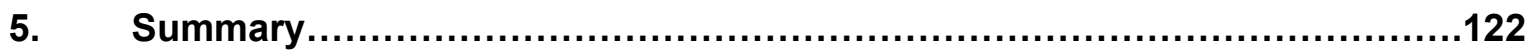

6. Abbreviations...................................................................... 124

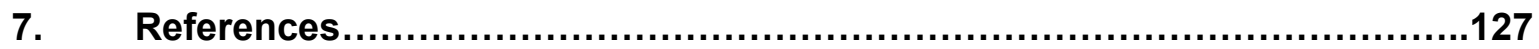




\section{Introduction}

One of the key features of plants is their ability to reduce carbon dioxide to sugars in the presence of sunlight and water as well as the subsequent transport of assimilated carbon to non-photosynthetic tissues. Partitioning of photosynthetic assimilates among organs is a critical process in plant development. Based on their ability/need to either produce or import assimilates, plant organs are classified as sources (photosynthetically active leaves and, to a less extent, shoots) or sinks. There are two types of sink organs/tissues developmental, such as roots, tubers, flowers, seeds and fruits, and optional, like pathogen infection sites, e.g. tumours induced by Agrobacterium tumefaciens, or symbiotic structures, e.g. nitrogen-fixing root nodules induced by symbiotic nitrogen-fixing bacteria. The subject of this thesis is the study of sugar partitioning mechanisms in one type of optional sinks, namely nitrogen-fixing root nodules. Phloem unloading, postphloem transport and the utilisation of sucrose, the main transport sugar of plants, are compared in nodules (optional sinks) and roots (developmental sinks).

\subsection{Degradation of sucrose in sink organs}

\subsubsection{The role of sucrose in the plant cell}

The major part of the organic carbon produced during photosynthesis is channelled into the synthesis of sucrose. Sucrose is a highly soluble sugar which can attain considerable concentrations without an apparent inhibitory effect on most biochemical reactions in the cell. This capacity makes sucrose a useful component contributing to the regulation of osmotic pressure and flow of water between cellular compartments. Sucrose can be transported across biological membranes, such as the plasmalemma and the tonoplast (reviewed by Sauer and Tanner, 1993). Being neutral, it does not interact electrostatically with other charged molecules in the cell. As a nonreducing molecule, it is relatively inert from interactions with other functional groups, particularly primary amines and oxidizing agents encountered in the biological milieu. The free energy of hydrolysis of sucrose is close to that of the $\gamma$-phosphoryl group of ATP. Therefore, the metabolic utilisation of the a-glucosyl moiety in sucrose is much more efficient in energy conservation than most other glycosides. As a major transportable metabolite in the plant, sucrose is delivered from the photosynthetic tissues to all plant organs, there to serve as source of organic carbons for building permanent structural elements and as metabolic fuel for the energy 
production. A large portion of the sucrose itself may accumulate and can be stored at high concentrations in sink organs, e.g. sugar beet (Saftner et al., 1983).

Utilization of sucrose as a source of carbon and energy depends on its cleavage into hexoses, and in plants this reaction is catalysed either by sucrose synthase (EC 2.4.1.13) or by invertase (EC 3.2.1.26).

\subsubsection{Sucrose synthase}

Sucrose synthase (SuSy) is recognized as an important enzyme of sucrose utilization in plant sink tissues (Ho, 1988). In spite of its name, SuSy is not active in sucrose biosynthesis in vivo, but in degradation. SuSy is a homotetrameric enzyme consisting of 92 to $93 \mathrm{kDa}$ subunits and catalyses the reversible, UDP-dependent cleavage of sucrose into UDP-glucose and fructose in a variety of plant sink tissues such as tubers, developing leaves and seeds, and root nodules. The resulting UDP-glucose (or glucose-1-phosphate) and fructose are used in various important metabolic pathways, including glycolysis, starch biosynthesis, and the synthesis of cellulose and callose (Delmer and Amor, 1995; Verma and Hong, 2001).

The highest activity of SuSy often occurs during rapid growth (e.g. in elongating maize leaves; Nguyen-Quoc et al., 1990) or during storage product deposition (e.g. in developing seeds; King et al., 1997). SuSy is a globular protein and generally considered to be a soluble cytosolic enzyme. However, a certain fraction of the enzyme was found to be associated with the plasma membrane (Amor et al., 1995; Carlson and Chourey, 1996), perhaps in a specific complex with the integral membrane protein glucane synthase (Verma and Hong, 2001). There is evidence suggesting that reversible phosphorylation of SuSy at Ser-15 (Huber et al., 1996) may control the binding to the plasma membrane, with the dephosphorylated enzyme being primarily associated with the membrane (Winter et al., 1997).

\subsubsection{Invertases}

Invertases (EC 3.2.1.26; $\beta$-fructosidases) catalyse the irreversible hydrolysis of sucrose to glucose and fructose. Three different types of invertase have been identified that are characterized by their intracellular location, $\mathrm{pH}$ optima and isoelectric points (Avigad, 1982), namely vacuolar, apoplastic and cytosolic.

Most plant species contain at least two isoforms of vacuolar invertase, which represent soluble proteins (soluble acid invertases) in the lumen of this acidic 
compartment (Sturm, 1999). Also, several isoforms of extracellular invertase (cell wall invertases, apoplastic invertases) have been detected that are ionically bound to the cell wall (Sturm, 1996; Tymowska-Lalanne and Kreis, 1998). Vacuolar and cell wall invertases share some biochemical properties, e.g. they cleave sucrose most efficiently between $\mathrm{pH}$ 4.5 and 5.0 and attack the disaccharide from the fructose residue. Thus, these so-called acid invertases are $\beta$-fructofuranosidases and also hydrolyze other $\beta$-fructose-containing oligosaccharides such as raffinose and stachyose. Additionally, plants have at least two isoforms of cytoplasmic invertase with $\mathrm{pH}$ optima for sucrose cleavage in the neutral or slightly alkaline range. Neutral and alkaline invertases are less well characterized but, in contrast to the acid invertases, these enzymes appear to be specific for sucrose (Sturm, 1999).

The following functions have been proposed for invertases:

- $\quad$ provision of the cells with substrates for respiration and with carbon skeletons for biosynthetic metabolism

- $\quad$ regulation of long-distance transport of sucrose by generating a sucrose gradient between source and sink tissues

- $\quad$ regulation of cell elongation, because the invertase reaction products, glucose and fructose, increase the osmotic pressure of cells

Different functions have been assigned to the different isoenzymes. High activity of an extracellular invertase is usually associated with rapidly growing tissues, and it has been suggested that this invertase is important for phloem unloading (Eschrich, 1980) and for determining sink strength (Ho, 1988). The role of extracellular invertase for sink/source regulation and sink metabolism is supported by a study on cultured cells of Chenopodium rubrum: the enzyme activity and mRNA levels of apoplastic invertase increased when heterotrophic metabolism was induced in photoautotrophic suspension culture cells (Roitsch et al., 1995).

The developmental functions of different invertases are reflected by their expression patterns. The analysis of isoform-specific steady-state transcript levels of five genes for acid invertases in carrot showed markedly different expression patterns specific for organ and stage of development (Sturm et al., 1995). Similar results were obtained for tomato (Godt and Roitsch, 1997). In addition to the organ- and development-specific regulation of gene expression, alterations in sugar composition and concentration markedly affect the expression of some of the acid invertases. In maize, $\mathrm{Xu}$ and coworkers (1996) identified two gene classes for soluble acid invertase with contrasting sugar responses. One class is up-regulated by increasing carbohydrate supply, whereas the second class in the same gene family is repressed by sugars and up-regulated by depletion of this resource. In contrast, in suspension cells of Chenopodium rubrum, the 
expression of soluble acid invertase was not affected by sugars, whereas the expression of cell wall invertase was enhanced (Roitsch et al., 1995). Acid invertases are also regulated by plant hormones, wounding and in response to pathogen infection (Ehneß and Roitsch, 1997; Rozenkranz et al., 2001; Sturm, 1999).

Another factor that has to be taken into account regarding invertase activities is the existence of specific inhibitors. A proteinaceous inhibitor of $17 \mathrm{kDa}$, inhibiting cell wall invertase in vitro, was isolated from a suspension culture of tobacco (Weil et al., 1994), and related amino acid sequences were also found in other plant genomes. A purified invertase inhibitor could also inhibit vacuolar acid invertase activity in vitro, but since the inhibitor is located in the apoplast in vivo, it should only be able to interact with the cell wall enzyme (Sander et al., 1996). Binding of the inhibitor to cell wall invertase is necessary but not sufficient for inhibition of catalytic activity. Thus, even though the two proteins are associated, for example, during a 40-d culture period of tobacco cells, the inhibition of invertase activity is only apparent during the later stages of the culture (Krausgrill et al., 1998). The inhibitor protein binds to the invertase and inhibits it at very low concentrations of sucrose. Thus, it is possible that this system protects the plant cell from sucrose exhaustion during sugar starvation. A vacuolar invertase inhibitor has been identified as well (Greiner et al., 1999).

\subsection{Transport of sugars}

\subsubsection{Phloem loading}

Long-distance transport of carbohydrates occurs in the phloem and is driven by differences in solute concentrations and osmotic potentials (Ho, 1988). In most plants, the most abundant carbon compound in the phloem is the disaccharide sucrose (Zimmermann and Ziegler, 1975). However, for a minority of plant species, the main translocated sugars fall into two groups, the sugar alcohols (mannitol and sorbitol) and oligosaccharides of the raffinose family (raffinose, stachyose and verbascose; Zamski and Schaffer, 1996). When such unusual carbohydrates predominate, sucrose is present as well. In dicotyledonous plants, a correlation between sugar types transported in the phloem and the anatomy and type of companion cells in minor veins, where phloem loading takes place, was demonstrated (Gamalei, 1984). Plants transporting mainly members of the raffinose family of oligosaccharides or sugar alcohols contain abundant symplastic connections between companion cells and bundle sheath cells, while plants transporting mainly sucrose show scarce or no symplastic connections. It is concluded that sucrose is transported into the companion cell-sieve element complex apoplastically 
via membrane transporters, while unusual carbohydrates are transported symplastically via plasmodesmata. Thus, based on their companion cell anatomy and their transport sugars, plants can be classified as apoplastic or symplastic phloem loaders, respectively. As a rule, phloem loading mechanisms are specific to plant families.

Interestingly, most symplastic phloem loaders represent woody plants, while amongst apoplastic phloem loaders herbaceous species dominate (Gamalei, 1984).

\subsubsection{Phloem unloading and post-phloem transport}

At the sink end of the phloem path, assimilates move from the sieve element-companion cell complexes to the sites of utilisation/storage of carbohydrates (phloem unloading). In most sinks, phloem unloading occurs symplastically, but in some cases this is interrupted by an apoplastic step (Patrick, 1997). The same mechanisms are applied for the transport of nutrients from cell to cell within tissues.

In constrast to phloem loading mechanisms, phloem unloading mechanisms are not specific for plant families. Unloading mechanisms can depend on the type of plant sink organ and on the developmental stage of the plant/organ. For example, during the elongation phase of potato stolon growth apoplastic sucrose unloading predominates, while during the first observable phases of tuberization a transition from apoplastic to symplastic phloem unloading occurs (Viola et al., 2001). Also during tomato fruit development, the mechanism of sucrose unloading is not constant. During the first stage of development, 0 to 35 days after anthesis, sucrose is unloaded symplastically through numerous plasmodesmata (N'tchobo et al., 1999). Later the symplastic connections are lost, and, sucrose is unloaded apoplastically (Ruan and Patrick, 1995).

\subsubsection{Symplastic sugar transport}

Sucrose can be transported symplastically via plasmodesmata (Figure 1.1; for review see Patrick, 1997). A diffusive efflux of assimilates from sieve elements to sink tissues, or from one sink tissue cell to another is driven by concentration differences of assimilates between both tissues/cells. Metabolism and intracellular compartmentation determine the cytoplasmic concentrations of sucrose in the sink cells. In sucrose-storing sinks, active vacuolar accumulation by a tonoplast sucrose $/ \mathrm{H}^{+}$antiporter (Greutert and Keller, 1993) could function to sustain low cytoplasmic sucrose concentrations that favour phloem unloading. Such a mechanism would depend on osmotic adjustment between the cytoplasm and vacuole to prevent vacuolar swelling. In contrast, for hexose utilizing or 
starch storing sinks, sucrose metabolism appears to play a more prominent role in governing phloem unloading through regulating sucrose levels in the cytoplasm (Stitt and Sonnewald, 1995). In this case, transport into intracellular compartments by facilitated diffusion is driven by cytoplasmic levels of metabolites resulting from sucrose hydrolysis. Thus, sucrose synthase (SuSy) activity in the cytosol of sink cells can determine the sink strength (Patrick, 1997).
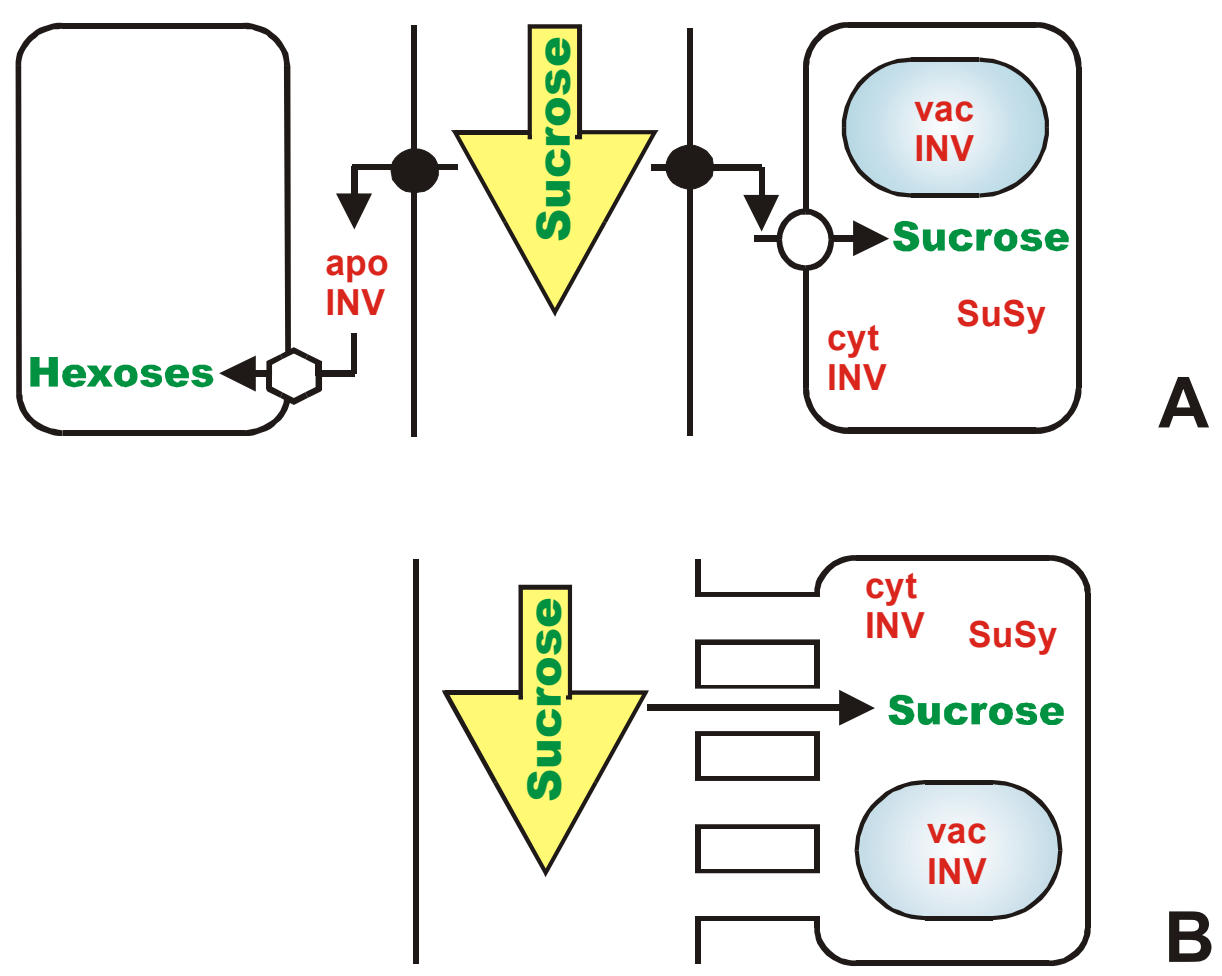

Figure 1.1. Phloem unloading mechanisms. (A) Apoplastic sugar transport. Sucrose is exported by an as yet uncharacterized sucrose efflux transporter (black circle) from the phloem into the apoplast, where it can be taken up via a sucrose transporter (open circle) directly into the sink cell, or it is hydrolysed by apoplastic invertase (apoINV) and is taken up into the sink cell in the form of hexoses via a hexose transporter (open hexagon). vacINV - vacuolar invertase; cytINV - cytosolic invertase; SuSy - sucrose synthase. (B) Symplastic phloem unloading occurs via plasmodesmata directly into the sink cell where sucrose is introduced into cell metabolism via cleavage by sucrose synthase, cytosolic or vacuolar invertase.

\subsubsection{Apoplastic phloem unloading and post-phloem transport}

According to the model proposed for apoplastic phloem unloading (Eschrich, 1980), sucrose is released from the phloem into the apoplast via sucrose efflux transporters, which have been postulated to function as facilitators or as proton antiporters (Walker et al., 1995). In the apoplast of sink tissues, sucrose can either be taken up directly into sink 
cells by sucrose transporters in the plasma membrane, or hydrolysed into glucose and fructose by apoplastic invertase. The hexoses produced are taken up by the sink cells via monosaccharide transporters in the plasma membrane (Figure 1.1; Büttner and Sauer, 2000). Thus, in case of apoplastic phloem unloading, the sink strength is determined by the activity of apoplastic invertase, and the amount and activity of plasma membrane sugar transporters.

Cells that are involved in apoplastic transport can display a specific differentiation. So-called transfer cells, characterized by intensive uptake of metabolites from the apoplast, have cell wall invaginations that substantially increase the surface area of the plasma membrane. However, uptake of sugars from the apoplast also occurs in cells with smooth cell walls. Apoplastic sugar transport can also occur after phloem unloading. It is often involved in sugar transport to sinks that contain different genomes, e.g. biotrophic relationships, symbioses, host-parasite relationships and seed loading (Day et al., 2001; Smith et al., 2001; Patrick et al., 2001). However, in many organs apoplastic barriers, e.g. lignified or suberized cell walls, exist between the phloem and the sink cells (Patrick, 1997).

\subsubsection{Sugar transporters in apoplastic sugar transport}

Apoplastic transport of carbohydrates depends on the existence of specific transporters that catalyse the membrane penetration of sugars. Two types of transporters are necessary to allow apoplastic transport. First, a transport protein is needed for the export of sucrose into the apoplast. Such proteins have not been identified to date. Second, transporters are needed for the import of sucrose or hexoses into the sink cell.

The first plant hexose transporter cDNA was cloned from the lower plant Chlorella kessleri (Sauer and Tanner, 1989). The cDNA (HUP1) was used as a probe for the identification of the first monosaccharide transporter from a higher plant, Arabidopsis (Sauer et al., 1990). In the meantime, monosaccharide transporters have been cloned from several plants (Büttner and Sauer, 2000), e.g. a sink-specific monosaccharide transporter from Nicotiana tabacum (Sauer and Stadler, 1993). Monosaccharide transporters comprise a large gene family in all plants examined thus far: Ricinus communis (eight genes; Weig et al., 1994), Chenopodium rubrum (seven genes; Roitsch and Tanner, 1994), and Arabidopsis thaliana (14 genes; Büttner and Sauer, 2000). Transporters catalysing the uptake of monosaccharides that most likely derive from extracellular sucrose hydrolysis have been identified in pollen grains (AtSTP2; Truernit et al.,1999; AtSTP4; Truernit et al., 1996), in guard cells of various Arabidopsis organs (AtSTP1; Büttner and Sauer, 2000), in root tips (AtSTP4; Truernit et al.,1996) and in 
leaves (AtSTP3; Büttner et al., 2000). The expression of plant monosaccharide transporter genes is not only developmentally regulated, but also controlled by environmental stimuli, such as pathogen infection (AtSTP4) or wounding (AtSTP3 and AtSTP4; Truernit et al., 1996; Büttner et al., 2000).

The hydropathy profiles for all plant monosaccharide transporters are very similar and suggest 12 membrane-spanning domains, a typical feature of all members of the major facilitator superfamily (MFS; Marger and Saier, 1993). Sequence analysis indicates that they may have evolved by gene duplication from an ancestral gene coding for a sixtransmembrane helix transporter (Büttner and Sauer, 2000).

The kinetic properties of monosaccharide transporters have been studied by their heterologous expression in yeast or in Xenopus oocytes (Bush, 1993; Büttner and Sauer, 2000). All eleven of the investigated monosaccharide transporters were shown to be sensitive to uncouplers of the transmembrane proton gradient and to accumulate their substrates inside the cells to concentrations exceeding the extracellular concentrations, indicating that they catalyse active transport. They all represent $\mathrm{H}^{+}$-symporters and accept pyranose monosaccharides (Büttner and Sauer, 2000).

The first sucrose transporter cDNA was isolated from spinach (SoSUT; Riesmeier et al., 1992). Meanwhile, sucrose transporters have been described in a wide variety of systems and termed SUT (from sucrose transporter) or SUC (from sucrose carrier). Eight sucrose transporter genes have been found in Arabidopsis (Williams et al., 2000; www.tigr.org). The SUT genes encode highly hydrophobic proteins. Like monosaccharide transporters, sucrose transporters contain twelve membrane-spanning domains. In fact, they are distantly related to the hexose transporter family (Sauer et al., 1994). In apoplastic phloem loading, sucrose transporters accumulate sucrose in the sieve elementcompanion cell (SE/CC) complex to drive long-distance transport. In some plants these sucrose transporters have been detected in sieve elements (Kühn et al., 1997) or in companion cells (Stadler et al., 1995). Sucrose transporters have also been found in particular root cells: DcSUT2 is expressed in storage parenchyma cells of carrot tap-roots where it seems to import sucrose for storage (Shakya and Sturm, 1997). In Arabidopsis roots, strong expression was found for the sucrose transporter SUC1, and weak expression levels were shown for SUC2 (Sauer and Stolz, 1994). The latter has been detected in phloem cells all over the plant, including root and stem phloem, where it may retrieve sucrose that has leaked into the apoplast or possibly catalyses the efflux of sucrose from the phloem (Truernit and Sauer, 1995) and participates in phloem unloading (Sauer et al., 1994). 


\subsection{The regulation of phloem unloading and sink strength in different systems}

Mechanisms of phloem unloading and sink strength regulation have been examined in several systems, including developmental sinks like seeds, storage organs and fruits, and optional sinks, like pathogen infection sites.

\subsubsection{Developmental sinks}

The systems best examined for phloem unloading mechanisms so far are seeds of different plants, including legumes (Weber et al., 1997). For instance, the transport mechanisms and the cellular pathways of sucrose were analyzed in detail in fava bean seeds at the filling stage (Patrick, 1997). The sieve elements of the phloem end in the seed coat and are symplastically connected with the coat cells. Phloem unloading and post-phloem transport through the seed coat occur via the symplast. From the coat cells, sugars are unloaded into the seed apoplast and must be taken up by the apoplastically isolated embryo. Active transport systems are present in different parts of the seed (Gahrtz et al., 1996). Transfer cell formation (see 1.2.2.2) is correlated with strong induction of the expression of the Vicia faba sucrose transporter gene VfSUT1 (Weber et al., 1997). The sucrose uptake system changes from the invertase-mediated unloading process, which provides the sink strength during the prestorage phase, to the storage phase, which probably allows the development of the cotyledons (Weber et al., 1996).

The fava bean seed system is a good example for the different roles in sink development that were proposed for apoplastic invertase and sucrose synthase. Expression of apoplastic invertase gene expression, which is usually associated with tissues characterized by high mitotic activity, was found here during embryo development, whereas expression of sucrose synthase was found during storage product deposition in the developing cotyledons (Heim et al., 1993; King et al., 1997). Possibly, the epidermal contact of the cotyledons with the seed coat provides a signal for transfer cell differentiation. An interesting analogy can be drawn from studies of pathogen-plant interactions. The parasites Orobanche and Cuscuta retrieve sugars from their hosts, probably by establishing a sucrose uptake system involving transfer cells, which only form after contact with the host vascular tissue (Ayres et al., 1996). 


\subsubsection{Optional sinks}

The formation of optional sinks represents a facultative event for the plant. Examples for optional sinks are sites of pathogen infection, for instance tumors induced by Agrobacterium tumefaciens, sites of wounding, or symbiotic structures like nitrogen-fixing root nodules. In order to understand the regulation of phloem unloading and post-phloem transport, it is important to know which sugar transport mechanisms take place in optional sinks.

The large number of additional metabolic tasks in wounded or infected tissues cannot be sufficiently energized by the endogenous resources of the respective cells. Carbohydrates have to be imported into the affected tissues, which can be achieved by the rapid and simultaneous induction of genes for extracellular invertases (Sturm and Chrispeels, 1990) and plasma membrane monosaccharide transporters (Truernit et al., 1996; Büttner et al., 2000). In case of symplastic phloem unloading and post-phloem transport to the facultative sink, the activities of cytoplasmic or vacuolar sucrose-degrading enzymes have to be increased.

An example for optional sinks displaying symplastic phloem unloading and post-phloem transport are plant tumours induced by Agrobacterium tumefaciens that contain a well developed vascular system (Pradel et al., 1999). The distribution of the fluorescent dye carboxyfluorescein (CF) in tumours induced on three host plants, Nicotiana benthamiana, Cucurbita maxima and Ricinus communis, demonstrated a clear symplastic pathway between the phloem of the host stem and the tumour parenchyma, and also a considerable capacity for subsequent cell-to-cell transport between tumor parenchyma cells (Pradel et al., 1999).

Symbiotic nitrogen-fixing root nodules represent another example of optional sinks with high metabolic activity that requires large amounts of carbohydrates. The analysis of the sink function of these nodules is the topic of this thesis.

\subsection{Nitrogen-fixing root nodule symbioses}

Nitrogen is the element that most commonly restricts plant growth. The biosphere nitrogen is continuously depleted by denitrification. Only some prokaryotes can form the enzyme complex nitrogenase that reduces dinitrogen to ammonia and thereby introduces it into the biosphere. Since nitrogenase is highly oxygen-sensitive, its formation has to be tightly controlled, or oxygen protection systems have to be provided. Some prokaryotes fix nitrogen in symbiosis with higher plants. In root nodule symbioses, nitrogen-fixing soil 
bacteria induce the formation of special organs, the root nodules, on their plant hosts. Inside nodule cells, the bacteria fix nitrogen and deliver the products of nitrogen fixation to the plant, while being supplied with carbon sources by the plant. Two groups of soil bacteria are able to enter root nodule symbiosis with higher plants: rhizobia - unicellular, Gram-negative bacteria, and actinomycetes of the genus Frankia - Gram-positive bacteria that grow in hyphal form. Rhizobia enter symbioses with legumes and one non-legume, Parasponia sp., a member of the Ulmaceae family (Pueppke and Broughton, 1999), whereas Frankia strains can interact with a diverse group of mostly woody dicotyledonous plants that are members of eight different families, collectively called actinorhizal plants (Benson and Silvester, 1993).

\subsubsection{Nitrogen fixation in nodules}

The biological reduction of dinitrogen to ammonia is carried out by two enzymes, dinitrogenase and dinitrogenase reductase. Together, these enzymes are often referred to as nitrogenase. Dinitrogenase is encoded by genes nifD and nifK, whereas dinitrogenase reductase is encoded by nifH. The name nif of these genes is derived from "nitrogen fixation". Nitrogenase is very sensitive to oxygen (Shaw and Brill, 1977), while the process of nitrogen fixation requires large amounts of energy provided by respiratory processes, leading to the so-called "oxygen dilemma" of nitrogen fixation. Therefore, the expression of nif-genes is strongly regulated and takes place only under nitrogen-limiting conditions and at very low oxygen concentrations, which may be achieved by the formation of oxygen diffusion barriers.

In legume nodules, an oxygen-diffusion barrier in combination with the high metabolic activity of the infected cells results in a low concentration of free oxygen in the area of nitrogen-fixing infected cells (Denison and Layzell, 1991). Within infected cells high levels of oxygen-binding proteins, leghemoglobins, provide an efficient transport of oxygen to the sites of respiration (Appleby, 1984). The oxygen barrier is present in the nodule parenchyma, which surrounds the inner tissue and encloses the peripheral nodule vascular system (Figure 1.2). The nodule parenchyma consists of layers of cells more or less devoid of intercellular spaces (Minchin, 1997).

Frankia can grow on dinitrogen as sole nitrogen source in the soil (Benson and Silvester, 1993). In order to provide oxygen protection for nitrogenase, Frankia forms vesicles at the end of hyphae or at short side branches of hyphae. These vesicles are surrounded by a multilayered envelope containing hopanoids, bacterial steroid lipids (Berry et al., 1993), and in them nitrogenase is formed in a low-oxygen environment (Meesters et al., 1985; Parsons et al., 1987). Several diverse mechanisms have evolved for oxygen control in 
actinorhizal nodules formed by different plant families. In actinorhizal nodules of Casuarina, Frankia does not form vesicles but nitrogen fixation takes place in differentiated hyphae (Berg and McDowell, 1987a), and an oxygen diffusion barrier is achieved by lignification of the walls of infected and adjacent uninfected cells (Berg and McDowell, 1987b). Casuarina nodules also contain high amounts of nodule-specific hemoglobin, thus facilitating oxygen transport to the sites of respiration (Fleming et al., 1987). In other actinorhizal plants, e.g. Datisca sp., no hemoglobin is present in nodules, and Frankia forms vesicles for nitrogen fixation (Benson and Silvester, 1993).

\subsubsection{Infection of plants and nodule formation}

Bacteria can enter plant roots either intracellularly or intercellularly (Pawlowski and Bisseling, 1996). During intracellular infections, the bacteria are always surrounded by a membrane of plant origin, allowing the plant to control the microsymbiont's access to nutrients.

Most herbaceous legumes, including Medicago truncatula, are infected intracellularly via root hairs. Bacterial signal factors, the Nod factors, induce the deformation of root hairs and the induction of cortical cell divisions that ultimately lead to the formation of a nodule meristem (reviewed by Mylona et al., 1995). When a Rhizobium is trapped in a curled root hair, a localized hydrolysis of the root hair cell wall is induced, the plasma membrane invaginates, and new cell wall material is deposited (Kijne, 1992). This leads to the formation of a tubular structure, an infection thread, which grows to a nodule primordium, afterwards the bacteria are released into the cells by a process resembling endocytosis (Basset et al., 1977). During this process, rhizobia become enclosed by a plant-derived membrane, the peribacteroid membrane (PBM), that results in the formation of the symbiosome (Roth and Stacey, 1989). In the symbiosomes, rhizobia differentiate into their endosymbiotic form, the bacteroids, and start to fix nitrogen (Newcomb, 1981). In several other rhizobial symbioses (Parasponia and some primitive legumes) the bacteria are not released from the infection threads and, the infection cells are filled with the branching infection threads (reviewed by Pawlowski and Bisseling, 1996).

In intracellularly infected actinorhizal plants like Casuarina glauca, bacterial hyphae also enter the plant root via infection-thread like structures (Torrey, 1976), which grow toward the dividing cells in cortex and infect them by intense branching within the cells, forming the so-called prenodule. Nodule primordium formation in actinorhizal plants is induced in the root pericycle and not in the root cortex as in legumes, therefore infection thread-like structures grow further from the prenodule to the pericycle and infect primordium cells, leading to nodule formation. 
During intercellular infection, rhizobia can penetrate through the gaps in the epidermis that can form where lateral roots or adventitious roots emerge from the main root or stem, respectively (Chandler et al., 1982; James et al., 1992), while Frankia hyphae can penetrate the roots between root epidermal cells. In actinorhizal plants Frankia hyphae colonize the apoplastic space of the root cortex growing through the middle lamellae while cortical cells secrete electron-dense material rich in pectin and proteins into the intercellular spaces (Miller and Baker, 1985; Racette and Torrey, 1989; Liu and Berry, 1991). Hyphal tips enter primordium cells as the host cell plasma membrane invaginates. Surrounded by the invaginated host plasma membrane and embedded in fibrillar hostderived material, the hyphae proliferate inside the infected primordium cells (Miller and Baker, 1985).

Both infection pathways occur in legumes as well as in actinorhizal symbioses. Similar to the nodule structure, the type of infection is determined by the host plant, but not by the microsymbiont. For example, Medicago and Casuarina are infected intracellularly, while Datisca is assumed to be infected intercellularly (Pawlowski, 2002).

\subsubsection{Nodule structure}

Mature legume nodules have a stem-like organization in that they have a peripheral vascular system (Figure 1.2), with infected cells in the inner tissue. Actinorhizal nodules, as well as nodules induced by rhizobia on Parasponia, are composed of modified lateral roots without root caps, a central vascular system (Figure 1.2) and infected cells in the expanded cortex. It has been suggested that the structural differences between legume and other root nodules may be due to the availability of a unique developmental program in legumes (Joshi et al., 1993; Hirsch and LaRue, 1997). Some legume cultivars can spontaneously form bacteria-free nodules (Truchet et al., 1989; Blauenfeldt et al., 1994) which are rich in amyloplasts, indicating that nodules may originally have developed as carbon storage organs (Joshi et al., 1993).

There are two types of legume nodules: determinate and indeterminate. Which type of nodule is formed depends on the host plant (Mylona et al., 1995; Doyle et al., 1997). Indeterminate nodules contain an apical meristem. As a consequence, a developmental gradient of infected cells is established along the nodule axis (Figure 1.2; Vasse et al., 1990 ) that can be divided into five zones. Directly below the meristem (I), cells become infected in the prefixation zone (II). At the distal end of the infection zone, rhizobia are released from infection threads, enclosed by plasma membrane-derived 

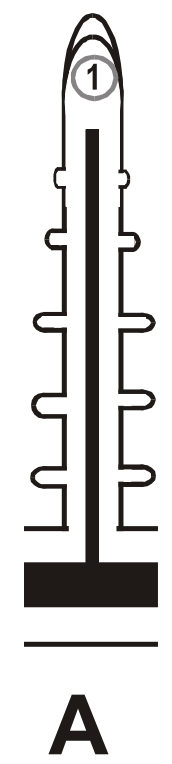

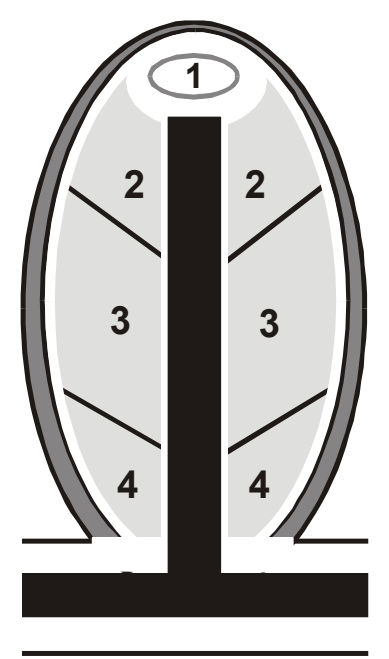

B

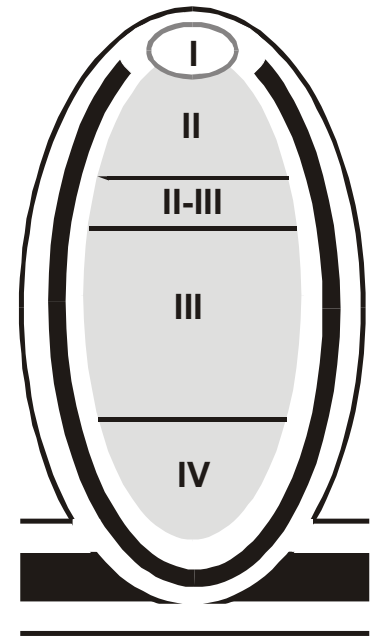

C

Figure 1.2. Schemes of longitudinal sections of roots and root nodules. (A) Scheme of a lateral root. The vascular system is labelled in black. Calyptra and root hairs are shown. 1 - meristem. (B) Scheme of an actinorhizal nodule lobe. The nodule periderm is labelled in dark grey. (C) Indeterminate legume root nodule. The zone containing the infected cells is labeled in light grey. Due to the activity of the apical meristem, a developmental gradient of infected cells is established along the nodule axis: $1(\mathrm{I})$ - meristem; 2(II) - pre-fixation zone/infection zone; II-III - intermediate zone of indeterminate legume nodule (C); 3(III) nitrogen-fixation zone; 4(IV) - senescence zone. $\mathbf{n}$ - vascular system.

peribacteroid membranes, and start to differentiate into their symbiotic form, the bacteroids. In the interzone (II-III), bacterial nitrogen fixation starts and takes place throughout the nitrogen fixation zone (III). In the senescence zone (IV), bacteria are degraded. In determinate nodules, the nodule meristem stops its activity early in nodule development, and new infected cells are formed by division of already infected cells. Accordingly, all cells of the inner tissue are more or less at the same developmental stage, and the spatial developmental gradient of the indeterminate nodules is substituted by a temporal one (Newcomb, 1981).

Actinorhizal nodules are coralloid organs composed of multiple modified lateral roots, the nodule lobes. Like lateral roots, actinorhizal nodule lobes have an indeterminate growth pattern, i.e. they also show a developmental gradient in the nodule cortex (Figure 1.2; Ribeiro et al., 1995). The meristem (1) is followed by the infection zone (2) where cells are invaded by Frankia hyphae and gradually filled with Frankia material, surrounded by the invaginating plasma membrane. When Frankia has differentiated for nitrogen fixation, either by vesicle formation or by differentiation of hyphae, the nitrogen fixation (3) zone starts. In the senescence zone (4), Frankia hyphae and vesicles are degraded by the plant. While in most actinorhizal nodules infected and uninfected cells are interspersed 
in the cortex, in nodules formed on roots of Datisca, the infected cells form a continuous patch on one side of the acentric stele (Figure 1.3; Hafeez et al., 1984).

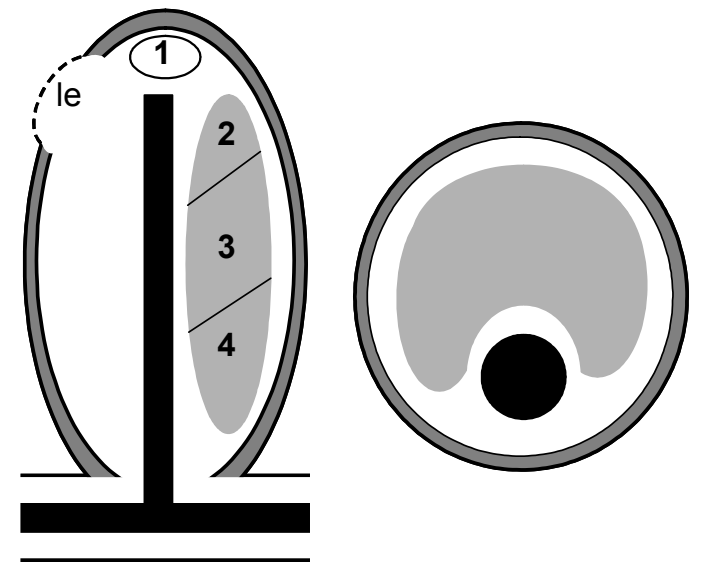

Figure 1.3. Scheme of a root nodule from Datisca sp. in longitudinal and cross section. The vascular system is labelled in black. Nodule lobes are surrounded by periderm which is shown in dark grey. For aeration, the periderm may be interrupted by lenticels (le). The infected cells are labelled in light grey. A developmental gradient of infected cells is established along the nodule axis: 1 - meristem; 2 infection zone; 3 - nitrogen fixation zone; 4 - senescence zone.

\subsubsection{Phylogenetic relationship of root nodule symbioses}

According to recent molecular phylogenetic analysis (Soltis et al., 1995), legume and actinorhizal symbioses belong to a single clade, the so-called rosid I clade, i.e. they go back to a common ancestor (Figure 1.4). These data suggest a single evolutionary origin of the susceptibility to gain the ability to enter nitrogen-fixing root nodule symbioses.

Independent studies concerning the molecular phylogeny of legumes and of actinorhizal plants have led to the hypothesis that on the basis of a common predisposition, symbiosis has developed independently three or four times in both systems, which is supported by the differences in nodule morphology and infection mechanisms within both systems (Doyle et al., 1997; Swensen, 1996). The question arises which feature was aquired by the ancestor of the rosid I clade that represented the predisposition that allowed the development of a root nodule symbiosis. This feature must be common to all root noduleforming plants, and is likely to be basal in nodule development.

\subsubsection{Carbon sources supplied by the host plant to nitrogen-fixing microsymbionts}

Within the symbiosis, the bacteria provide the plant with fixed nitrogen, while the plant provides the bacteria with carbon sources. In legume nodules, bacteria are supplied with dicarboxylic acids by the host plant (reviewed by Streeter, 1995). It has been assumed that dicarboxylic acids might also be the carbon source for symbiotic Frankia. While the analysis of enzyme activities in Frankia vesicle clusters isolated from nodules of Alnus 


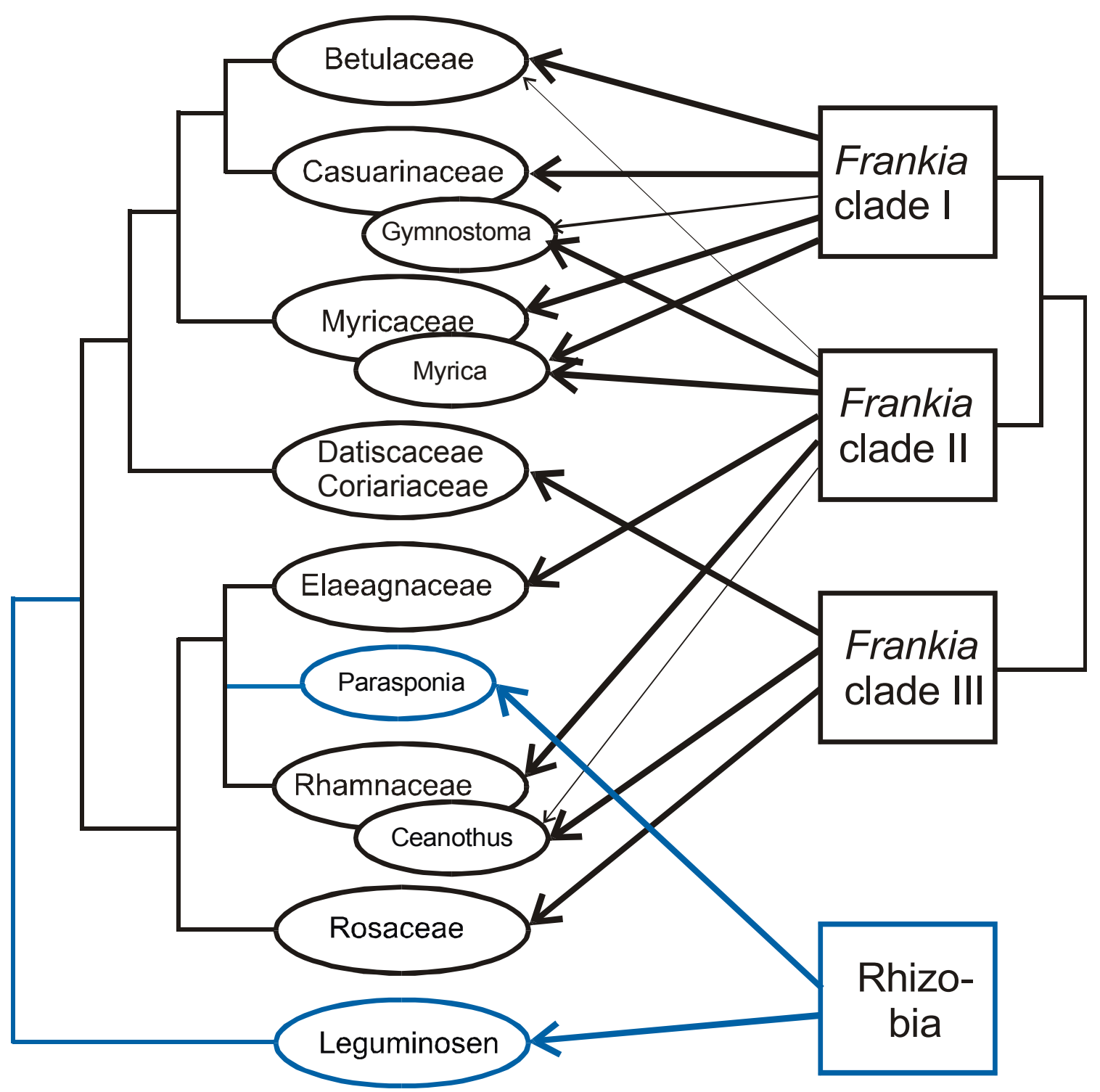

Figure 1.4. The relationships between groups of symbiotic plants and rhizobia and Frankia are shown in a simplified scheme (Wall, 2000; Benson and Clawson, 2000). Thick arrows connecting Frankia clades with the plant families/genera indicate that members of those clades are commonly associated with the plants. Thin arrows indicate that members of those clades have been isolated from or detected in an effective or ineffective nodule of a member of the plant genus/family at least once. Some actinorhizal genera (Gymnostoma, Myrica, Ceanothus) differ in microsymbiont specificity from the rest of the plant family they belong to. No members of Frankia Clade III have been isolated yet. Host specificity exists within the Frankia clades, i.e., not all members of a clade can nodulate all plants associated with that clade. (Figure modified after Pawlowski, 2002). 
and Hippophae yielded results consistent with this hypothesis (Akkermans et al., 1983), experiments on 14CO2 uptake of detached Alnus nodules were inconclusive (HussDanell, 1990; see review by Huss-Danell, 1997). The carbon preferences of Frankia in the free-living state might provide a clue. Frankia strains have been divided into two genomic groups A and B based on DNA homology (Lechevallier and Lechevallier, 1990), and into four different clades based on $16 \mathrm{~S}$ rRNA sequences (Normand et al., 1996). Clade IV comprises Frankia-like strains that cannot fix nitrogen; hence, there are three different clades of symbiotic Frankia strains. This grouping does not map with the differentiation into genomic groups. Furthermore, the 16S rRNA taxonomy includes non-culturable Frankia strains that could not be assigned to a genomic group. In the free-living state, Frankia strains of genomic group A tend to grow fairly on both sugars and organic acids, while strains of genomic group B grow variably on organic acids and poorly, if at all, on sugars. The carbon source mostly used in culturing Frankia strains is propionic acid. However, the endosymbionts of several actinorhizal plants, including Datisca, have not been isolated yet. Based on their 16S rRNA and nifH gene sequences, it has been concluded that many non-isolated Frankia strains including the endosymbiont of Datisca do not belong to any group of Frankia strains isolated so far (Mirza et al., 1994; Normand et al., 1996; Figure 1.4). Hence it is unclear whether this group of strains in particular, or Frankia strains in general, are fed other carbon sources than dicarboxylates during symbiosis.

\subsubsection{Carbon transport and metabolism in nitrogen-fixing root nodules}

Root nodules represent strong carbon sinks. They need assimilates as energy source for the microsymbionts, to provide carbon skeletons for the assimilation of the ammonium produced by the microsymbionts, for growth and, with the exception of Casuarina (E. Duhoux, personal communication) for starch biosynthesis.

In legume root nodules, several lines of evidence indicate that SuSy is essential for the cleavage of sucrose translocated from the shoots to the roots in support of nodule metabolism. First, the levels of SuSy mRNA and protein in soybean nodules are 10-20 times higher than those in root tissues (Thummler and Verma, 1987). Second, the SuSy gene is known to be predominantly expressed in nodules from Vicia faba and Medicago truncatula compared to uninfected roots, stems, leaves and other organs (Küster et al., 1993; Hohnjec et al., 1999). Third, several authors have demonstrated that various abiotic stress conditions (e.g. drought, salt, nitrate treatments) that decrease symbiotic nitrogen fixation in soybean nodules also dramatically reduce the mRNA, protein and activity levels 
of SuSy (Gordon et al., 1997; González et al., 1995). Finally, a pea mutant with severely reduced activity of nodule-enhanced SuSy was incapable of an effective root nodule symbiosis (Gordon et al., 1999). These results, however, do not preclude that invertases present in nodules (Gordon, 1991) play an important role in nodule carbon metabolism in specific stages of development.

Few studies have been performed on the possibilities of symplastic and apoplastic carbon transport in nodules. Ultrastructural investigation of nodules of 27 genera of legumes demonstrated plasmodesmal connections between sieve element and pericycle cells and also showed that pericyle cells, like infected cells and endodermal cells, were symplastically connected (Pate et al., 1969). For seven genera of legumes, transfer cells were described in the pericycle, but precise investigation showed that they are localized next to xylem elements and cell wall protuberances are especially developed on the walls contiguous with the xylem (Pate et al., 1969). Light and electron microscopy of indeterminate Vicia faba nodules also revealed a block between vascular tissue and inner cortex, represented by Casparian bands on the radial cell walls of the vascular endodermis and the so-called nodule endodermis, a cell layer in the nodule cortex surrounding the inner tissue and the nodule vascular system, and by the suberin coat of endodermis cells (Abd-Alla et al., 2000).

But symplastic metabolite passage is possible due to high plasmodesmal frequencies found between the vascular endodermis and the inner cortex (Abd-Alla et al., 2000). It was also demonstrated that there are very few plasmodesmata between infected cells of the central tissue, whereas uninfected cells can represent a symplastic continuity (AbdAlla et al., 2000).

\subsection{Aim of this thesis}

One very basal feature in root nodule development is the establishment and maintenance of the carbon sink function of the nodule. The aim of this thesis was to characterize sugar partitioning mechanisms in nitrogen-fixing root nodules. Three diverse model systems were chosen (Table 1.1): one legume symbiosis (Medicago truncatula - Sinorhizobium meliloti) and two actinorhizal symbioses from different Frankia subclades (Figure 1.4; Datisca glomerata, Casuarina glauca). The possilibities were (a) that carbon partitioning mechanisms in nodules would resemble those established in roots. If all three model plants would be similar here, root carbon partitioning mechanisms might represent the common basic feature that was required for the establishment of nitrogen-fixing symbiosis. If all three would be different, the symbiosis would put no specific requirements 
on carbon partitioning mechanisms. On the other hand, if (b) carbon partitioning mechanisms in roots of the three model systems differed, while those in nodules were similar, the symbiosis would put specific requirements on carbon partition. Either way, the results of the comparison would deepen our understanding of the interaction between plants and nitrogen-fixing bacteria.

Table 1.1. Characteristics of the studied model systems for root nodule symbioses.

\begin{tabular}{|l|c|c|c|}
\hline Characteristics & Medicago truncatula & Datisca glomerata & Casuarina glauca \\
\hline $\begin{array}{l}\text { Microsymbiont } \\
\text { Infection mechanism } \\
\text { Oxygen-carrying } \\
\text { protein } \\
\text { Oxygen barrier }\end{array}$ & $\begin{array}{c}\text { Sinorhizobium meliloti } \\
\text { Intracellular } \\
\text { Leghemoglobin }\end{array}$ & $\begin{array}{c}\text { Frankia subclade III } \\
\text { Intercellular } \\
\text { No hemoglobin found }\end{array}$ & $\begin{array}{c}\text { Frankia subclade I } \\
\text { Intracellular } \\
\text { Symbiotic hemoglobin }\end{array}$ \\
$\begin{array}{l}\text { Microsymbiont in free } \\
\text { culture }\end{array}$ & Nodule parenchyma & $\begin{array}{c}\text { Mitochondria at } \\
\text { vesicle base }\end{array}$ & $\begin{array}{c}\text { Strong lignification of } \\
\text { infected cells }\end{array}$ \\
$\begin{array}{l}\text { Phloem loading } \\
\text { mechanism }\end{array}$ & Apoplastic & Not isolated & + \\
\hline
\end{tabular}

To characterize carbon partitioning mechanisms in these three systems, the following aspects were examined:

- $\quad$ Contents and identity of dominating sugars in nodules compared to roots

- Activities of SuSy and of the different invertases

- Localization of sucrose-cleaving enzymes

- $\quad$ Expression levels of SuSy and sugar transporters

- Isolation of the cDNAs of hexose transporters expressed in nodules, and biochemical characterization of their protein products

The last of these aims was proposed since in nodules of Datisca, the expression of a monosaccharide transporter had been localized by in situ hybridization specifically to the infected cells (Wabnitz, 1998). 


\section{Materials and methods}

For all methods, except for biochemical methods, only sterile pipette tips, glass and plastic ware were used. All solutions for molecular biological methods were prepared using water of MilliQ grade (dd $\mathrm{H}_{2} \mathrm{O}$ ), autoclaved or filter sterilised, if not otherwise described.

\subsection{Materials}

\subsubsection{Plant material}

Medicago truncatula: $\quad$ cv. Jemalong, genotype A-17 (Barker et al., 1990)

Datisca glomerata: $\quad$ seeds were kindly provided by Alison M. Berry, University of California (Davis, CA, USA)

Casuarina glauca: $\quad$ seeds were supplied by the Desert Development Centre (Cairo, Egypt)

\subsubsection{Bacterial and yeast strains}

Plant infection:

\begin{tabular}{lll} 
Host plant & Symbiont & Reference \\
\hline $\begin{array}{l}\text { Medicago truncatula } \\
\text { Datisca glomerata }\end{array}$ & $\begin{array}{l}\text { Sinorhizobium meliloti 1021 } \\
\text { actinomycetes from crushed }\end{array}$ & Meade et al., 1982 \\
& nodules & \\
Casuarina glauca & Frankia strain Thr & Girgis et al., 1990
\end{tabular}

\section{Cloning:}

Escherichia coli DH5a (Woodcock et al., 1989).

Genotype: $\mathrm{F}^{-}$( $\left.\phi 80 \mathrm{dlacZ} \Delta M 15\right)$ recA1 endA1 gyrA96 thi-1 $h s d R 17\left(\mathrm{r}_{\mathrm{k}}{ }^{-} \mathrm{m}_{\mathrm{k}}{ }^{+}\right)$supE44 relA1 deoR $\Delta($ lacZYA-argF) U169

Analysis of transport activity for plant hexose transporters:

Saccharomyces cerevisiae strain EBY.VW4000 (Wieczorke et al., 1999) 
Genotype: $h x t 134::$ loxP $h x 154::$ loxP $h t \times 164::$ IoxP $h t x 144::$ loxP $h t x 124::$ loxP $h t \times 94::$ IoxP

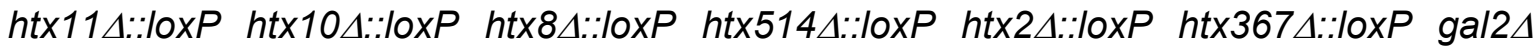

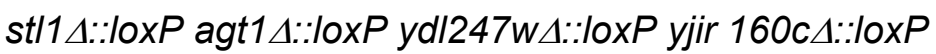

\subsubsection{Oligonucleotides (Primers)}

\begin{tabular}{|c|c|}
\hline Name & Sequence \\
\hline DgHT fs5 & 5'-CCC TTC TCT СTT TAT CTC C-3' \\
\hline$D g H T f s 3$ & 5'-CAG ATA CAT CAA ATT TGA CCC-3' \\
\hline DgHT 5'race1 & 5'-GTC GGG AAG GAG TAG CGA-3' \\
\hline DgHT 5'race2 & 5'-CTC CTC TGT ACT TGT AGG GA-3' \\
\hline for & 5'-GTA AAA CGA CGG CCA GT-3' \\
\hline MtHT fs & 5'-CCC AAC CAG CAT AGA ATT AAA CTA ACA GTG-3' \\
\hline MtHT 5'race1 & 5'-GAA GAA CAC GAC CCA AAA TGA GC-3' \\
\hline MtHT 5'race2 & 5'-ATC CTT AGA CAA AAC AGC GTT CGA-3' \\
\hline MM1 & 5'- GGC CAC GCG TCG ACT AGT ACG GGI IGG GII GGG IIG - 3' \\
\hline MM2 & 5'- GGC CAC GCG TCG ACT AGT AC - 3' \\
\hline MM3 & $5^{\prime}-$ CTC GAG GAT CCG CGG CCG CT 18 - 3' \\
\hline MM4 & 5'- CTC GAG GAT CCG CGG CCG C - 3' \\
\hline PmDgHT-for & $\begin{array}{l}\text { 5'-CCG GAA TTC AAG CTT GTA AAA GAA ATG CCG GCC GTC } \\
\text { GGA GG-3' }\end{array}$ \\
\hline PmDgHT-rev & $5^{\prime}$-CTA AAA ATA ACC CTC CCC CCA AAC-3' \\
\hline PmMtHT-for & $\begin{array}{l}\text { 5'-CCG CTC GAG AAG CTT GTA AAA GAA ATG GCT GGT GGG } \\
\text { GTT TTA CCA GTG-3' }\end{array}$ \\
\hline PmMtHT-rev & 5'-TTC ACT AGT GAT TCT CGA GGA TCC GC-3' \\
\hline $\operatorname{Rev}$ & 5'-AGC GGA TAA CAA TTT CAC ACA GGA-3' \\
\hline T3 & 5'- TAA CCC TCA CTA AAG GGA - 3' \\
\hline$T 7$ & $5^{\prime}$ - TAA TAC GAC TCA CTA TAG GG - 3' \\
\hline$d T_{20}$ & 5'-TTTTTTTTTTTTTTTTTTTTT-3' \\
\hline
\end{tabular}

\subsubsection{Plasmids}

$\begin{array}{lll}\text { p-Bluescript }^{\circledR} \text { II KS }(+) & \text { Amp }^{R} & \text { Stratagene, La Jolla, CA, USA } \\ \text { p-GEM }{ }^{\circledR} \text {-T Easy } & \text { Amp }^{R} & \text { Promega, Madison,WI, USA } \\ \text { pNEV-E } & \text { Amp }^{\text {R. }} \text {; URA3 } & \text { Sauer and Stolz (1994) }\end{array}$




$\begin{array}{lll}\text { pNEV-X } & \text { Amp }^{\mathrm{R}} ; \text { URA3 } & \text { Sauer and Stolz (1994) } \\ \text { pP001-VS } & \text { Amp }^{\mathrm{R}} & \text { B.Reiß, personal } \\ & & \text { communication } \\ \text { pRT 105 } & \mathrm{Amp}^{\mathrm{R}} & \text { Topfer et al. (1993) } \\ \text { pSPORT } & \text { Amp }^{\mathrm{R}} & \text { Gibco BRL, Eggenstein, } \\ & & \text { Germany }\end{array}$

\subsubsection{Enzymes}

\subsubsection{Restriction enzymes}

Restriction enzymes Xbal, EcoR321 (EcoRV), ACC65I (Kpnl), Smal, Pstl, Sdal (Sse8387I), Eco105I (SnaBI) were obtained from MBI Fermentas (Vilnius, Lithuania) and BamHI, HindIII, EcoRI, Sstl, Sstll, Sall, Pstl from Gibco BRL (Eggenstein, Germany).

\subsubsection{Other enzymes and kits}

Taq-Polymerase

DNA-Polymerase I Large Fragment (Klenow Fragment)

MLV Reverse Transcriptase

Thermoscript $^{\mathrm{TM}}$-RT-PCR System

RNase A

T4 DNA-Ligase

Lysozyme

Mung bean nuclease

ABI PRISM dRhodamine Terminator Cycle Sequencing Ready Reaction Kit Qiagen Gel Extraction Kit Qiaprep Spin Miniprep Kit Qiaprep Spin Maxiprep Kit Peq Lab E.Z.N.A. Plasmid Miniprep II Kit Invisorb Spin-Plant-RNA Mini Kit
Biometra, Göttingen, Germany

MBI Fermentas, Vilnius, Lithuania

MBI Fermentas, Vilnius, Lithuania Gibco BRL, Eggenstein, Germany Sigma, Deisenhofen, Germany Gibco BRL, Eggenstein, Germany Sigma, Deisenhofen, Germany Epicentre Technologies, Madison, WI, USA

PE Applied Biosystems, Weiterstadt, Germany

Qiagen, Hilden, Germany

Qiagen, Hilden, Germany

Qiagen, Hilden, Germany

Peq Lab Biotechnologie $\mathrm{GmbH}$, Erlangen, Germany Invitek, Berlin, Germany 


\subsubsection{Chemicals}

Agar

Agarose

Ampicillin

Arbutin

Bovine Extract

Casamino Acids (CAA)

Coomassie Brilliant Blue G 250

5-Bromo-4-chloro-3-indolyl $\beta$-D-

galactopyranoside (X-Gal)

Dimethylformamide (DMF)

Dimethyl sulfoxide (DMSO)

Deoxynucleotide triphosphates (dNTPs)

Dithiothreitol (DTT)

Ethidium bromide

Ethylendiamine tetraacetic acid (EDTA)

$\mathrm{D}(+)$-Glucose

Yeast extract

Yeast nitrogen base w/o amino acids

Isopropyl $\beta$-D-thiogalactopyranoside (IPTG)

Kanamycin

$\beta$-Mercaptoethanol

Orange $G$

Polyclar AT

$\mathrm{D}(+)$-Sucrose

Select Pepton 140

Trishydroxymethylaminomethane (Tris)

Other chemicals
Gibco BRL, Eggenstein, Germany

Gibco BRL, Eggenstein, Germany

Sigma, Deisenhofen, Germany

Sigma, Deisenhofen, Germany

Difco, Becton Dickinson $\mathrm{GmbH}$, Heidelberg, Germany

Difco, Becton Dickinson $\mathrm{GmbH}$, Heidelberg, Germany

Serva, Heidelberg, Germany

Roche Molecular Biochemicals, Mannheim, Germany

Sigma, Deisenhofen, Germany

Sigma, Deisenhofen, Germany

Roche Molecular Biochemicals,

Mannheim, Germany

Gibco BRL, Eggenstein, Germany

Sigma, Deisenhofen, Germany

Merck, Darmstadt, Germany

Merck, Darmstadt, Germany

Gibco BRL, Eggenstein, Germany

Difco, Becton Dickinson $\mathrm{GmbH}$, Heidelberg, Germany

AppliChem, Darmstadt, Germany

Sigma, Deisenhofen, Germany

Merck, Darmstadt, Germany

Sigma, Deisenhofen, Germany

Serva, Heidelberg, Germany

Carl Roth GmbH \& Co, Karlsruhe, Germany

Gibco BRL, Eggenstein, Germany

Sigma, Deisenhofen, Germany

Merck, Darmstadt, Germany

Sigma, Deisenhofen, Germany 


\subsubsection{Other materials and devices}

Filters and membranes:

Hybond $\mathrm{N}$

3MM-filter paper

Miracloth

\section{Devices:}

Transilluminator FLX-20M

ABI Prism 310 Genetic Analyser

Phospho-Imager Fuji BAS-1000

Thermocycler PTC-100

Personal Cycler

Liquid scintillation analyzer 1900TR
Amersham Pharmacia Biotech, Freiburg,

Germany

Whatman, Madistone, Kent, UK

Schütt Labortechnik GmbH, Göttingen,

Germany

Vilber Lourmat, Marne La-Vallet, France

PE Applied Biosystems, Foster City, CA, USA

Raytest, Sprockhövel, Germany

Biozym, Hessisch Oldendorf, Germany

Biometra, Göttingen, Germany

Canberra Packard GmbH, Dreieich, Germany

Centrifuges:

Megafuge 1.0

Heraeus Sepatech, Osterode, Germany

Biofuge pico

Eppendorf centrifuge $5415 \mathrm{R}$

Heraeus Sepatech, Osterode, Germany

Eppendorf AG, Hamburg, Germany

SORVALL $@-R C-3 B$ Refrigerated

Sorvall $\mathrm{GmbH}$, Bad Homburg, Germany

Superspeed Centrifuge

Ultracentrifuge L-80

Beckman Instruments, München, Germany

\subsubsection{Culture media}

\subsubsection{Plant media}

Hydroculture medium (Hoagland und Arnon, 1938)

\begin{tabular}{|c|c|c|c|}
\hline \multirow{6}{*}{ per 1l: } & \multicolumn{2}{|c|}{ Strength } & \multirow{6}{*}{$\begin{array}{l}\text { Macro element stock solutions: } \\
1 \mathrm{M} \mathrm{KH} \mathrm{KO}_{4} \\
1 \mathrm{M} \mathrm{MgSO} \\
1 \mathrm{M} \mathrm{KNO} \\
1 \mathrm{M} \mathrm{Ca}\left(\mathrm{HO}_{3}\right)_{2} \cdot 4 \mathrm{H}_{2} \mathrm{O}\end{array}$} \\
\hline & $1 / 2$ & $1 / 4$ & \\
\hline & $2 \mathrm{ml}$ & $1 \mathrm{ml}$ & \\
\hline & $4 \mathrm{ml}$ & $2 \mathrm{ml}$ & \\
\hline & $10 \mathrm{ml}$ & $5 \mathrm{ml}$ & \\
\hline & $10 \mathrm{ml}$ & $5 \mathrm{ml}$ & \\
\hline
\end{tabular}




\begin{tabular}{|c|c|c|}
\hline $2 \mathrm{ml}$ & $1 \mathrm{ml}$ & $\begin{array}{l}\text { Micro elements stock solution } \\
2.86 \mathrm{~g} / / \mathrm{H}_{3} \mathrm{BO}_{3} \\
1.81 \mathrm{~g} / \mathrm{l} \mathrm{MnCl}_{2} \cdot 4 \mathrm{H}_{2} \mathrm{O} \\
0.22 \mathrm{~g} / \mathrm{l} \mathrm{ZnSO} \mathrm{Zn}_{4} \cdot 7 \mathrm{H}_{2} \mathrm{O} \\
0.08 \mathrm{~g} / \mathrm{l} \mathrm{CuSO} \cdot 5 \mathrm{H}_{2} \mathrm{O} \\
0.025 \mathrm{~g} / / \mathrm{I} \mathrm{Na}_{2} \mathrm{MoO}_{4} \cdot 2 \mathrm{H}_{2} \mathrm{O} \\
0.025 \mathrm{~g} / \mathrm{l} \mathrm{CoCl} \cdot 6 \mathrm{H}_{2} \mathrm{O}\end{array}$ \\
\hline $10 \mathrm{ml}$ & $5 \mathrm{ml}$ & $\begin{array}{l}\text { Fe-EDTA-stock solution: } \\
5.56 \mathrm{~g} / \mathrm{l} \mathrm{FeSO} \mathrm{SO}_{4} \cdot 7 \mathrm{H}_{2} \mathrm{O} \\
7.45 \mathrm{~g} / \mathrm{l} \mathrm{Na} \mathrm{Na}_{2}-\mathrm{EDTA} \\
\text { adjust } \mathrm{pH} \text { to } 5.5\end{array}$ \\
\hline
\end{tabular}

Aeroponic culture medium (Lullien et al., 1987)

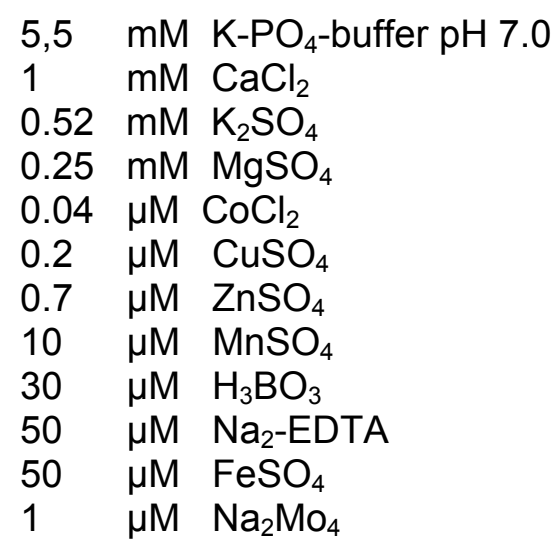

$\mathrm{K}-\mathrm{PO}_{4}$-buffer was prepared as sterile $100 \times$ stock solution, $\mathrm{pH} 7.0$, containing $58.92 \mathrm{~g} / \mathrm{l}$ $\mathrm{K}_{2} \mathrm{HPO}_{4}$ and $41.08 \mathrm{~g} / \mathrm{K} \mathrm{KH}_{2} \mathrm{PO}_{4}$. For the other components $1000 \times$ stocks were prepared separately and autoclaved. $\mathrm{FeSO}_{4}$ solution should be made fresh.

\section{Fåhraeus Medium (Fåhraeus, 1957)}

For $1 \mathrm{I}$ of medium (nodulation nitrogen-free medium):

$\begin{array}{lll}0.5 \mathrm{ml} & 1,0 \mathrm{M} & \mathrm{MgSO}_{4} \\ 1.0 \mathrm{ml} & 0,7 \mathrm{M} & \mathrm{KH}_{2} \mathrm{PO}_{4} \\ 2.0 \mathrm{ml} & 0,4 \mathrm{M} & \mathrm{NaH}_{2} \mathrm{PO}_{4} \\ 2.5 \mathrm{ml} & 20 \mathrm{mM} & \mathrm{Fe} \mathrm{EDTA} \mathrm{EDT} \\ 100 \mu \mathrm{l} & 1 \mathrm{mg} / \mathrm{l} & \mathrm{MnSO}_{4} \\ 100 \mu \mathrm{l} & 1 \mathrm{mg} / \mathrm{l} & \mathrm{CuSO}_{4} \\ 100 \mu \mathrm{l} & 1 \mathrm{mg} / \mathrm{l} & \mathrm{ZnSO}_{4} \\ 100 \mu \mathrm{l} & 1 \mathrm{mg} / \mathrm{l} & \mathrm{H}_{3} \mathrm{BO}_{4} \\ 100 \mu \mathrm{l} & 1 \mathrm{mg} / \mathrm{l} & \mathrm{Na}_{2} \mathrm{MoO}_{4}\end{array}$

The $\mathrm{pH}$ was adjusted to 6.5 with $\mathrm{H}_{2} \mathrm{SO}_{4}$ and then $1.25 \mathrm{ml}$ of $1 \mathrm{M} \mathrm{CaCl}_{2}$ was added.

\subsubsection{Bacterial media}

- Media for Escherichia coli: 


\section{$\underline{\text { LB Medium (Luria-Bertani Medium) (Sambrook et al., 1989) }}$}

Per liter:

$$
\begin{array}{rll}
5 \mathrm{~g} & \text { Yeast Extract } \\
10 \mathrm{~g} & \text { Select Pepton } 140 \\
10 \mathrm{~g} & \mathrm{NaCl}
\end{array}
$$

The $\mathrm{pH}$ was adjusted to 7.5 with $5 \mathrm{~N} \mathrm{NaOH}$. For solid LB medium, $1.5 \%(\mathrm{w} / \mathrm{v})$ agar per liter were added.

\section{SOC-Medium (Sambrook et al., 1989)}

All glassware used for the preparation of SOC medium was autoclaved filled with dd $\mathrm{H}_{2} \mathrm{O}$ to remove remains of detergents.

Per liter: $\quad 5 \quad \mathrm{~g}$ Yeast Extract

20 g Select Pepton 140

$10 \mathrm{ml} 1 \mathrm{M} \mathrm{NaCl}$

\section{$2.5 \mathrm{ml} 1 \mathrm{M} \mathrm{KCl}$}

The volume was adjusted to 1 liter with dd $\mathrm{H}_{2} \mathrm{O}$. After autoclaving for 10 minutes filter sterilized solutions were added:

$$
\begin{array}{ll}
10 \mathrm{ml} & 1 \mathrm{M} \mathrm{MgCl}_{2} \\
10 \mathrm{ml} & 1 \mathrm{M} \mathrm{MgSO}_{4} \\
10 \mathrm{ml} & 1 \mathrm{M}_{\text {Glucose }}
\end{array}
$$

\section{$\underline{\text { TB Medium [Terrific Broth] (Tartof and Hobbs, 1987) }}$}

Per liter:

To $900 \mathrm{ml}$ of $\mathrm{dd} \mathrm{H}_{2} \mathrm{O}$ were added: $12 \mathrm{~g}$ Select Pepton 140

$24 \mathrm{~g}$ Yeast Extract

$4 \mathrm{ml} \quad$ Glycerol

After autoclaving for 20 minutes, the solution was cooled to $60^{\circ} \mathrm{C}$ or less, and $100 \mathrm{ml}$ of a sterile solution of $\mathrm{K}_{-} \mathrm{PO}_{4}$-buffer $\left(0.17 \mathrm{M} \mathrm{KH}_{2} \mathrm{PO}_{4}, 0.72 \mathrm{M} \mathrm{K}_{2} \mathrm{HPO}_{4}\right)$ were added. For $\mathrm{K}^{-\mathrm{PO}_{4}-}$ buffer $2.31 \mathrm{~g} \mathrm{KH}_{2} \mathrm{PO}_{4}$ and $12,54 \mathrm{~g} \mathrm{~K}_{2} \mathrm{HPO}_{4} \cdot 3 \mathrm{H}_{2} \mathrm{O}$ were dissolved in $90 \mathrm{ml}$ of dd $\mathrm{H}_{2} \mathrm{O}$, the volume was adjusted to $100 \mathrm{ml}$ with dd $\mathrm{H}_{2} \mathrm{O}$.

- Media for Sinorhizobium meliloti:

$\underline{\text { TY-medium }}$

$\begin{array}{lrl} & 5 \mathrm{~g} & \text { Select Pepton } 140 \\ 3 \mathrm{~g} & \text { Yeast Extract } \\ 0.9 \mathrm{~g} & \mathrm{CaCl}_{2} \cdot 2 \mathrm{H}_{2} \mathrm{O}\end{array}$


$\underline{\text { YEB-medium (van Larebeke et al., 1977) }}$

Per liter:

$$
\begin{array}{ll}
5 \mathrm{~g} & \text { Bovine Extract } \\
1 \mathrm{~g} & \text { Yeast Extract } \\
5 \mathrm{~g} & \text { Select Pepton } 140 \\
5 \mathrm{~g} & \text { Sucrose }
\end{array}
$$

The $\mathrm{pH}$ was adjusted to 7.2-7.3 with $\mathrm{NaOH}$

- Medium for Frankia:

BAP Medium (Fontaine et al., 1986)

Stock solutions:

Per liter:

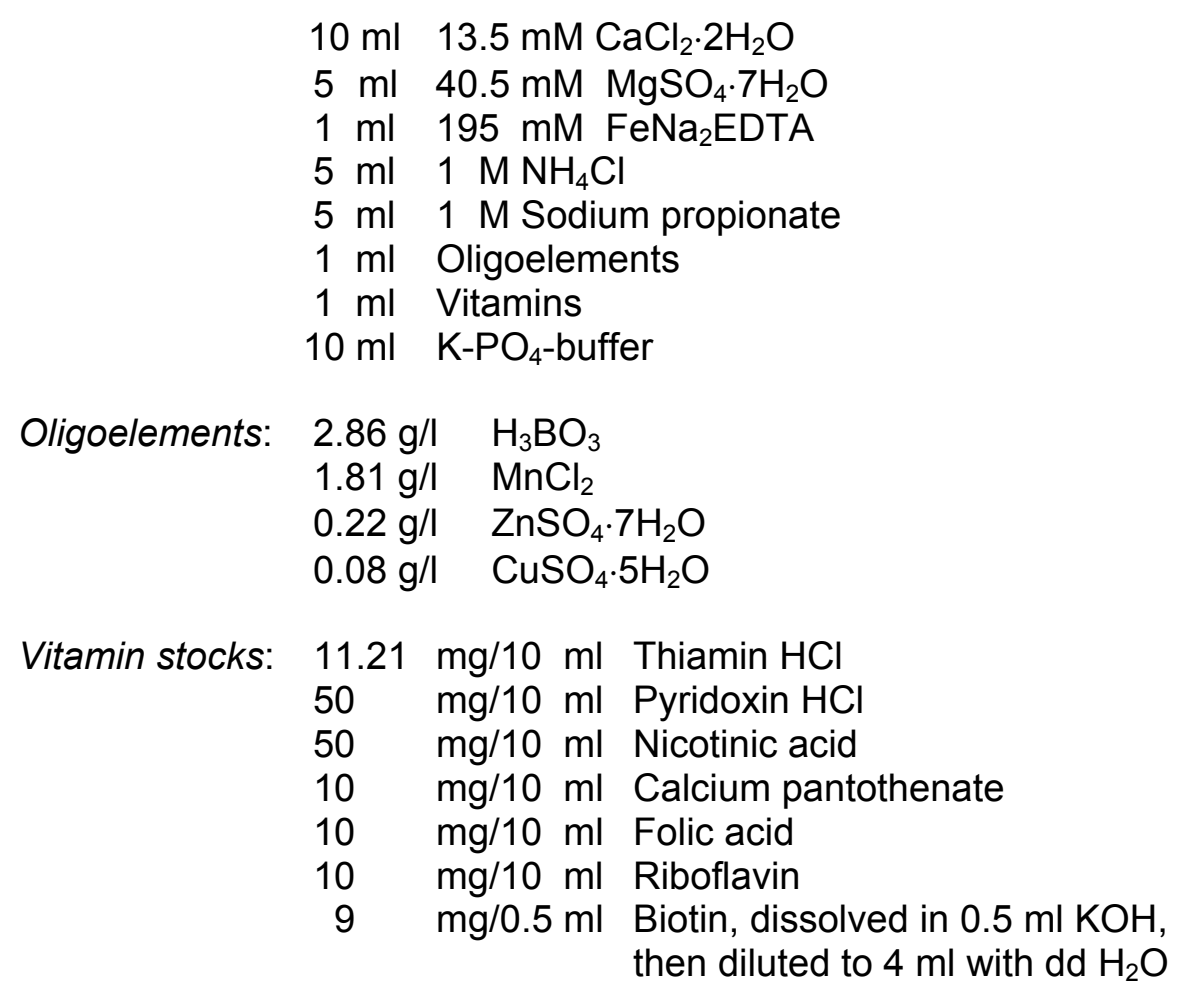

Vitamin stocks were stored at $-20^{\circ} \mathrm{C}$. To prepare $100 \mathrm{ml}$ vitamin mix $1 \mathrm{ml}$ of each stock was used.

$\mathrm{K}-\mathrm{PO}_{4}-$ buffer:

$560 \mathrm{ml} \quad 1 \mathrm{M} \quad \mathrm{KH}_{2} \mathrm{PO}_{4}$

$320 \mathrm{ml} \quad 1 \mathrm{M} \quad \mathrm{K}_{2} \mathrm{HPO}_{4} \cdot 3 \mathrm{H}_{2} \mathrm{O}$

$\mathrm{pH}$ was adjusted to 6.7 with $10 \mathrm{~N} \mathrm{KOH}$

\subsubsection{Media for Saccharomyces cerevisiae}

$\begin{array}{ll}\text { YPM - medium } & 1 \%(\mathrm{w} / \mathrm{v}) \text { Yeast extract } \\ & 2 \%(\mathrm{w} / \mathrm{v}) \text { Peptone } \\ & 2 \%(\mathrm{w} / \mathrm{v}) \text { Maltose }\end{array}$




$\begin{array}{ll}\text { CAA - medium } & 1 \%(\mathrm{w} / \mathrm{v}) \text { Casamino Acids } \\ & 2 \%(\mathrm{w} / \mathrm{v}) \text { Maltose } \\ & 0.67 \%(\mathrm{w} / \mathrm{v}) \text { YNB w/o amino acids } \\ & 1: 50(\mathrm{v} / \mathrm{v}) 1 \mathrm{mg} / \mathrm{ml} \text { Tryptophan stock solution }\end{array}$

For agar plates $2 \%$ agar (w/v) were added before autoclaving. L-Tryptophan was dissolved at $60-70{ }^{\circ} \mathrm{C}$. The solution was filter-sterilized and stored at $4{ }^{\circ} \mathrm{C}$. Tryptophan was added to CAA-medium at $50{ }^{\circ} \mathrm{C}$ before making plates.

\subsubsection{Medium additives}

\begin{tabular}{lccc}
\hline \multicolumn{1}{c}{ Additives } & Solvent & $\begin{array}{c}\text { Stock solution } \\
\text { concentration }\end{array}$ & $\begin{array}{c}\text { Final } \\
\text { concentration }\end{array}$ \\
\hline Ampicillin & $\mathrm{H}_{2} \mathrm{O}$ & $100 \mathrm{mg} / \mathrm{ml}$ & $100 \mu \mathrm{g} / \mathrm{ml}$ \\
Kanamycin & $\mathrm{H}_{2} \mathrm{O}$ & $50 \mathrm{mg} / \mathrm{ml}$ & $50 \mu \mathrm{g} / \mathrm{ml}$ \\
IPTG & $\mathrm{H}_{2} \mathrm{O}$ & $0,1 \mathrm{M}$ & $0,2 \mathrm{mM}$ \\
X-Gal & DMF & $2 \%(\mathrm{w} / \mathrm{v})$ & $0,004 \%$ \\
& & & \\
\hline
\end{tabular}

Stock solutions dissolved in $\mathrm{H}_{2} \mathrm{O}$ were filter sterilized. All medium additives were kept at $-20^{\circ} \mathrm{C}$.

\subsection{Plant culture methods and growth conditions}

Datisca glomerata and Casuarina glauca seeds were germinated and grown for three and five to six months, respectively, in soil ( $T 25$ Frühstorfer Erde $®$ ) mixed with one third volume of sand. Then they were transferred into aerated hydroculture in $1 / 4$ strength Hoagland's medium (Hoagland and Arnon, 1938; see 2.1.8.1.).

Noninfected plants of Medicago truncatula genotype A-17 (cv. Jemalong) were grown in a soil-sand mixture (see above) for three weeks and then transferred either to hydroculture in Fåhraeus Medium (Fåhraeus, 1957; see 2.1.8.1.) for root material or in aeroponic culture with Lullien medium for root and nodule material (Lullien et al., 1987; see 2.1.8.1.). After one week in aeroponic culture they could be infected with Sinorhizobium meliloti 1021 cells (Meade et al., 1982) grown in TY medium and washed with dd $\mathrm{H}_{2} \mathrm{O}$. Nodules were harvested after 10-14 days (aeroponic culture). 
D. glomerata was infected with actinomycetes from crushed nodules of $D$. glomerata plants grown in soil and C. glauca was infected with Frankia strain Thr (Girgis et al., 1990) grown in BAP Medium (Fontaine et al., 1986, see 2.1.8.2.) and washed with dd $\mathrm{H}_{2} \mathrm{O}$ 3-4 times. Nodules of $D$. glomerata and C. glauca were harvested 4-8 weeks after infection.

The greenhouse conditions were: temperature $22{ }^{\circ} \mathrm{C} / 18{ }^{\circ} \mathrm{C}$ (day/night), light intensity $200 \mu \mathrm{mol}$ photons $\times \mathrm{m}^{-2} \times \mathrm{s}^{-1}$ in winter and $400 \mu \mathrm{mol}$ photons $\mathrm{m}^{-2} \mathrm{~s}^{-1}$ in summer, 60 $65 \%$ humidity.

\subsection{RNA isolation from plant tissue}

\subsubsection{RNA isolation from Medicago truncatula and Datisca glomerata (modified after Burgos et al., 1995)}

$\begin{array}{lll}\text { Homogenization Buffer (HB): } & 100 \mathrm{mM} & \text { Tris/HCl, pH } 9.0 \\ & 100 \mathrm{mM} & \mathrm{NaCl} \\ 15 \mathrm{mM} & \text { EDTA } \\ & 0.5 \% & \text { N-Lauroylsarcosin (Sigma) }\end{array}$

Store at room temperature in $50 \mathrm{ml}$ aliquots

Plant tissue was ground in liquid nitrogen into a fine powder and transferred into 50 $\mathrm{ml}$ Falcon tubes, containing $5 \mathrm{ml}$ homogenization buffer, $5 \mathrm{ml}$ phenol/chloroform mixture (1:1) and $35 \mu \mathrm{l}$ ß-mercaptoethanol per $1 \mathrm{~g}$ of plant material. After homogenizing for 2 minutes using a IKA Ultra-Turrax ${ }^{\circledR}$ T-25 Basic Homogenizer (Ika-Werke GmbH \& Co. KG, Staufen, Germany), 350 H 3 M sodium acetate ( $\mathrm{pH}$ 5.4) were added per $\mathrm{g}$ tissue, and the mixture was homogenized again for $30 \mathrm{sec}$. Then the homogenate was poured into phenol/chloroform resistant $13 \mathrm{ml}$ tubes and centrifuged in a SORVALL $®-R C-3 B$ Refrigerated Superspeed Centrifuge (SORVALL GmbH, Bad Homburg, Germany) in a SS 34 rotor at $10 \mathrm{krpm}$ for $10 \mathrm{~min}$ at $4{ }^{\circ} \mathrm{C}$.

After centrifugation, the proteins of the cell homogenate formed a solid interphase between the water phase and the organic phase. The water phase was transferred into a new $13 \mathrm{ml}$ tube, an equal volume of phenol/chloroform was added, and the tube was vortexed and centrifuged again at $10 \mathrm{krpm}$ for $10 \mathrm{~min}$ at $4{ }^{\circ} \mathrm{C}$. Then the supernatant was transferred again into a new $13 \mathrm{ml}$ tube and an equal volume of isopropanol was added. After vortexing, the mixture was incubated at $-20{ }^{\circ} \mathrm{C}$ for $20-60$ minutes. At this step 
nucleic acids precipitated and could be pelleted by a 10 min centrifugation step in the SS 34 rotor at $10 \mathrm{krpm}$ and $4{ }^{\circ} \mathrm{C}$.

The pellet was washed with $2 \mathrm{ml} 70 \%(\mathrm{v} / \mathrm{v})$ ethanol to remove salts and centrifuged for $5 \mathrm{~min}$ in a SS 34 rotor at $10 \mathrm{krpm}$ and $4{ }^{\circ} \mathrm{C}$. The pellet was resuspended in $900 \mu \mathrm{ldd} \mathrm{H}_{2} \mathrm{O}$ and transferred into an $1.5 \mathrm{ml}$ Eppendorf tube for extraction with $500 \mu \mathrm{l}$ phenol/chloroform mixture (1:1) followed by an extraction of supernatant with $500 \mu \mathrm{l}$ chloroform. The supernatant was then transferred to a new Eppendorf tube and the volume was adjusted to $900 \mu \mathrm{l} .300 \mu \mathrm{l}$ (1/3 Vol.) $8 \mathrm{M} \mathrm{LiCl}$ were added and RNA was precipitated on ice for 3 hours, followed by 10 min of centrifugation at $4{ }^{\circ} \mathrm{C}$ and $13 \mathrm{krpm}$. The pellet was washed with $70 \%(\mathrm{v} / \mathrm{v})$ ethanol, resuspended in $50-100 \mu \mathrm{l} \mathrm{H}_{2} \mathrm{O}$ at $65{ }^{\circ} \mathrm{C}$ for $5 \mathrm{~min}$ and then cooled on ice. The insoluble material was removed by a $5 \mathrm{~min}$ centrifugation step. The supernatant was transferred to a new Eppendorf tube, and the intactness and concentration of the isolated RNA was tested on a $1 \%(\mathrm{w} / \mathrm{v})$ agarose gel (see 2.6.1.) in a detergent-treated gel chamber.

\subsubsection{RNA isolation from Casuarina glauca}

The RNA isolation from Casuarina is difficult because of the high polyphenol content of the plant that interferes with nucleic acid isolation procedures. Therefore different methods and kits were applied for Casuarina RNA isolation. The best results were obtained with the „Invisorb Spin Plant RNA Mini Kit“(Invitek, Berlin, Germany). The purification procedure was conducted according to recommendations of the manufacturer with a few adaptations.

About $100 \mathrm{mg}$ plant material were ground in liquid nitrogen with ca. $50 \mathrm{mg}$ of Polyclar ${ }^{\circledR}$ AT (Serva, Heidelberg, Germany) to a fine powder and transferred into a $2 \mathrm{ml}$ Eppendorf tube. After the liquid nitrogen had evaporated, 500-800 $\mu \mathrm{l}$ of Lysis Solution RP were added to the plant powder followed by vortexing for $1 \mathrm{~min}$ and $2 \mathrm{~min}$ of incubation at room temperature. To remove cell debris, the sample was centrifuged for $5 \mathrm{~min}$ at 13 krpm. The supernatant was pipetted onto a DNA-Binding Spin Filter which was placed in a $1.5 \mathrm{ml}$ Eppendorf tube and incubated for $1 \mathrm{~min}$ at room temperature. After a centrifugation for $1 \mathrm{~min}$ at $10 \mathrm{krpm}$ at room temperature, $1 / 2$ vol. of absolute ethanol was added to the RNA-containing flow-through and the mix was transferred onto an RNA-Binding Spin Filter in a $1.5 \mathrm{ml}$ Eppendorf tube. After $1 \mathrm{~min}$ incubation at room temperature, the sample was centrifuged for $30 \mathrm{sec}$ at $10 \mathrm{krpm}$ in order to bind the RNA to the filter. The flow-through was discarded, and the filter was washed with $600 \mu$ l wash buffer R1 by a centrifugation for $30 \mathrm{sec}$ at $10 \mathrm{krpm}$. This step was repeated twice with $500 \mu \mathrm{l}$ of wash buffer R2. Then the filter was centrifuged again for the removal of remains of wash buffer at $12 \mathrm{krpm}$ for 2 
min and placed in a new Eppendorf tube. The RNA was eluted by direct pipetting of 40-60 $\mu \mathrm{l}$ elution buffer onto the membrane, followed by $2 \mathrm{~min}$ of incubation at room temperature and a centrifugation for $1 \mathrm{~min}$ at $10 \mathrm{krpm}$. After this step, the RNA was kept on ice before testing the RNA concentration on an $1 \%$ agarose gel (see 2.6.1.), or stored at $-80{ }^{\circ} \mathrm{C}$.

\subsection{Isolation of plasmid DNA from bacteria and yeast}

\subsubsection{Plasmid mini-preparation protocol „,Triton Boiling“}

This method comprised an effective and fast method for the isolation of plasmid DNA from bacteria for a quick characterization with restriction enzymes.

$4 \mathrm{ml}$ of LB medium (see 2.1.8.2.), containing an appropriate antibiotic, were inoculated with a single bacterial colony and incubated overnight at $37^{\circ} \mathrm{C}$ with vigorous shaking. $1.5 \mathrm{ml}$ of overnight culture were poured into an Eppendorf tube and spun down at $13 \mathrm{krpm}$ for $1 \mathrm{~min}$. The remainder of the overnight culture could be stored at $4{ }^{\circ} \mathrm{C}$ for $1-2$ days. The supernatant was removed to leave the bacterial pellet as dry as possible. Bacterial pellets were resuspended by vortexing in $150 \mu \mathrm{l}$ cold STEL buffer (8 \% sucrose; 5 \% Triton X 100; $50 \mathrm{mM}$ Tris- $\mathrm{HCl}, \mathrm{pH}$ 8.0; $50 \mathrm{mM}$ EDTA; $0.5 \mathrm{mg} / \mathrm{ml}$ lysozyme) and boiled for $30 \mathrm{sec}$ at $100{ }^{\circ} \mathrm{C}$. Cell debris with genomic DNA was sedimented by $20 \mathrm{~min}$ of centrifugation at $13 \mathrm{krpm}$ at room temperature. The pellet was removed with a sterile toothpick, and the supernatant was mixed with $180 \mu \mathrm{l}$ isopropanol and centrifuged again at $13 \mathrm{krpm}$ for $5 \mathrm{~min}$ to pellet the plasmid DNA. The pellet was then washed with $500 \mu \mathrm{l} 70$ $\%$ ethanol, spun down for $5 \mathrm{~min}$ at $13 \mathrm{krpm}$, dried at $37{ }^{\circ} \mathrm{C}$ and finally resuspended in 50

$\mu \mathrm{l}$ RNase- $\mathrm{H}_{2} \mathrm{O}\left(0.2 \mathrm{mg} / \mathrm{ml}\right.$ RNase A) for $10 \mathrm{~min}$ at $37^{\circ} \mathrm{C}$. DNA was stored at $-20^{\circ} \mathrm{C}$.

\subsubsection{Mini preparation of bacterial plasmid DNA for the sequence analysis}

For sequence analysis, the plasmid DNA was isolated using a QIAprep® Spin Miniprep Kit (Qiagen, Hilden, Germany), which allows a fast preparation of pure DNA. The QIAprep miniprep procedure is based on the alkaline lysis of bacterial cells followed by the adsorption of DNA on a silica gel membrane in the presence of a high salt concentration. The DNA was eluted from the column with $50 \mu \mathrm{ldd} \mathrm{H}_{2} \mathrm{O}$. 


\subsubsection{Maxi preparation of bacterial plasmid DNA}

This method was used for the preparation of large amounts of plasmid DNA from bacteria. For this procedure, $50 \mathrm{ml}$ of TB medium (see 2.1.8.2.), containing an appropriate antibiotic, were inoculated with a single bacterial colony and incubated overnight at $37^{\circ} \mathrm{C}$ with vigorous shaking. The overnight culture was distributed over four $13 \mathrm{ml}$ centrifugation tubes and centrifuged for $10 \mathrm{~min}$ at $4.3 \mathrm{krpm}$ in a Megafuge 1.0 (Heraeus Sepatech, Osterode, Germany). The supernatant was discarded, and the pellet could be stored at $-20^{\circ} \mathrm{C}$.

For DNA preparation the Peq Lab E.Z.N.A. Plasmid Miniprep Kit II (Peq Lab Biotechnologie $\mathrm{GmbH}$, Erlangen, Germany) was used, which allows to isolate large amounts of very pure plasmid DNA. This procedure, conducted as described in the standard Peq Lab protocol, is based also on the alkaline lysis of bacterial cells followed by the adsorption of DNA to a silicagel membrane. $13 \mathrm{ml}$ of overnight culture was used per preparation. The plasmid DNA was eluted from the column with $120 \mu \mathrm{ld} \mathrm{H}_{2} \mathrm{O}$ with a 5 min incubation step at $37^{\circ} \mathrm{C}$ before the last centrifugation.

\subsubsection{Preparation of plasmid DNA from yeast}

For the quick preparation of plasmid DNA from yeast, a medium size yeast colony ( $\varnothing$ ca. $3 \mathrm{~mm}$ ) was picked and transferred to $200 \mu \mathrm{l}$ of lysis buffer $(100 \mathrm{mM} \mathrm{NaCl}, 10 \mathrm{mM}$ Tris (pH 8.0), $1 \mathrm{mM}$ EDTA, $0.1 \%$ (w/v) SDS). Then an equal volume of glass beads $(\varnothing 0.45 \mathrm{~mm})$ was added, and the sample was vortexed at top speed for $1 \mathrm{~min}$. After an extraction with $200 \mu \mathrm{l}$ of a phenol/chloroform mixture (2:1), the plasmid DNA was precipitated with ethanol (see 2.5.1.) and finally resuspended in $50 \mu \mathrm{l}$ of $d d \mathrm{H}_{2} \mathrm{O}$. To obtain enough DNA for the characterization of the plasmid by digestion with restriction enzymes, E.coli was transformed with 5-10 $\mu \mathrm{l}$ of plasmid DNA prepared from yeast (2.13.2.) and a plasmid DNA minipreparation (2.4.1.) was performed.

\subsection{Concentration and purification of DNA or RNA solutions}

\subsubsection{Precipitation of nucleic acids}

DNA or RNA precipitation was used to concentrate very dilute samples of nucleic acids or to change salt/buffer composition. For this purpose, the DNA (or RNA) sample was mixed 
with 0.1 volume of $3 \mathrm{M}$ sodium acetate $(\mathrm{pH} \mathrm{5.2)}$ and 2.5 volumes of absolute ethanol, and precipitated at $-20{ }^{\circ} \mathrm{C}$ for at least one hour. After centrifugation for $15 \mathrm{~min}$ at $13 \mathrm{krpm}$, the supernatant was taken off and the pellet was washed with $70 \%$ ethanol to remove excess salt. After centrifugation for $10 \mathrm{~min}$ at $13 \mathrm{krpm}$, the pellet was dried at $37^{\circ} \mathrm{C}$ to remove the remains of ethanol. Finally, the pellet was resuspended in an appropriate volume of dd $\mathrm{H}_{2} \mathrm{O}$ or buffer.

\subsubsection{Phenol-chloroform extraction and precipitation of DNA}

To remove proteins from DNA solution the same volume (at least $200 \mu \mathrm{l}$ ) of a phenol/chloroform mixture $(1: 1, v / v)$ was added. The mixture was vortexed and centrifuged for 5 min at $13 \mathrm{krpm}$. Then the supernatant was extracted the same way with one volume of chloroform. After this step, 0.1 volume of $3 \mathrm{M}$ sodium acetate $(\mathrm{pH} 5.4)$ and 2.5 volume absolute ethanol were added to the supernatant to precipitate DNA as described above (2.5.1.).

This method was used to purify for instance the linearised form of a cloning vector from restriction enzymes and buffer salts before ligation.

\subsection{Electrophoretic separation of DNA and RNA}

\subsubsection{TEA-Agarose gel electrophoresis}

DNA and RNA concentrations or fragment size were tested on $1 \%(\mathrm{w} / \mathrm{v})$ agarose gels in $1 \times$ TEA buffer (40 mM Tris-acetate $\mathrm{pH} 8.3 ; 2 \mathrm{mM}$ EDTA) as gel- and running buffer. The gel was supplied with $0.25 \mu \mathrm{g} / \mathrm{ml}$ ethidium bromide (Sigma, Deisenhofen, Germany) to make nucleic acids visible under UV-light (366 nm wave length; Transilluminator FLX20M, Vilber Lourmat, Marne La-Vallet, France).

$1 \mu \mathrm{l}$ of DNA or RNA solution was mixed with $2 \mu$ of orange loading dye (50\% glycerol; 10 $\mathrm{mM} \mathrm{NaH}{ }_{2} \mathrm{PO}_{4}, \mathrm{pH} 7.0 ; 0.4 \%$ Orange $\mathrm{G}$ (Sigma, Deisenhofen, Germany)). The electrophoresis was conducted at $70 \mathrm{~V} .1 \mu \mathrm{g}$ of $\lambda$-Phage DNA, restricted with Pstl was used as length and quantity standard. Gel documentation was performed using the program PhotoFinish ${ }^{\circledR} 3.0$ (WordStar Atlante Technology Center Inc., Marietta, GA, USA). 
For quantification and quality estimation of RNA, gel box, combs and gel carrier were pre-treated with $1 \%$ SDS solution $(\mathrm{w} / \mathrm{v})$ for $1 \mathrm{~h}$ to denature RNases. Afterwards they were thoroughly rinsed with tap water to remove remains of SDS, which bind ethidium bromide.

\subsubsection{Separation of RNA on agarose gel for Northern blots}

For Northern blots, RNA samples were separated on denaturing formaldehyde agarose gels $(1.2 \%(w / v)$ agarose). For a gel of $13.5 \times 16 \mathrm{~cm}, 3 \mathrm{~g}$ agarose were dissolved in $150 \mathrm{ml}$ dd $\mathrm{H}_{2} \mathrm{O}$ by heating in a microwave oven. After cooling to $70{ }^{\circ} \mathrm{C}, 20 \mathrm{ml} 10 \times \mathrm{MEN}$ buffer (200 mM MOPS, $10 \mathrm{mM}$ EDTA, $80 \mathrm{mM}$ sodium acetate, $\mathrm{pH}$ adjusted to 7.0 with $\mathrm{NaOH}$ ) and $33 \mathrm{ml} 37 \%$ formaldehyde solution were added and the gel was poured.

Per slot, ca. $10 \mu \mathrm{g}$ of RNA in $9 \mu \mathrm{H} \mathrm{H}_{2} \mathrm{O}$ were denatured at $65{ }^{\circ} \mathrm{C}$ for 10 min together with $21 \mu \mathrm{l}$ of Northern mix ( $3 \mu \mathrm{l} 10 \times$ MEN; $12 \mu \mathrm{l}$ deionised formamide; $3 \mu \mathrm{l} 37 \%$ formaldehyde solution; $3 \mu \mathrm{l}$ blue marker-mix, prepared from $15 \mu \mathrm{l} 10 \mathrm{mg} / \mathrm{ml}$ ethidium bromide stock and $85 \mu \mathrm{l}$ blue loading dye $(0,1 \%(\mathrm{w} / \mathrm{v})$ xylene cyanol; 0,2 $\mathrm{g} / \mathrm{ml}$ sucrose; $250 \mathrm{mM}$ EDTA; $0,5 \mathrm{mg} / \mathrm{ml}$ bromphenol blue)). After loading of the RNA samples, all slots were filled with $1 \times$ MEN running buffer. Electrophoresis was performed for ca. 2.5 hours at 100-130 V. Ca.1 $\mathrm{h}$ after start of the electrophoresis, the gel was photographed to document the quantities of RNA loaded.

\subsection{Northern blot hybridization}

\subsubsection{RNA transfer to nylon membranes (Northern blotting)}

The gel with electrophoretically separated RNA samples (see 2.6.2.) was put on blotting paper ( $3 \mathrm{MM}$, Watman, Maidstone, UK) that had been soaked in $20 \times \mathrm{SSC}(3 \mathrm{M} \mathrm{NaCl}, 300$ $\mathrm{mM}$ sodium citrate, $\mathrm{pH} 7.0$ ) and the ends of which were placed in $20 \times \mathrm{SSC}$ solution. Then a nylon membrane (Hybond ${ }^{\mathrm{TM}}-\mathrm{N}$, Amersham Pharmacia Biotech, Buckinghamshire, UK), wetted in dd $\mathrm{H}_{2} \mathrm{O}$ was incubated for 15-20 min in 20× SSC, placed on the gel and covered with 3 layers of whatman 3 MM paper soaked in $20 \times$ SSC and finally with a dry, about 5 $\mathrm{cm}$ thick stack of paper towels of about $5 \mathrm{~cm}$ height. A weight of about $1 \mathrm{~kg}$ was placed on the paper towel stack and the capillary transfer of RNA onto the membrane proceeded 
overnight. The Hybond-N membrane was washed in $2 \times$ SSC, followed by baking for 2-3 hours at $80^{\circ} \mathrm{C}$. The membrane was stored in a plastic bag at $4{ }^{\circ} \mathrm{C}$ before use.

\subsubsection{DNA probe labelling with $\alpha-\left[{ }^{32} P\right]-d A T P$}

About $25 \mathrm{ng}$ of DNA fragment isolated from a gel were denatured for $5 \mathrm{~min}$ at $100{ }^{\circ} \mathrm{C}$ in a total volume of $27 \mu \mathrm{l}$ and then put on ice. $6.5 \mu \mathrm{l}$ OLB-buffer, $1 \mu \mathrm{l} 20 \mu \mathrm{g} / \mu \mathrm{l}$ of BSA, $1 \mu \mathrm{l}$ $(2 \mathrm{U} / \mu \mathrm{l})$ Klenow Fragment (DNA-Polymerase I Large Fragment; MBI Fermentas, Vilnius, Lithuania) and $2 \mu \mathrm{l} \alpha-\left[{ }^{32} \mathrm{P}\right]-\mathrm{dATP}$ (ca. $20 \mu \mathrm{Ci}$, specific activity $111 \mathrm{Tbq} / \mathrm{mmol}$; Hartmann Analytic, Braunschweig, Germany) were added. After incubation for $45-60 \mathrm{~min}$ at $37^{\circ} \mathrm{C}$, nonincorporated nucleotides were removed using the Concert ${ }^{\mathrm{TM}}$ Rapid PCR Purification System (Gibco BRL, Eggenstein, Germany). The labelled probe was boiled for 5 min at $95{ }^{\circ} \mathrm{C}$ for denaturation and then shortly cooled down on ice before being added to the hybridization buffer (see 2.7.3.).

OLB-buffer:

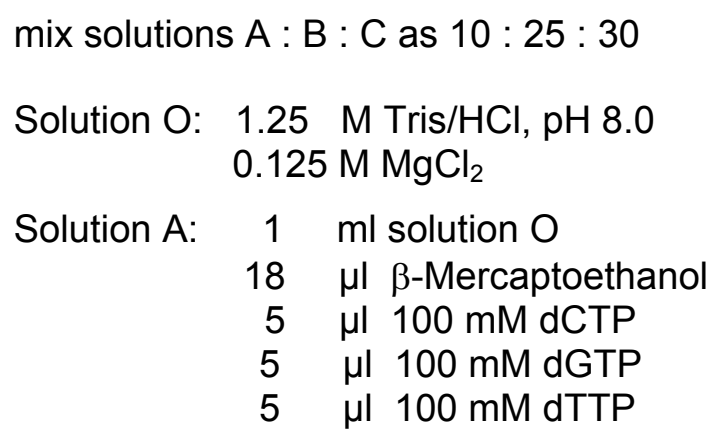

Solution B: 2 M HEPES, pH 6.6 adjusted with $\mathrm{NaOH}$

Solution C: $21.6 \mathrm{OD}_{260}$ units/ml Hexadeoxynucleotides (Amersham Pharmacia Biotech, Freiburg, Germany), dissolved in TE (10 mM Tris/HCl, pH 7.5; 1 mM EDTA)

\subsubsection{Hybridization}

A Northern blot of ca. $4 \times 7 \mathrm{~cm}^{2}$ was sealed into a plastic bag containing $13 \mathrm{ml}$ of hybridization buffer and incubated in a shaking water bath at $65{ }^{\circ} \mathrm{C}$ for at least $45 \mathrm{~min}$ before the denatured radio-labelled probe (see 2.7.2.) was added. Hybridization was performed for at least 16 hours at $65^{\circ} \mathrm{C}$ in a shaking water bath. After hybridization, the membrane was washed twice at $65{ }^{\circ} \mathrm{C}$ for $20 \mathrm{~min}$ in $2 \times$ SSC, $0.1 \%$ SDS (low stringency wash) or once for $20 \mathrm{~min}$ in $2 \times$ SSC, $0.1 \%$ SDS and once for $20 \mathrm{~min}$ in $0.5 \times$ SSC, $0.1 \%$ 
SDS (high strigency wash) at $65{ }^{\circ} \mathrm{C}$ to remove non-specifically bound DNA. Then the membrane was dried on 3MM paper, wrapped up in plastic foil and exposed in a phosphoimager cassette (Fuji BAS-1000; Raytest, Sprockhoevel, Germany) for a maximum of 72 hours. The image was analyzed with the computer program Tina 2.0 (Raytest, Sprockhoevel, Germany).

Hybridization buffer:

Stock solutions:
$5 \times$ SSC, $5 \times$ Denhardt's, $0.5 \%$ SDS

$20 \times$ SSC: $3 \mathrm{M} \mathrm{NaCl}, 0.3 \mathrm{M}$ sodium citrate, $\mathrm{pH} 7.0$

50× Denhardt's: $1 \%(w / v)$ Ficoll 400 $1 \%(w / v)$ PVP 40 $1 \%(w / v) B S A$

The hybridization buffer and stock solutions were stored at $-20^{\circ} \mathrm{C}$

\subsection{First strand cDNA synthesis (Reverse transcription)}

For cDNA synthesis ca. 2-3 $\mu \mathrm{g}$ RNA and 500 pmol of $5^{\prime}$-specific primer or oligo( $\left.\mathrm{dT}_{20}\right)$ primer (see 2.1.3.) were incubated for $5 \mathrm{~min}$ at $65^{\circ} \mathrm{C}$ in a volume of $11 \mu$ to denature the secondary structure of RNAs and to allow the primer to bind to the mRNA, and then placed on ice. For 5'-RACE, a gene specific primer was used on $20 \mu \mathrm{g}$ total RNA.

Afterwards, the cDNA synthesis mix from ThermoScript ${ }^{\mathrm{TM}} \mathrm{RT}$-PCR System (Gibco BRL, Karlsruhe, Germany) was added:

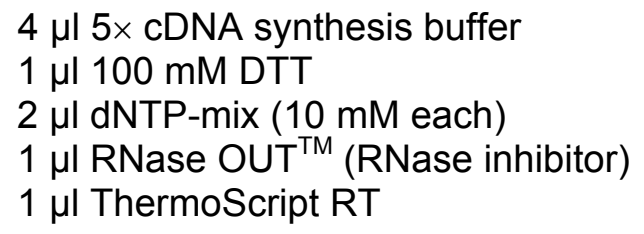

The reaction mixture was incubated for 1 hour at $55{ }^{\circ} \mathrm{C}$ and then the reaction was stopped by 5 min heating at $85^{\circ} \mathrm{C}$. cDNA was kept at $-20^{\circ} \mathrm{C}$ until use.

\subsection{Amplification of DNA fragments}

DNA sequences localized between two known sequences can be amplified using the polymerase chain reaction (PCR; Mullis and Faloona, 1987) 


\subsubsection{Polymerase chain reaction (PCR)}

A typical program for PCR includes denaturing, annealing and elongation steps. Denaturation occurs at $94{ }^{\circ} \mathrm{C}$, which separates both strands of the DNA. The following cooling to the annealing temperature, for example $55{ }^{\circ} \mathrm{C}$, allows the hybridization of primers to single stranded DNA molecules. Then at $72{ }^{\circ} \mathrm{C}$, the optimal temperature for Taq polymerase (from the thermophilic bacterium Thermus aquaticus), the primer is elongated, forming a double-stranded DNA molecule, identical to the original DNA. The multiple repetition of this cycle leads to the exponential amplification of the sequence between the primer binding sites.

For a standard PCR the following components were pipetted together:

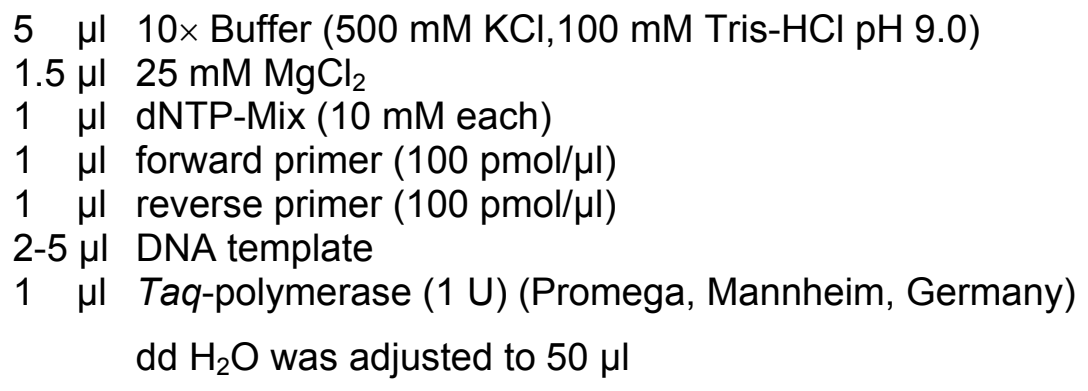

The programmed DNA thermal cyclers MJ Research PTC 100 (Biozym, Hessisch Oldendorf, Germany) or TGradient (Biometra, Göttingen, Germany) were used with the standard program:

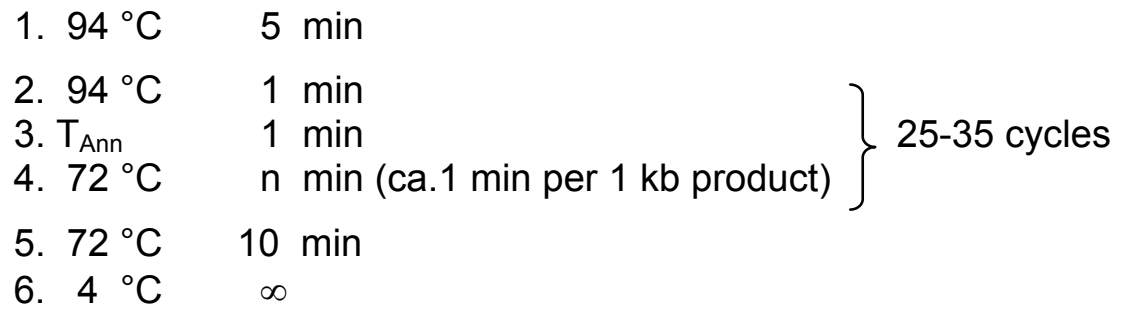

$\mathrm{T}_{\text {Ann }}$ is the annealing temperature of the primer pair used and it should be $2-3{ }^{\circ} \mathrm{C}$ lower than the melting temperature $\left(T_{m}\right)$ of this primer pair (see 2.9.2.). After the reaction, $5 \mu \mathrm{l}$ of the reaction mixture were analyzed on a TEA-agarose gel (see 2.6.1.).

\subsubsection{Design of synthetic oligonucleotide primers}

PCR primers should be composed of 18-30 nucleotides, with a GC content of $40-60 \%$ and end on a $\mathrm{G}$ or $\mathrm{C}$ nucleotide. The primers used together in one PCR should have approximately the same melting temperature. This temperature can be calculated as follows:

$$
\mathrm{T}_{\mathrm{m}}\left[{ }^{\circ} \mathrm{C}\right]=69.3+0.41 *[\% \mathrm{G} / \mathrm{C}]-650 / \mathrm{n} \text {, }
$$


where $\mathrm{n}$ is the number of nucleotides in the primer. The primers should not be able to form any strong secondary structures in order to allow successful hybridisation with the complementary DNA sequence.

\subsection{Rapid amplification of cDNA ends (RACE): 5'-RACE}

The RACE (Frohman et al., 1988) is used to obtain full size cDNA sequences, when only a partial cDNA is available. To amplify the sequence between the known fragment and the 5 '-end, a 5'-RACE is performed.

At first, a reverse transcription reaction is performed with a gene-specific primer derived from the known part of the sequence. This is followed by cDNA tailing with IATP or dCTP using terminal deoxynucleotidyl transferase. The homopolymeric tails of the cDNAs are used to bind an anchor primer (5'- CTC GAG GAT CCG CGG CCG CT $18-3^{\prime}$ or 5'-GGC CAC GCG TCG ACT AGT ACG GGI IGG GII GGG IIG-3', respectively) in the following PCR, together with a second gene-specific primer that binds within the known sequence upstream of the primer used for reverse transcription. Here, ca. $20 \mu \mathrm{g}$ total RNA were used for cDNA synthesis according to 2.8 .

To remove unincorporated nucleotides after the RT reaction, the Concert ${ }^{\mathrm{TM}}$ Rapid PCR Purification System (Gibco BRL, Eggenstein, Germany) was used. The CDNA was eluted from the column with $50 \mu \mathrm{l}$ of $1 \times$ TdT buffer. The purified cDNA was used in the terminal deoxynucleotidyl transferase (TdT) reaction (Roychoudhury et al., 1976). The reaction mixture contained:

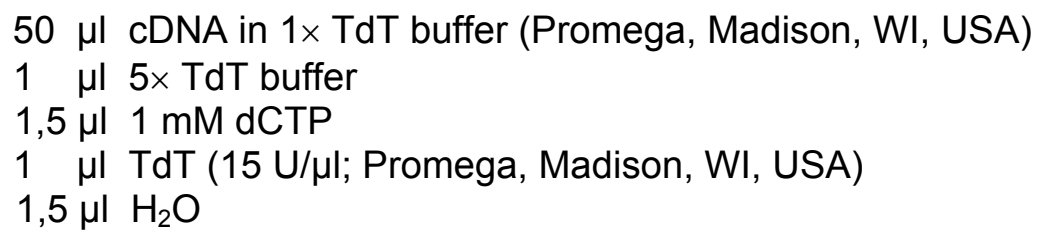

The reaction was carried out at $37{ }^{\circ} \mathrm{C}$ for $30 \mathrm{~min}$ and then stopped by $5 \mathrm{~min}$ incubation at $70^{\circ} \mathrm{C}$.

The PCR reaction for amplification of the $5^{\prime}$-part of the cDNA could be conducted in two different ways. For one step PCR, the anchor primer (see above) was used together with the second gene specific primer. For two-step PCR, first the template was amplified in a reaction involving the anchor primer and the first gene-specific primer, and then a second reaction was performed with a primer hybridizing to the non-homopolymeric part of the anchor primer (MM4 or MM4 new, see 2.1.3.) and the second gene specific primer. 
In each case, $5 \mu \mathrm{l}$ of the TdT-reaction was used for the first PCR. The second PCR was based on $2 \mu \mathrm{l}$ of the first PCR-mixture product.

\subsection{DNA sequencing}

DNA sequencing was based on the principle of Sanger et al. (1977), using a kit containing dideoxynucleotides labelled with dRhodamin („ABI PRISM dRhodamine Terminator Cycle Sequencing Ready Reaction Kit“; Perkin Elmer Applied Biosystems, Weiterstadt, Germany). The differently labelled ddNTPs have different absorption and emission spectra from 450 to $650 \mathrm{~nm}$, so that each of the four nucleotide types could be detected individually on a sequencer. The following reaction mixture for the polymerase reaction was used:

$\begin{array}{cl}2 \mu \mathrm{l} & \text { Terminator Ready Reaction Mix } \\ 200-300 \mathrm{ng} & \text { Plasmid DNA } \\ 5 \mathrm{pmol} & \text { Sequencing primer } \\ \text { ad } 10 \mu \mathrm{l} & \mathrm{dd} \mathrm{H}_{2} \mathrm{O}\end{array}$

Mostly, vector specific primers were used as sequencing primers (T3, T7, for (M13 forward primer), rev (M13 reverse primer); see 2.1.3.). The polymerase reaction was conducted in the programmed Thermocycler PTC ${ }^{\text {тм }}$ (Biozym, Hessisch Oldendorf, Germany) with the following program:

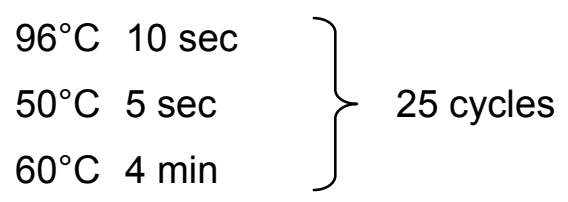

After the reaction, un-incorporated nucleotides were removed via an ethanol precipitation. $1 \mu \mathrm{l} \mathrm{Na-acetate/EDTA}$ buffer (1.5 M Na acetate; $250 \mathrm{mM}$ EDTA, pH $\geq 8.0$ ) and $36 \mu \mathrm{l}$ of $99.6 \%$ ethanol were added to the reaction mixture, mixed with a pipette and incubated for at least $45 \mathrm{~min}$ on ice. The precipitate was collected by centrifugation for 15 min at $13000 \mathrm{rpm}$, washed in $100 \mu$ of $70 \%$ ethanol and centrifuged again for $10 \mathrm{~min}$ at $13000 \mathrm{rpm}$. Afterwards the supernatant was discarded. The pellet was dried at $90{ }^{\circ} \mathrm{C}$ for $1 \mathrm{~min}$, resuspended in $20 \mu \mathrm{l}$ of Template Suppression Reagent (Perkin Elmer Applied Biosystems, Weiterstadt, Germany) and finally denatured at $95{ }^{\circ} \mathrm{C}$ for $2 \mathrm{~min}$. The sample was sequenced automatically in an ABI Prism 310 Genetic Analyser (Perkin Elmer Life Sciences Ltd, UK). 
Amino acid and nucleotide sequences of known cDNAs, proteins and vectors were obtained from GenBank at the National Center for Biotechnology Information (Altschul et al., 1990; http://www.ncbi.nlm.nih.gov). For the alignment of sequences, the Wisconsin Package programm from Genetics Computer Group (GCG; Madison, WI, USA) was applied which was available through the Gesellschaft für wissenschaftliche Datenverarbeitung Göttingen (GWDG). The programs seqed, map, bestfit, lineup, assemble, peptidesort and translate were used.

The full length sequences of the $M$. truncatula and $D$. glomerata hexose transporter cDNAs were obtained from SEQLAB Sequence Laboratories Göttingen $\mathrm{GmbH}$ (Göttingen, Germany).

\subsection{Cloning methods}

\subsubsection{Digestion with restriction enzymes}

Restriction enzymes recognize sequences in double-stranded DNA and cut them corresponding to enzyme specificity, producing „blunt ends“, or cohesive („sticky“) ends of DNA with overhanging $5^{\prime}$ - or $3^{\prime}$-ends. Reaction conditions were as recommended by the manufacturers. For characterization of plasmid DNA mini-preparation (see 2.4.1.) $5 \mathrm{U}$ restriction enzyme were used per $1 \mu \mathrm{g}$ DNA. For fragment isolation from clone vector or vector linearization $20 \mathrm{U}$ enzyme per $10 \mu \mathrm{g}$ DNA were used. Digestion was carried out for at least 1 hour at $37^{\circ} \mathrm{C}$.

\subsubsection{Phosphatase treatment}

To increase the probability of the insertion of a fragment into a plasmid during ligation, the digested plasmids were in some cases treated with alkaline phosphatase. This enzyme removes the phosphate residue on the $5^{\prime}$-end of a DNA double strand, and thus prevents vector religation. Afterwards only ligation with an insert carrying an intact $5^{\prime}$-phosphate group is possible. Phosphatase treatment can be very helpful when ligating (see 2.12.5.) vector and insert with "blunt" ends, which otherwise results in very low insertion efficiency.

After digestion (2.12.1) with a restriction enzyme, the reaction mixture was supplied with 0.1 volume of $10 \times$ dephosphorylation buffer and $1 \mu$ of alkaline phosphatase (20 U/ $\mu \mathrm{l}$, stored at $4{ }^{\circ} \mathrm{C}$; Roche Molecular Biochemicals, Mannheim, Germany). Then incubation followed at $37^{\circ} \mathrm{C}$ for $30 \mathrm{~min}$. Before ligation, the linearized plasmid was purified 
from restriction enzyme and phosphatase by phenol-chloroform extraction (2.5.2.) and ethanol precipitation (2.5.1.).

10× dephosphorylation buffer:

$$
\begin{array}{lr}
\text { Tris/ } \mathrm{HCl} \mathrm{pH} 8.5 & 0.5 \mathrm{M} \\
\text { EDTA } & 1 \mathrm{mM}
\end{array}
$$

\subsubsection{Filling-in of $5^{\prime}$ overhanging ends with Klenow fragment}

When a fragment had to be cloned, but no compatible restriction site was available in the vector, blunt-end cloning was performed. In this case, restriction enzymes producing either blunt or 5' overhanging ends were used, and for the latter, single-stranded DNA ends were filled-in using Klenow fragment (MBI Fermentas, Vilnius, Lithuania) to obtain blunt ends. A fill-in reaction contained:

$\begin{array}{ll}\text { 10× Klenow buffer } & 4 \mu \mathrm{l} \text { (MBI Fermentas) } \\ \text { Klenow fragment } 2 \mathrm{U} / \mu \mathrm{l} & 1 \mu \mathrm{l}(\text { ca. } 1 \mathrm{U} \text { per } \mu \mathrm{g} \text { DNA) } \\ 10 \mathrm{mM} \text { dNTPs } & 4 \mu \mathrm{l} \\ \text { DNA } & 2 \mu \mathrm{g} \\ \text { dd } \mathrm{H}_{2} \mathrm{O} & \mathrm{ad} 40 \mu \mathrm{l}\end{array}$

The reaction took place at $37^{\circ} \mathrm{C}$ for no longer than 20 min to prevent that Klenow polymerase, after using up the free dNTPs, acted as $3^{\prime} \rightarrow 5^{\prime}$ exonuclease. The DNA fragment was purified from enzyme and nucleotides via an agarose gel using the QIAquick ${ }^{\mathrm{TM}}$ Gel Extraction Kit (see 2.12.4.).

\subsubsection{Isolation of DNA fragments from agarose gels}

After the digestion of DNA with restriction enzymes or after PCR, the fragments produced could be separated on an agarose gel (see 2.6.1.) with large slots holding up to $50 \mu \mathrm{l}$ of reaction mixture. The DNA band of interest was excised with a scalpel under UV-light and then extracted from the gel using the QIAquick ${ }^{\mathrm{TM}}$ Gel Extraction Kit (Qiagen, Hilden, Germany). This kit is based on the selective binding of nucleic acids to kiesel gel particles at high salt concentrations. DNA was eluted with $25 \mu \mathrm{ld} \mathrm{H}_{2} \mathrm{O}$, and the DNA concentration in the eluate was determined by running $1 / 10$ volume on an agarose gel. 


\subsubsection{Ligation}

Ligation is the formation of a phosphodiester bond between the $5^{\prime}$-end and 3 '-end of one or two DNA molecules, catalyzed by DNA ligase. DNA ligase requires a free - $\mathrm{OH}$ group at the $3^{\prime}$-end of one DNA chain and a phosphate group at the $5^{\prime}$-end of the other. If either both fragments or open plasmid have "blunt" ends or if they have compatible cohesive ends, ligation is possible.

Ligations were conducted at $15^{\circ} \mathrm{C}$ overnight in a volume of $10 \mu \mathrm{l}$, containing about $10 \mathrm{ng}$ vector, $100 \mathrm{ng}$ insert, $2 \mu \mathrm{l} 5 \times$ ligation buffer $(660 \mathrm{mM}$ Tris/ $\mathrm{HCl}, \mathrm{pH} 7.6 ; 50 \mathrm{mM}$ $\mathrm{MgCl}_{2} ; 10 \mathrm{mM}$ DTT; $10 \mathrm{mM} \mathrm{ATP}$ ) and 1-5 units of T4-Ligase (Gibco BRL, Eggenstein, Germany).

PCR products were ligated into the cloning vector pGEM ${ }^{\circledR}-\mathrm{T}$ Easy (Promega, Madison, WI, USA). This vector has $3^{\prime}$ overhanging T-residues on both sides of the insertion site which makes it suitable for the cloning of PCR products because Taq and Tth polymerases leave overhanging $A$ residues on the $3^{\prime}$-ends of amplified DNA fragments. In this case a ligation reaction contained:

$0.5 \mu \mathrm{l} \mathrm{pGEM}{ }^{\circledR}-\mathrm{T}$ Easy Vector $(50 \mathrm{ng} / \mu \mathrm{l})$

$5.0 \mu \mathrm{l} 2 \times$ Ligase buffer (Promega)

$1.0 \mu \mathrm{l} \mathrm{T4}$ DNA ligase (Promega)

$3.5 \mu \mathrm{l} \mathrm{PCR}$ product

2× T4 DNA ligase buffer: $60 \mathrm{mM}$ Tris/ $\mathrm{HCl} \mathrm{pH} 7.8$

$20 \mathrm{mM} \mathrm{MgCl} 2$

$20 \mathrm{mM}$ DTT

$2 \mathrm{mM}$ ATP

Five $\mu \mathrm{l}$ of a ligation reaction were used for transformation of E.coli DH5a (see 2.13.2.), the rest of the reaction was kept for a few days at $4{ }^{\circ} \mathrm{C}$ in case that the transformation had to be repeated.

\subsection{Transformation of Escherichia coli}

\subsubsection{Preparation of competent E.coli cells}

To obtain optimal competent cells, the glassware used in the protocol had to be free of any detergents. For this purpose, glassware was first autoclaved filled with $\mathrm{dd} \mathrm{H}_{2} \mathrm{O}$ to remove traces of detergents, and then autoclaved again empty.

The preparation of competent E.coli cells (strain $\mathrm{DH} 5 \alpha$, see 2.1.2. for genotype) was conducted according to the method of Inoue et al. (1990) with some modifications. This 
method produces competent cells with high transformation efficiency, which could be stored for a long time at $-80^{\circ} \mathrm{C}$.

Five $\mathrm{ml} \mathrm{SOC}$ medium in a $50 \mathrm{ml}$ Falcon tube were inoculated with $\mathrm{DH} 5 \alpha$ and incubated (shaking) overnight at $37^{\circ} \mathrm{C}$. Then the overnight culture was transferred into a 2 I Erlenmeyer flask containing $200 \mathrm{ml} \mathrm{SOC}$ medium and incubated further at $37^{\circ} \mathrm{C}$ up to an $\mathrm{OD}_{600}$ of 0.2 . Then the incubation proceeded at $18{ }^{\circ} \mathrm{C}$ until an $\mathrm{OD}_{600}$ of $0.3-0.4$ was reached and the cells could be harvested. For this purpose the culture was divided into four Falcon tubes and centrifuged at $4000 \mathrm{rpm}$ in a Megafuge 1.0 (Heraeus Sepatech, Osterode, Germany) at $4{ }^{\circ} \mathrm{C}$ for $10 \mathrm{~min}$. Each of the bacterial pellets was resuspended on ice in $15 \mathrm{ml}$ of cold transformation buffer, followed by incubation on ice for $15 \mathrm{~min}$. Afterwards, the cell suspensions were collected into two Falcon tubes and centrifuged for $10 \mathrm{~min}$ at $4000 \mathrm{rpm}$ and $4{ }^{\circ} \mathrm{C}$. Each pellet was resuspended in $10 \mathrm{ml}$ of cold transformation buffer and supplied with $350 \mu \mathrm{l}$ of DMSO under light shaking. After 5 min incubation on ice, $350 \mu \mathrm{l}$ of DMSO were added again to the cell suspension under light shaking, followed again by $5 \mathrm{~min}$ incubation on ice. Then the competent cells were aliquoted into sterile Eppendorf tubes (200 $\mu$ l per tube) and shock-frozen in liquid nitrogen. Competent cells were stored at $-80^{\circ} \mathrm{C}$.

Transformation buffer:

10 mM PIPES

$15 \mathrm{mM} \mathrm{CaCl}_{2}$

$250 \mathrm{mM} \mathrm{KCl}$

$\mathrm{pH}$ adjusted to 6.7 with $\mathrm{KOH}$

ad $55 \mathrm{mM} \mathrm{MnCl}_{2}$

sterile filtration

\subsubsection{Transformation of competent E.coli cells}

To transform E.coli DH5 $\alpha$, a $200 \mu$ l aliquot of competent cells was thawed on ice. Then 5 $\mu \mathrm{l}$ of ligation mixture (see 2.12.5.) or $0.5-1 \mu \mathrm{l}$ of plasmid DNA was added to the competent cells, mixed by pipetting and incubated on ice for $20 \mathrm{~min}$. After a $30 \mathrm{sec}$ heat shock at $42{ }^{\circ} \mathrm{C}$, the sample was transferred back on ice and $1 \mathrm{ml} \mathrm{SOC}$ medium (see 2.1.8.2.) was added. In SOC medium, the bacteria were incubated for 1 hour at $37^{\circ} \mathrm{C}$. Then, they were plated on two plates (200 and $1000 \mu \mathrm{l}$ of culture, respectively) for selection on LB-agar with the appropriate antibiotics and incubated overnight at $37^{\circ} \mathrm{C}$. 


\subsubsection{Characterization of transformants}

The appearance of antibiotic resistant colonies shows the success of the transformation. The presence of the insert in the vector has to be shown by plasmid isolation and restriction.

Some vectors (for example, pGEM ${ }^{\circledR}$-T Easy (Promega, Madison, WI, USA) or pBluescript $^{\circledR}$ II KS (+/-) (Stratagene, La Jolla, CA, USA)) allow a blue-white colony selection on LB-Amp-IPTG-X-Gal indicator plates (see 2.1.8.2. and 2.1.8.4.). These vectors contain a poly-linker in the coding region of E.coli gene lacZ', encoding the $\alpha$ peptide of $\beta$-galactosidase, and part of the lac operon promoter. Bacteria containing a vector without insert are characterized by an intact lacZ gene. IPTG induces the expression of the lac promoter, i.e. of $\beta$-galactosidase, which metabolises the colourless $X-G a l$ into a blue product, so colonies containing the empty vector can be recognised by their blue colour. Successful cloning of an insert in pGEM ${ }^{\circledR}-T$ Easy or pBluescript ${ }^{\circledR}$ II KS $(+/-)$ interrupts the coding sequence of the $\beta$-galactosidase, and therefore, recombinant clones can usually be identified by their white colour on IPTG/X-Gal containing plates. In some cases, however, blue colonies can result from inserts that are cloned in-frame with the lacZ gene.

For plasmid characterization, plasmid DNA has to be isolated (see 2.4.1.) from selected clones followed by digestion with (an) appropriate restriction enzyme(s) (see 2.12.1.). This reveals the presence and the size of insert after electrophoretic separation of the digested DNA on an agarose gel.

If white-blue selection of clones is not possible, a PCR (see 2.9.1.) can be applied for the identification of positive (insert-containing) colonies: the so-called "colony PCR". At the same time, colony PCR can be used to determine the orientation of the insert in the vector (sense or antisense), using an insert-specific and vector-specific primer. For this purpose, single growing bacterial colonies were picked with a toothpick and each was first used to inoculate $10 \mu \mathrm{ldd} \mathrm{H}_{2} \mathrm{O}$ in $0.5 \mathrm{ml}$ Eppendorf tubes, and then $4 \mathrm{ml}$ LB medium with the appropriate antibiotic. For a screening 20-40 colonies were picked. LB cultures were incubated overnight at $37{ }^{\circ} \mathrm{C}$ with shaking. The Eppendorf tubes containing $\mathrm{dd} \mathrm{H}_{2} \mathrm{O}$ with bacteria were used for colony PCR. Insert- or vector-specific primers were used.

After the PCR program was finished the products could be electrophoretically separated on an agarose gel (see 2.6.1.) to choose a clone with an insert of the expected size/orientation for mini-preparation of plasmid DNA (see 2.4.1.). 
Colony PCR reaction mixture:

$\begin{array}{ll}2.5 \mu \mathrm{l} & 10 \times \text { Taq-buffer } \\ 1.5 \mu \mathrm{l} & 25 \mathrm{mM} \mathrm{MgCl}_{2} \\ 0.5 \mu \mathrm{l} & 10 \mathrm{mM} \text { dNTP } \\ 0.5 \mu \mathrm{l} & 3^{\prime} \text {-primer } \\ 0.5 \mu \mathrm{l} & 5^{\prime} \text {-primer } \\ 0.5 \mu \mathrm{l} & \text { Taq polymerase } \\ 10 \mu \mathrm{l} & \text { template (dd } \mathrm{H}_{2} \mathrm{O} \\ \text { inoculated with bacteria) } \\ \text { ad } 25 \mu \mathrm{l} \quad \mathrm{H}_{2} \mathrm{O}\end{array}$

\section{PCR program:}

$94^{\circ} \mathrm{C} 5$ min (lysis of bacteria)

$94{ }^{\circ} \mathrm{C} 30 \mathrm{sec}$

$\mathrm{T}_{\text {Ann }} \quad 30 \mathrm{sec}$

$72{ }^{\circ} \mathrm{C} 1 \mathrm{~min} / 1 \mathrm{~kb}$ product 30 cycles

$72{ }^{\circ} \mathrm{C} 10 \mathrm{~min}$

\subsection{Yeast transformation}

The yeast strain Saccharomyces cerevisiae EBY.VW.4000 (Wieczorke et al., 1999; see 2.1.2. for genotype) was used to investigate in vivo transport activity of plant hexose transporters. Yeast transformation was carried out corresponding to the protocol of Sauer and Stolz (2000).

Cells were grown overnight in $25 \mathrm{ml}$ of complete medium YPM (see 2.1.8.3.) on a rotary shaker at $29{ }^{\circ} \mathrm{C}$. Then the $\mathrm{OD}_{600}$ of the cells was determined and they were diluted into $50 \mathrm{ml}$ of pre-warmed $\left(29{ }^{\circ} \mathrm{C}\right)$ YPM to a final $\mathrm{OD}_{600}$ of 0.5 . Afterwards, cells were grown to an $\mathrm{OD}_{600}$ of 2.0 and harvested by centrifugation at $3000 \times \mathrm{g}$ for $3 \mathrm{~min}$. The

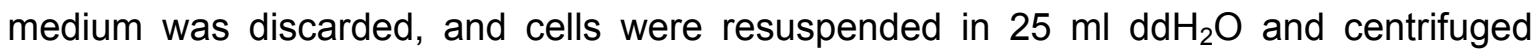
again. After the supernatant had been discarded, cells were resuspended in $1 \mathrm{ml}$ of 100 $\mathrm{mM}$ lithium acetate and transferred to a $1.5 \mathrm{ml}$ microcentrifuge tube. The cells were pelleted at top speed for $15 \mathrm{sec}$. The supernatant was removed with a pipette. Finally, cells were resuspended in $0.5 \mathrm{ml}$ of $100 \mathrm{mM}$ lithium acetate and divided into 10 portions of $50 \mu \mathrm{l}$ each, yielding 10 samples for 10 transformations. The cells were pelleted for $15 \mathrm{sec}$ and, after the supernatant had been removed with a pipette, to each tube was added in the given order:

$$
\begin{array}{rl}
240 \mu \mathrm{l} & 50 \%(\mathrm{w} / \mathrm{v}) \mathrm{PEG} \\
36 \mu \mathrm{l} & 1 \mathrm{M} \text { lithium acetate } \\
25 \mu \mathrm{l} & \text { carrier DNA (see below) } \\
50 \mu \mathrm{l} & \text { dd } \mathrm{H}_{2} \mathrm{O} \text { with } 1-5 \mu \mathrm{g} \text { of plasmid DNA }
\end{array}
$$

Each tube was vortexed vigorously to resuspend the cells and then incubated first at $30{ }^{\circ} \mathrm{C}$ for $30 \mathrm{~min}$, and then at $42{ }^{\circ} \mathrm{C}$ for $20 \mathrm{~min}$. After centrifugation for $60 \mathrm{sec}$ at $5000 \times$ $\mathrm{g}$, the supernatant was removed with a pipette and the pellet was resuspended in $1 \mathrm{ml}$ of dd $\mathrm{H}_{2} \mathrm{O}$ by pipetting up and down. Aliquots of 2-200 $\mu \mathrm{l}$ were plated on selection medium (CAA for NEV-constructs; see 2.1.8.3.), and plates were incubated at $29^{\circ} \mathrm{C}$ for $2-4$ days. 
Carrier DNA: High molecular weight DNA from salmon testes was added to TE buffer (10 mM Tris/ $\mathrm{HCl} \mathrm{pH}$ 8.0, $1 \mathrm{mM}$ EDTA) to a final concentration of $2 \mathrm{mg} / \mathrm{ml}$ and dispersed by repeated pipetting and vigorous stirring on a magnetic stirrer. Stirring was stopped when the viscosity of the solution had decreased. Aliquots were stored at $-20^{\circ} \mathrm{C}$ and heat-denatured by boiling at $100{ }^{\circ} \mathrm{C}$ for 5 min prior to use, followed by quick chilling on ice.

\subsection{Bacterial and yeast glycerol cultures}

Original strains of E. coli, S. meliloti or S. cerevisiae, or strains containing characterized plasmids were grown overnight in $5-20 \mathrm{ml}$ of full medium supplemented with the appropriate antibiotic(s) (for bacterial strains) at the appropriate temperature $\left(37^{\circ} \mathrm{C}\right.$ for $E$. coli, $28-30{ }^{\circ} \mathrm{C}$ for yeast). $200 \mu \mathrm{l}$ of $87 \%$ glycerol were pipetted into plastic tubes with screw tops and autoclaved. $800 \mu \mathrm{l}$ of bacterial or yeast culture were added, vortexed, shock-frozen in liquid nitrogen and stored at $-80{ }^{\circ} \mathrm{C}$.

\subsection{Extraction of sugars}

\subsubsection{Chloroform-methanol extraction}

To isolate water-soluble sugars from roots and nodules, chloroform-methanol extraction was used. Nodules or roots were frozen in liquid nitrogen, stored at $-80{ }^{\circ} \mathrm{C}$ and ground to a fine powder in liquid nitrogen using mortar and pestle. About $300 \mathrm{mg}$ of powder were put in a pre-cooled $10 \mathrm{ml}$ plastic tube on ice containing $5 \mathrm{ml}$ of a chloroform/methanol mixture $(1.5: 3.5 \mathrm{v} / \mathrm{v})$, mixed shortly and incubated on ice for $30 \mathrm{~min}$. Then $3 \mathrm{ml}$ of $\mathrm{dd} \mathrm{H}_{2} \mathrm{O}$ were added to the homogenate, and the sample was mixed vigorously for $2 \mathrm{~min}$. The separation of two phases (the upper water/methanol phase and the lower chloroform phase) was achieved by centrifugation of the samples at $5000 \mathrm{rpm}$ for $5 \mathrm{~min}$ in a Hettich EBA $3 \mathrm{~S}$ centrifuge (Hettich, Tuttlingen, Germany). The upper (aqueous) phase was saved in a round-bottom evaporation glass and the rest was extracted once again with 3 $\mathrm{ml}$ of water. The aqueous phases were combined and dried completely in a rotary evaporator at $37{ }^{\circ} \mathrm{C}$. The dried residues were dissolved in $1.5 \mathrm{ml}$ ultra pure $\mathrm{H}_{2} \mathrm{O}$ (Millipore), filtered through a syringe with a cellulose-nitrate membrane filter $(0.45 \mu \mathrm{m}$; Schleicher and Schuell, Dassel, Germany) and stored at $-80^{\circ} \mathrm{C}$. 


\subsubsection{Preparative isolation of unknown sugars / sugar derivates from Datisca}

Analysis of the sugars from Datisca glomerata roots and nodules showed these organs contained high concentrations of an unknown sugar derivate (up to 6 and $13.5 \mu \mathrm{mol} / \mathrm{g} \mathrm{FW}$ in roots and nodules, respectively, when calculated on the basis of molecular weight of ribitol, a sugar with the nearest retention time to the unknown HPLC peak). This unknown metabolite ("D") was isolated for the analysis of its chemical structure by NMR, conducted at the Institute for Organic Chemistry, University of Göttingen.

The method of Pharr et al. (1987) was used with some modifications. $150 \mathrm{~g}$ of $D$. glomerata were ground to a powder in liquid nitrogen and extracted in 1.5 I of a chloroform/methanol mixture on ice for $30 \mathrm{~min}$ (see 2.16.1.). Then, $900 \mathrm{ml} \mathrm{dd} \mathrm{H}_{2} \mathrm{O}$ were added and phases were separated by centrifugation for at least $20 \mathrm{~min}$ at $11600 \times \mathrm{g}$ (Sorvall DuPont, Dreieich, Germany; rotor GS3). The upper (aqueous) phase containing the water-soluble metabolites was saved. The rest was extracted once again with $900 \mathrm{ml}$ dd $\mathrm{H}_{2} \mathrm{O}$. The upper phases from both centrifugation steps were combined and the volume was reduced to $100 \mathrm{ml}$ in a rotary evaporator at $37^{\circ} \mathrm{C}$. Then, cations were removed from the extract by adding $20 \mathrm{~g}$ of a cation exchanger Dowex® $50 \mathrm{~W} \times 8\left(200-400\right.$ mesh, in $\mathrm{H}^{+}$form) (Serva Electrophoresis, Heidelberg, Germany) and stirring for $30 \mathrm{~min}$. The extract was filtered through a paper to remove Dowex particles, and the procedure was repeated with 1/10 volume of Polyclar ${ }^{\circledR}$ AT (Serva) to remove polyphenols and polysaccharides. Polyclar ${ }^{\circledR}$ AT was pelleted by $10 \mathrm{~min}$ centrifugation in a Megafuge 1.0 (Heraeus Sepatech, Osterode, Germany). The volume of the supernatant was reduced to $10 \mathrm{ml}$ in a rotary evaporator at $37^{\circ} \mathrm{C}$ and the concentrate was applied to an anion exchange column of $50 \mathrm{~cm}$ length and $2.8 \mathrm{~cm}$ diameter filled with Dowex ${ }^{\circledR} 1 \times 8$ (100-200 mesh, $\mathrm{OH}^{-}$-form). Passing the extract through the column allowed to remove anions and at the same time provided a separation of the extract into fractions with different sugar composition. The elution was done with $0.2 \mathrm{M} \mathrm{NaOH}$ at a rate of $2.5 \mathrm{ml} / \mathrm{min}$. 200 fractions of $5 \mathrm{ml}$ per fraction were collected. Sugar composition of the fractions was determined by HPLC (see 2.17.). "D" eluted after about 2 hours and was found in the fractions No. 59 to 70 . No other sugars were detectable in these fractions. The "D"-containing fractions were combined and neutralized using $5 \mathrm{M} \mathrm{HCl}$. This step was necessary because the presence of $0.2 \mathrm{M} \mathrm{NaOH}$ in the eluate might lead to the condensation (caramelisation) of sugars under alkaline conditions during the following concentration of the combined fractions. Then, the volume of the combined fractions was reduced to $10 \mathrm{ml}$ in the rotary evaporator at $37^{\circ} \mathrm{C}$. In this step a very high concentration of $\mathrm{NaCl}$ (up to $2 \mathrm{M}$ ) was achieved which could disturb the following sugar analysis. Therefore, $\mathrm{NaCl}$ and " $\mathrm{D}$ " were separated by descendent paper chromatography. Two pieces of $18 \mathrm{~cm} \times 45 \mathrm{~cm}$ chromatography paper 
Whatman Chr 17 were used. The running solution was n-propanol : ethyl acetate : $\mathrm{H}_{2} \mathrm{O}=$ $7: 1: 2(\mathrm{v} / \mathrm{v})$. For the detection of the isolated sugars, thin strips were cut off and developed in detection solution ( $2.5 \mathrm{ml}$ of a saturated $\mathrm{AgNO}_{3}$ solution in $500 \mathrm{ml}$ acetone) for $2.5 \mathrm{~min}$. The strips were then transferred to the stop solution $\left(10 \mathrm{~g} \mathrm{NaOH}\right.$ in $15 \mathrm{ml} \mathrm{H}_{2} \mathrm{O}$ added to $500 \mathrm{ml}$ of $96 \%$ ethanol). $\mathrm{NaCl}$ moved along the chromatogram faster than " $\mathrm{D}$ ". The part of the chromatogram containing " $D$ " was cut into pieces and " $D$ " was eluted with $200 \mathrm{ml} \mathrm{dd} \mathrm{H}_{2} \mathrm{O}$ in an ultrasonication bath for 20 min (Branson Sonifier B 15, Branson Ultrasonics Corp., Geneva, Switzerland). The elution was repeated three times. The eluates $(600 \mathrm{ml}$ in total) were combined and the volume was reduced in a rotary evaporator at $37{ }^{\circ} \mathrm{C}$ to concentrate " $D$ ". Then, the end concentration of " $D$ " was determined by HPLC (see 2.17.). A $1 \mathrm{ml}$ aliquot of this solution was dried in a Speed Vac concentrator and used for analysis of the chemical structure by NMR at the Institute for Organic Chemistry at the University of Göttingen.

Analysis of the sugar contents of Datisca glomerata roots and nodules revealed also a high concentration of another sugar related compound with a HPLC retention time close to that of myo-inositol, called "M". Its preparative isolation was carried out simultaneously with the isolation of "D" (described above) from the same extract. "M" was detected in fractions No. 30 to 50 . No other sugars were detectable in these fractions. Isolation proceeded as described above. Aliquots of $\mathrm{M}$ were also dried in a Speed Vac Concentrator (Bachofer, Reutlingen, Germany) and used for the analysis of its chemical structure by nuclear magnetic resonance spectroscopy (NMR) and mass spectroscopy, and the NMR correlation spectroscopy methods $\mathrm{H}, \mathrm{H}-\mathrm{COSY}$ and $\mathrm{C}, \mathrm{H}-\mathrm{COSY}$ by $\mathrm{Dr}$. R. Fortte at the Institute for Organic Chemistry at the University of Göttingen (in laboratory of Prof. Tietze).

\subsubsection{Ethanol extraction}

About $300 \mathrm{mg}$ root material was frozen in liquid nitrogen and then transferred into $8 \mathrm{ml}$ scintillation tubes with $2 \mathrm{ml} 10 \mathrm{mM}$ HEPES buffer in $80 \%$ ethanol $(\mathrm{pH} \mathrm{7.0)}$ prewarmed to $80{ }^{\circ} \mathrm{C}$, and incubated in a shaking water bath at $80{ }^{\circ} \mathrm{C}$ for $30 \mathrm{~min}$. Then the supernatant was transferred to a round-bottom evaporation glass and the rest was extracted again with $1 \mathrm{ml} 10 \mathrm{mM}$ HEPES buffer in $70 \%$ ethanol (pH 7.0). The supernatant was combined with the extract in a round-bottom evaporation glass, and the pellet was extracted again with $1 \mathrm{ml} 10 \mathrm{mM}$ HEPES buffer in $50 \%$ ethanol $(\mathrm{pH} \mathrm{7.0)}$ for $30 \mathrm{~min}$ in a shaking water bath at $80{ }^{\circ} \mathrm{C}$. All supernatants were combined in the evaporation glass and dried completely in a rotary evaporator at $37^{\circ} \mathrm{C}$. The dried residues were dissolved in $2 \mathrm{ml}$ ultra 
pure $\mathrm{H}_{2} \mathrm{O}$ (Millipore), filtered through a syringe with a cellulose-nitrate membrane filter $\left(0.45 \mu \mathrm{m}\right.$; Schleicher and Schuell) and stored at $-80{ }^{\circ} \mathrm{C}$.

\subsubsection{Perchlorate extraction}

About $300 \mathrm{mg}$ root material was frozen in liquid nitrogen, stored at $-80^{\circ} \mathrm{C}$ and ground to a fine powder in liquid nitrogen using mortar and pestle. After the liquid nitrogen was evaporated, $1 \mathrm{ml}$ perchloric acid solution (10\% $\mathrm{HClO}_{4}, 5 \mathrm{mM}$ EGTA) was added to the powder and ground further without cooling. After the sample had melted, it was transferred into an Eppendorf tube using a pipette with a cut-off tip and centrifuged for 3 $\min$ at $13 \mathrm{krpm}$. The supernatant was transferred into new $2 \mathrm{ml}$ Eppendorf tubes, neutralized to $\mathrm{pH}$ 7.0-7.5 using potassium hydroxide-triethanolamine solution $(5 \mathrm{M} \mathrm{KOH}$, $1 \mathrm{M}$ TEA) and incubated for $15 \mathrm{~min}$ on ice. Then precipitated $\mathrm{KClO}_{4}$ was spun down by 10 min centrifugation at $13 \mathrm{krpm}$, and the supernatant was saved in a new Eppendorf tube and stored at $-80^{\circ} \mathrm{C}$.

\subsubsection{Acetone extraction}

Roots were frozen in liquid nitrogen, stored at $-80{ }^{\circ} \mathrm{C}$ and ground to a fine powder in liquid nitrogen using mortar and pestle. About $650 \mathrm{mg}$ of powder were put in a pre-cooled $10 \mathrm{ml}$ plastic tube on ice containing $5 \mathrm{ml}$ of $90 \%$ acetone. Sugars were extracted overnight by shaking at $4{ }^{\circ} \mathrm{C}$. Afterwards, the sample was centrifuged at $4300 \mathrm{rpm}$ in a Megafuge 1.0 (Heraeus Sepatech, Osterode, Germany) at $4{ }^{\circ} \mathrm{C}$ for $10 \mathrm{~min}$. The supernatant was transferred to a round-bottom evaporation glass and dried completely in a rotary evaporator at $37{ }^{\circ} \mathrm{C}$. The dried residues were dissolved in $1.5 \mathrm{ml}$ ultra pure $\mathrm{H}_{2} \mathrm{O}$ (Millipore), filtered through a syringe with a cellulose-nitrate membrane filter $(0.45 \mu \mathrm{m}$; Schleicher and Schuell) and stored at $-80^{\circ} \mathrm{C}$.

\subsection{Sugar analysis by high-performance liquid chromatography (HPLC)}

Sugars in root and nodule extracts were assayed by HPLC using pulse amperometrical detection. The sugars were separated over an anion exchange column MA1 (CarboPAC10; Dionex Corp, Sunnyvale, CA, USA) with a pre-column (CarboPAC10 Guard; Dionex Corp), which allowed a better resolution of polyols and cyclitols, and eluted with $600 \mathrm{mM} \mathrm{NaOH}$ using a LC-9A pump from Shimatzu (Kyoto, Japan) with a flow rate of 
$0.4 \mathrm{ml} \mathrm{min}{ }^{-1}$. Sodium hydroxide solution was prepared using Millipore water purified with helium for 15 min to prevent the formation of $\mathrm{NaHCO}_{3} . \mathrm{NaOH}(50 \%)$ of the purest commercially available quality was used (Malinckrodt Baker B.V., Deventer, The Netherlands) in order to obtain a stable baseline.

The autosampler (\# 2157, LKB Pharmacia, Gräfelfing, Germany) was thermostated at $12{ }^{\circ} \mathrm{C}$. Sugars were detected by a thin layer amperometric cell (ESA, Model 5200, Chelmsford, MA, USA) with a gold electrode. A Pulse Amperometric Detector (Coulochem II, ESA, Chelmsford, MA, USA) was set according to the following scheme:

$\begin{array}{llll}\text { pulse mode } & \text { voltage } & \text { duration } & \text { Measure } \\ \text { Measurement } & 50 \mathrm{mV} & 500 \mathrm{~ms} & 400 \mathrm{~ms} \\ \text { Clearance } & 700 \mathrm{mV} & 540 \mathrm{~ms} & \\ \text { Regeneration } & -800 \mathrm{mV} & 540 \mathrm{~ms} & \end{array}$

The calibration was done with sugar concentrations of $50 \mu \mathrm{M}, 100 \mu \mathrm{M}, 250 \mu \mathrm{M}$ and $500 \mu \mathrm{M}$. Myo-inositol, sorbitol, ribitol, mannitol, glucose, fructose, ribose, sucrose, raffinose, verbascose and stachyose were used as standards and showed a linear range of the detector response between 50 and $500 \mu \mathrm{M}\left(r^{2}=0.99\right)$. Sugar hydrolysis products were compared with another calibrated standard, containing myo-inositol, arabitol, xylitol, fucose, ribose, galactose, glucose, fructose and rhamnose. Plant samples were diluted before measurements to provide concentrations within the linear range. The evaluation of chromatograms was performed with the integrated program Peaknet 5.1 (Dionex, Idstein, Germany).

\subsection{Sugar analysis}

To identify the unknown saccharides isolated from Datisca glomerata and termed "M" and "D" (see 2.16.2), the identity of the sugar residues and the conformation of the bonds had to be determined. For this purpose, $M$ and $D$ were hydrolyzed using both hydrochloric acid and with different glycosidases.

\subsubsection{Acid hydrolysis}

For hydrolysis of $\mathrm{D}$ and $\mathrm{M}$ by hydrochloric acid, each saccharide was boiled for 1 hour in 1 $\mathrm{M} \mathrm{HCl}$ in the total volume of $50 \mu \mathrm{l}$ with a substrate concentration of about $0.5-1 \mathrm{mM}$. In preparation for HPLC analysis, the sample was twice vacuum evaporated and then dissolved in $50 \mu \mathrm{ldd} \mathrm{H}_{2} \mathrm{O}$. For HPLC analysis the sample was diluted 1:2. 


\subsubsection{Enzymatic hydrolysis}

To determine whether the isolated saccharides represented $\alpha$-galactosylated compounds, an $\alpha$-galactosidase reaction was performed in $30 \mathrm{mM}$ sodium citrate buffer $(\mathrm{pH} 4.6)$ with a substrate concentration in a range of $0.5-1 \mathrm{mM}$. The reaction volume was $50 \mu \mathrm{l}$, and the reaction was started by adding $1 \mu \mathrm{l}$ a-galactosidase from green coffee bean $(0.05 \mathrm{U} / \mu \mathrm{l}$; Sigma). The reaction was stopped after 5,10 and $20 \mathrm{~min}$, respectively, by boiling for 3 $\min$. The samples were centrifuged for $5 \mathrm{~min}$ at $13000 \mathrm{rpm}$, and the supernatants were diluted 1:2 for HPLC analysis (see 2.17.).

To determine whether the isolated saccharides contained glucose at the nonreducing end, they were treated with $\alpha$ - and $\beta$-glucosidases, which hydrolyze terminal non-reducing $\alpha$ - and $\beta$-D-glucose residues, respectively. The reactions were performed in acetate buffer $(71 \mathrm{mmol} / /$; EDTA $0.96 \mathrm{mmol} / \mathrm{l})$ with $\mathrm{pH} 6.0$ for the $\alpha$-glucosidase reaction and 5.0 for the $\beta$-glucosidase reaction. The acetate buffer stock solution (0.1 M; EDTA $1.35 \mathrm{mM}$ ) was prepared the following way: $0.57 \mathrm{ml}$ acetic acid ( $96 \%$ ) were added to $80 \mathrm{ml}$ of $\mathrm{dd} \mathrm{H}_{2} \mathrm{O}$, then $50 \mathrm{mg}$ EDTA disodium salt monohydrate was dissolved in this solution, the $\mathrm{pH}$ was adjusted to 6.0 with $1 \mathrm{~N}$ sodium hydroxide and the final volume was adjusted to $100 \mathrm{ml}$ with dd $\mathrm{H}_{2} \mathrm{O}$. The reaction was performed in a volume of $50 \mu \mathrm{l}$ with a substrate concentration in the range of $0.5-1 \mathrm{mM}$ and was started by adding either $1 \mu \mathrm{l} \alpha-$

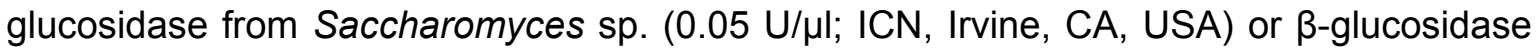
from almonds (0.05 $\mathrm{U} / \mu \mathrm{l}$; Sigma). In each case, the reaction was stopped after 5, 10 and $20 \mathrm{~min}$, respectively, by boiling for $3 \mathrm{~min}$. The samples were centrifuged for $5 \mathrm{~min}$ at 13 krpm, and the supernatants were diluted 1:2 for HPLC analysis (see 2.17.).

To prove the bond configuration between rhamnose and glucose in the isolated sugars, as well as the position of rhamnose at the non-reducing end, they were hydrolyzed with naringinase ( $\alpha$-rhamnosidase) from Penicillum decumbens $(0.05 \mathrm{U} / \mu \mathrm{l}$; Sigma). The reaction was conducted in $50 \mu \mathrm{l}$ of $0.1 \mathrm{M}$ sodium acetate buffer $(\mathrm{pH} 4)$ with a substrate concentration in the range of $0.5-1 \mathrm{mM}$ at $40{ }^{\circ} \mathrm{C}$, and started by adding $1 \mu \mathrm{l}$ enzyme. The reaction was stopped after 5, 10 and $20 \mathrm{~min}$, respectively, by boiling for 3 $\min$. The samples were centrifuged for $5 \mathrm{~min}$ at $13000 \mathrm{rpm}$, and the supernatants were diluted 1:2 for HPLC analysis (see 2.17.). 


\subsection{Sucrose synthase extraction and assay}

\subsubsection{Extraction of sucrose synthase (SuSy)}

The procedure was based on the method described by Winter et al. (1998). Plant tissue was ground to a fine powder in a mortar under liquid nitrogen and homogenized with 4 $\mathrm{ml} / \mathrm{g}$ plant material extraction buffer A (100 mM MOPS, $\mathrm{pH} 7.5 ; 10 \mathrm{mM} \mathrm{MgCl} ; 0.5 \mathrm{mM}$ $\mathrm{CaCl}_{2}$; $1 \mathrm{mM}$ EDTA; $2 \mathrm{mM}$ DTT; $20 \mathrm{mM} \mathrm{NaF} ; 1 \mathrm{mM}$ PMSF; $100 \mathrm{mM}$ sucrose). The homogenate was filtered through four layers of Miracloth (Schütt Labortechnik GmbH, Göttingen, Germany) and centrifuged at $100000 \times \mathrm{g}$ for $1 \mathrm{~h}$ at $4{ }^{\circ} \mathrm{C}$. The supernatant was desalted by centrifugal filtration on Sephadex-G25 (PD 10 desalting columns; Amersham Pharmacia Biotech, Freiburg, Germany), equilibrated with desalting buffer B (50 mM MOPS, pH 7.5), and concentrated in Fugisep Maxi ${ }^{\circledR}-30$ concentrators (Intersep, Witten, Germany) for $1 \mathrm{~h}$ at $4{ }^{\circ} \mathrm{C}$. Afterwards SuSy activity was assayed immediately. The protein concentration was determined according to Bradford (1976; see 2.23.).

\subsubsection{Sucrose synthase activity assay}

For the sucrose synthase assay, the following reaction mixture was prepared in a microcentrifuge tube and kept for a few minutes at the room temperature:

$\begin{array}{ll}60 \mu \mathrm{l} & \text { Buffer B (50 mM MOPS, pH 7.5) } \\ 30 \mu \mathrm{l} & 8 \mathrm{mM} \text { UDP in buffer B } \\ 30 \mu \mathrm{l} & 14 \mathrm{mM} \mathrm{MgCl}_{2}, 0.3 \mathrm{mM} \mathrm{CaCl}_{2} \\ 30 \mu \mathrm{l} & 0.8 \mathrm{M} \text { sucrose in buffer B }^{2}\end{array}$

The reaction was started by adding $100 \mu$ l extract, incubated for $10 \mathrm{~min}$ at $30{ }^{\circ} \mathrm{C}$ and stopped by boiling for $10 \mathrm{~min}$. Then, denatured protein was spun down by centrifuging for 10 min at $4{ }^{\circ} \mathrm{C}$, and the supernatant was transferred into a new microcentrifuge tube.

Sucrose synthase is a glycosyltransferase, converting sucrose into UDP-glucose and fructose in the presence of UDP. The sucrose synthase activity was analysed via determination of the UDP-glucose concentration in the following assay:

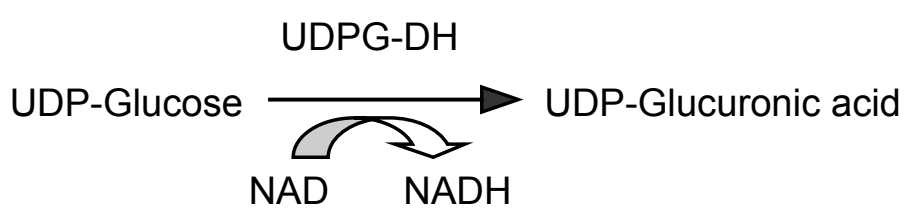


For the spectrophotometric assay of UDP-glucose, $900 \mu \mathrm{l}$ of assay buffer $(200 \mathrm{mM}$ glycine, $\mathrm{pH}$ 8.9; $5 \mathrm{mM} \mathrm{MgCl}_{2}$ ), $20 \mu \mathrm{l} 0.1 \mathrm{M} \mathrm{NAD}^{+}$and $100 \mu \mathrm{l}$ of sample were mixed in a cuvette. The reaction was started by adding $10 \mathrm{mU}$ UDP-Glucose-Dehydrogenase (Sigma). The measurements were conducted on a two wavelength spectrophotometer (Sigma ZFP 22; Sigma instrumente $\mathrm{GmbH}$, Berlin, Germany). The activity was calculated as the increase in absorbance due to the formation of NADPH using a molar extinction coefficient for NADPH of $6.18 \mathrm{mmol}^{-1} \mathrm{~cm}^{-1}$ at $334 \mathrm{~nm}$.

\subsection{Invertase extraction and assay}

\subsubsection{Extraction of invertase}

Plant tissue was ground to a fine powder in liquid nitrogen and homogenized with homogenization buffer ( $2 \mathrm{ml} / \mathrm{g}$ fresh weight (FW) tissue). PVPP (200 mg/g FW) was added to $D$. glomerata and C. glauca powder to bind polyphenols and polysaccharides. The homogenate was centrifuged at $6000 \times \mathrm{g}$ for $10 \mathrm{~min}$ at $4{ }^{\circ} \mathrm{C}$. The supernatant (cytosolic and vacuolar fraction) represented the soluble enzyme preparation. The pellet (cell-wall fraction) was washed three times with $\mathrm{dd} \mathrm{H}_{2} \mathrm{O}$ at $4{ }^{\circ} \mathrm{C}$ and finally resuspended again in dd $\mathrm{H}_{2} \mathrm{O}$. Both enzyme preparations were dialyzed against $12.5 \mathrm{mM} \mathrm{K}-\mathrm{Phosphate}$ buffer $(\mathrm{pH}$ 7.4 adjusted with $\mathrm{KH}_{2} \mathrm{PO}_{4}$ ) for 45 min twice and then overnight at $4{ }^{\circ} \mathrm{C}$. Afterwards the probes were collected into Eppendorf tubes and assayed for invertase activity (see 2.20.2.) or stored at $-80^{\circ} \mathrm{C}$ before analysis.

Homogenisation buffer:

$200 \mathrm{mM}$ HEPES/NaOH, pH 7.5
$3 \quad \mathrm{mM} \mathrm{DTT}$
$3 \quad \mathrm{mM} \mathrm{MgCl}_{2}$
$1 \mathrm{mM}$ EDTA
$2 \%$ glycerol

for $40 \mathrm{ml}$ :

$16 \mathrm{ml} 0.5 \mathrm{M}$ stock

$240 \mu \mathrm{l} 0.5 \mathrm{M}$ stock

$120 \mu \mathrm{l} 1 \mathrm{M}$ stock

$80 \mu \mathrm{l} 0.5 \mathrm{M}$ stock

$920 \mu \mathrm{l} 87 \%$ stock

$10 \mathrm{ml}$ aliquots of the homogenization buffer were kept at $-20^{\circ} \mathrm{C}$. PMSF (Merck, Darmstadt, Germany), dissolved in ethanol, and benzamidine (Sigma-Aldrich, Taufkirchen, Germany), dissolved in $\mathrm{dd} \mathrm{H}_{2} \mathrm{O}$, were added to the homogenisation buffer to the final concentrations of $0.1 \mathrm{mM}$ and $1 \mathrm{mM}$, respectively, directly before use. 


\subsubsection{Invertase activity assay}

Invertase activity was tested according to the method described by Sung et al. (1989) with some modifications. Invertase is a hydrolase, cleaving sucrose irreversibly into glucose and fructose. For the assay, $30 \mu \mathrm{l}$ of $1 \mathrm{M}$ sucrose stock solution were mixed with $470 \mu \mathrm{l}$ of reaction buffer in an Eppendorf tube. $\mathrm{K}_{2} \mathrm{HPO}_{4} /$ citric acid buffers were used for the different enzymes $(\mathrm{pH} 4.35$ for apoplastic invertase, $\mathrm{pH} 5.0$ for vacuolar invertase, $\mathrm{pH} 6.8$ for cytosolic invertase). $100 \mu$ l extract (cytosolic or vacuolar invertase) or cell wall suspension (apoplastic invertase) was added to start the reaction. The reaction mixture was incubated for $30 \mathrm{~min}$ at $26^{\circ} \mathrm{C}$, then put on ice and immediately analysed for glucose concentration (see below).

$\begin{array}{ll}\begin{array}{l}\text { Reaction buffer type 40/70 } \\ \text { for apoplastic invertase }\end{array} & \begin{array}{l}40 \mathrm{mM} \text { citric acid } \\ 70 \mathrm{mM} \mathrm{K} \mathrm{HPO}_{4} \\ \text { adjusted to } \mathrm{pH} 4.35\end{array} \\ \begin{array}{l}\text { Reaction buffer type 40/70 } \\ \text { for vacuolar invertase }\end{array} & \begin{array}{l}70 \mathrm{mM} \text { citric acid } \\ \text { adjusted to pH } 5.0\end{array} \\ & 20 \mathrm{mM} \text { citric acid } \\ \text { Reaction buffer type 20/160 } & 160 \mathrm{mM} \mathrm{K} \mathrm{HPO}_{4} \\ \text { for cytosolic invertase } & \text { adjusted to pH } 6.8\end{array}$

To determine the glucose concentration in the invertase reaction mixture the following combined assay was used:

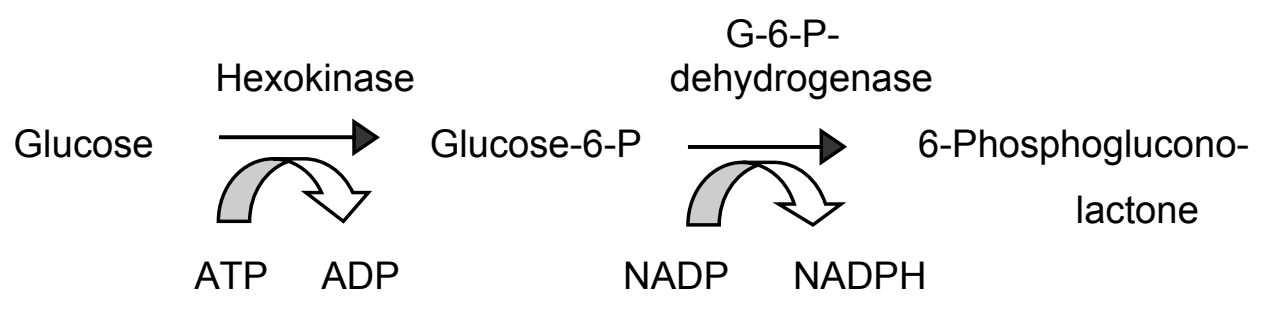

For each glucose determination, the following solutions were mixed in a cuvette: $475 \mu$ of reaction buffer for glucose determination (100 mM HEPES, $\mathrm{pH}$ 7.2; $5 \mathrm{mM}$ $\mathrm{MgCl}_{2}$ ), $25 \mu \mathrm{l}$ of mastermix (400 $\mu 100$ mM ATP; $400 \mu \mathrm{l} 30$ mM NADP ${ }^{+} ; 35 \mathrm{U}$ of G-6-PDH in $200 \mu \mathrm{l}$ reaction buffer) and $100 \mu \mathrm{l}$ invertase assay mixture. The reaction was started by adding $2 \mathrm{U}$ of hexokinase. 
The concentration of NADPH formed was detected photometrically on a doublebeam photometer Uvikon 932 (Kontron, Milan, Italy). The glucose concentration was calculated as the increase in absorbance due to the equivalent formation of NADPH using a molar extinction coefficient for NADPH of $6.22 \mathrm{mmol}^{-1} \mathrm{~cm}^{-1}$ at $340 \mathrm{~nm}$. The reaction was considered complete when there was no more increase of the $O D_{340}$.

The amount of glucose formed in the invertase reaction is equivalent to the amount of sucrose cleaved in this reaction. Therefore, results of invertase activity assay are presented as nmol sucrose cleaved per milligram protein per minute. Protein content in extracts was determined according to the method of Bradford (1976, see 2.23.). BSA was used for the calibration curve.

\subsection{In situ glucose and acid (apoplastic) invertase activity staining}

Glucose can be detected via the formation of a coloured reaction product by glucose oxidase and peroxidase in the presence of diaminobenzidine (DAB). About $200 \mu \mathrm{m}$ thick tissue slices were hand cut. For glucose staining the slices were denatured at $65^{\circ} \mathrm{C}$ in dd $\mathrm{H}_{2} \mathrm{O}$ for $3-10 \mathrm{~min}$ and transferred to reaction medium. To stain the sites of invertase activity the slices were washed extensively in $\mathrm{dd} \mathrm{H}_{2} \mathrm{O}$ to remove endogenous glucose and then transferred into reaction medium, supplied with $100 \mathrm{mM}$ sucrose. The reaction was carried out for $3-4$ hours at $37^{\circ} \mathrm{C}$ (or overnight at room temperature).

After the incubation, the slices were washed with $d d \mathrm{H}_{2} \mathrm{O}$ and then photographed under a microscope. Brown precipitate indicates the presence of glucose or acid (apoplastic) invertase activity, respectively.

Reaction medium: $\quad 200 \mathrm{mM} \quad$ Tris/citrate $\mathrm{pH}$ adjusted to 6.0 with a citric acid

$20 \mu \mathrm{g} / \mathrm{ml}$ glucose oxidase (Sigma Chemical, St. Louis, MO, USA)

$250 \mu \mathrm{g} / \mathrm{ml} \quad$ horseradish peroxidase (Sigma)

$300 \mu \mathrm{g} / \mathrm{ml}$ diaminobenzidine (DAB) (Sigma)

\subsection{Total protein isolation from plant material}

Plant tissue (50 -100 mg) was ground to a fine powder in a mortar under liquid nitrogen, transferred into a $1.5 \mathrm{ml}$ Eppendorf tube and immediately supplied with $200 \mu \mathrm{l}$ extraction buffer (see below). An identical volume of TE-saturated phenol was added to the sample, vortexed and incubated on ice for at least 5 minutes. For phase separation, the 
homogenate was centrifuged for $10 \mathrm{~min}$ at $10000 \times \mathrm{g}$ at $4{ }^{\circ} \mathrm{C}$. The phenol phase (upper phase) was transferred into a new Eppendorf tube. Protein precipitation was achieved by adding five volumes of $100 \mathrm{mM}$ ammonium acetate $(\mathrm{w} / \mathrm{v})$ in methanol and incubating for $16 \mathrm{~h}$ at $-20{ }^{\circ} \mathrm{C}$. After a centrifugation step at $10000 \times \mathrm{g}$ for $10 \mathrm{~min}$ at $4{ }^{\circ} \mathrm{C}$ the supernatant was discarded and the pellet was washed with $80 \%$ acetone $(\mathrm{v} / \mathrm{v})$ and dried under vacuum in a Speed Vac Concentrator (Bachofer, Reutlingen, Germany). The pellet was dissolved in a small volume (20-50 $\mu$, depending on protein quantity) of denaturing buffer and incubated for $1 \mathrm{~min}$ at $100{ }^{\circ} \mathrm{C}$. Then protein concentration of the sample was determined according to Bradford (see 2.23.). Protein samples were stored at $-20^{\circ} \mathrm{C}$.

\begin{tabular}{|c|c|c|}
\hline \multirow[t]{6}{*}{ Extraction buffer } & $700 \mathrm{mM}$ & sucrose \\
\hline & $500 \mathrm{mM}$ & Tris-HCl \\
\hline & $100 \mathrm{mM}$ & $\mathrm{KCl}$ \\
\hline & $50 \mathrm{mM}$ & EDTA \\
\hline & $\mathrm{pH} 9.5$ & \\
\hline & $2 \%(v / v)$ & $\beta$-mercaptoethanol, freshly added \\
\hline \multirow[t]{4}{*}{ Denaturing buffer } & $10 \mathrm{mM}$ & Tris-HCl \\
\hline & $2 \%(w / v)$ & SDS \\
\hline & $\mathrm{pH} 9.5$ & \\
\hline & $2 \%(v / v)$ & $\beta$-mercaptoethanol, freshly added \\
\hline
\end{tabular}

\subsection{Bradford protein concentration determination}

The Bradford test (Bradford, 1976) is a colorimetric method to quantify the protein content of solutions. The amount of Coomassie Brilliant Blue G 250 (Serva, Heidelberg, Germany) binding to protein is determined. The staining develops within 5-10 min. Then the protein complex is stable for about $30 \mathrm{~min}$. By comparison with a calibration curve obtained with a standard protein (fatless BSA), the protein concentration in a sample can be estimated. Every experiment requires a new calibration curve.

$5 \mu \mathrm{l}$ of the sample was filled up with dd $\mathrm{H}_{2} \mathrm{O}$ to a total volume of $500 \mu \mathrm{l}$. Then 500 $\mu \mathrm{l}$ staining solution was added to the sample, mixed and incubated for $10 \mathrm{~min}$ at room temperature. The $\mathrm{OD}_{595}$ was measured in a spectrophotometer (Uvikon 932; Kontron, Milan, Italy). As a reference, $5 \mu \mathrm{l}$ of sample buffer was taken and prepared as described for the protein sample. 
Staining solution: $70 \mathrm{mg} / 50 \mathrm{ml}$ abs. EtOH Coomassie Brilliant Blue G-250

\author{
$600 \mathrm{ml} \quad \mathrm{H}_{2} \mathrm{O}$ \\ $100 \mathrm{ml} \quad 85 \% \mathrm{H}_{3} \mathrm{PO}_{4}$ \\ volume was adjusted to $1000 \mathrm{ml}$ with dd $\mathrm{H}_{2} \mathrm{O}$ \\ and the solution was filtered through $3 \mathrm{MM}$ paper
}

\title{
2.24. Sodiumdodecyl sulfate polyacrylamide gel electrophoresis (SDS- PAGE)
}

The SDS-PAGE method is based on the method of Laemmli (1970). SDS is an anionic detergent that has two effects on proteins: first, it leads to disbanding of oligomeric structures, resulting in a relaxed conformation and, second, it binds in excess in a constant relation (1.4 g SDS/1 g protein) to the protein, which leads to an equal negative charge per mass unit. Therefore, in the presence of SDS, proteins can be separated based on their molecular weight.

The negatively charged SDS-protein complexes run towards the anode in an electrical field. To separate these complexes, the molecular-sieve properties of polyacrylamide gel (PAA-Gel) are used, where the mobility of most proteins is reversely proportional to the decimal logarithm of their molecular weight. The discontinuous buffer system of Laemmli (1970) leads to the concentration of probes on the transition state between a stacking gel and a separation gel, resulting in a higher resolution of the following separation of proteins. To determine the molecular weight of unknown proteins, a marker containing some proteins with molecular weights of 14-97 kDa („Low Molecular Weight Calibration Kit“; Amersham Pharmacia, Freiburg, Germany) or 9 to $185 \mathrm{kDa}$ ("Bench Mark" PM Prestained Protein Ladder", Invitrogen, Groningen, Netherlands) was loaded on the same gel. The pore size of a PAA-gel depends on relation between the concentrations of acrylamide to cross-linking $\mathrm{N}-\mathrm{N}^{\prime}$-methylenbisacrylamide. The acrylamide quota and the cross-linking degree are the values that characterize a polyacrylamide gel. To separate total protein extracts and detect sucrose synthase (SuSy), consisting of 92- to 93-kDa subunits (Hohnjec et al., 1999), a PAA-gel containing 6 or $7.5 \%$ polyacrylamide in the separating gel and $4 \%$ acrylamide in the stacking gel were prepared. The separating range was 60 to $200 \mathrm{kDa}$ in $6 \%$ and 40 to $200 \mathrm{kDa}$ in 7.5 $\%$ PAA-gel. Gel plates, spacer and combs as well as gel camera were ordered from Biometra (Göttingen, Germany). 


\subsubsection{Buffers and solutions for analytic SDS-PAGE}

Acrylamide / Bisacrylamide

(30\% T/2.7 \% C) stock solution (30\%)

$4 \times$ Stacking gel buffer

$4 \times$ Separating gel buffer

$10 \%$ Ammonium persulfate

$10 \times$ SDS Electrophoresis buffer

$5 \times$ Sample buffer
$29.2 \%(\mathrm{w} / \mathrm{v})$ acrylamide

$0.8 \%(w / v)$ N,N'-methylene bisacrylamide Dissolve in $100 \mathrm{ml} \mathrm{dd} \mathrm{H}_{2} \mathrm{O}$ and filter through 3 MM paper

Store at $4-10{ }^{\circ} \mathrm{C}$

$500 \mathrm{mM} \quad$ Tris- $\mathrm{HCl} \quad \mathrm{pH} 6.8$

$0.4 \%(w / v) \quad$ SDS

$1.5 \mathrm{M} \quad$ Tris- $\mathrm{HCl} \quad \mathrm{pH} 8.8$

$0.4 \%(w / v) \quad$ SDS

$10 \%(\mathrm{w} / \mathrm{v}) \quad$ Ammonium persulfate (in dd

$\mathrm{H}_{2} \mathrm{O}$ ) (APS) solution stored at $10^{\circ} \mathrm{C}$

$\begin{array}{ll}250 \mathrm{mM} & \text { Tris } \\ 1.92 \mathrm{M} & \text { Glycine } \\ 1 \%(\mathrm{w} / \mathrm{v}) & \text { SDS } \\ \mathrm{pH} 8.2-8.4 & \text { (not adjusted) }\end{array}$

$60 \quad \mathrm{mM} \quad$ Tris- $\mathrm{HCl}(\mathrm{pH} 6.8)$

$2 \%(\mathrm{v} / \mathrm{v}) \quad \beta$-Mercaptoethanol

$25 \%(\mathrm{v} / \mathrm{v}) \quad$ Glycerol

$2 \%(w / v) \quad$ SDS

$0.1 \%(\mathrm{v} / \mathrm{v}) \quad$ Bromphenol blue

\subsubsection{Pouring the SDS-Polyacrylamide gel}

Glass gel plates were cleaned with acetone or ethanol, silicon spacer tubes and combs were cleaned with water. The glass plates were joined together to form the cassette and clamped in vertical position. Solutions for stacking and separating gel were mixed as described in the table below. To start the polymerisation, TEMED $\left(\mathrm{N}, \mathrm{N}^{\prime} \mathrm{N}^{\mathrm{i}}, \mathrm{N}^{\mathrm{s}}\right.$ Tetramethylene diamine) solution was added to the separating gel solution. The gel solution was mixed and poured into the gel chamber up to $1 \mathrm{~cm}$ under the ends of the 
comb slots. To ensure that the gel polymerized with a smooth surface, a $2 \mathrm{~mm}$ layer of $\mathrm{dd}$ $\mathrm{H}_{2} \mathrm{O}$ was carefully poured on the gel using a Pasteur pipette. Because of the great difference in density between $\mathrm{dd} \mathrm{H}_{2} \mathrm{O}$ and the gel solution, the water is spread across the surface of the gel without much mixing. When the gel was set, a clear refractive index change could be seen between the polymerised gel and the overlaying water. Then the overlaying water was poured off and TEMED was added to the stacking gel solution to start polymerisation. The stacking gel was poured into the gel cassette until the solution reached the upper edge and the slot-forming comb was put into the solution before leaving the gel to set. $30 \mathrm{~min}$ to 1 hour later, the comb was removed from the gel, and the gel slots were rinsed with electrophoresis buffer to remove any rests of non-polymerised acrylamide solution.

The data of the following table are based on the stock solutions and buffers given in 2.24.1. The volume is sufficient for two mini gels $(8.5 \mathrm{~cm} \times 7.5 \mathrm{~cm})$.

Separating gel, $7.5 \%(15 \mathrm{ml})$ : $\quad$ Acrylamide stock solution $(30 \%) \quad 3.750 \mathrm{ml}$

$\begin{array}{lc}4 \times \text { Separating gel buffer } & 3.750 \mathrm{ml} \\ \text { dd } \mathrm{H}_{2} \mathrm{O} & 7.410 \mathrm{ml} \\ 10 \% \text { APS solution } & 75 \mu \mathrm{l} \\ \text { TEMED (add before pouring the gel) } & 15 \mu \mathrm{l}\end{array}$

Stacking gel, $4 \%$ (5 ml):

$\begin{array}{lr}\text { Acrylamide stock solution (30\%) } & 0.670 \mathrm{ml} \\ 4 \times \text { Stacking gel buffer } & 1.250 \mathrm{ml} \\ \text { dd } \mathrm{H}_{2} \mathrm{O} & 3.050 \mathrm{ml} \\ 10 \% \text { APS solution } & 30 \mu \mathrm{l} \\ \text { TEMED (add before pouring the gel) } & 5 \mu \mathrm{l}\end{array}$

The resulting end concentrations were:

Stacking gel Separating gel

$\begin{array}{lcc}\text { Tris/HCl pH } 6.8 & 0.13 \mathrm{M} & - \\ \text { Tris/HCl pH } 8.8 & - & 0.38 \mathrm{M} \\ \text { SDS } & 0.1 \%(\mathrm{w} / \mathrm{v}) & 0.1 \%(\mathrm{w} / \mathrm{v}) \\ \text { Acrylamide } & 4.6 \%(\mathrm{w} / \mathrm{v}) & 7.5 \%(\mathrm{w} / \mathrm{v}) \\ \text { N,N-Methylene bisacrylamide } & 0.12 \%(\mathrm{w} / \mathrm{v}) & 0.33 \%(\mathrm{w} / \mathrm{v}) \\ \text { APS } & 0.06 \%(\mathrm{w} / \mathrm{v}) & 0.05 \%(\mathrm{w} / \mathrm{v})\end{array}$




\subsubsection{Probe preparation and SDS polyacrylamide gel electrophoresis (SDS-PAGE)}

Ca. $15 \mu \mathrm{g}$ protein per slot were used for immunoblotting and 10-30 $\mathrm{\mu g}$ protein for Coomassie stained gels.

The samples were supplemented with sample buffer to a final concentration of $\geq$ $1 \times$ sample buffer to ensure proper solubilisation of the proteins and solubilised for $15 \mathrm{~min}$ at RT by sucking the solution up and down with a pipette. Then the samples were boiled at $95{ }^{\circ} \mathrm{C}$ for $3 \mathrm{~min}$ and centrifuged afterwards at top speed (13 $000 \mathrm{rpm}$ ) for $5 \mathrm{~min}$ in a table top microcentrifuge to sediment insoluble material. After removing the spacers, the gel cassette was assembled with the electrophoresis unit, and first the top and then the bottom reservoir were filled with $1 \times$ SDS electrophoresis buffer (see 2.24.1.). Then the appropriate volume of sample was filled up to $10 \mu \mathrm{l}$ with sample buffer (see 2.24.1.) and loaded into the SDS gel slot using a microsyringe. Every empty slot on the gel was filled in with $10 \mu \mathrm{l}$ sample buffer. The electrophoresis was run under a constant current of $25 \mathrm{~mA}$ $(500 \mathrm{~V}, 100 \mathrm{~W})$ and was continued until the Bromphenol blue reached the bottom of the gel (about 1.5 hours). Then the gel cassette was removed from the electrophoresis unit and opened, and the gel was taken out to stain in Coomassie or to mount a Western blot.

\subsubsection{Coomassie staining of SDS polyacrylamide gels}

Coomassie staining serves to detect proteins in an SDS polyacrylamide gel. For this purpose, the gel was fixed after electrophoresis and stained in staining solution (see below) for at least 30 min and then destained in wash solution for about 1-2 hours until the gel background was colourless. After washing, the gel could be stored for a long time in dd $\mathrm{H}_{2} \mathrm{O}$. Alternatively, it could first be soaked in $10 \%$ glycerol for $30 \mathrm{~min}$ and then dried under vacuum.

Coomassie staining solution

$0.25 \%(w / v) \quad$ Coomassie ${ }^{\circledR}$ Brilliant Blue R 250

$40 \%(\mathrm{v} / \mathrm{v})$ Methanol

$10 \%(v / v) \quad$ Acetic acid

Washing solution

$50 \%(\mathrm{v} / \mathrm{v}) \quad$ Methanol

$10 \%(\mathrm{v} / \mathrm{v}) \quad$ Acetic acid 


\subsection{Western blot}

With Western blotting it is possible to identify and quantify proteins in a total protein extract by use of specific antibodies.

\subsubsection{Protein transfer to a nitrocellulose membrane}

After the separation of protein probes by SDS-PAGE (see 2.24.3.) the gel was fixed in a Western blot camera. The mounting order of the blot was the following (from anode to kathode):

- $\quad$ three layers of blotting paper (3MM), wetted in blotting buffer

- SDS gel, equilibrated in blotting buffer for $15 \mathrm{~min}$

- nitrocellulose membrane (Hybond ECL Nitrocellulose Membrane; Amersham Pharmacia Biotech, Freiburg, Germany), wetted in blotting buffer, cut corresponding to gel size.

- three layers of wet 3MM blotting paper

Protein transfer was performed overnight at $4{ }^{\circ} \mathrm{C}$ in the Western blot chamber filled with blotting buffer at a constant current of $90 \mathrm{~mA}$.

$\begin{array}{lll}\text { Blotting buffer: } & \text { Tris } & 25 \mathrm{mM} \\ & \text { Glycine } & 192 \mathrm{mM} \\ & \text { Methanol } & 20 \%(\mathrm{v} / \mathrm{v})\end{array}$

\subsubsection{Staining of the blot}

The nitrocellulose membrane was taken out of the blotting system and stained for two minutes in Ponceau red solution to check the protein transfer. The staining is reversible, so after washing with dd $\mathrm{H}_{2} \mathrm{O}$ the bands of marker proteins and the sample order were marked with a pencil on the protein side of the membrane. Then, the blot was cut off to the required size.

$\begin{array}{lll}\text { Ponceau red solution: } & \text { Ponceau S } & 2 \%(\mathrm{w} / \mathrm{v}) \\ & \text { Trichloroacetic acid } & 3 \%(\mathrm{w} / \mathrm{v})\end{array}$




\subsubsection{Immunological detection of transferred proteins}

Specific proteins were identified on the nitrocellulose membrane by the indirect immunological method. First a non-labelled primary antibody binds to the antigen. In the second step, this antigen-antibody complex is bound by the secondary antibody which represents the bacterial protein $A$ that binds immunoglobulins of many species. The secondary antibody is conjugated with an enzyme, horseradish peroxidase. This allows visualising the labelled proteins after incubation with a horseradish peroxidase substrate, which is converted into a coloured or luminescent product.

\section{$\underline{\text { Reaction with antibodies }}$}

To reduce the unspecific binding capacity of nitrocellulose, the membrane was incubated with the primary antibodies in an appropriate dilution (1:1000 to 1:5000) in the presence of Block buffer for 2 hours at room temperature on a swinging shaker. Then the blot was washed once shortly and three times for $15 \mathrm{~min}$ with TBS-T to remove unspecifically bound $\operatorname{lgG}$ molecules. Then followed an incubation with secondary antibodies conjugated with peroxidase (1:3000 to 1:10000 in TBS-T) "Anti Rabbit-Protein A Horseradish Peroxidase Conjugate"; Bio-Rad, München, Germany) for $1 \mathrm{~h}$ at room temperature. Afterwards the wash steps with TBS-T were repeated: shortly once and three times for 15 min and finally one 15 min wash step with TBS.

$\begin{array}{llr}\text { TBS: } & \text { Tris/HCl pH 7.5 } & 50 \mathrm{mM} \\ & \mathrm{NaCl} & 150 \mathrm{mM} \\ & & \\ \text { TBS-T: } & \begin{array}{l}\text { Triton-X-100 } \\ \text { in TBS }\end{array} & \\ & & \\ & & 1 \%(\mathrm{v} / \mathrm{v}) \\ \text { Block buffer: } & \text { Dry milk powder } & \\ & \text { in TBS-T } & \end{array}$

\section{Peroxidase detection by "Enhanced Chemiluminiscence"}

The method of "Enhanced Chemiluminiscence" (ECL) serves as a sensitive detection of a protein A-coupled peroxidase. Under alkaline conditions, peroxidase catalyses the oxidation of luminol by $\mathrm{H}_{2} \mathrm{O}_{2}$, which results in the emission of light. This reaction is enhanced by phenol. The half time of this reaction is about $1 \mathrm{~h}$.

The nitrocellulose membrane was put flat, without air bubbles, on a thin plastic foil with the protein side up. $2 \mathrm{ml}$ ECL-Solution 1 and $2 \mathrm{ml}$ ECL-solution 2 (Amersham 
Pharmacia Biotech, Freiburg, Germany) were mixed, poured on the membrane and incubated for 1 min under swinging. After the reaction, the liquid was removed and the membrane was covered by plastic foil without air bubbles and immediately exposed to Hyperfilm ECL (Amersham Pharmacia Biotech) for $1 \mathrm{~min}$ in the dark. Another exposition for $10 \mathrm{~min}$ was performed and based on the results a third exposition was performed for the optimal time period (10 sec, $30 \mathrm{sec}$ or 1 hour). After taking off, the film was developed in Kodak Develop and Fix Solutions (Kodak, Rochester, NY, USA).

\subsection{Measurement of sugar uptake in yeast}

Yeast cells transformed with a pNEV-based expression construct with the putative hexose transporter (2.14.) were grown overnight in the appropriate selection medium (2.1.8.3.) up to an $\mathrm{OD}_{600}$ of 1 . Then the cells were harvested by centrifugation for $5 \mathrm{~min}$ at room temperature in a Megafuge 1.0 at $4500 \mathrm{rpm}$, and the pellet was washed twice with $50 \mathrm{mM}$ $\mathrm{Na}-\mathrm{P}_{\mathrm{i}}$-buffer $\mathrm{pH} 5.5$ (for determination of the $\mathrm{pH}$ optimum, buffers with $\mathrm{pH}$ in the range of $3.0-7.3$ had been tested) with centrifugation steps as described above. Finally, the cells were resuspended in the same buffer to an $\mathrm{OD}_{600}$ of 10 . Before sugar uptake measurements, the cell suspension was stored on ice for a maximum of 10 hours.

For a series of measurements, $1 \mathrm{ml}$ of cell suspension was pre-incubated in a 25 $\mathrm{ml}$ Erlenmeyer flask for $1-2 \mathrm{~min}$ at $30{ }^{\circ} \mathrm{C}$ under vigorous shaking. Then $11 \mu \mathrm{l}$ of $10 \mathrm{mM}$ $\left[{ }^{14} \mathrm{C}\right]$-labelled substrate was added to a final substrate concentration of $100 \mu \mathrm{mol}$ in the mixture to start the sugar uptake. The labelled substrate solution was prepared by mixing $10 \mu \mathrm{l} 10 \mathrm{mM}$ of non-radioactive ("cold") substrate and $1 \mu \mathrm{l}$ of $\left[{ }^{14} \mathrm{C}\right]$-labelled substrate (for example, ca. $0.2 \mu \mathrm{Ci}\left[{ }^{14} \mathrm{C}\right]$-glucose from Amersham Pharmacia Biotech, Little Chalfont, UK).

Samples of $100 \mu \mathrm{l}$ were taken at given intervals after adding the substrate (10 sec, $30 \mathrm{sec}, 1,2,3,5,10 \mathrm{~min})$, filtered on nitrocellulose filters $(0.8 \mu \mathrm{m}$ pore size; Hölzer, Dorfen, Germany) and washed with an excess of $\mathrm{dd} \mathrm{H}_{2} \mathrm{O}$. Incorporation of radioactivity was determined by scintillation counting. For every measurement series, $100 \mu \mathrm{l}$ of the total sample was counted to obtain the value for overall radioactivity. To calculate the concentration of substrate accumulated in yeast cells, the cell volume (in $\mu l$ of packed cells, p.c.) was determined using Hematocrite tubes for the centrifugation of $1 \mathrm{ml}$ cell sample for $5 \mathrm{~min}$ at $3000 \times \mathrm{g}$. $30 \%$ of the total volume was taken up by the intracellular volume. 
For analyzing energization, $10 \mu \mathrm{l}$ of absolute ethanol were added after $1 \mathrm{~min}$ of pre-incubation, and incubated for one min before the uptake test was started. To analyze the influence of inhibitors on the uptake of glucose, the plasma membrane uncouplers CCCP (carbonyl cyanide m-chlorophenylhydrazone) and DNP (2,4-Dinitrophenol) were added to the sample to a final concentration of $50 \mu \mathrm{M}$ before the uptake reaction was started.

\subsection{Statistic evaluation of experimental data}

The results shown represent either the typical results of the all experimental series conducted or the summary results. In the last case the arithmetic average value \pm the standard deviation (SD) are performed. The number of the conducted experiments was at least 3 , when it is not otherwise noted in the text.

$$
\begin{aligned}
& \text { Average value }=\frac{\sum \text { Arguments of single measurements }}{\text { Number of measurements }(n)} \\
& S D=\sqrt{\frac{\sum_{i=1}^{n}\left(x_{i}-x\right)^{2}}{n-1}}
\end{aligned}
$$




\section{Results}

\subsection{Sugar contents in roots and nodules}

In most plants, sucrose is the main form of carbon transported in the phloem from source to sink organs. After phloem unloading, it can reach the sink cells in the form of sucrose or as its component hexoses, glucose and fructose (Sonnewald and Willmitzer, 1992). In addition to supporting sink cell metabolism in roots, carbon allocated to the roots also supports nodule formation and the growth of symbiotic microorganisms in root nodules. To get an overview of the sugar metabolism in roots and root nodules, it was important first to analyse the soluble sugars in roots and nodules of the three model systems: one legume symbiosis (Medicago truncatula - Sinorhizobium meliloti) and two actinorhizal symbioses from different Frankia subclades (see 1.5). Extracts of soluble sugars from roots and nodules were obtained using the chloroform-methanol extraction (2.16.1). Sugar contents were determined via HPLC (2.17).

\subsubsection{Sugar contents in roots and nodules of Medicago truncatula}

The main sugars detected in Medicago extracts were glucose and sucrose. The relative amounts of these two sugars were similar in roots and nodules, with the sucrose concentrations being about 2 times higher than the glucose concentrations (Figure 3.1). The contents of fructose were below the detection limit. The only compound with increased amounts in nodules compared to roots was a substance that had similar retention time to sugar-alcohols in analysis by HPLC, but which could not be identified with available standards ("unknown M1" in Figure 3.1). This compound might represent pinitol (1-D-3-O-methyl-chiro-inositol), the major cyclitol of legumes, which is present in all organs of the plant (Smith and Phillips, 1980) or D-ononitol (4-O-methyl-myo-inositol), which has been described as a nodule-specific sugar alcohol for Pisum sativum (Skøt and Egsgaard, 1984; Romanov et al., 1995). Another unknown sugar ("unknown M2" in Figure 3.1) was detected only in Medicago root extracts, not in nodule extracts. 


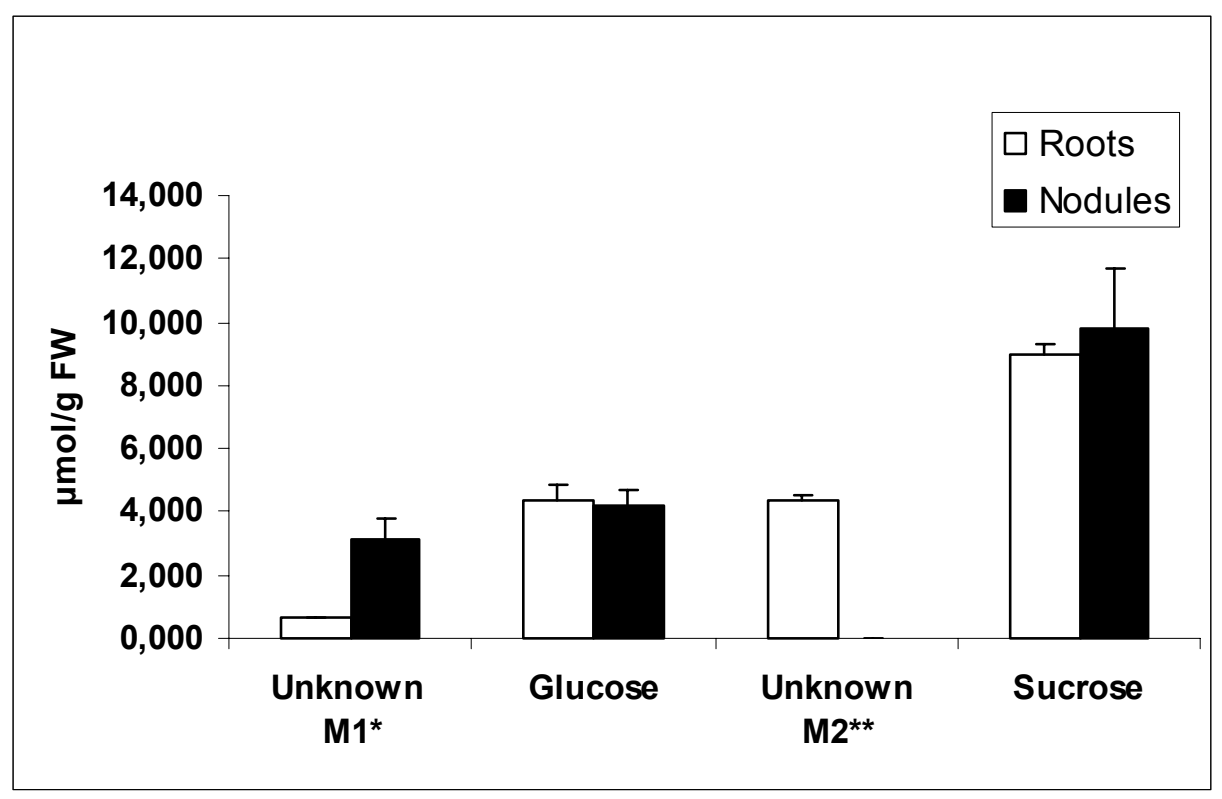

Figure 3.1. Concentrations of soluble sugars in roots and nodules of Medicago truncatula $(\mu \mathrm{mol} / \mathrm{g} \mathrm{FW})$. The concentrations of the unknown sugars were estimated on the basis of the molecular weight of the standard components with the most similar retention time: * myo-inositol; ${ }^{* *}$ - fructose. A representative result of three independent experiments with three parallel samples each is shown.

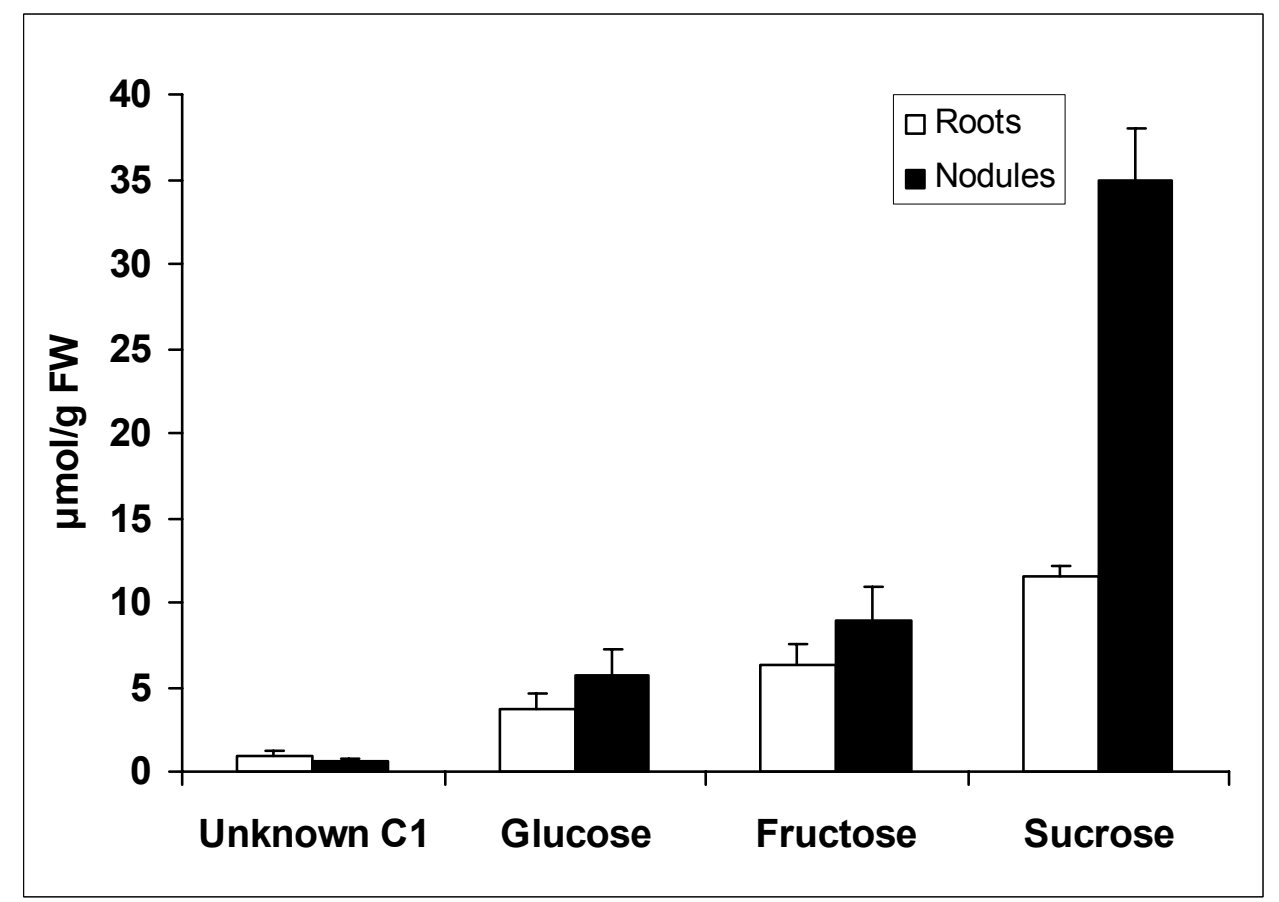

Figure 3.2. Concentrations of soluble sugars in roots and nodules of Casuarina glauca. The concentration of the unknown compound $\mathrm{C} 1$ was estimated based on the molecular weight of myo-inositol, the sugar-alcohol with the most similar retention time.A representative result of three independent experiments with three parallel samples each is shown. 


\subsubsection{Sugar contents in Casuarina glauca}

In extracts of roots and nodules of Casuarina glauca, glucose, fructose, sucrose and small amounts of sugar-alcohols were detected (Figure 3.2).

Concentrations of glucose and fructose were not significantly different in roots and nodules. The main sugar compound in roots as well as in nodules of Casuarina was sucrose. Moreover, sucrose contents were strongly increased in nodules compared to roots, with a nodule sucrose concentration of about $35 \mu \mathrm{mol} / \mathrm{g} \mathrm{FW}$, compared to about 12 $\mu \mathrm{mol} / \mathrm{g} \mathrm{FW}$ in roots.

\subsubsection{Sugar contents in Datisca glomerata}

The sugar profile of Datisca glomerata (Figure 3.3) was very different from those of Medicago and Casuarina. Altogether, the total sugar content was higher in Datisca nodules compared to roots. In nodules, glucose and sucrose concentrations were similar (about 4.5-4.8 $\mu \mathrm{mol} / \mathrm{g} \mathrm{FW}$ ), whereas fructose concentrations were as high as $8 \mu \mathrm{mol} / \mathrm{g}$ FW. As with Medicago nodules, two unknown compounds were found, the concentrations of which were strongly increased in Datisca nodules compared to roots. One of these substances was termed "M", because its retention time in HPLC was most similar to that of myo-inositol (Figure 3.3; Figure 3.4).

The other major unidentifiable component of Datisca soluble sugar extracts had a retention time close to that of ribitol (Figure 3.3; Figure 3.4). Based on the molecular weight of ribitol, the concentrations of the unknown sugar in roots and in nodules were about 5 and $13.5 \mu \mathrm{mol} / \mathrm{g} \mathrm{FW}$, respectively. This compound was termed "D", from Datisca.

\subsubsection{Isolation and characterization of two unknown carbohydrates from Datisca glomerata}

For identification of the two unknown compounds in soluble sugar extracts from Datisca, large-scale sugar isolation was performed for $D$ and $M$ as described in 2.16.2, using chloroform-methanol extraction, separation of sugar extract into fractions using anion exchange column and sodium hydroxide as eluate and paper chromatography purification from sodium chloride formed after neutralisation.

The detailed analysis of the chemical structure of $D$ and $M$ was conducted by nuclear magnetic resonance spectroscopy (NMR) and mass spectroscopy, and the NMR 


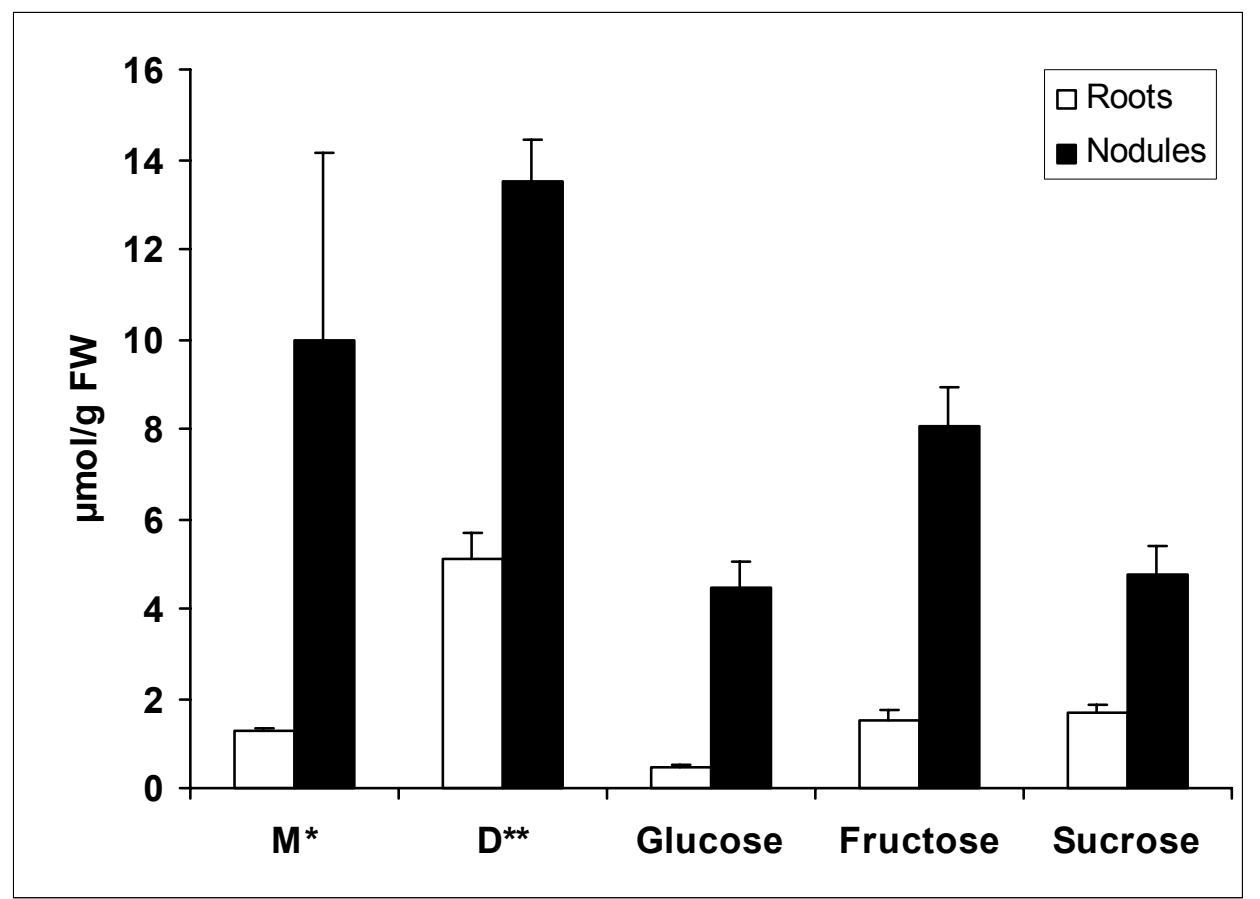

Figure 3.3. Concentrations of soluble sugars in roots and nodules of Datisca glomerata. The concentrations of the unknown sugar components were estimated based on the molecular weight of myo-inositol $\left(^{*}\right)$ and ribitol $\left({ }^{* *}\right)$, the sugar compounds with the HPLC retention times most similar to that of $M$ and $D$, respectively (see text).

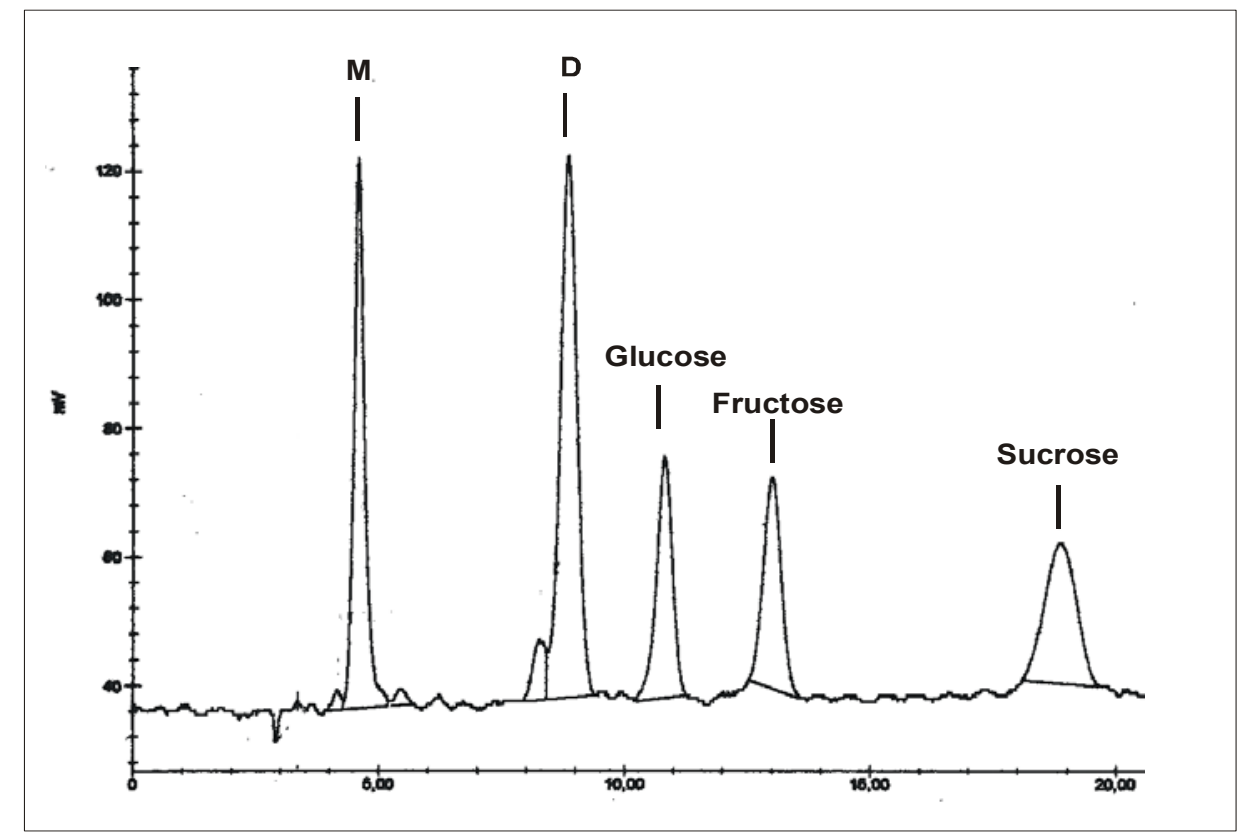

Figure 3.4. HPLC diagram of an extract of soluble sugars from nodules of Datisca glomerata. Two components, $\mathrm{M}$ and $\mathrm{D}$, could not be identified with the standards available. X-axis: time [min], Y-axis: HPLC detection signal [mV]. 
correlation spectroscopy methods $\mathrm{H}, \mathrm{H}-\mathrm{COSY}$ and $\mathrm{C}, \mathrm{H}-\mathrm{COSY}$ by $\mathrm{Dr}$. R. Fortte at the Institute for Organic Chemistry at the University of Göttingen in the laboratory of Prof. Tietze.

The ${ }^{13} \mathrm{C}-\mathrm{NMR}$ spectrum of $\mathrm{D}$ showed twelve signals, whereas in the NMR spectrum of $M 13$ signals were observed, indicating that $M$ contains an additional $C 1$-unit. According to the ${ }^{13} \mathrm{C}$-NMR spectrum, $\mathrm{D}$ does not contain any carbonyl groups or aromatic or olefinic carbons, but an acetal and one anomeric hemiacetal carbons. These signals were found at $\delta=98$ and $\delta=88.93$, respectively. The methyl group resonates at $\delta=17.59$. The ${ }^{13} \mathrm{C}$-NMR spectrum of compound $\mathrm{M}$ was similar to $\mathrm{D}$, except for the presence of an additional O-methyl group at $\delta=58$.

Based on the first NMR results, it was proposed that the isolated compounds represent disaccharides one of which was methylated. To determine the monosaccharide components of these disaccharides, acid catalysed hydrolysis of $D$ and $M$ was performed using $1 \mathrm{M} \mathrm{HCl}$ at $100{ }^{\circ} \mathrm{C}$ for 1 hour. The products were D-glucose and L-rhamnose (Figure 3.5) in a $1: 1$ ratio as determined by HPLC on a MA1 column with $0.5 \mathrm{M} \mathrm{NaOH}$ as eluant. Therefore, it was assumed that $D$ and $M$ were glycosides of L-rhamnose and D-glucose. Since enzymatic digestion of $D$ and $M$ by $\alpha$-glucosidase and $\beta$-glucosidase (2.18.2), respectively, did not lead to hydrolysis, glucose could not be the sugar at the non-reducing end of either D or M. Since no methylated sugar was detected in the HPLC analysis, it was assumed that the $\mathrm{O}$-methyl group of $\mathrm{M}$ was located at the anomeric $\mathrm{C}$ atom.

Based on the results of NMR and mass spectrometry as well as on results of enzymatic digestions, the structures of $M$ and $D$ represented in Figure 3.6 were proposed. However, the configurations of the glycosidic bonds and the O-methyl bond were still unclear.

To find out the connected positions of the monosaccharide units, acyl protection of all hydroxy groups was performed with an 1:2 mixture of acetic acid anhydride $\left(\mathrm{Ac}_{2} \mathrm{O}\right)$ and pyridine and catalytic amounts of of 4-dimethylaminopyridine (DMAP) (see Figure 3.7). The connected positions were identified via the NMR correlation spectroscopy methods $\mathrm{H}, \mathrm{H}-\mathrm{COSY}$ and $\mathrm{C}, \mathrm{H}-\mathrm{COSY}$. The acylation of a secondary hydroxyl group leads to the chemical shift of protons at the corresponding carbon atom and shows a $\delta$ value of about 5.0. This shift was detected for the secondary hydroxyl groups at $2 a / b, 3 a / b$ and $4 a / b$. The corresponding 6a-protons showed a shift about $\delta=3.7$, indicating that this carbon atom carried no free hydroxyl group. Hence, these results showed that the connection between the monosaccharides is $1 \mathrm{~b}$ to $6 \mathrm{a}$.

For the determination of the configuration of the bond between the monosaccharide units the $\mathrm{H}, \mathrm{H}-\mathrm{COSY}$ and $\mathrm{C}, \mathrm{H}-\mathrm{COSY}$ NMR-spectroscopy was used. Here, for the proton at 


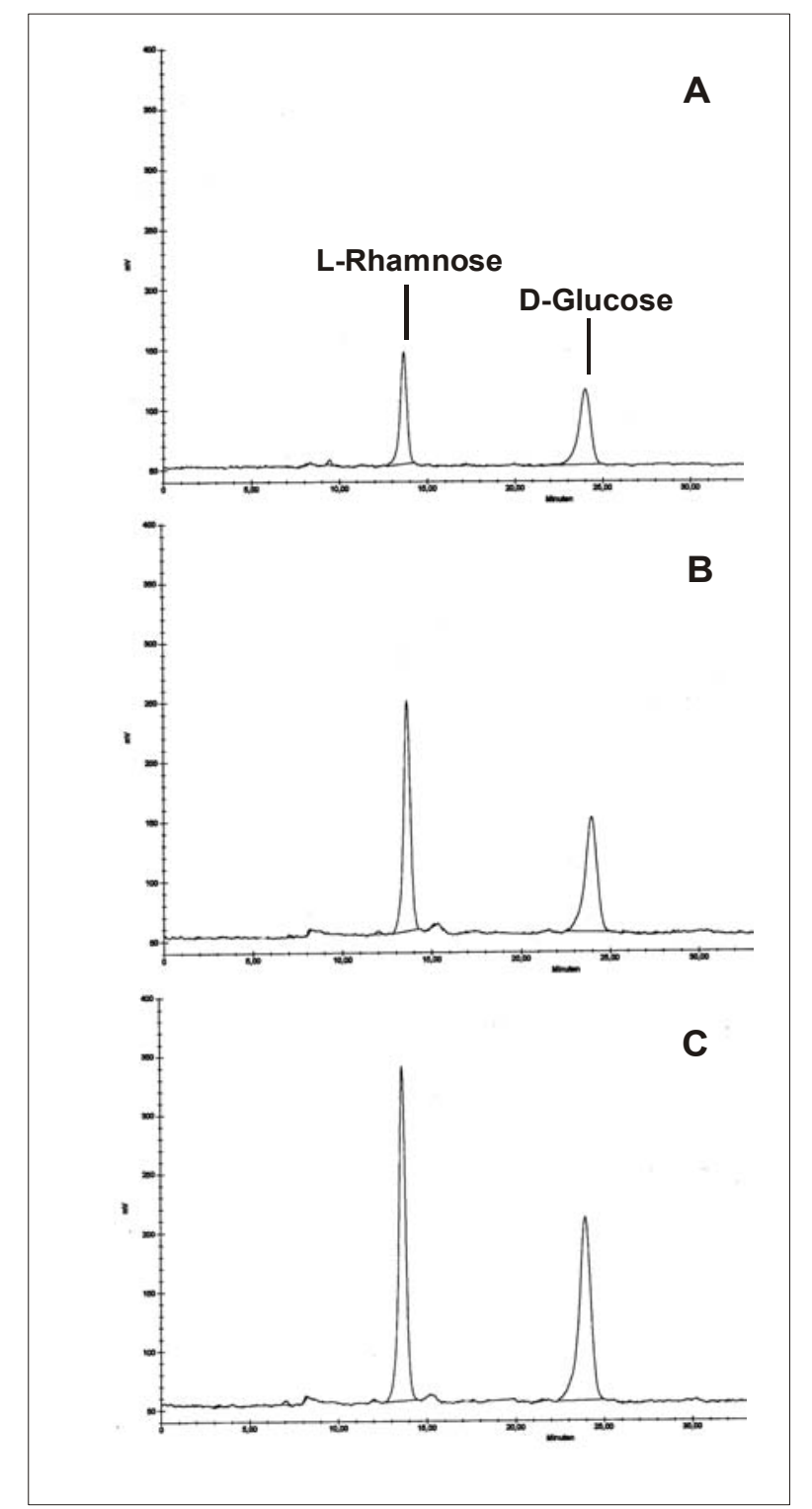

Figure 3.5. HPLC identification of the hexose components of the disaccharide $D$ from Datisca glomerata. A: Standard representing a solution of L-rhamnose and D-glucose $(200 \mu \mathrm{mol}$ each); B: Products of the $\mathrm{HCl}$ hydrolysis of $\mathrm{D}$; $\mathbf{C}$ : standard $\mathbf{A}$ was added to the hydrolysis product $\mathbf{B}$, and since no additional signals appear, the two peaks of $\mathbf{B}$ represent L-rhamnose and D-glucose, respectively. $\mathrm{X}$-axis: time [min], Y-axis: HPLC detection signal $[\mathrm{mV}]$.

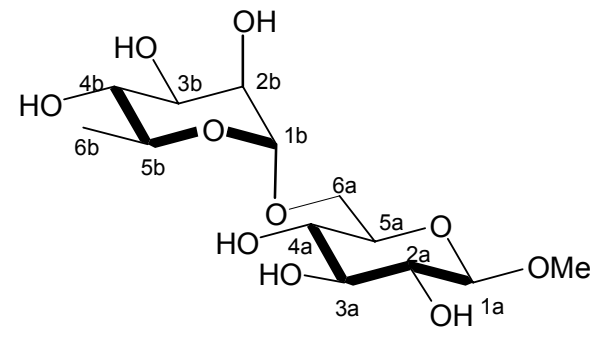

M

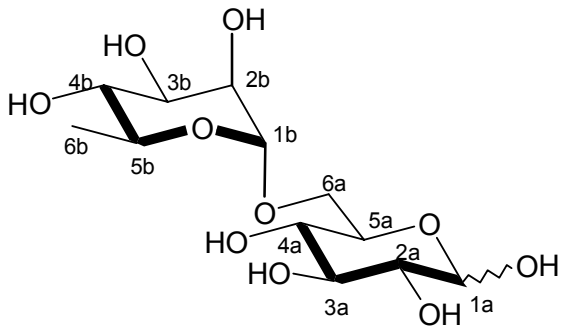

D

Figure 3.6. Structures of the compounds $M$ and D. Both sugars are comprised of Lrhamnose and D-glucose moieties, with the difference that $\mathrm{M}$ represents O-methyl-ester of $D$ at the $C 1$ atom of glucose. Thus, $D$ represents $\alpha$-L-rhamnopyranosid-(1 $\rightarrow 6)$-glucose (rutinose), and $M$ represents $\alpha$-L-rhamnopyranosid- $(1 \rightarrow 6)-(1-O-\beta-D-m e t h y l g l u c o s e)$ (methylrutinose). 
the position $1 \mathrm{~b}$ of $\mathrm{M}^{\prime}$ and $\mathrm{D}^{\prime}$, a singlet was found at $\delta=4.76$ and 4.62 , respectively, that is typical for a $\alpha$-glycosidic linkage.

For the proton at carbon atom $1 \mathrm{a}$ of compound $\mathrm{M}^{\prime}$ a doublet was found with a coupling constant of $8.0 \mathrm{~Hz}$ that represents the expected value for a $\beta$-glycosidic linkage. Therefore, it was concluded that the bond between glucose and the O-methyl group in $M$ has the $\beta$ configuration.

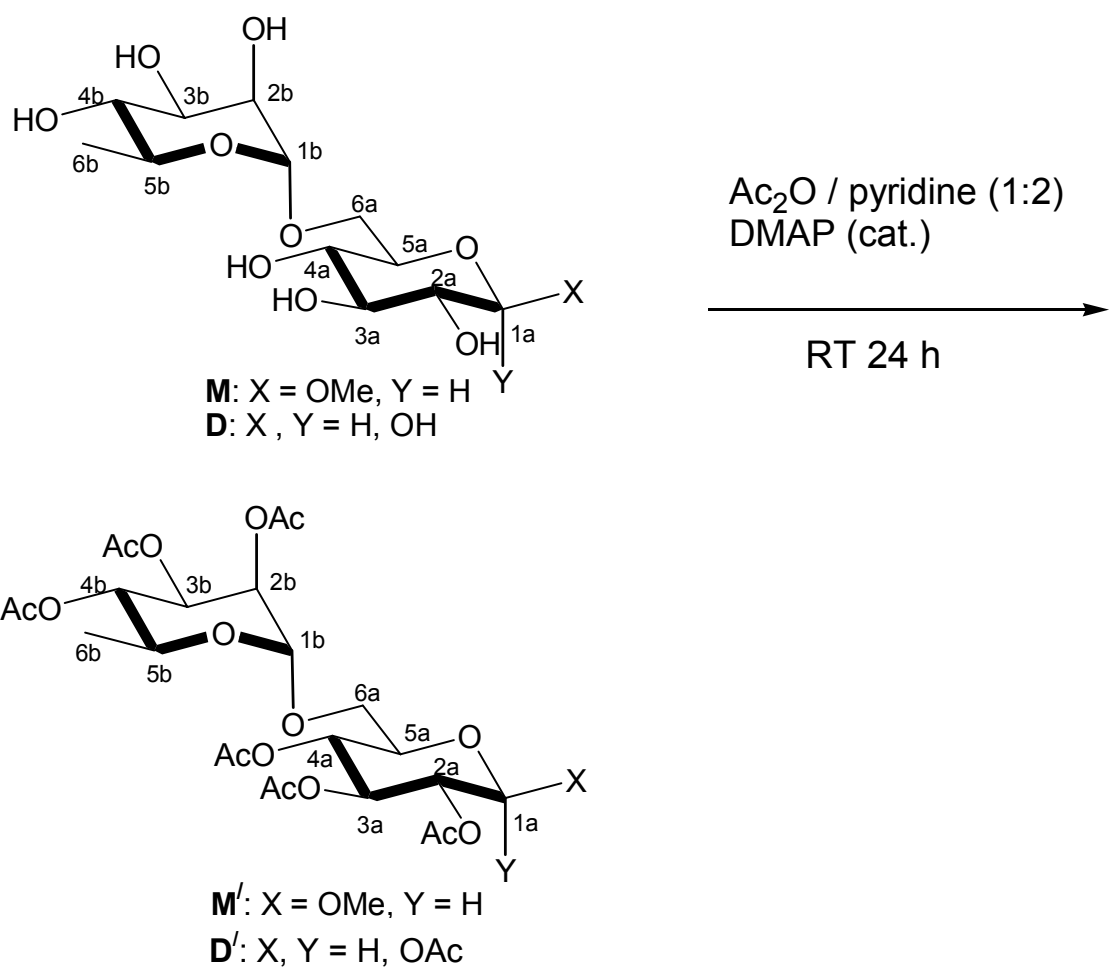

Figure 3.7. Scheme of the acylation of the free hydroxyl groups for the identification of the glycosidic bond in M and D.

The molecular mass of compounds M $(340 \mathrm{~g} / \mathrm{mol})$ and $D(326 \mathrm{~g} / \mathrm{mol})$ was confirmed by the electron spray ionisation method (ESI) and the chemical ionisation method $(\mathrm{Cl})$ : for $D$ it was equal to $349.5 \mathrm{~g} / \mathrm{mol}$, which represents the molecular mass of $D$ plus $\mathrm{Na}^{+}(\mathrm{ESI})$, and for $\mathrm{M}$ it represented $358 \mathrm{~g} / \mathrm{mol}$ which equals the molecular mass of $\mathrm{M}$ plus $\mathrm{NH}_{4}{ }^{+}(\mathrm{Cl})$.

Summarising the data on the chemical structure of the novel compounds $D$ and $M$ isolated from Datisca glomerata, they represent $\alpha$-L-rhamnopyranosyl-(1 $\rightarrow 6)-1-O-m e t h y l-$ ß-D-glucose and $\alpha$-L-rhamnopyranosyl-(1 $\rightarrow 6)$-D-glucose, respectively (Figure 3.6).

This was confirmed by enzymatic analysis. Treatment of both $D$ and $M$ with naringinase, a $\alpha$-rhamnopyranosidase from Penicillum decumbens (Sigma), yielded Lrhamnose and D-glucose (Figure 3.8), although in case of $M$ the substrate was not cleaved completely; the cleavage stopped after an incubation time of about $5 \mathrm{~min}$. 


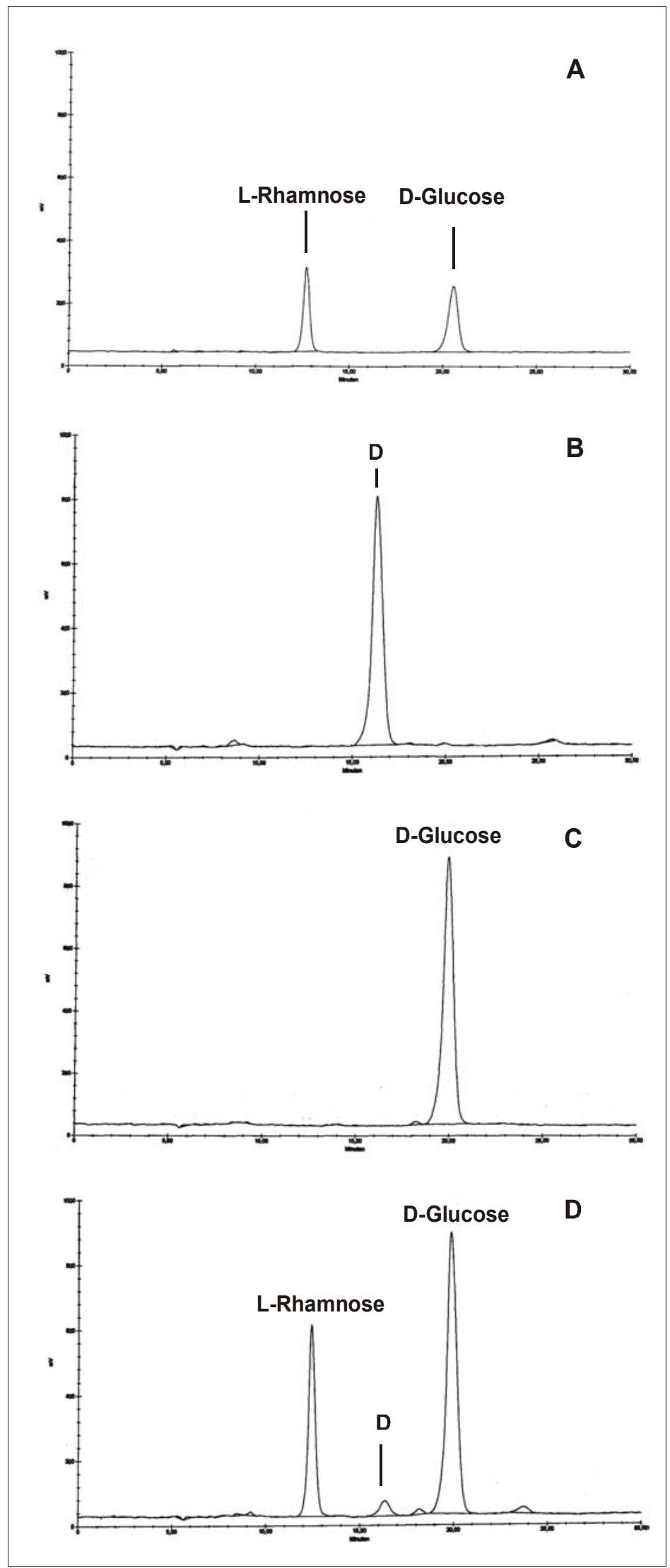

Figure

3.8.

HPLC

chromatograms demonstrating the enzymatic determination of the configuration of the bond between L-rhamnose and Dglucose of the disaccharide $D$ from Datisca glomerata using $\alpha$-L-rhamnosidase treatment.

A: Standard representing a solution of L-rhamnose and Dglucose (200 $\mu \mathrm{mol}$ each); B: Standard representing a 2 mmol solution of sugar D; C: Control reaction with water without substrate shows a contamination of the commercial enzyme naringinase ( $\alpha$-L-rhamnosidase) with polysaccharides and $\beta$ glucosidase, leading to the formation of glucose in the absence of added substrate; D: products of the naringinasemediated digestion of $D$ after 10 min reaction time represent $\mathrm{L}$ rhamnose and D-glucose. $\mathrm{X}-$ axis: time [min], Y-axis: HPLC detection signal [mV]. 
Nevertheless, it was confirmed that both $D$ and $M$ represent disaccharides with $L-$ rhamnose at the non-reducing end and that the bond between their monosaccharide moieties is in the $\alpha$-configuration. Thus, roots and nodules of Datisca contain high amounts of $\alpha$-L-rhamnosyl-D-glucosides.

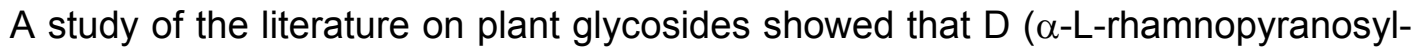
$(1 \rightarrow 6)$-D-glucose) is known as rutinose and has been described as the glycoside part of many flavonglycosides, i.e. rutin, galanginoside, cannabin, datiscin and datinoside. These flavonglycosides have been isolated and characterized from another species of the Datiscaceae, Datisca cannabina (Zapesochnaya and Pangarova, 1976). Rutinose has not yet been described as a free sugar in plants.

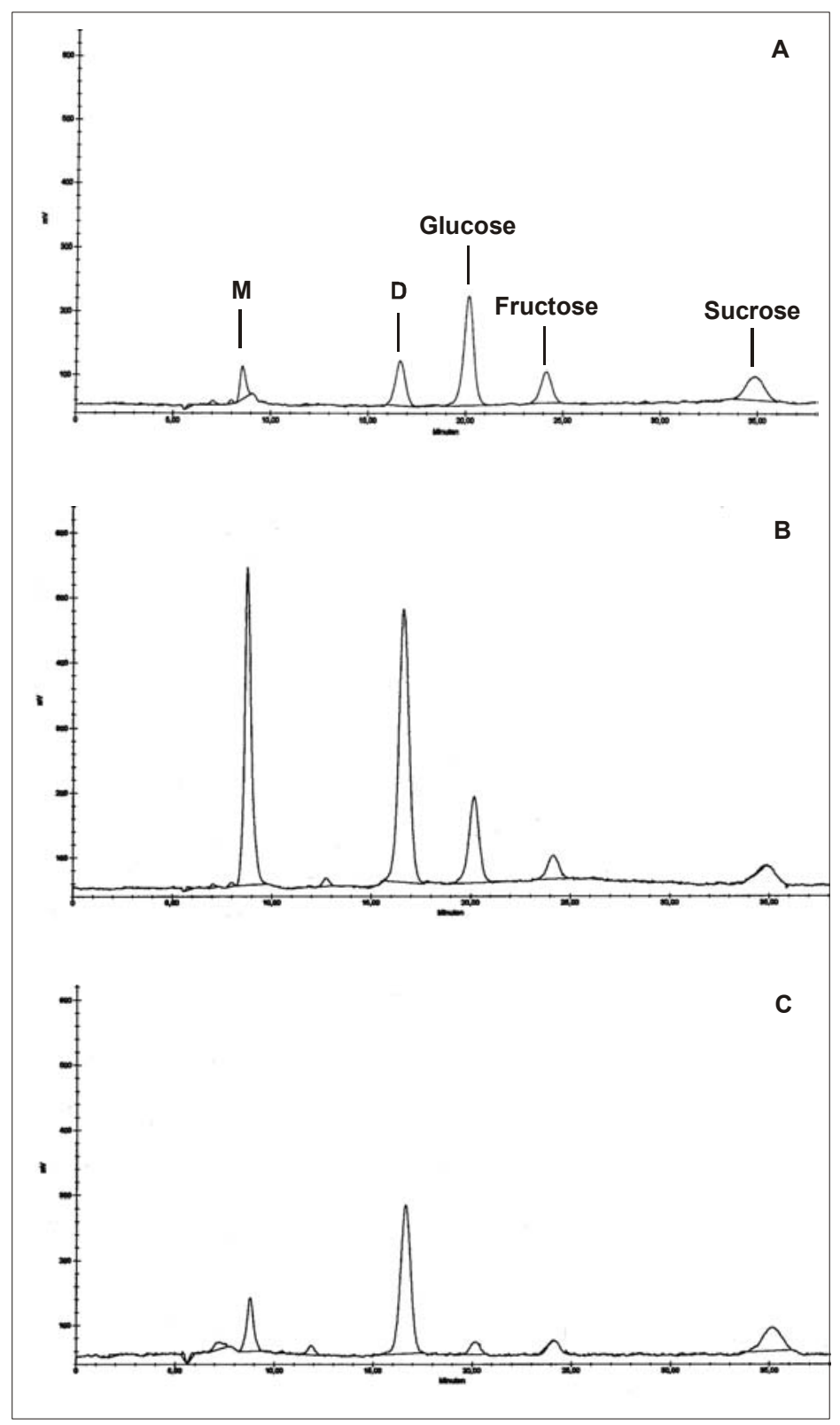

Figure 3.9. HPLC diagramms of the root sugar extracts from Datisca glomerata. A: Ethanol extract; B: Standards of 200 $\mu \mathrm{mol}$ isolated M (1-Omethylrutinose) and $1 \mathrm{mM} \mathrm{D}$ (rutinose) were added to ethanol extracts to confirm the sugar identity; C: Chloroform/methanol extract. $X$-axis: time [min], Y-axis: HPLC detection signal [mV]. 
Accordingly, M ( $\alpha$-L-rhamnopyranosyl-(1 $\rightarrow 6)-1-O-m e t h y l-ß-D-g l u c o s e)$ could be named 1-O-methylrutinose. Like rutinose, this sugar is not known among free plant metabolites. To ensure that the methylation of the anomeric C-atom was no artefact of the isolation method, namely the chloroform/methanol extraction (2.16.2), alternative methods for total sugar extractions were applied to confirm the natural occurence of 1-Omethylrutinose. HPLC analysis of Datisca root extracts obtained with ethanol, perchlorate or acetone (2.16.3-2.16.5) confirmed the occurrence of 1-O-methylrutinose in total sugar extracts independently of the presence of a potential methyl donor. The HPLC diagram of the ethanol extract is shown in Figure 3.9, whereas the results for perchlorate and acetone extractions are not shown.

Moreover, methylrutinose and ethylrutinose were chemically synthesised from rutinose by Dr. R. Fortte at the Institute for Organic Chemistry at the University of Göttingen in laboratory of Prof. Tietze. The comparison of the synthesised alkylated products with rutinose and 1-O-methylrutinose isolated from Datisca via NMR and thin layer chromatography (TCL) on silicagel plates showed that during chemical synthesis, only $\alpha$-methyl- and $\alpha$-ethylglycosides of rutinose were formed, whereas the natural component represents a $\beta$-methylglycoside (see above). Hence, it was confirmed that $\mathrm{O}$ methylrutinose does not represent a chemical artefact in Datisca sugar extracts.

\subsubsection{Sugar contents in roots, nodules and leaves of Datisca after determination of the molecular mass of the novel sugars}

Sugars were extracted with chloroform/methanol for HPLC analysis. The concentrations of the two unknown components termed $M$ and $D$ in the total sugar extracts had previously been estimated based on the molecular weight of myo-inositol and ribitol, respectively, as components with the closest retention time (see 3.1.3). After the isolation and determination of chemical structure and molecular mass of the unknown sugar components $M$ (1-O-methylrutinose) and $D$ (rutinose) (see 3.1.3.1), new concentration standards were prepared to estimate the real concentrations of $M$ and $D$ and to compare them with concentrations of glucose, fructose and sucrose in the same extracts. Additionally, leaf extracts were analysed for the presence of methylrutinose and rutinose to find out whether these two sugars are only present in sink- or also in source organs. The results are presented in Figure 3.10. 


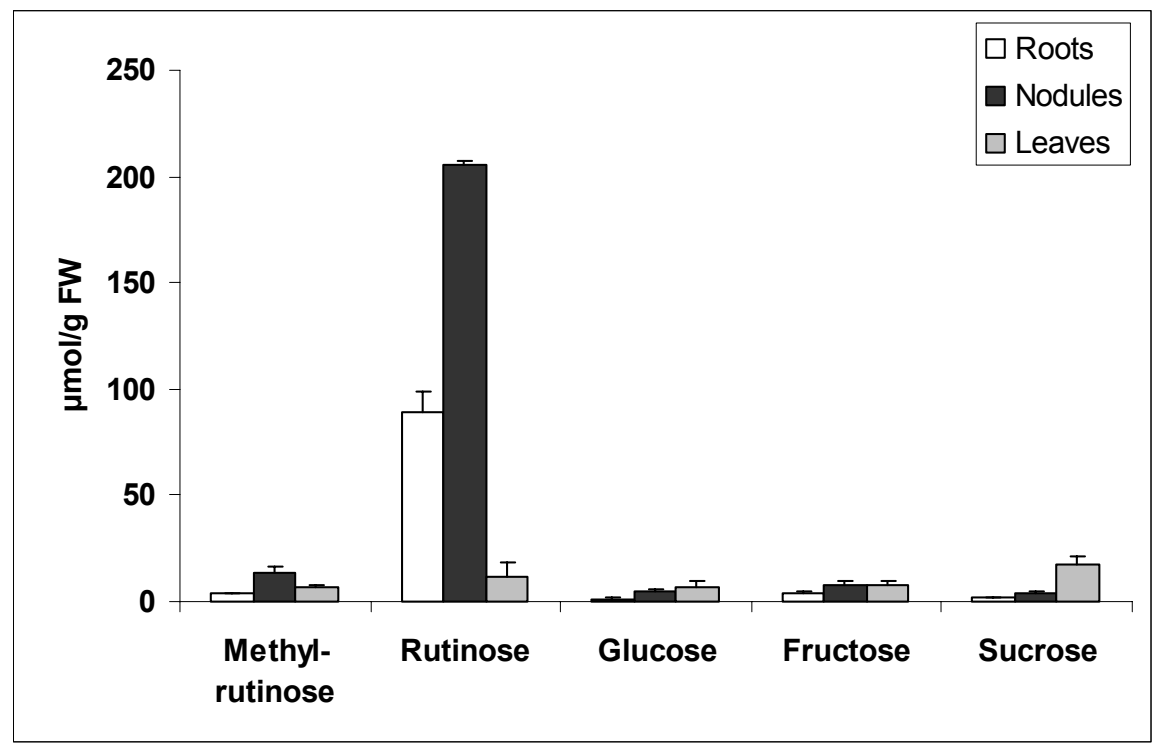

Figure 3.10. Concentrations of soluble sugars in roots, nodules and leaves of Datisca glomerata. The concentrations of the novel sugars methylrutinose (M) and rutinose (D) were estimated using concentration standards prepared from the isolates (see 3.1.3.1).

\subsection{Activities of sucrose cleaving enzymes in roots and root nodules}

Sink organs of most plant species are supplied with carbon and energy in the form of sucrose. The channelling of sucrose into sink metabolism requires its cleavage by one of several isoforms of invertase (cytosolic, apoplastic or vacuolar) or SuSy, which are localized in different subcellular compartments. These activities regulate the entry of sucrose into distinct biochemical pathways, such as respiration or biosynthesis of cell wall polysaccharides and storage reserves. Other vital roles for the sucrose-cleaving enzymes include invertase activity at the site of phloem unloading and vacuolar invertase and sucrose synthase in sink organs, which drives the long-distance transport of sucrose. In order to understand the differences of sugar metabolism in roots and root nodules, the activities of these enzymes were compared.

\subsubsection{Invertase activities}

Invertase is a hydrolase that cleaves sucrose irreversibly into glucose and fructose. Invertase activities were measured in soluble protein extracts and cell wall suspensions of Medicago, Datisca and Casuarina. The activities of the three different invertase isoforms were analysed based on their $\mathrm{pH}$ optima: 4.35 for apoplastic invertase; 5.0 for the 
vacuolar invertase and 6.8 for the cytosolic isoform, which is also called alkaline invertase (see 2.20.2). The $\mathrm{pH}$ optima of apoplastic and vacuolar invertase were rather similar, but these enzymes could be distinguished based on their solubility, because apoplastic invertase is insoluble.

In Medicago, cytosolic invertase activities were somewhat increased in nodules compared to roots, but both apoplastic and vacuolar invertase activities were strongly reduced in nodules compared to roots (Figure 3.11A). In Datisca, the activities of all three types of invertases were dramatically reduced in nodules compared to roots (Figure 3.11B). In Casuarina, vacuolar invertase activities were similar in nodules and roots, while apoplastic and cytosolic invertase activities were strongly reduced in nodules compared to roots (Figure 3.11C). Thus, in all systems examined, apoplastic invertase activities were strongly reduced in nodules compared to roots. The highest specific activity of apoplastic invertase among the plants examined in this work was observed for roots of Casuarina (about $5 \mathrm{nmol}$ sucrose cleaved per min per mg protein). Extremely high vacuolar invertase activities were found in roots of Datisca.
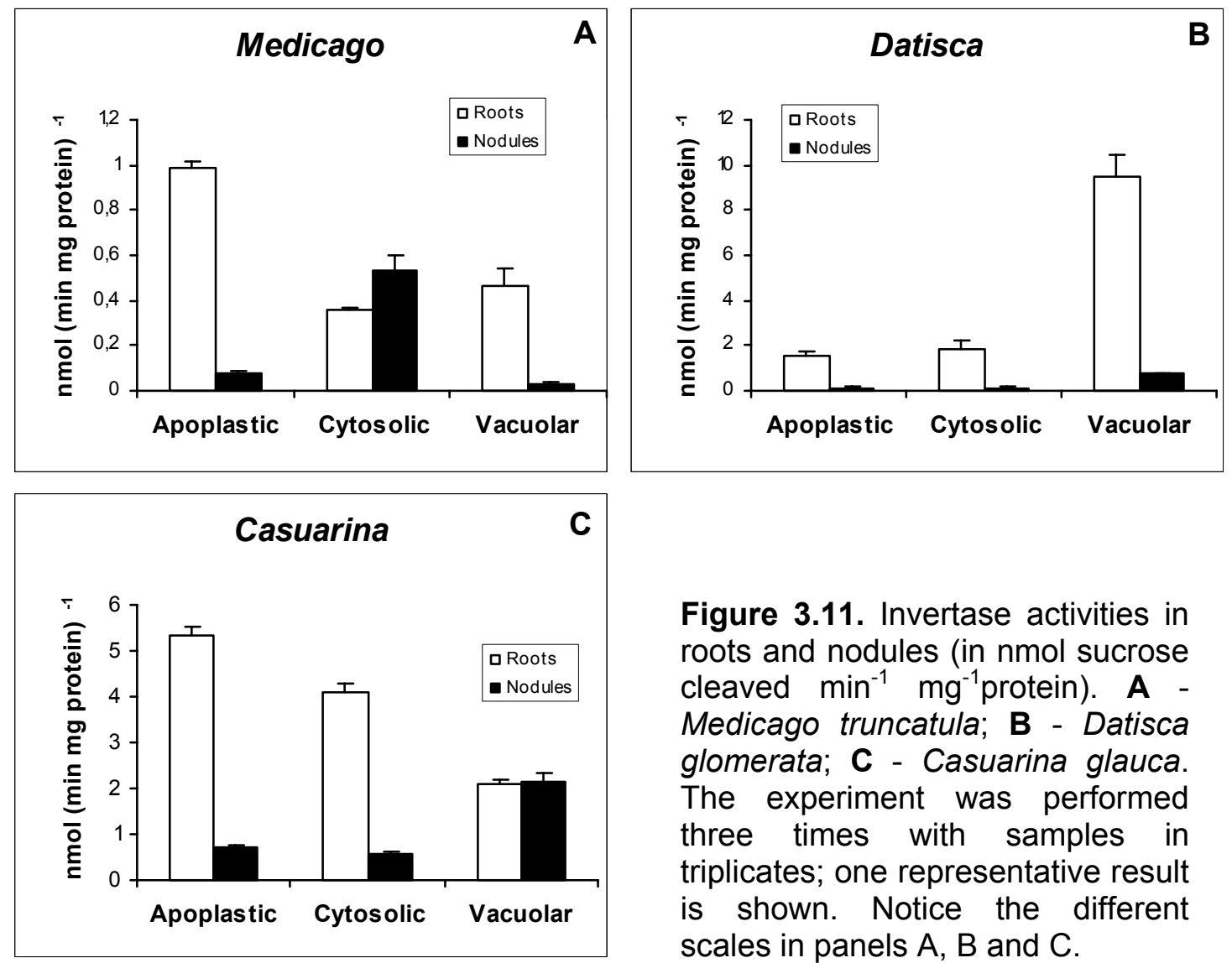

Figure 3.11. Invertase activities in roots and nodules (in nmol sucrose cleaved $\mathrm{min}^{-1} \mathrm{mg}^{-1}$ protein). A Medicago truncatula; B - Datisca glomerata; C - Casuarina glauca. The experiment was performed three times with samples in triplicates; one representative result is shown. Notice the different scales in panels A, B and C. 


\subsubsection{Sucrose synthase activities}

Sucrose degradation by SuSy seems to be the primary pathway in mature legume nodules (Kouchi et al., 1988; Anthon and Emmerich, 1990). Sucrose synthase is a glycosyltransferase that converts sucrose into UDP-glucose and fructose in the presence of UDP. Although SuSy is able to synthesise sucrose under appropriate conditions, there is good evidence that sucrose synthase is primarily involved in its breakdown in vivo (Xu et al., 1989; Geigenberger et al., 1993).

SuSy activity was determined via UDP-glucose formation (see 2.19.2). No differences could be found in the SuSy activities of roots and nodules of Medicago truncatula, while in Datisca glomerata SuSy activity in nodules was slightly reduced compared to roots (Figure 3.12A; Table 3.1). However, when activities were expressed per $g$ fresh weight as compared to the specific activity, SuSy was much more active in nodules than in roots in both plant species (Figure 3.12B; Table 3.1). All attempts to extract SuSy activity from Casuarina glauca tissues failed. This may have been due to the fact that $80 \%$ of the protein from the extract was lost during desalting. When the desalted extracts were tested for SuSy activity, some apparent UDP-glucose formation as denoted by NAD reduction by UDP-glucose dehydrogenase could be observed in Casuarina nodule extracts. However, this activity could not be due to SuSy because it was not inhibited by arbutin, a phenylglycoside inhibitor of SuSy.
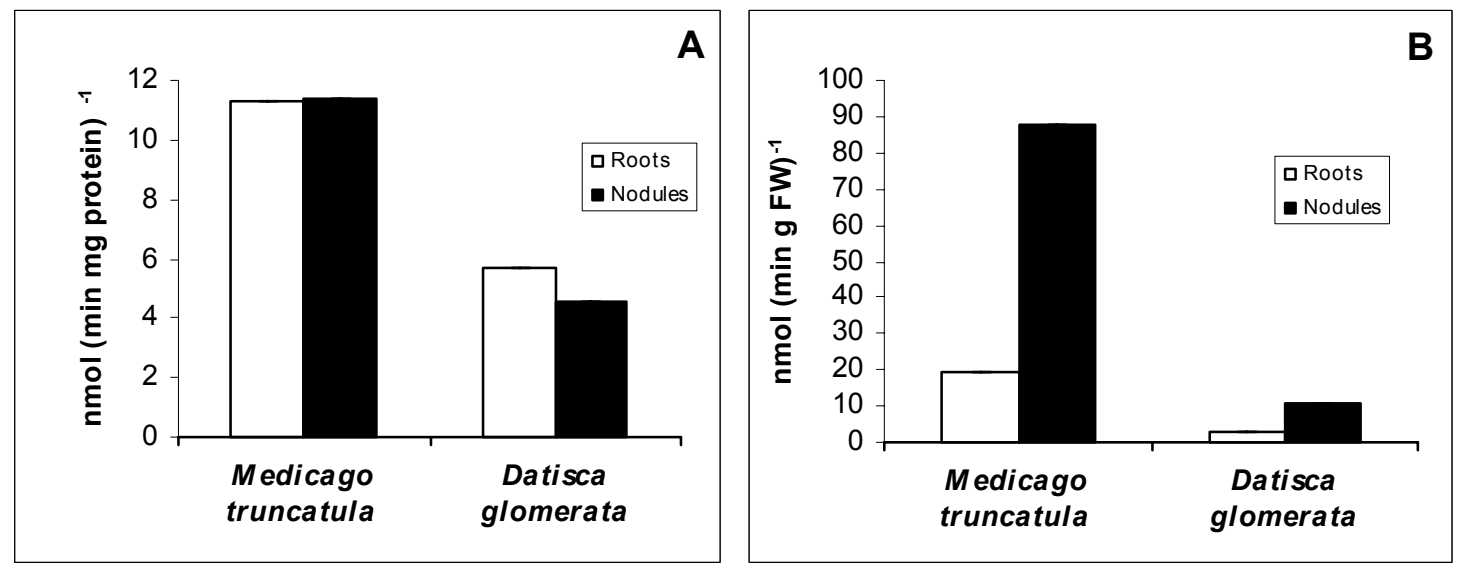

Figure 3.12. Sucrose synthase activity (in nmol sucrose cleaved) in roots and nodules of M. truncatula and D. glomerata. A - activity calculated per mg protein; B - activity calculated per $\mathrm{g}$ FW. The experiment was performed three times; one representative result is shown. Error bars are not visible since errors were $0.003 \%$ maximally (see Table 3.1). 
Table 3.1. Sucrose synthase activities in roots and nodules of $M$. truncatula and $D$. glomerata.

\begin{tabular}{|c|c|c|c|c|}
\hline \multirow[b]{2}{*}{ Host plant } & \multicolumn{2}{|l|}{ Roots } & \multicolumn{2}{|l|}{ Nodules } \\
\hline & $\begin{array}{l}\text { nmol sucrose } \\
\text { cleaved/min/mg } \\
\text { protein }\end{array}$ & $\begin{array}{l}\text { nmol sucrose } \\
\text { cleaved/min/g } \\
\text { FW }\end{array}$ & $\begin{array}{l}\text { nmol sucrose } \\
\text { cleaved } / \mathrm{min} / \mathrm{mg} \\
\text { protein }\end{array}$ & $\begin{array}{l}\text { nmol sucrose } \\
\text { cleaved/min/g } \\
\text { FW }\end{array}$ \\
\hline $\begin{array}{l}\text { Medicago } \\
\text { truncatula }\end{array}$ & $11.3 \pm 0.0004$ & $19.4 \pm 0.0002$ & $11.4 \pm 0.0014$ & $88.1 \pm 0.0027$ \\
\hline $\begin{array}{l}\text { Datisca } \\
\text { glomerata }\end{array}$ & $5.7 \pm 0.0006$ & $2.6 \pm 0.0001$ & $4.5 \pm 0.0002$ & $10.6 \pm 0.0002$ \\
\hline
\end{tabular}

In root extracts, NADH formation could already be observed before the UDPglucose determination was started by the addition of UDP-glucose dehydrogenase. This artefactual activity might be the result of UDP-glucose formation by UDP-glucose pyrophosphorylase in the crude extract.

The data show that generally, in both roots and nodules of Medicago, SuSy activities are more than 20-fold higher than cytosolic invertase activities (Figure 3.11A). SuSy activities were also significantly higher than cytosolic invertase activities in nodules and roots of Datisca (3 times higher in roots, 34 times higher in nodules; Figure 3.12B).

\subsubsection{In situ localization of acid invertase activity}

A glucose oxidase reaction in the presence of horseradish peroxidase and diaminobenzidine (DAB) causes the production of $\mathrm{H}_{2} \mathrm{O}_{2}$, which is then used by peroxidase to oxidize diaminobenzidine (DAB), leading to the formation of a brown precipitate. On hand sections of plant material, after removal of apoplastic glucose by washing and the addition of sucrose, this staining method can be used to visualize the places of acid, i.e. apoplastic or vacuolar invertase activity (Kim et al., 2000). Alternatively, when invertases are inactivated by heat treatment before the reaction medium is added, this method allows to visualize sites of glucose accumulation.

The method did not work for both Casuarina roots and nodules, because it was impossible to identify brown precipitates in the strongly lignified and polyphenol-containing tissues of this plant. Therefore, only results obtained with Medicago and Datisca are presented below. 


\subsubsection{In situ localization of glucose in roots and nodules}

There was no significant staining for glucose in roots of Medicago and Datisca (Figures $3.13 \mathrm{~A}$ and $3.13 \mathrm{~B})$. It was very surprising to find strong glucose staining in the nitrogenfixing infected cells of Datisca nodules (Figure 3.14A; for Datisca nodule morphology, see Figure 1.3). However, this staining turned out to be an artefact, because a similar reaction was also observed when nodules were incubated in reaction mixture without glucose oxidase (Figure 3.14B). It is likely that in Datisca nodule sections stained for glucose, the brown precipitate was due to the presence of $\mathrm{H}_{2} \mathrm{O}_{2}$ (see above) produced by the symbiotic bacteria.

As in roots, no significant staining for glucose was found for Medicago nodules, where only infected cells showed weak glucose staining (Figure 3.15A).

\subsubsection{In situ localization of acid invertase in roots and nodules}

A different pattern of acid invertase activity was observed in roots of Medicago and Datisca. Medicago roots showed invertase activity in the cortex, whereas Datisca roots only showed activity in the stele (Figure 3.13). Thus, in Medicago apoplastic hydrolysis of sucrose in the course of apoplastic sugar transport takes place in the entire root cortex, while in Datisca, it only takes place in the vascular system, indicating that sugar transport in the root cortex occurs symplastically.

Invertase activity staining could not be performed with Medicago nodules, since DAB was reduced in the infected cells independently of the presence of glucose oxidase (Figure 3.15). Like the glucose staining in Datisca nodules, this could be explained by the production of $\mathrm{H}_{2} \mathrm{O}_{2}$ by the bacteria in infected cells. In Datisca nodules, no acid invertase activity could be detected (Figure 3.14). In nitrogen-fixing infected cells, a light brown staining was observed sometimes, but it was much weaker than the colouring found in the same cells during glucose staining (Figure 3.14). This is in accordance with the lack of invertase activity in Datisca nodules (see 3.2.1.). Thus, either incomplete removal of glucose in the washing steps, and/or also the production $\mathrm{H}_{2} \mathrm{O}_{2}$ by the bacteria could be an explanation for this weak staining. 


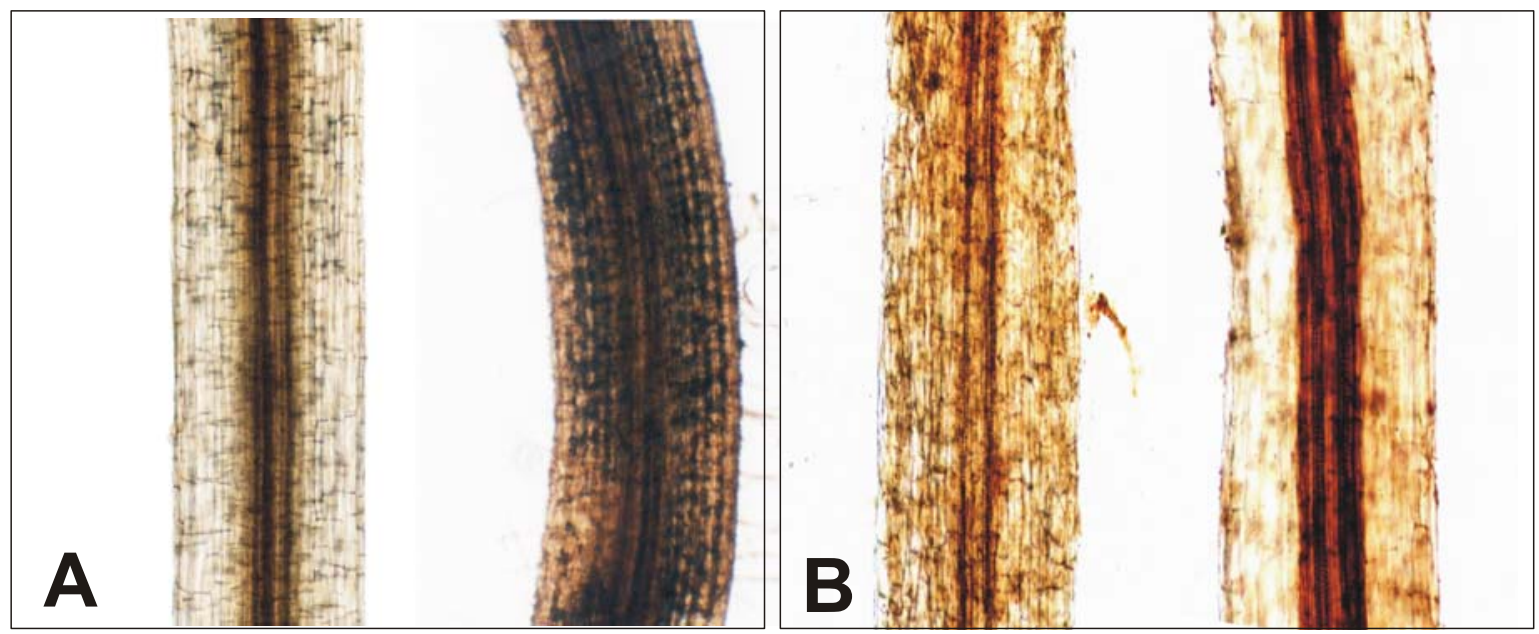

Figure 3.13. In situ staining of glucose and apoplastic invertase activity in Medicago and Datisca roots. (A) Medicago roots: left - staining of glucose leads to some brown precipitate in the vascular system; right - staining of acid invertase activity yields a brown precipitate all over the root cortex. (B) Datisca roots: left - staining of glucose yields a weak brown colour in the vascular system; right - staining of acid invertase activity leads to strong accumulation of brown precipitate in the vascular system.
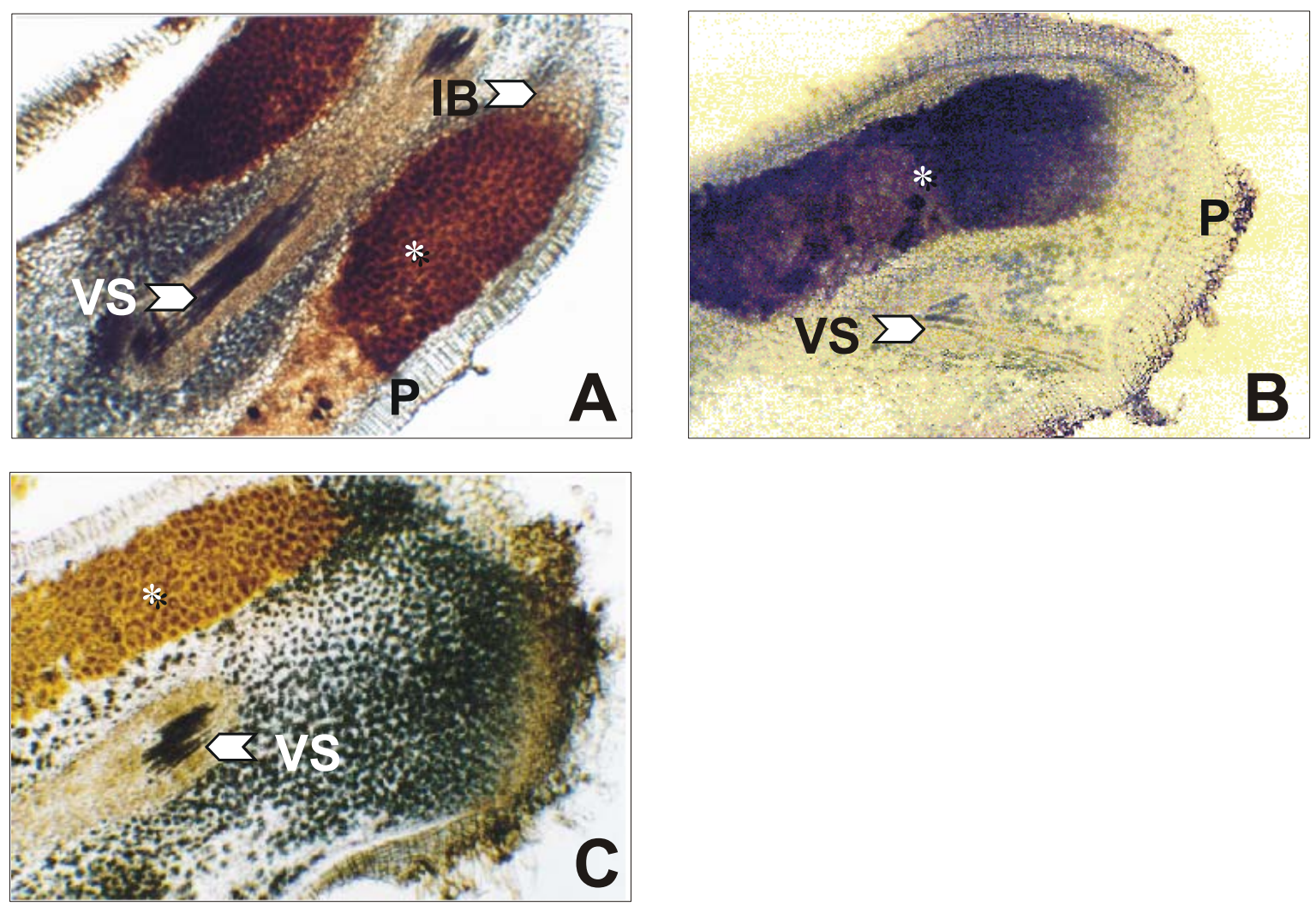

Figure 3.14. In situ staining of glucose and acid invertase activity in Datisca nodules. VS vascular system; IB - beginning of infection; P - periderm; * - nitrogen-fixing infected cells. (A) Glucose staining: nitrogen-fixing infected cells stained brown due to the presence of glucose. (B) Negative control for (A) in the absence of glucose oxidase. The nitrogenfixing infected cells also accumulated a brown precipitate. (C) Staining for invertase activity: no acid invertase activity staining could be found in Datisca nodules. 

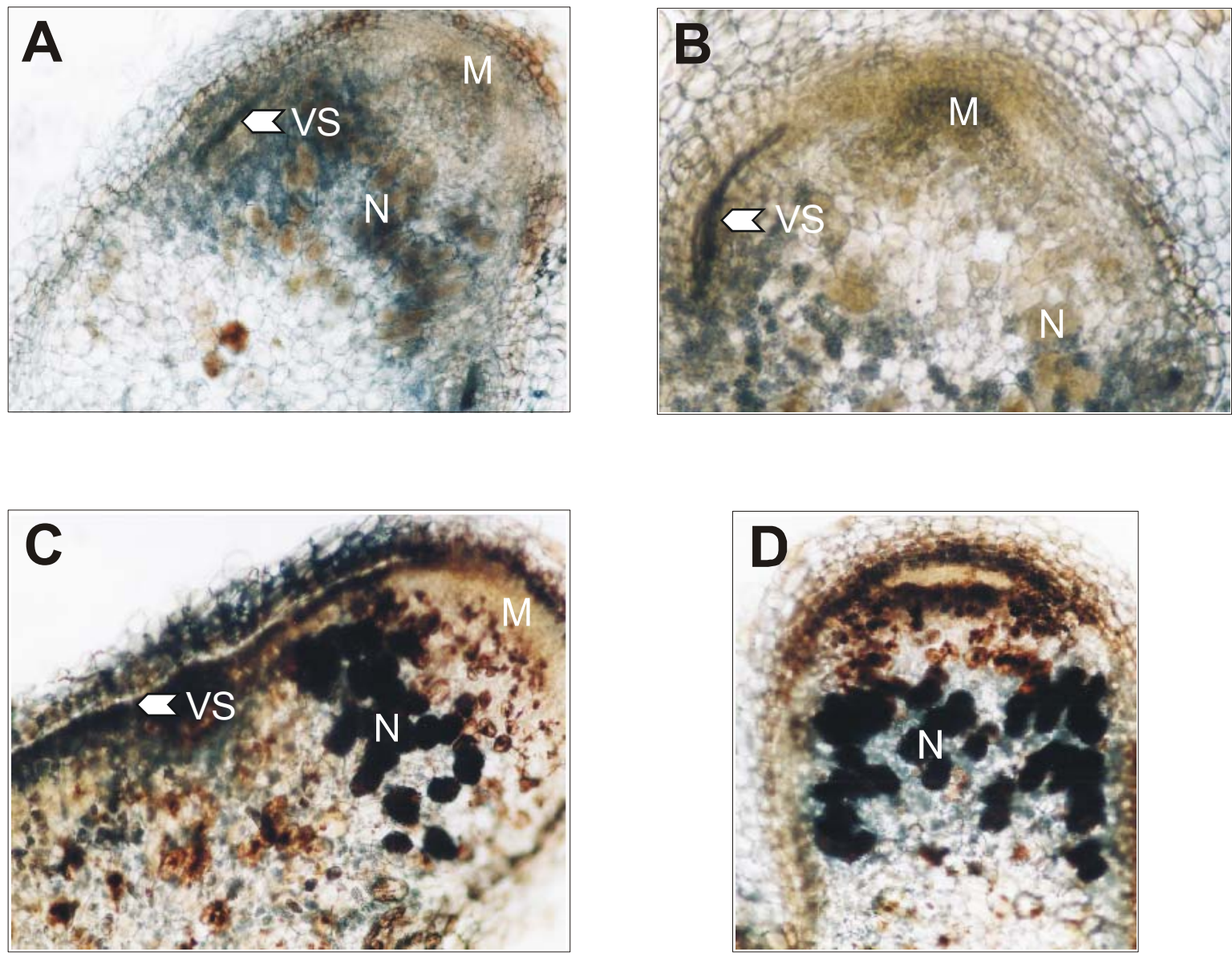

Figure 3.15. In situ staining of glucose and acid invertase activity in Medicago nodules show background in infected cells. Staining of root nodules for glucose (A) and invertase activity (C) in complete reaction mixtures led to the accumulation of brown precipitate in the infected cells in (C). Control staining without glucose oxidase for glucose (B) and invertase activity (D) led to similar amounts of brown precipitate in (D), but not in (B). For nodule structure see Figure 1.2. M - meristem; N - nitrogen-fixation zone; VS - vascular system.

\subsection{Expression levels of sucrose synthase and sugar transporters in roots and nodules}

Sucrose cleaving enzymes are regulated on the transcriptional and post-translational level, while for sugar transporters, so far only transcriptional regulation has been shown (Winter and Huber, 2000; Krausgrill et al., 1998; Ehneß and Roitsch, 1997; Truernit et al., 1996; Büttner et al., 2000). To understand which control mechanisms are employed to regulate sugar partitioning in nodules and roots, expression levels of SuSy and sugar transporters were examined by RNA gel blot hybridization analysis. Invertase expression could not be analysed this way, since invertases are encoded by large gene families with rather divergent sequences (see e.g. Godt and Roitsch, 1997; Tymowska-Lalanne and 
Kreis, 1998), the characterization of which was not possible within the scope of this project.

\subsubsection{Expression levels of sucrose synthase (RNA gel blot hybridization analysis)}

Expression levels of sucrose synthase were compared in roots, nodules and leaves of the three model plants by RNA gel blot hybridization. The results are shown in Figure 3.16. In order to maximize the chance to detect all members of the sucrose synthase gene family, Medicago RNA was hybridized with a heterologous probe, namely a SuSy cDNA fragment from another legume, Vicia faba (Küster et al., 1993). Datisca and Casuarina RNA gel blots were hybridized with homologous cDNA probes (Wabnitz, 1998), since no cDNAs from close relatives were available.

In Medicago, SuSy expression was strongly increased in nodules compared to roots, while in Datisca, the expression of SuSy was only slightly induced in nodules compared to roots. The RNA gel blot hybridization results of Casuarina showed the opposite results: less SuSy transcripts were detected in nodules than in roots (Figure 3.16).

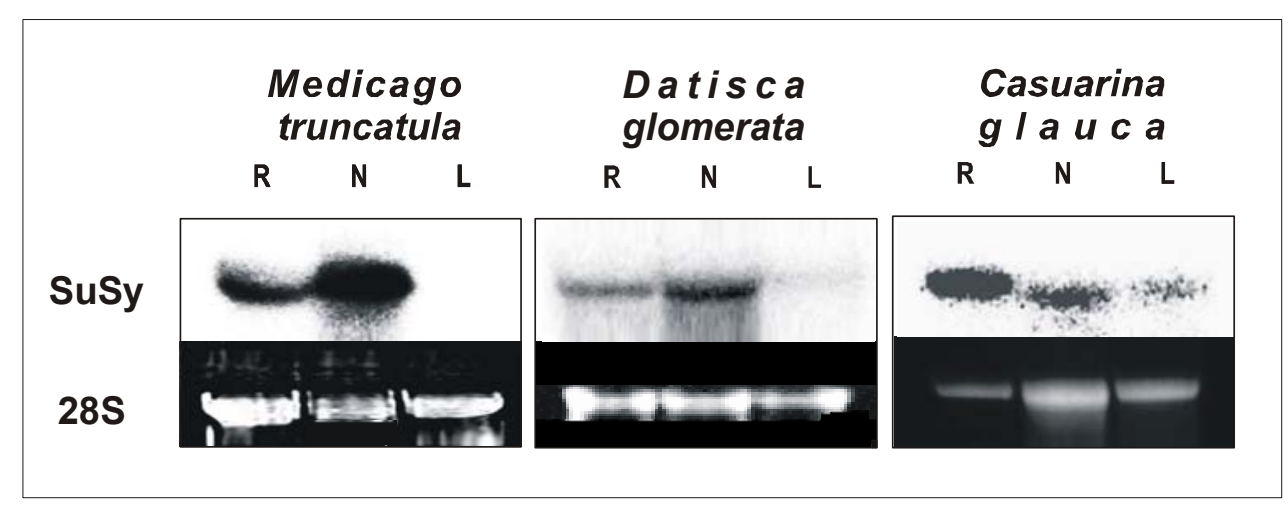

Figure 3.16. SuSy gene expression levels in Medicago, Datisca and Casuarina roots (R), nodules $(\mathrm{N})$ and leaves (L). 28S rRNA served as a control for the amount of RNA per slot. These experiments were performed at least three times. One representative result is shown.

No expression of SuSy was detected in Medicago leaves, and very low amounts of SuSy transcripts were detected in Datisca leaves. The lack of detectable SuSy transcripts in leaves is normal for source organs, where sucrose is synthesized, and not degraded (Sturm and Tang, 1999). However, the enzyme has also been localized in the sieve tubecompanion cell complex of source leaves (Nolte and Koch, 1993), where it appears to be involved in the hydrolysis of a small proportion of the incoming sucrose to maintain a 
proton gradient across the plasma membrane of companion cells for phloem loading (Lerchl et al., 1995). The relatively high expression levels of SuSy in Casuarina leaves are due to the fact that morphologically, these "leaves" represent branchlets with the true leaves reduced to tiny scales, i.e. mixed leaf and stem material. The role of SuSy in stems is not completely clear, because only hypocotyls of radish, sunflower and cotton were analysed with respect to SuSy (Rouhier and Usuda, 2001; Kutschera and Heiderich, 2002; Ruan et al., 1997). In sunflower hypocotyls the SuSy activity was implicated in cellulose synthesis (Kutschera and Heiderich, 2002) as it had already been shown for developing cotton seeds (Ruan et al., 1997). In hypocotyls of radish, high levels of SuSy were found in companion cells of the phloem (Rouhier and Usuda, 2001), where besides its potential function in the production of precursors for respiration, SuSy could also play a role in callose accumulation, and therefore in the regulation of both cell-to-cell and longdistance transport in plants. However SuSy protein was also found in the xylem parenchyma and some cortical cells, where its role remains unclear (Rouhier and Usuda, 2001).

\subsubsection{Levels of sucrose synthase protein (Protein blot analysis)}

Enzyme activity can be regulated both on the transcription level and posttranscriptionally. SuSy is extensively regulated on all levels, including reversible protein phosphorylation and interaction with the actin cytoskeleton (Winter and Huber, 2000). The finding that similar levels of SuSy enzyme activity were found in roots and nodules of Medicago and Datisca, while the levels of SuSy mRNA were different in roots and nodules of all three model plants, raised the question of how SuSy activity is regulated at the posttranscriptional level.

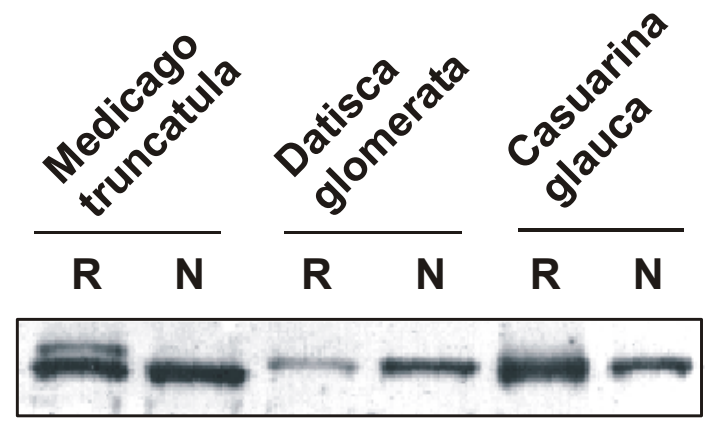

Figure 3.17. Immunodetection of sucrose synthase in total protein extracts from roots $(R)$ and nodules $(N)$ of Medicago, Datisca and Casuarina, separated by PAGE (2.24-2.25). $15 \mu \mathrm{g}$ of total protein were applied per slot. This experiment was performed three times. One representative result is shown. 
The amounts of SuSy were analysed by the protein blot analysis of total protein extracts from roots and nodules (2.25) from the three plant systems with an antibody raised against SuSy from cotyledons of Vicia faba (Ross and Davies, 1992; kindly provided by N. Hohnjec, University of Bielefeld). The results are shown in Figure 3.17. Increase of SuSy protein levels in nodules compared to roots could be found only in nodules of Datisca, which contain a single immunoreactive protein of approximately 92$\mathrm{kDa}$. For Casuarina glauca, also a single immunoreactive protein of the same mass was detected, but the amounts of SuSy were reduced in nodules compared to roots. So, for Datisca and Casuarina the amounts of protein are in accordance with mRNA expression levels. However, in Medicago nodules, only a slight increase in the amount of the immunoreactive $92 \mathrm{kDa}$ protein was detected compared to roots. This does not reflect the mRNA levels, but is in accordance with SuSy enzyme activities in both organs (Figure 3.12A). A second immunoreactive protein of slightly higher molecular weight was detected in extracts of uninfected roots of Medicago, which is consistent with the results obtained by Hohnjec et al. (1999).

\subsubsection{Expression levels of sugar transporters in roots, nodules and leaves}

The organ-specific expression of sucrose and hexose transporters was analysed by RNA gel blot hybridisation in roots, nodules and leaves of the three model plants. For the sucrose transporter of Medicago, a heterologous probe from Vicia faba was used (Weber et al., 1997), while a homologous probe was used for the hexose transporter of Medicago (Wabnitz, 1998). The expression levels of the sucrose transporter (MtST) were strongly reduced in nodules compared to roots, and the expression levels of the hexose transporter $(M t H T)$ in nodules were below the detection limit (Figure 3.18). For Datisca only homologous probes were used (Wabnitz, 1998). Here, the expression of the hexose transporter was strongly induced in nodules compared to roots, while sucrose transporter expression was below the detection limit in both nodules and roots as well as in leaves (Figure 3.18; data not shown for the sucrose transporter). For Casuarina, only hexose transporter expression was examined since no sucrose transporter cDNA fragment could be amplified by PCR with the degenerate primers that had been used successfully for Datisca (Wabnitz, 1998). Casuarina hexose transporter expression was strongly induced in nodules compared to roots, as in Datisca (Figure 3.18). Interestingly, in both Casuarina and Datisca, hexose transporter expression levels were very low in roots, while in Medicago roots high expression levels of both hexose and sucrose transporters were found, indicating that root sugar partitioning mechanisms differ significantly between the legume Medicago and the two actinorhizal plants. 


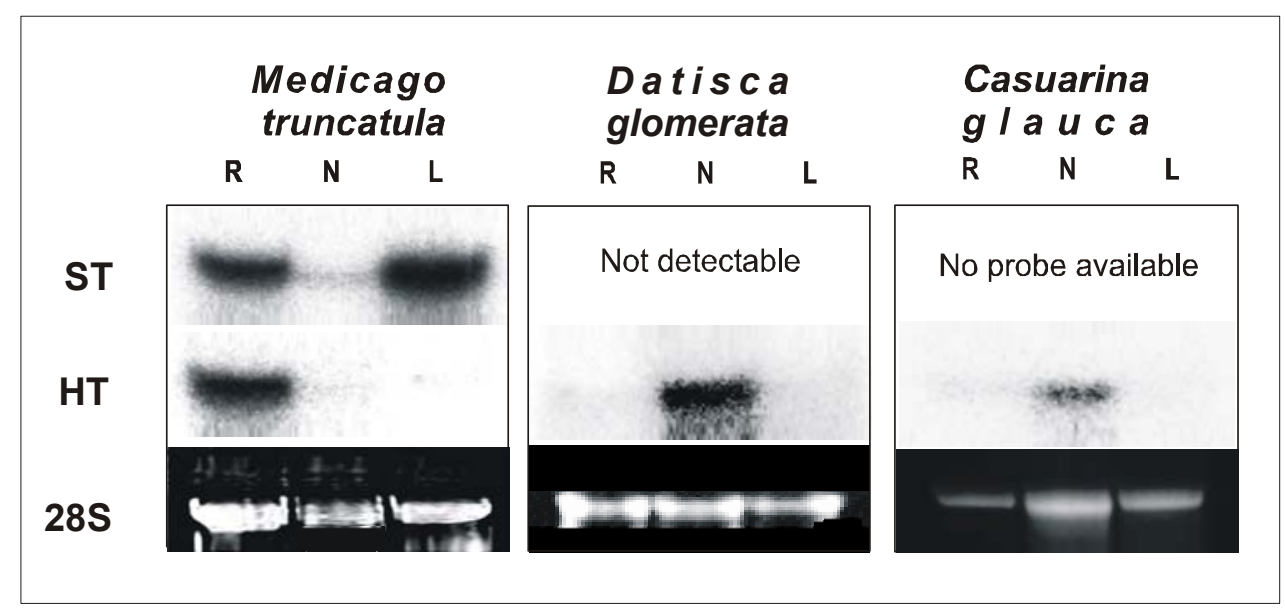

Figure 3.18. Sucrose transporter (ST) and hexose transporter (HT) gene expression in Medicago, Datisca and Casuarina roots $(R)$, nodules $(N)$ and leaves $(L)$. 28S rRNA serves as a control for the amounts of RNA per slot. These experiments were performed at least three times. One representative result is shown.

\subsection{Isolation and characterization of hexose transporter cDNAs}

In previous studies, evidence had been obtained that the hexose transporters from Medicago (Figure 3.19) and Datisca (Figure 3.20) had special properties with respect to their primary structure and expression patterns. The hexose transporter cDNA fragment that had been amplified from Medicago nodule cDNA differed in the C-terminal region from all other hexose transporters known thus far (Wabnitz, 1998; amino acids 404 to Cterminus in Figure 3.21). In situ hybridization analysis of the expression pattern of the hexose transporter from Datisca (Figure 3.20) had revealed that its expression was confined to the infected cells of the nodules (Wabnitz, 1998). In combination with the data on the extremely low apoplastic invertase activity in Datisca nodules obtained in this thesis (3.2.1.), this expression pattern suggested a function of the transporter in feeding hexose to the microsymbionts (see 4.4.). Therefore, one of the aims of this study was to obtain full size cDNAs from both genes in order to analyse the transport activity of the encoded proteins in yeast.

\subsubsection{Full size cDNA of the Medicago truncatula hexose transporter (MtHT)}

At the beginning of this study, only ca. $500 \mathrm{bp}$ of the $3^{\prime}$ end of cDNA had been isolated, namely the sequence of the original PCR product and the $3^{\prime}$ RACE products (Wabnitz, 1998; Figure 3.19). For MtHT, the $3^{\prime}$ end of the cDNA had been used to isolate 
1 GAATTCGATTCCCAACCAGCATAGAATTAAACTAACAGTGATTCACCCATAAAGTTAAGTTTGGTGCTAT

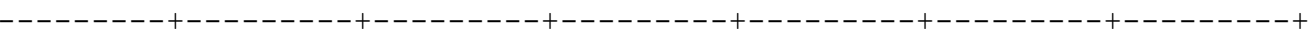

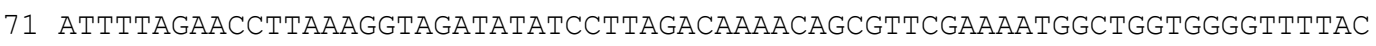

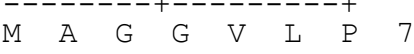

141 CAGTGGATAGTACACCAGTGGCAGTAACTGCCATCAATATTGGTGGCAAGTTAACACTCTCAATCATCAT

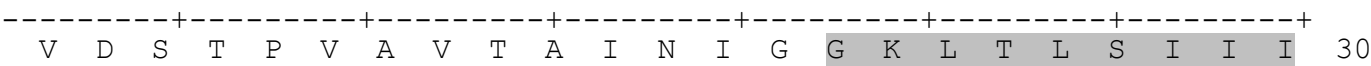

211 TACCTGCATAGTTGCTGCATCCGGTGGCCTTCTTTATGGATATGATCTCGGAGTTTCAGGAGGTGTTACA

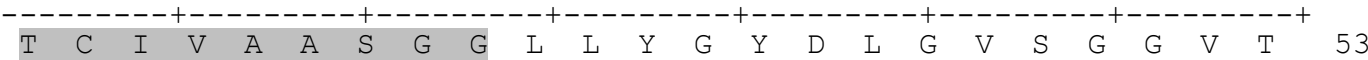

241 ACGATGGTGCCATTTCTCCAAAAATTCTTTCCAGACATTCTGAGAAAGGCAGCCAGTGCCGAAGTGAATA T M V P F L Q K F F P D I L R K A A S A E V N M 77

351 TGtATTGTGTGTATGATAGTCAAATATTGACACTATTTACGTCTTCTCTTTATCTAGCTGGATTAGTGTC

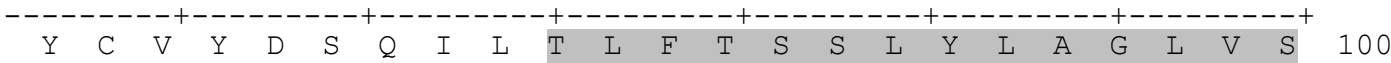

421 ATCCATTGCAGCTAGCAAAgTCACGGCGGCTTATGGTCGGAGAAACGTCATCATAATAGGAGGTGCTCTC

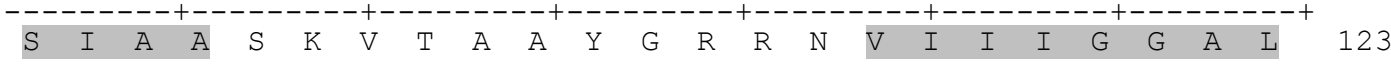

491 TTCATTGCCGGTGGCGCCATTAATGGTGGTTCGGAAAATATCCCCATGCTCATTTTGGGTCGTGTTCTTC

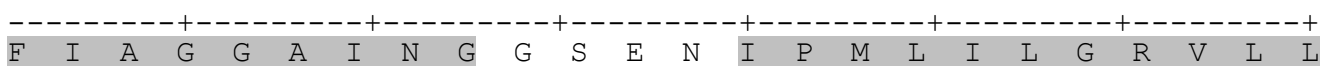

561 TTGGGTTTGGGGTTGGTTTCACTAATCAAGCTGCACCGTTGTACCTATCTGAAACTGCTCCCCCAAAATG $\begin{array}{llllllllllllllllllllllll}G & F & G & V & G & F & T & N & Q & A & A & P & L & Y & L & S & E & T & A & P & P & K & W & 170\end{array}$

631 GCGAGGCACTTTTAACACGGGCTTTCAGTTCTTCTTGGGAATTGGTGTAGTCGCTGCCGGCTGCATAAAC

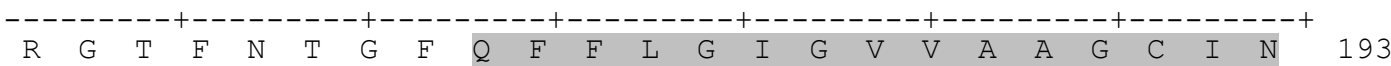

701 TACGCCACGGCCAAGCACACATGGGGATGGAGACTCTCTCTTGGACTTGCAGTGGTTCCTGCAGCTGTGA

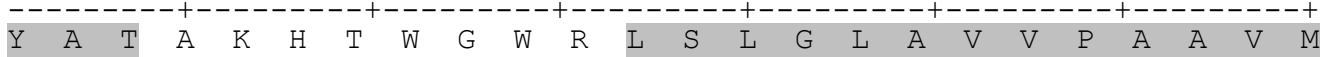

771 TGACAATCGGTTCCTTCCTCATTACCGATACACCAAACGGCTTGGTAGAACGTGGTAAGATAGAGCAAGC T I G S F L I T D T P N G L V E R G K I E Q A 240

841 CAAACAAGCCTTACGCAAAATTAGAGGATCCTCGGTTGATATTGAACCCGAGTTAGAAGAACTTATCAAG

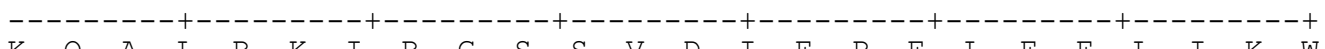
$\begin{array}{lllllllllllllllllllllllll}K & Q & A & L & R & K & I & R & G & S & S & V & D & I & E & P & E & L & E & E & \text { L } & \text { I } & K & W & 263\end{array}$

911 TGGACAGAAATTGCGAAATCAGTGCAACAAGAGCCCTTTAAAACCATATTAAAAAGGGAATATCGACCTC

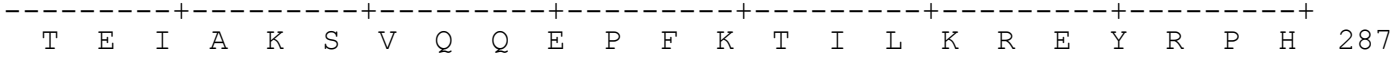

981 ACTTGGTGATGGCATTTGCAATCCCGTTTTTCCAACAGCTTACAGGGATCAATATTGTAGCCTTTTATTC $\begin{array}{clllllllllllllllllllllllll}\text { L } & \text { V } & \text { M } & \text { A } & \text { F } & \text { A } & \text { I } & \text { P } & \text { F } & \text { F } & \text { Q } & \text { Q } & \text { L } & \text { T } & \text { G } & \text { I } & \text { N } & \text { I } & \text { V } & \text { A } & \text { F } & \text { Y } & \text { S } & 310\end{array}$ 
1051 ACCCAACCTCTTTCACTCTGTGGGTTTTGGACACGACGGAGCTTTACTTTCCGCCATTATACTTGGATCT

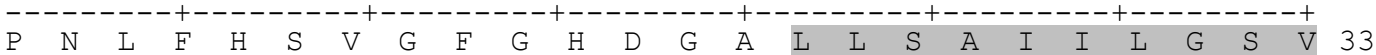

1121 GTTAGCCTTTTGTCTAACCTTATCTCTGCTGGTATTGTTGATCGAATTGGTCGAAGATTCTTGTTCATAT S L L S N L I S A G I V D R I G R R F L F I S 357

1191 CTGGGGGAATATGATGCTTGTCTGCTTGATTGCTGTGTCCATTGTCCTGGCAGTGGTGACTGGTGTTGA

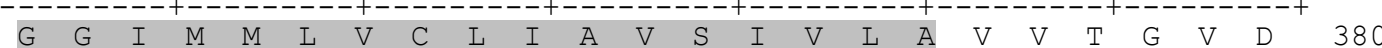

1261 TGGTACAAAGGACATATCCAAGGGCAATGCAATAGTGGTATTGGTGCTATTGTGTTTCTACTCTGCAGGT

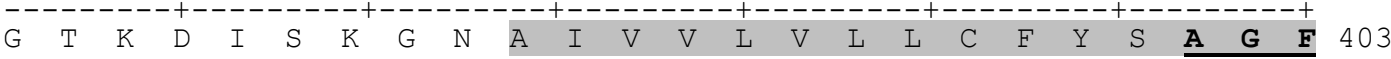

1331 TTTGGTTGGTCATGGGGTCCATTAACATGGCTTATTCCAAGTGAGATTTTCCCAGTAAAAATAAGAACCA

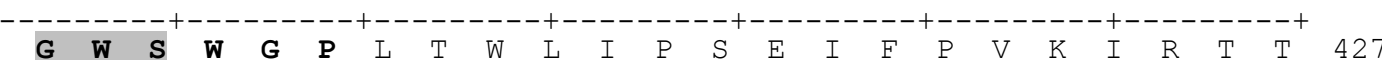

1401 CAGGACAAAGCATAGCTGTTGCTGTGCAATTCATAATAATCTTTGTGTTATCGCAAACATTCTTGACAAT

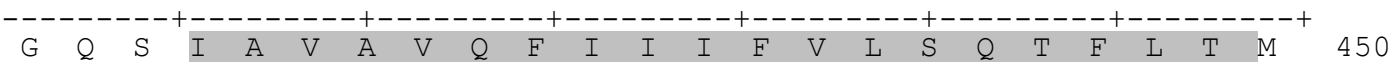

1471 GTTATGCCACATGAAGTTTGGGGCCTTCGTCTTCTATGCTTTTTGGGTTATTGTGATGACTCTGTTTGTT

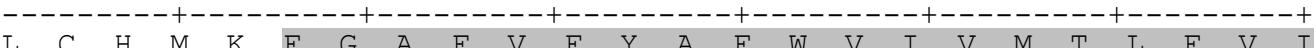

1541 ATCTTCTTCTTGCCTGAGACCAAAGGAATTCCTTTGGAGTCAATGTACACTATATGGGGCAGACACTGGT $--------+---------+--------+--------+--------+---------+---------+$

1611 TTTGGTCTCGGTATGTTAAAGGACAAGAGGTCCTAGAAAATCTCCCATGAAGTTTTTAACACTTTTTATG

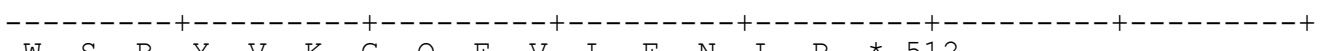
$\begin{array}{llllllllllllllllllll}W & S & R & Y & V & K & G & Q & E & V & L & E & N & L & P & * & 512\end{array}$

1681 ATTGATTTATTATTTTTAAAGAAGTCAATGCACATGCATTATATCTTGACAAAATTGTGCAGCATTGGCT

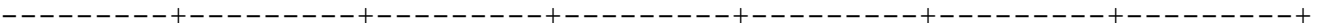

1751 TCATAAAAATAAATCAATAATAAAAGAAATGTAATCAATAATAACGTCTCAAAAATAATGTATTGATTGT

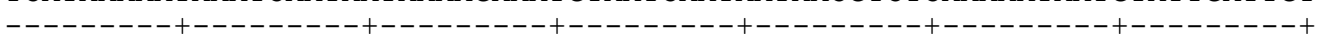

1821 TAATGTTAAAAAAAAAAAAAAAAAAAAAGCGGCCGCGGATCCTCGAGAATCACTAGTGAATTC

Figure 3.19. DNA sequence and deduced amino acid sequence of the $M$. truncatula hexose transporter (MtHT). Shadowed amino acid sequences represent the membranespanning domains predicted by the method of Rost et al. $(1995 ; 1996)$. Numbers to the right refer to the predicted amino acid sequence of MtHT. Underlining denotes potential phosphorylation consensus sequences. The amino acid sequences that had been used to design the original degenerate oligonucleotide primers are underlined and labelled by bold print. 
a cDNA clone from a cDNA library made from RNA of young Medicago nodules (MtHTN15;Wabnitz, 1998; Gamas et al., 1996). However, this clone was not full size but started at nucleotide 442 of the full size sequence that was finally obtained in this thesis. Thus, 5' RACEs had to be performed for cDNA. The cDNA sequences available were used for generating primers for $5^{\prime}$-RACEs. The sequences of all primers used are presented in 2.1.3.

For MtHT 5'-RACE, reverse transcription was performed with the first genespecific primer MtHT 5'race1. Based on the C-tailed first-strand CDNA (2.10.), two PCRs were performed using for the first PCR the anchor primer MM1 and primer MtHT 5'race1 (PCR program was $94{ }^{\circ} \mathrm{C} 30 \mathrm{~s}, 35$ cycles of $94{ }^{\circ} \mathrm{C} 30 \mathrm{~s}, \mathrm{~T}_{\text {ann }}=61^{\circ} \mathrm{C} 30 \mathrm{~s}, 72{ }^{\circ} \mathrm{C} 90 \mathrm{~s}$, followed by $72{ }^{\circ} \mathrm{C}$ for $10 \mathrm{~min}$ in the presence of $1.5 \mathrm{mM} \mathrm{MgCl}_{2}$ ). For the second PCR the anchor-specific primer MM2 and second gene-specific primer MtHT 5'race2 were used (PCR program as described above, except that the $\mathrm{T}_{\text {ann }}$ was $58^{\circ} \mathrm{C}$ ). A PCR product of about 500 bp was cloned in pGEM-T Easy and sequenced. The 5 '-end sequence was used to design another primer, MtHT fs, which in combination with the primer MM4 was used to amplify the full size cDNA. First strand cDNA was transcribed with primer MM3 from nodule mRNA, and the full size cDNA was amplified with the following PCR program: $94{ }^{\circ} \mathrm{C} 5 \mathrm{~min}, 35$ cycles of $94{ }^{\circ} \mathrm{C} 1 \mathrm{~min}, 60^{\circ} \mathrm{C} 1 \mathrm{~min}, 72{ }^{\circ} \mathrm{C} 2 \mathrm{~min}$, followed by $72{ }^{\circ} \mathrm{C}$ for 10 min. The full size cDNA was cloned in PGEM-T Easy and both strands were sequenced.

The DNA sequence and the deduced amino acid sequence of $M$. truncatula hexose transporter $(\mathrm{MtHT})$ are presented in Figure 3.19. The full size clone comprises 1883 nucleotides, 1536 of which represent an ORF that is predicted to encode a protein of 512 amino acids with an estimated molecular mass of $55.41 \mathrm{kDa}$. The $5^{\prime}$-untranslated region includes 121 nucleotides, and $3^{\prime}$-untranslated region is composed of 226 nucleotides.

The protein encoded by $M t H T$ is predicted to be an extremely hydrophobic integral membrane protein with 12 transmembrane domains according to a hydropathy plot (Figure 3.19; Rost et al., 1995; 1996).

\subsubsection{Full size cDNA of the Datisca glomerata hexose transporter (DgHT)}

At the beginning of this study, only ca. 500 bp of the $3^{\prime}$ end of cDNA had been isolated (Wabnitz, 1998; Figure 3.20). The cDNA sequences available were used for generating primers for $5^{\prime}$-RACEs. The sequences of all primers used are presented in 2.1.3.

For $D g H T 5^{\prime}-\mathrm{RACE}$, reverse transcription was performed with a first gene-specific primer DgHT 5'race1. Based on the C-tailed first-strand cDNA (2.10.), the first PCR was performed using an anchor primer MM1 and above-mentioned primer DgHT 5'race1 (PCR 
1 GAATTCGATTCCCTTCTCTCTTTATCTCCTTTTCATCACTCCCCTCTTTCTCTCCTCGCAAAAGAAGTCA

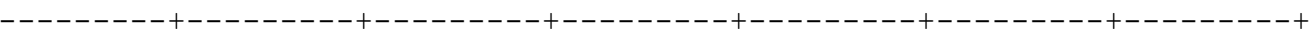

71 GAGATAAAGGACGAAAACATGCCGGCCGTCGGAGGAATCGTTGTCGGTGGCAGTAAAAAGGAGTATCCCG $\begin{array}{lllllllllllllllllll}M & P & A & V & G & G & I & V & V & G & G & S & K & K & E & Y & P & G & 18\end{array}$

141 GCAACCTTACTCCTTATGTCACCATAACATGCATTGTTGCCGCTATGGGTGGTCTGATTTTCGGTTACGA

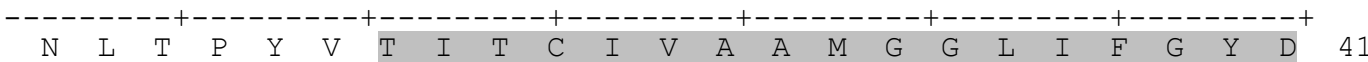

211 TATTGGAATTTCAGGTGGGGTGACGTCAATGGATTCATTCTTGAAGAAATTCTTCCCGGCGGTTTACCGG I G I S G G V $\mathrm{G}$ S $M$ M $\mathrm{D}$ S $\mathrm{S}$ L

241 AAAAAAGAGTTGGATTCGACGACGAACCAGTACTGTCAGTACGACAGTCAGACTCTGACGATGTTCACGT

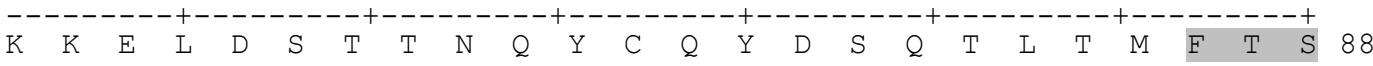

351 CTTCTCTTTATTTGGCTGCTCTGCTCGCTTCGATAGTGGCTTCCACCATCACCCGTAAATTCGGCAGGAG

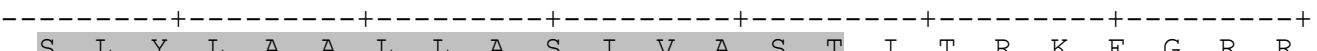

421 ATTATCCATGCTCTTCGGCGGCATTCTGTTCTGTGCCGGTGCTATCATCAATGGCTTCGCCCAGGCTGTT $\begin{array}{llllllllllllllllllllllll}L & S & M & L & F & G & G & I & L & F & C & A & G & A & I & I & N & G & F & A & Q & A & V & 134\end{array}$

491 TGGATGCTCATTCTCGGTCGTATGTTTCTCGGTTTTGGTATTGGGTTTTCCAATCAGTCTGTGCCACTCT

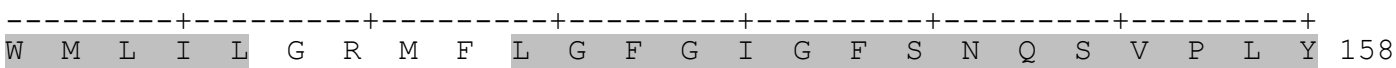

561 ACCTCTCAGAGATGGCTCCCTACAAGTACAGAGGAGCATTAAACATAGGCTTCCAATTATCAATCACAAT

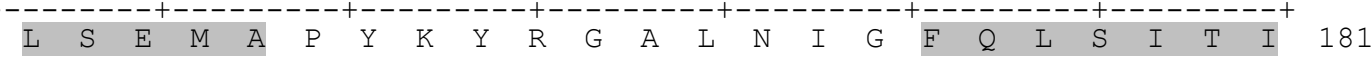

631 TGGAATATTGGTAGCAAATGTGTTAAATTACTTCTTTGCCAAGATCAGGGGCGGCTGGGGATGGCGGTTG

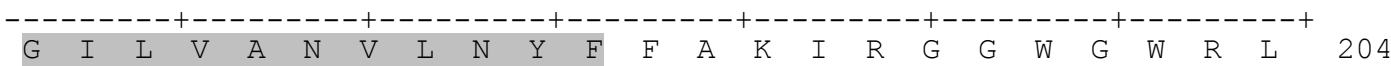

701 AgCTTAGGTGGCGCAATGGTCCCAGCCCTTATCATCACGGTCGGATCGCTACTCCTTCCCGACACACCCA

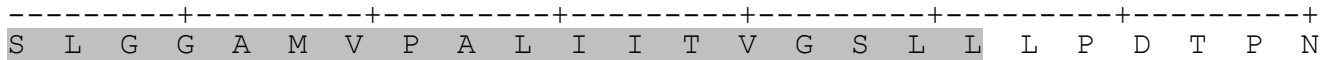

771 ACTCATTAATCGAGCGTGGCAACCGAGACGAAGCCCGCAGCAAACTCCAAAGGGTTCGAGGCGTTGATGA $\begin{array}{rllllllllllllllllllllll}\mathrm{S} & \mathrm{L} & \mathrm{I} & \mathrm{E} & \mathrm{R} & \mathrm{G} & \mathrm{N} & \mathrm{R} & \mathrm{D} & \mathrm{E} & \mathrm{A} & \mathrm{R} & \mathrm{S} & \mathrm{K} & \mathrm{L} & \mathrm{Q} & \mathrm{R} & \mathrm{V} & \mathrm{R} & \mathrm{G} & \mathrm{V} & \mathrm{D} & \mathrm{D}\end{array}$

841 CGTGGACGAGGAGTTTAACGATCTGGTGGCGGCAAGTGAAGAGTCAAAGCAAGTGGAACATCCTTGGACT

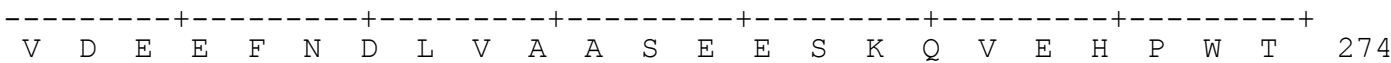

911 AACCTGTTGAGGAGGAAGTACAGACCTCATCTTGCAATGGCTATACTAATTCCTTTCTTCCAGCAACTTA

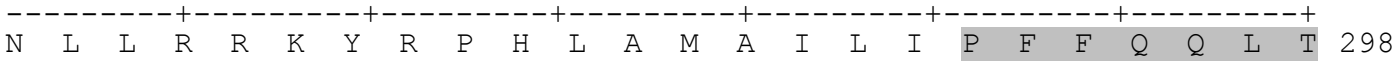

981 CCGGCATCAATGTGATTATGTTTTACGCGCCTGTTTTGTTTAACACCATTGGGTTTGGAAGTGATGCTTC $\begin{array}{llllllllllllllllllllllll}G & I & N & V & I & M & F & Y & A & P & V & \text { L } & \text { F } & \text { N } & \text { T } & \text { I } & G & \text { F } & \text { G } & \text { S } & \text { D A } & \text { A } & 321\end{array}$ 
1051 GCTCATGTCGGCTGTGATTACTGGCTGTGTTAATGTCGCTGGGACTTTGGTTTCTATTTATGGGGTTGAT $\begin{array}{lllllllllllllllllllllllll}\text { L } & M & \text { S } & A & V & I & T & G & C & V & N & V & A & G & T & L & V & S & I & Y & G & V & D & 344\end{array}$

1121 AAGTGGGGAAGGAGGTTCCTTTTCCTTGAGGGTGGATTTCAAATGTTGATTTGCCAGGCGGTTGTAGCAG

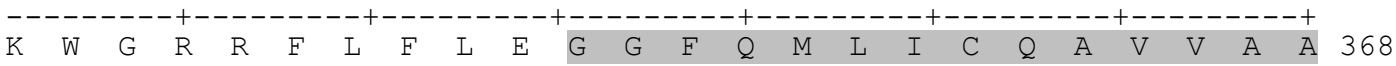

1191 CTGCAATTGGTGCTAAATTTGGAGTAAATGGAAATCCAGGAGAACTGCCAAAATGGTATGCGATAGTGGT

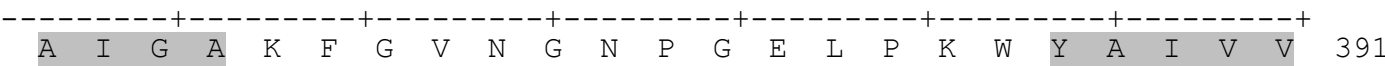

1261 GGTGCTGTTCATATGCATATATGTAGCAGGGTTCTCTTGGTCATGGGGTCCTCTAGGTTGGCTAGTGCCA

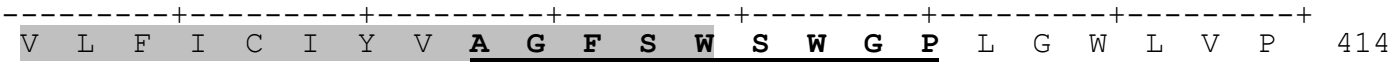

1331 AGTGAAAGTTTCCCCTTAGAAATACGGTCAGCTGCTCAAAGTATCAATGTCTCTGTCAACATGATCTTCA S E S F P L E I R S A A O S I N V S V N M I F T

1401 CATTTGCTATAGCTCAAATCTTCTTGACAATGCTTTGCCACTTGAAATTCGGTTTATTCATTTTCTTCGC

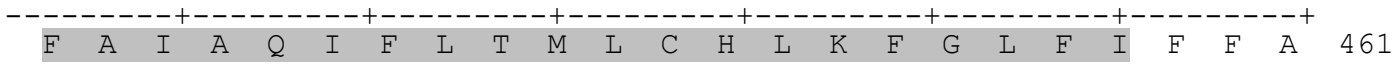

1471 CTTCTTCGTGGTTGTCATGTCTATCTTCGTCTACTTCTTCTTGCCCGAGACTAAGGGAATCCCGATCGAA $\begin{array}{llllllllllllllllllllllllllll}\text { F } & \text { F } & \text { V } & \text { V } & \text { V } & \text { M } & \text { S } & \text { I } & \text { F } & \text { V } & \text { Y } & \text { F } & \text { F } & \text { L } & \text { P } & \text { E } & \text { T } & \text { K } & \text { G } & \text { I } & \text { P } & \text { I } & \text { E } & 484\end{array}$

1541 GAGATGGGCAGAGTATGGAAGTCACATTGGTACTGGTCAAGATTTGTTACTGATGCTGATTACACTATTG

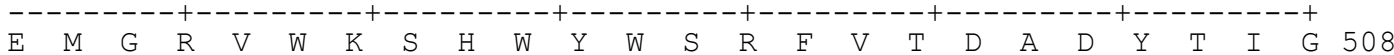

1611 GATCAGGAGTTGAGATGGGAAAGGGAGCGCAGGAGCTTAAGAATATTTAAGTTTAATGTTTGGGGGGAGG ---------+---------+---------+---------+---------+---------+---------+ $\begin{array}{llllllllllllllll} & G & V & E & M & G & K & G & A & Q & E & L & K & N & I & *\end{array} 23$

1681 GTTATTTTTAGATTATTTTTTTCTATCTAGTAAATAGAAGTTTGGGTCAATATTAAATTAAGAACATATG

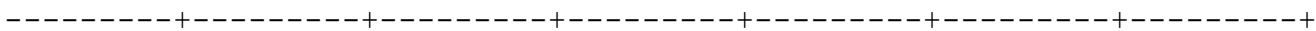

1751 AATGGGTCAAATTGATGTATCTGAATCACTAGTGAATTC 1790

---------+---------+---------+---------+

Fig. 3.20. DNA sequence and deduced amino acid sequence of the $D$. glomerata hexose transporter (DgHT). Shadowed amino acid sequences represent the membrane-spanning domains predicted by the method of Rost et al. (1995; 1996; see 3.4.3.). Numbers to the right refer to the predicted amino acid sequence of $\mathrm{DgHT}$. Underlining denotes potential phosphorylation consensus sequences. The amino acid sequences that had been used to design the original degenerate oligonucleotide primers are underlined and labeled by bold print. 
program was $94{ }^{\circ} \mathrm{C} 30 \mathrm{~s}, 35$ cycles of $94{ }^{\circ} \mathrm{C} 30 \mathrm{~s}, 58{ }^{\circ} \mathrm{C} 30 \mathrm{~s}, 72{ }^{\circ} \mathrm{C} 30 \mathrm{~s}$, followed by 72 ${ }^{\circ} \mathrm{C}$ for $10 \mathrm{~min}$ in the presence of $1.5 \mathrm{mM} \mathrm{MgCl}_{2}$ ). For the second PCR another anchorspecific primer MM2 and second gene-specific primer DgHT 5'race2 were used (PCR program as described above). A 480 bp PCR product was cloned into pGEM-T Easy and sequenced. The $5^{\prime}$-end sequence was used as a template to design primer DgHT fs5, which together with the primer from the $3^{\prime}$-end sequence $D g H T$ fs 3 was used to amplify the full size cDNA with the following PCR program: $94{ }^{\circ} \mathrm{C} 5 \mathrm{~min}, 35$ cycles of $94{ }^{\circ} \mathrm{C} 1 \mathrm{~min}$, $52{ }^{\circ} \mathrm{C} 1 \mathrm{~min}, 72{ }^{\circ} \mathrm{C} 2 \mathrm{~min}$, followed by $72{ }^{\circ} \mathrm{C}$ for $10 \mathrm{~min}$. For this purpose, first strand cDNA was transcribed with primer $d T_{20}$ from nodule mRNA. The full size cDNA was cloned in PGEM-T Easy and both strands were sequenced.

The cDNA sequence and the deduced amino acid sequences of the hexose transporter (DgHT) from Datisca nodules are shown in Figure 3.20. The full size cDNA clone comprises 1790 nucleotides, 1569 of which represent an ORF encoding a protein of 523 amino acids with an estimated molecular mass of $57.64 \mathrm{kDa}$. The $5^{\prime}$-untranslated region consists of 88 and the $3^{\prime}$-untranslated region of 133 nucleotides. Like the other members of the hexose transporter protein family, the protein encoded by $D g H T$ is predicted to be an extremely hydrophobic integral membrane protein with 12 transmembrane domains (Rost et al., 1995; 1996).

\subsubsection{Protein sequence analysis of $\mathrm{DgHT}$ and MtHT}

The deduced amino sequences of $\mathrm{DgHT}$ and MtHT exhibit similarity to known plant hexose transporters, with the highest levels of identity for DgHT to the hexose transporters AtSTP1 from Arabidopsis and MtSTP1 from Medicago (83.3 and 83.2\%, respectively), and for MtHT to AtSTP1 from Arabidopsis (55.1\%; Table 3.2, Figure 3.21; references see figure legend).

Hydropathy analysis reveals that like the other plant hexose transporters, DgHT and MtHT are extremely hydrophobic and predicted to represent integral membrane proteins with 12 membrane spanning domains (Figures 3.19 and 3.20), a typical feature of transporters belonging to the major facilitator superfamily described by Marger and Saier (1993). The MtHT and DgHT sequences also contain conserved sequence motifs previously identified among sugar transporters, including PETKG at the end of membrane-spanning domain 12 and two potential phosphorylation consensus sequences (Figures 3.19 and 3.20). 

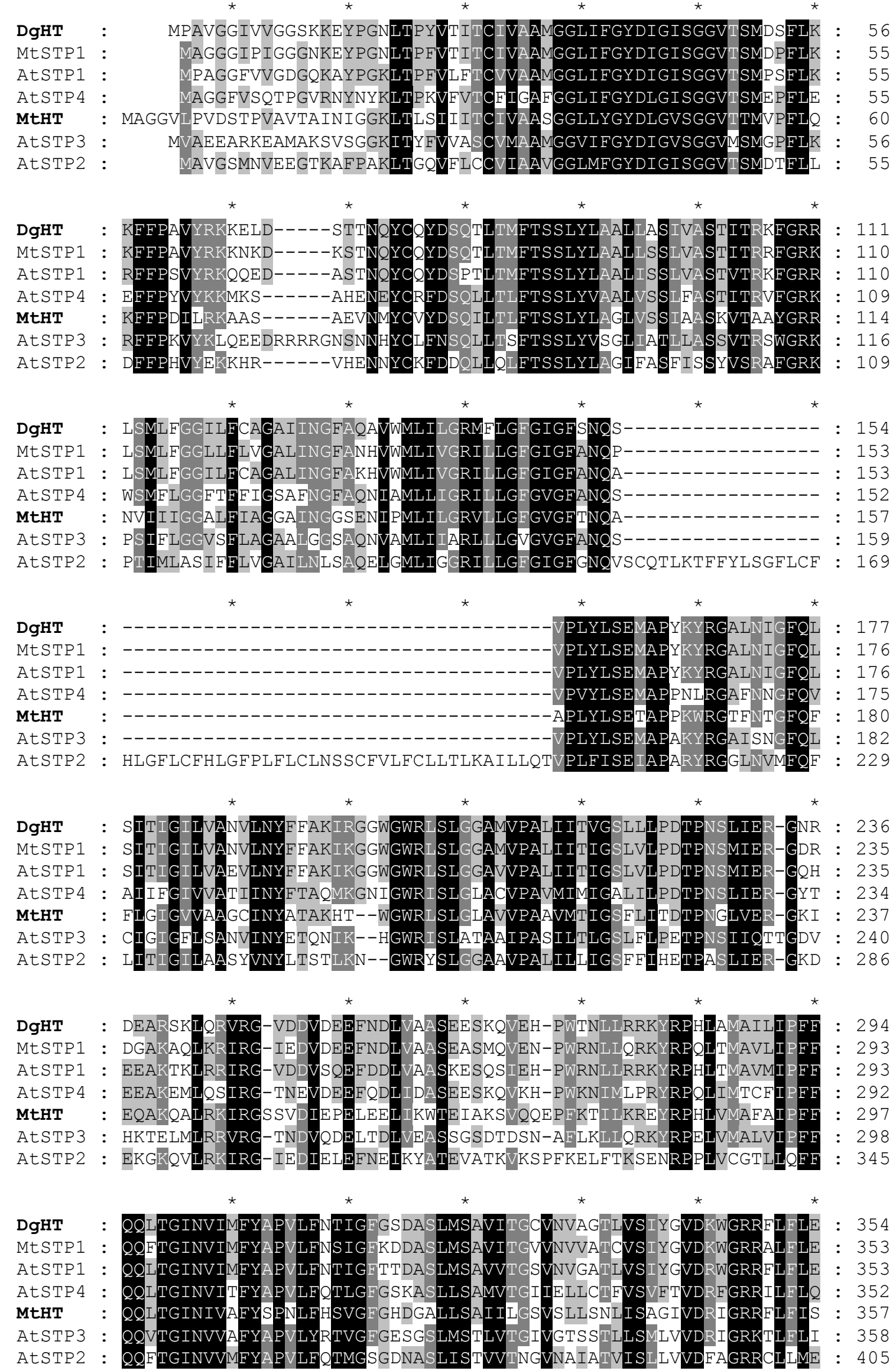

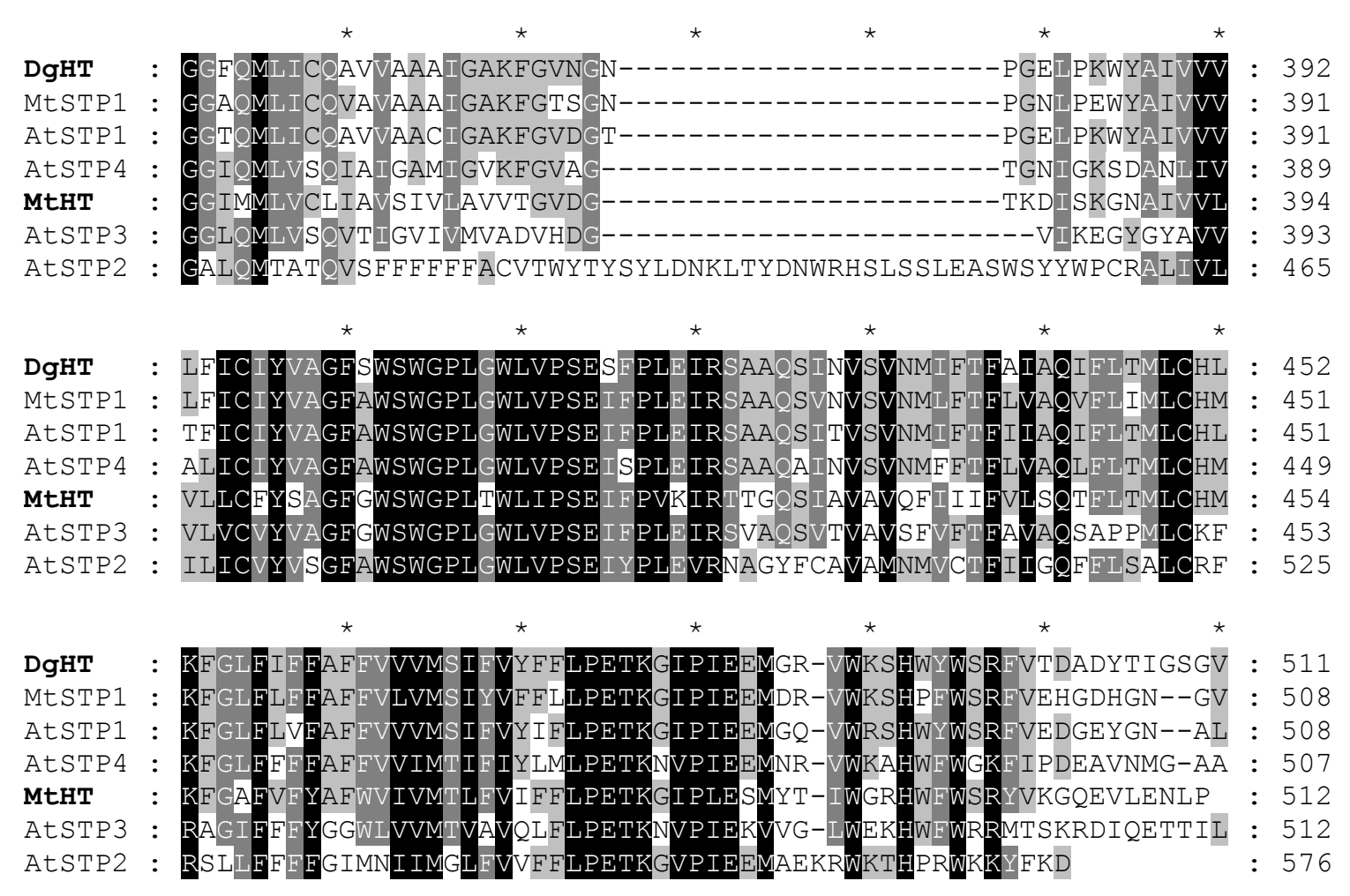

$\begin{array}{lll}\text { DgHT } & : \text { EMGKGAQELKNI } & : 523 \\ \text { MtSTP1 } & : \text { EMGKGAPKNV } & : 518 \\ \text { AtSTP1 } & : \text { EMGKNSNQAGTKHV } & : 522 \\ \text { AtSTP4 } & : \text { EMQQKSV } & : 514 \\ \text { AtSTP3 }: \text { SH } & : 514\end{array}$

Figure 3.21. Alignment of the deduced amino acid sequences of DgHT and MtHT with amino acid sequences of known monosaccharide transporters from Arabidopsis and Medicago: AtSTP1 (Sauer et al., 1990), AtSTP2 (GenBank Accession No. AAF79565.1), AtSTP3 (Büttner et al., 2000) and AtSTP4 (Truernit et al., 1996) from Arabidopsis and MtSTP1 from Medicago roots (Harrison, 1996). - indicates gaps introduced to maximize the homology, inverse print indicates identical amino acids at conserved positions in all proteins. Amino acids conserved in six of the proteins are labelled in dark grey with inverse print, those conserved in four or five proteins are shaded in light grey. Sequence alignment was performed using the program ClustalW from EMBL, Heidelberg (http://dot.imgen.bcm.tmc.edu:9331/multi-align/Options/clustalw.html). The alignment was presented using the editor GeneDoc (Nicholas et al., 1997). 
Table 3.2. Percentage of identical and similar amino acid residues shared by different hexose transporters. Sequence comparisons were performed using the program bestfit of the GCG program package (Altschul et al., 1990).

\begin{tabular}{|c|c|c|c|c|c|c|c|}
\hline \multicolumn{8}{|c|}{$\%$ Identity } \\
\hline & $\mathrm{DgHT}$ & MtHT & MtSTP1 & AtSTP1 & AtSTP2 & AtSTP3 & AtSTP4 \\
\hline $\mathrm{DgHT}$ & & 54.7 & 83.2 & 83.3 & 50.5 & 53.9 & 63 \\
\hline MtHT & 66.6 & & 52 & 55.1 & 46.8 & 47.4 & 52.4 \\
\hline MtSTP1 & 88.2 & 63.9 & & 80.7 & 52.1 & 55 & 63.6 \\
\hline AtSTP1 & 88 & 67.5 & 86.4 & & 50.2 & 56.3 & 62.6 \\
\hline AtSTP2 & 61.6 & 59.7 & 64 & 60.7 & & 48.3 & 48.6 \\
\hline AtSTP3 & 63.9 & 61.2 & 64.1 & 64.7 & 58.9 & & 54.5 \\
\hline AtSTP4 & 73.1 & 64 & 73.4 & 72.2 & 59.1 & 64.2 & \\
\hline
\end{tabular}

\subsection{Functional characterization of the hexose transporters by expression in yeast}

To demonstrate that $D g H T$ and $M t H T$ encode functional hexose transporters it was necessary to functionally characterize them in a heterologous expression system that lacked endogenous hexose transporters. For this purpose, the yeast strain EBY.VW4000 of Saccharomyces cerevisiae in which the hexose transporter genes had been deleted was chosen (Wieczorke et al., 1999).

\subsubsection{Construction of shuttle vectors for the heterologous expression of $M t H T$ and $D g H T$ in yeast}

For the yeast expression studies, the hexose transporter cDNAs were subcloned into the expression vector pNEV-E (Sauer and Stolz, 1994) under the control of the strong promoter of the yeast plasma membrane $\mathrm{H}^{+}$-ATPase (PMA1; Serrano et al., 1986).

In order to achieve optimal expression levels, the $5^{\prime}$-untranslated region had to be removed from the hexose transporter CDNA and to be replaced by the sequence $5^{\prime}$ AAGCTTGTAAAAGAA-3' from the $5^{\prime}$-untranslated region of the sucrose transporter PmSuc2 from Plantago major (N. Sauer, personal communication). 


\subsubsection{Cloning of MtHT in pNEV-X}

The new sequence was introduced in MtHT via a PCR reaction with specific primers. As forward primer, PmMtHT-for (5'-CCG CTC GAG AAG CTT GTA AAA GAA *ATG GCT GGT GGG GTT TTA CCA GTG-3') was used. This primer contains the Xhol-restriction site (bold), the PmSUC2-5'-UTR (underlined) and the beginning of an ORF ( ${ }^{*}$ ). As reverse primer, PmMtHT-rev 5'-TTC ACT AGT GAT TCT CGA GGA TCC GC-3' was used which is derived from the $3^{\prime}$-untranslated region of MtHT. The product of the reaction was cloned in PGEM-T Easy, where its sequence was confirmed. The insert was excised with Xhol using the Xhol-restriction site in the primer PmMtHT-for at the $5^{\prime}$-end of the recombinant cDNA and the Xhol-restriction site at the $3^{\prime}$ of the untranslated region of MtHT, and cloned in the Xhol-site of pNEV-X. The plasmid with MtHT in sense orientation was named pX-MNHs; the plasmid with antisense orientation of MtHT was named pX-MNHas and used as negative control. The plasmids are shown in Figure 3.22.
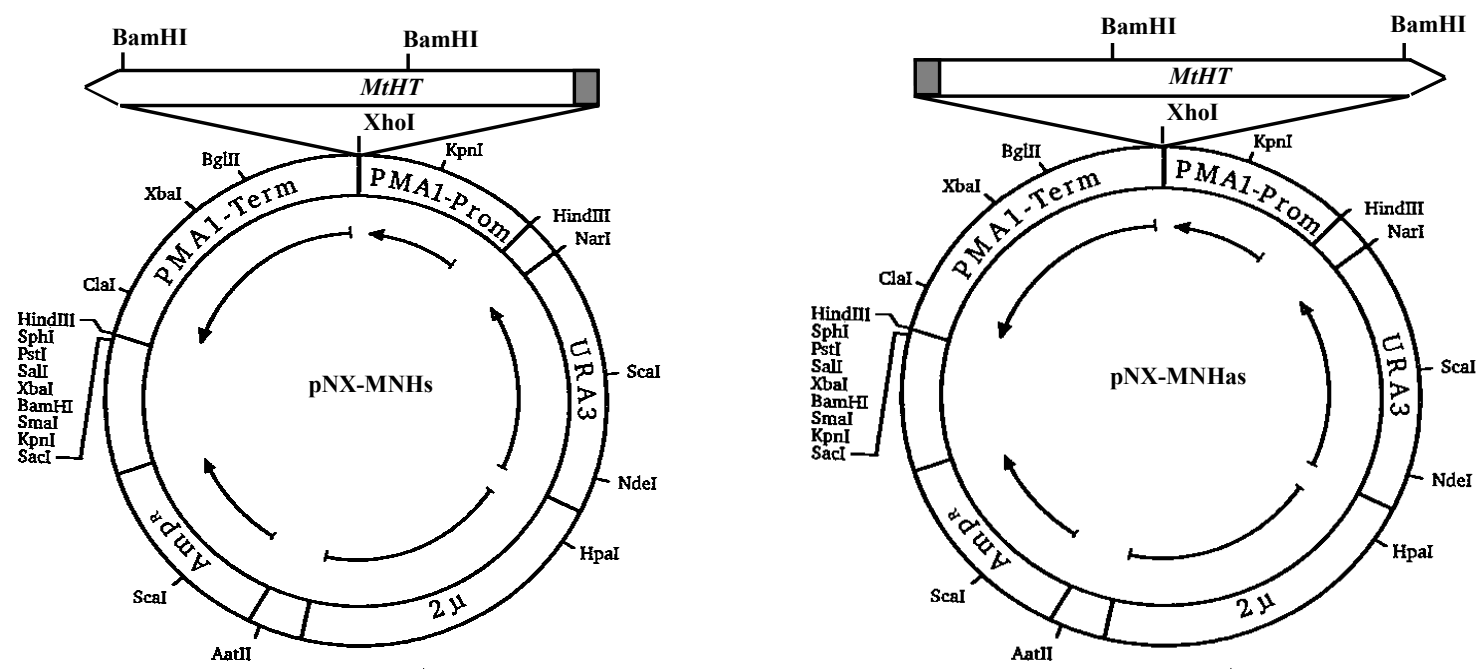

Figure 3.22. E. coli / S. cerevisiae shuttle vector pNEV-X (Sauer and Stolz, 1994), carrying the MtHT cDNA in sense (pNX-MNHs) and antisense orientation (pNX-MNHas), respectively.

\subsubsection{Cloning of $D g H T$ in pNEV-E}

The same strategy was used to clone $D g H T$ in the yeast expression vector pNEV-E, which is identical to pNEV-X except in that it contains an EcoRI instead of an Xhol site between promoter and terminator (Sauer and Stolz, 1994). The $5^{\prime}$-untranslated region of 
$D g H T$ was substituted by the $5^{\prime}$-untranslated region of PmSUC2 by PCR with the following primers: PmDgHT-for 5'-CCG GAA TTC AAG CTT GTA AAA GAA *ATG CCG GCC GTC GGA GG-3' and PmDgHT-rev 5'-CTA AAA ATA ACC CTC CCC CCA AAC-3'. The forward primer contains the EcoRI restriction site (bold), the PmSUC2-5'-UTR (underlined) and the beginning of the ORF of $\mathrm{DgHT}\left({ }^{*}\right)$, and the reverse primer is derived from the 3'-untranslated region of $D g H T$. The PCR product was cloned in PGEM-T Easy, and after its sequence had been confirmed, it was excised with EcoRI, using the EcoRI restriction sites in the primer PmDgHT-for at the 5'-end of the recombinant cDNA, and the $E c o R I$ restriction site in the polylinker of the vector at the 3 '-end. The fragment obtained, PmSUC2-5'-UTR-DgHT, was ligated in the EcoRI restriction site between the PMA1promotor and the PMA1-terminator of pNEV-E. The plasmid with $D g H T$ in sense orientation was named pE-DNHs, and the plasmid with $D g H T$ in anti-sense orientation (negative control) was named pE-DNHas. The plasmids are shown in Figure 3.23.
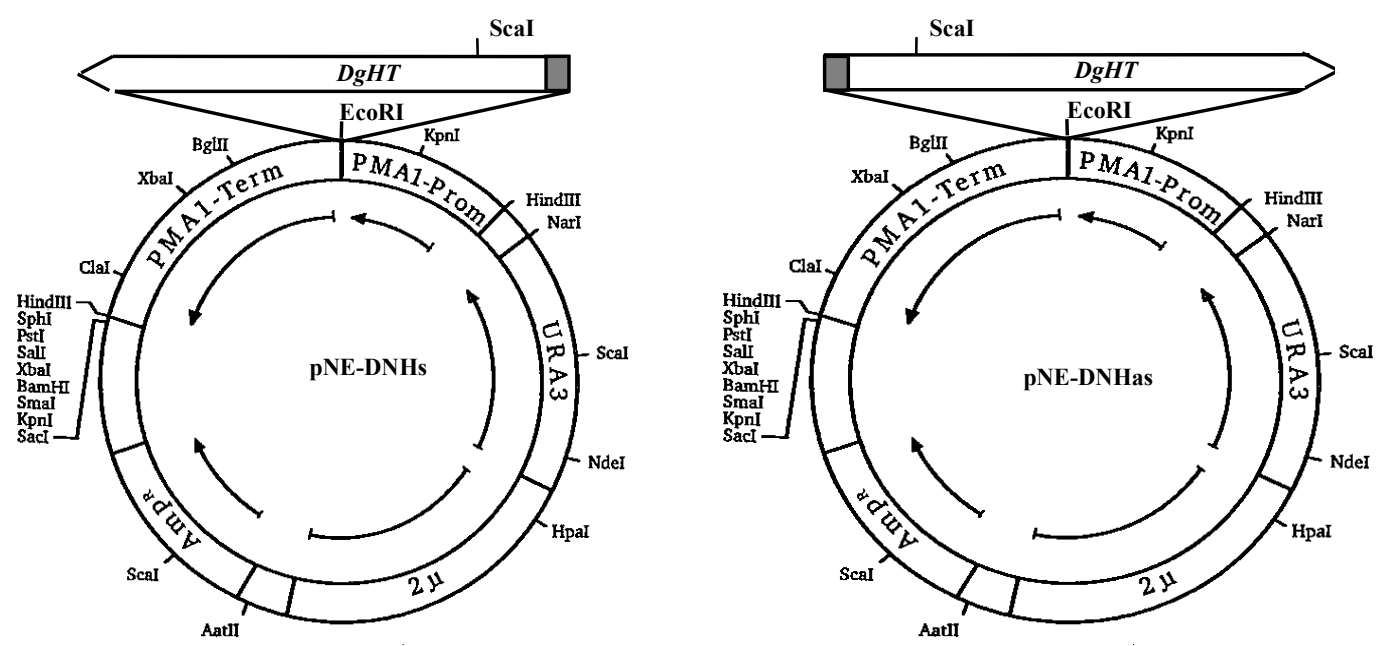

Figure 3.23. E. coli / S. cerevisiae shuttle vector pNEV-E (Sauer and Stolz, 1994) carrying the $D g H T$ cDNA in sense (pNE-DNHs) and antisense orientation (pNE-DNHas), respectively.

\subsubsection{Sugar uptake studies with yeast strains expressing MtHT and DgHT}

In the Saccharomyces cerevisiae strain EBY.VW4000 (Wieczorke et al., 1999), all endogenous hexose transporter genes have been deleted. It can be grown in maltose as carbon source. Therefore, this strain can be used to analyse substrate specificity and other characteristics of heterologous hexose transporters. 


\subsubsection{Functional characterization of MtHT}

Hexose uptake studies with EBY.VW4000(pNX-MNHs) and EBY.VW4000(pNX-MNHas) did not reveal any uptake activity of MtHT. Of several monosaccharides tested as potential substrates (D-glucose, 3-O-methylglucose, D-galactose, D-fructose, D-mannose, D-xylose and D-ribose), none were taken up by either EBY.VW4000(pE-MNHs) or EBY.VW4000(pE-MNHas). This may be due to a PCR error in the sequence of MtHT since the original cDNA sequence was derived from a PCR product (3.4.1), the error might have accured already during the original amplification. It is also possible that MtHT does not in fact represent a hexose transporter. It has been shown that a member of the PTR family of nitrate and oligopeptide transporters transports malate (Jeong et al., submitted). However, a PCR error is the most likely explanation.

\subsubsection{Functional characterization of DgHT}

Hexose uptake studies (see 2.26.) with EBY.VW4000(pNE-DNHs) and EBY.VW4000(pNE-DNHas) showed that DgHT accepts several monosaccharides as substrates (D-glucose >> D-galactose $\geq D$-xylose > D-mannose; see Figure 3.24). Under the same conditions no uptake of D-ribose, D-fructose and of the non-metabolizable glucose analogue 3-O-methylglucose (3-OMG) could be detected.

The $\mathrm{K}_{\mathrm{m}}$ value of $\mathrm{DgHT}$ for glucose was $43 \mu \mathrm{M}$ (Figure 3.25), which is in the range of $\mathrm{K}_{\mathrm{m}}$ values of other plant sugar transporters, such as AtSTP1 in Arabidopsis (20 $\mu \mathrm{M}$; Stolz et al., 1994), VfSTP1 in Vicia faba (30 $\mu \mathrm{M}$; Weber et al., 1997), RcHEX3 in Ricinus communis (80 $\mu \mathrm{M}$; Weig et al., 1994). The $\mathrm{V}_{\max }$ of $\mathrm{DgHT}$ amounts to $2 \mathrm{nmol} \mu \mathrm{l}^{-1}$ p.c. $\mathrm{h}^{-1}$ (p.c., packed cells; see 2.26).

The energy dependence of monosaccharide transport by DgHT was analysed using D-glucose. No glucose transport was demonstrated in yeast cells expressing DgHT in antisense orientation (Figure 3.26). The results presented in Figure 3.26 show that $\mathrm{DgHT}$ catalyzes the uptake of glucose in an energy-dependent manner: (i) uptake rates for glucose increased in the presence of added energy souce, namely the $1 \%$ ethanol, while (ii) uncouplers of transmembrane proton gradients, namely $50 \mu \mathrm{M} 2,4$-dinitro phenol (DNP) or $50 \mu \mathrm{M}$ carbonyl cyanide-m-chlorophenylhydrazone (CCCP), completely abolished glucose uptake by DgHT. 


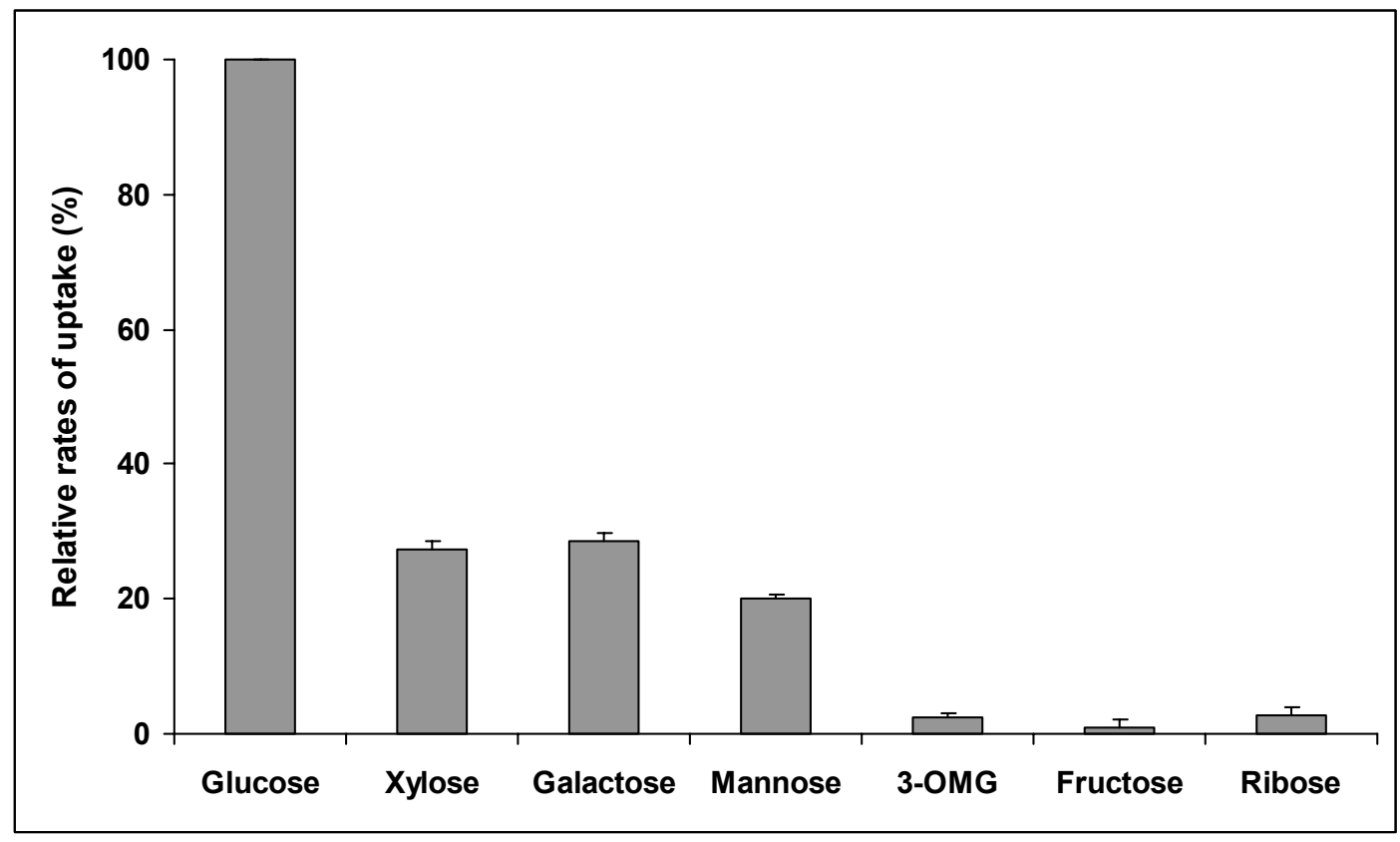

Figure 3.24. Substrate specificity of DgHT in S. cerevisiae EBY.VW4000. Uptake rates of varying substrates were compared with the glucose uptake rate, which was taken as $100 \%$ value $(2.26)$.

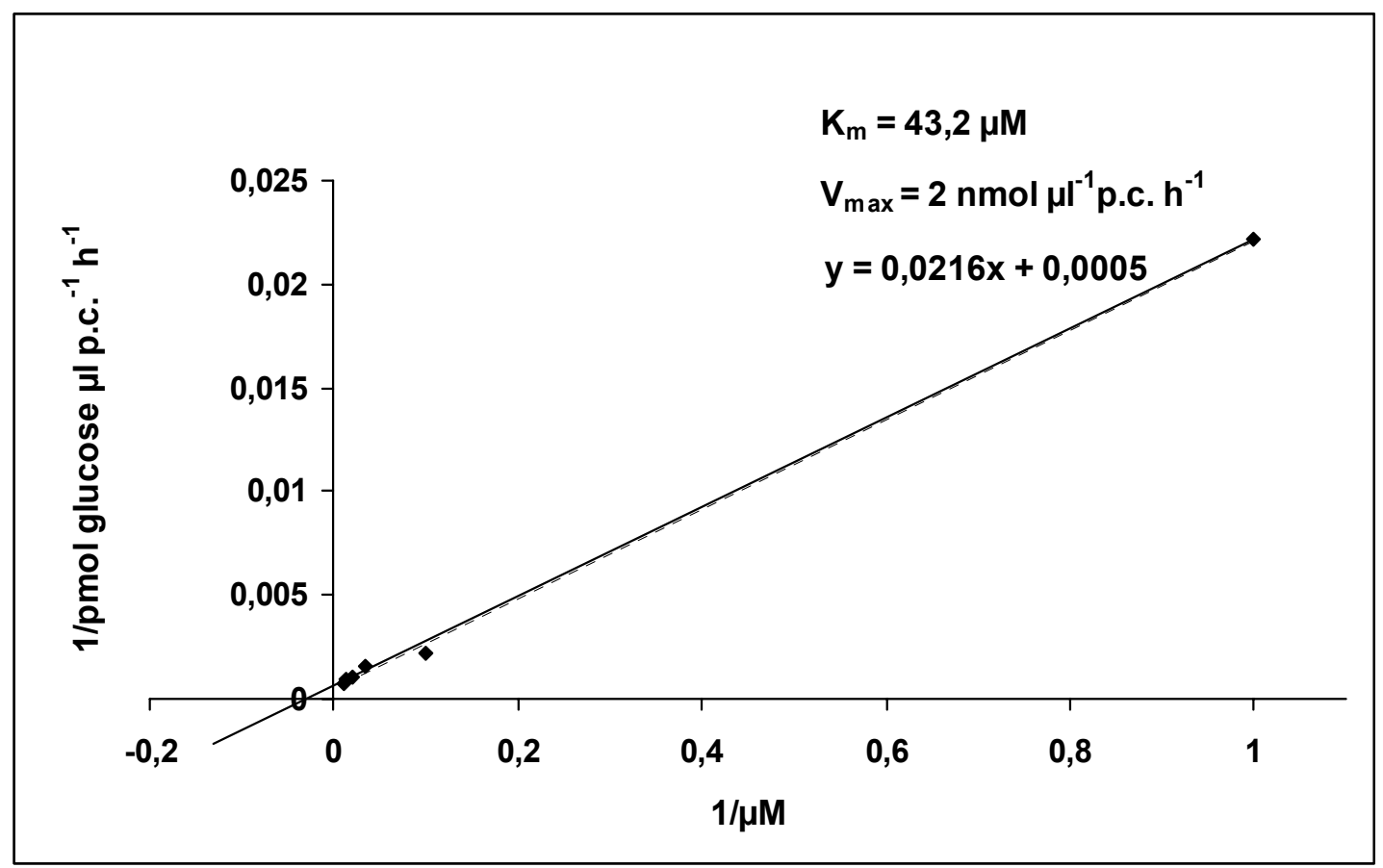

Figure 3.25. The Lineweaver-Burk diagram for determination of $K_{m}$ and $V_{\max }$ of monosaccharide transporter DgHT. p.c., packed cells. 


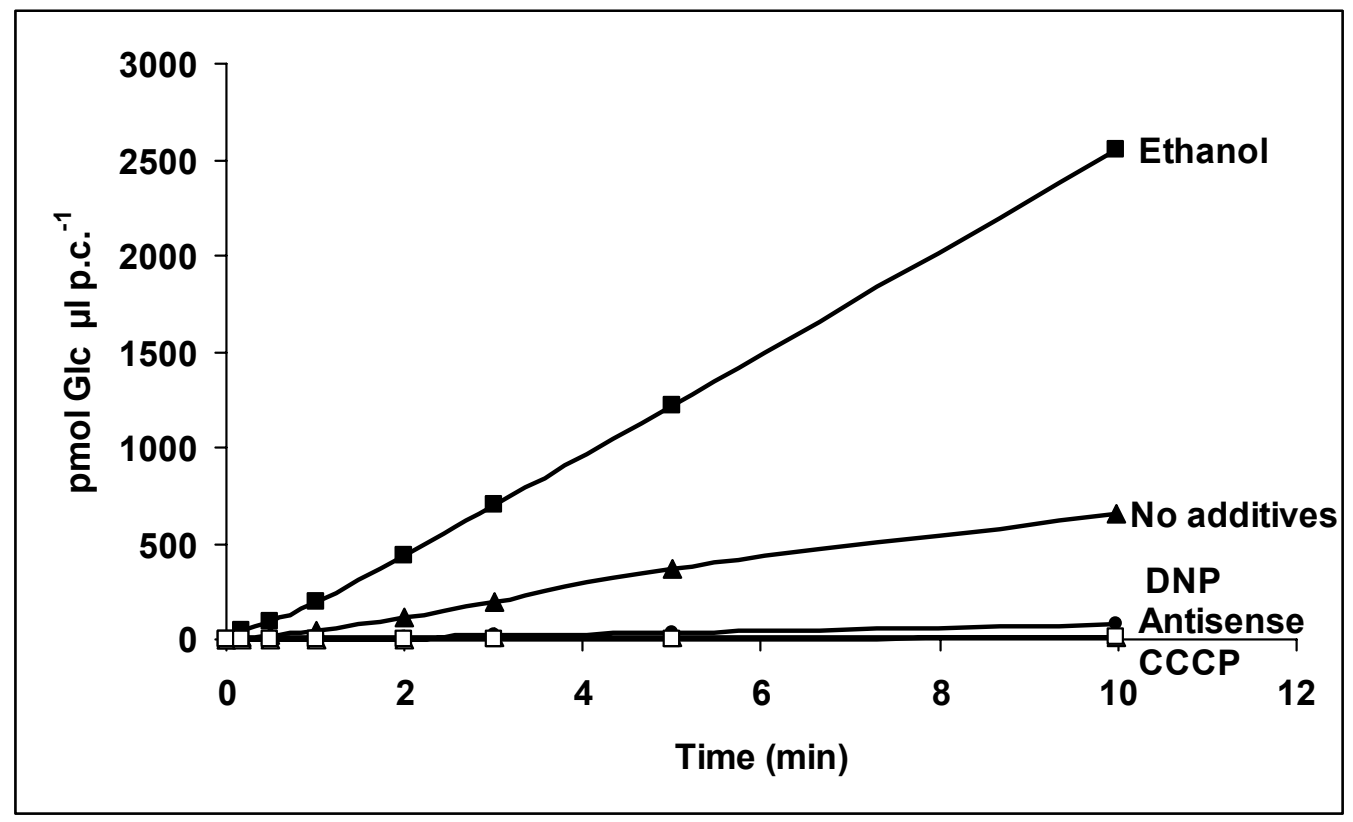

Figure 3.26. Functional characterization of DgHT in $S$. cerevisiae EBY.VW4000. Transport of ${ }^{14} \mathrm{C}$-glucose was determined in $S$. cerevisiae cells expressing $D g H T$ under the control of the $S$. cerevisiae plasmamembrane $\mathrm{H}^{+}$-ATPase (PMA1) promoter without additives $(\boldsymbol{\Delta})$, in the presence of $1 \%$ ethanol $(\boldsymbol{\bullet}), 50 \mu \mathrm{M}$ 2,4-dinitrophenol $(\mathrm{DNP}, \bullet)$, or 50 $\mu \mathrm{M}$ carbonyl-cyanid-m-chlorophenylhydrazon (CCCP, $\square)$. Transport of glucose into $S$. cerevisiae cells expressing $D g H T$ in antisense orientation $(\Delta)$ was determined as negative control. The initial concentration of ${ }^{14} \mathrm{C}$-D-glucose in the medium was $0.1 \mathrm{mM}$ in all experiments.

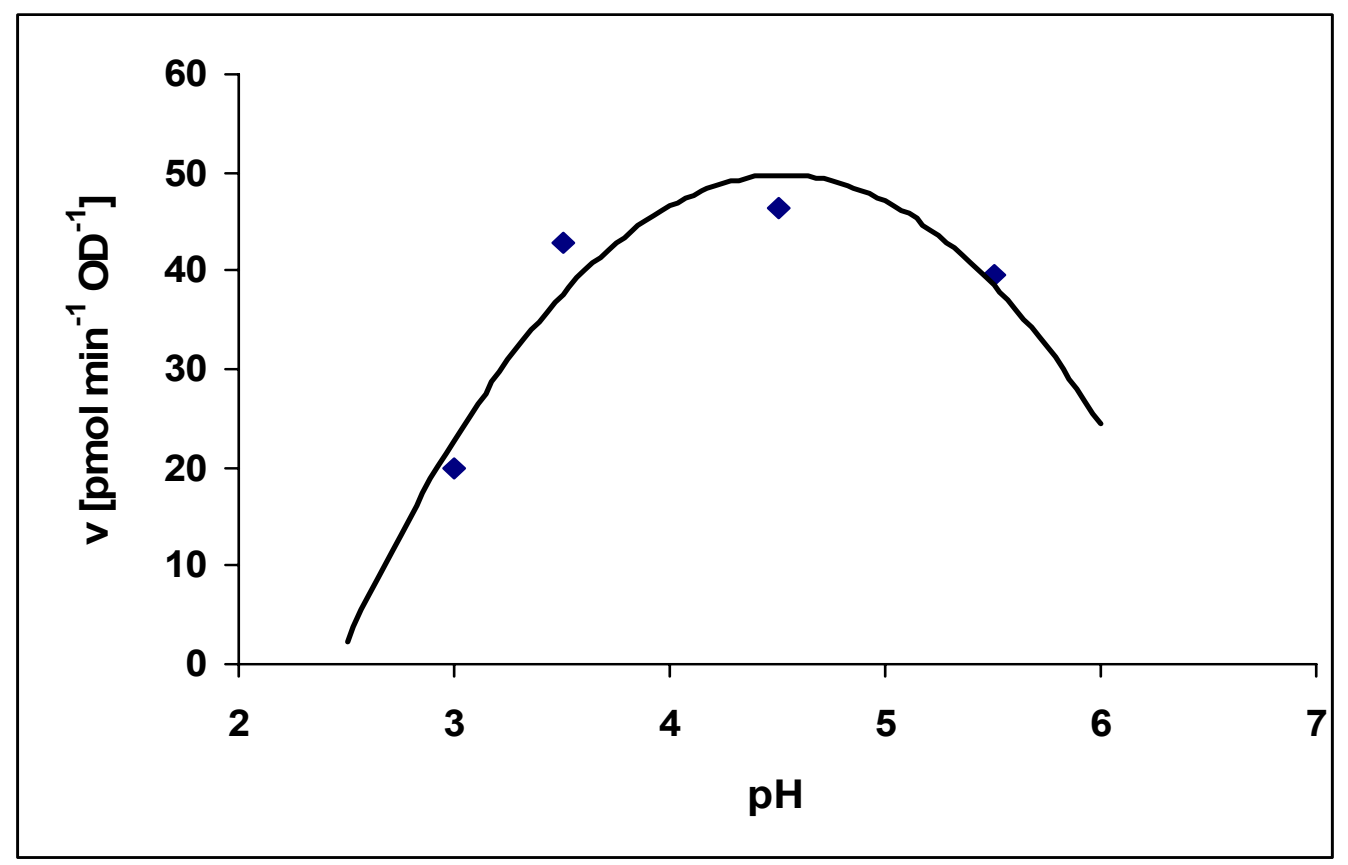

Figure 3.27. Uptake rates of ${ }^{14} \mathrm{C}-\mathrm{D}$-glucose by $\mathrm{DgHT}$ in $S$. cerevisiae EBY.VW4000 at different $\mathrm{pH}$ values. Two parallel samples were measured for each $\mathrm{pH}$ value. 
These results show that like all other plant hexose transporters examined thus far, DgHT is a high affinity, energy-dependent monosaccharide transporter, probably a $\mathrm{H}^{+}$symporter, with broad substrate specificity.

Relative rates of D-glucose uptake by $\mathrm{DgHT}$ were compared using buffer systems with different $\mathrm{pH}$ values (Figure 3.27). The $\mathrm{pH}$ optimum of $\mathrm{DgHT}$ is about 4.5, whereas the $\mathrm{pH}$ optimum of most other plant monosaccharide transporters examined is about 5.5 (M. Büttner, personal communication) 


\section{Discussion}

Carbon partitioning in symbiotic structures is a complex phenomenon that depends on various morphological and biochemical features of both plant and microsymbiont. Three different symbiotic systems, one legume symbiosis (Medicago truncatula - Sinorhizobium meliloti) and two actinorhizal symbioses from different subclades of actinorhizal plants (Figure 1.4; Datisca glomerata, Casuarina glauca), were studied in order to understand carbon partitioning mechanisms in nitrogen-fixing root nodules.

There are two possibilities of sucrose unloading from the phloem - symplastically (through plasmodesmata from sieve elements directly into the cells of sink organs) or apoplastically (via specific transporters through membranes into the apoplast and then again by transporters into the next cells; see Figure 1.1). Analysis of expression levels and distribution of hexose and sucrose transporters, as well as of activities of sucrose degrading enzymes (sucrose synthase and invertases) and sugar contents in nitrogenfixing root nodules was performed in order to understand carbon partitioning.

An important question for the understanding of nodule metabolism is which metabolites are delivered to the microsymbiont as carbon sources. In legumes, these metabolites are known to be dicarboxylic acids (Whitehead et al., 1995). The situation in actinorhizal plants is not yet clear but in analogy to the legume system, dicarboxylic acids have been suggested to be provided to symbiotic Frankia (Huss-Danell, 1997). However, in course of the analysis of hexose transporter expression patterns (Wabnitz, 1998) and of invertase activities in Datisca nodules in this study, results were obtained that suggested that the carbon sources for the microsymbiont in this plant were in fact hexoses.

\subsection{Cytological information on putative mechanism of carbon transport in root nodules}

Frequencies of plasmodesmal connections between specific cell types, as well as the presence of cell wall modifications that would block apoplastic transport, can yield information about transport mechanisms. No ultrastructural studies have been performed in this thesis, but literature data will be summarized here. 


\subsubsection{Medicago}

Up to now, no comprehensive cytological analysis of Medicago truncatula nodules has been performed. Nevertheless, the results of the analysis of other legume nodules may be useful to understand $M$. truncatula nodule structure.

In seven of 27 legume genera examined, including Medicago, a special cell type with strongly developed cell wall protuberances, so-called transfer cells, was found in the pericycle of the vascular system (Pate et al., 1969). The inner side of these cells is opposed to the walls of xylem and phloem elements, indicating that apoplastic uptake of sugars from the phloem and/or secretion of nitrogenous compounds, particular amides, into the bundle apoplast, is taking place in these cells (Pate et al., 1969).

In Vicia faba nodules, symplastic movement of carbohydrates from the phloem via the vascular endodermis to the inner cortex is most probable, due to the endodermal Casparian band and extensive plasmodesmal connections (Abd-Alla et al., 2000). In the central tissue, plasmodesmata are also numerous at the interfaces of uninfected cells with infected and uninfected cells, but nearly absent between pairs of infected cells, as was shown for determinate nodules of Glycine max as well as for indeterminate nodules of $V$. faba (Selker and Newcomb, 1985; Abd-Alla et al., 2000). The extensive interconnection of uninfected cells and their connection to infected cells via plasmodesmata suggests that they play a role in metabolite transport. In contrast to the central tissue of determinate nodules, the low number of uninfected cells in the central tissue of indeterminate $V$. faba nodules suggests an additional apoplastic transport pathway to the infected cells in this plant (Selker and Newcomb, 1985; Abd-Alla et al., 2000).

Therefore, the following model of sugar transport could be proposed for Medicago based on cytological observations: sugar unloading from the phloem occurs via the apoplastic pathway and sugars could be transported to the infected cells symplastically using the symplastic network of uninfected cells, or apoplastically when the number of uninfected cells is insufficient.

\subsubsection{Cytology of roots and nodules of Datisca glomerata}

In the lobes of nodules formed on Datisca roots, infected cells are organized in a continuous patch that is up to 20 cell layers deep. This would render impossible the supply of nutrients from uninfected cells to infected cells, as it was supposed for Medicago. Roots of Datisca contain a multilayered pericycle with suberized cell walls (Pawlowski et al., submitted), indicating that post-phloem transport in roots is symplastic. 
However, since the vascular system of nodules does not contain cells with suberized walls, both apoplastic and symplastic phloem unloading and post-phloem transport are possible here. However, the presence of fluorescent material, i.e. polyphenolics, in the walls of the endodermis of the nodule vascular system (Figure 4.1) indicates that here, apoplastic transport is blocked, so symplastic transport is needed to cross this cell layer.

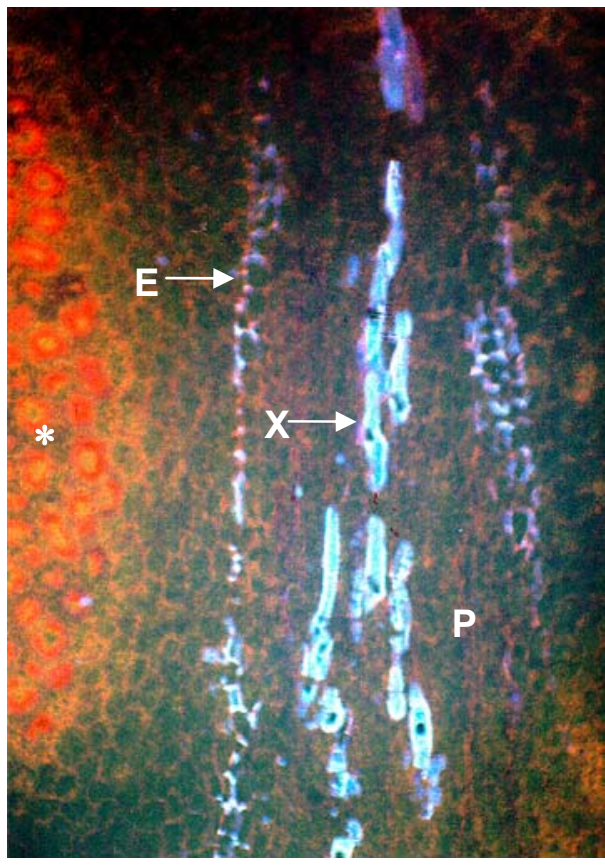

Figure 4.1. Dark field micrograph of a longitudinal section of a Datisca nodule lobe photographed under fluorescent light. No fluorescent material can be detected in the walls of the phloem $(P)$ of the nodule vascular bundle, but the cell walls of the endodermis (E) show bright autofluorescence. The photographed region is located next to the fixation zone of the infected cells $(*)$. X - xylem (Courtesy from K. Pawlowski, unpublished).

\subsubsection{Cytology of roots and nodules of Casuarina glauca}

In the cortex of nodules of Casuarina, infected and uninfected cells are interspersed. Cells infected by Frankia are characterized by strong lignification of their cell walls (Berg and McDowell, 1987b) that together with the low volume of intercellular space in the infection zone (Zeng et al., 1989) restricts oxygen diffusion and therefore protects the oxygensensitive bacterial nitrogenase. These morphological features disable apoplastic transport into infected cells. The cell walls of uninfected cells of the nodule cortex and cells of the multilayered pericycle of the nodule vascular system are not lignified (Pawlowski, 2002). No analysis of the distribution of plasmodesmata has been performed for Casuarina nodules to date, but the density of infected cells in the cortex is too high to postulate apoplastic sugar transport to the uninfected cells and symplastic transport from there to the infected cells. Altogether, based on current cytological information, symplastic transport of nutrients is expected to take place in the nodule cortex, while both symplastic 
and apoplastic pathways are possible for phloem unloading and post-phloem transport to the nodule cortex.

\subsection{Expression levels and patterns of hexose transporter genes in roots and nodules}

According to the apoplastic model of phloem unloading, this pathway depends on the presence of several types of specific transporters that catalyse the membrane penetration of sugars (Eschrich, 1980; Sauer et al., 1994; Figure 1.1A). Therefore, apoplastic transport activities can be implied from the expression levels and patterns of sugar transporter genes.

\subsubsection{Medicago}

It has been shown in this study that in Medicago, apoplastic sugar transport as signified by the expression levels of hexose and sucrose uptake transporter genes (MtHT and MtST; Figure 3.18) plays a major role in roots. Similarly, M. Harrison (1996) has shown previously that the expression levels of the hexose transporter gene MISTP1 which is homologous but not identical with MtHT, were higher in roots of Medicago than in stems or in young or old leaves. The situation in nodules was different. The sucrose transporter MtST was expressed at extremely low levels in nodules, and expression of the hexose transporter MtHT in nodules could not be detected by RNA gel blot hybridization (Figure 3.18). In previous experiments, Medicago nodules had been grown in hydroponic culture in Fåhraeus medium (Fåhraeus, 1957) where nodules needed two times longer to develop than in aeroponic culture in Lullien's medium (Lullien et al., 1987). These plants had displayed the same high expression levels for MtHT and MtST in nodules as in roots (Wabnitz, 1998; Schubert et al., submitted). Therefore, while in roots the expression levels of sugar transporter genes seem to be independent of the growth conditions, in nodules this process is regulated, probably by oxygen supply. The data obtained indicate that sugar partitioning mechanisms in Medicago change from apoplastic in roots to symplastic in nodules in aeroponic culture. There are only few studies in wheat on the modulation of plasmodesmal-mediated cell-to-cell transport roots under anaerobic stress, that do not give a final answer if the plasmodesmata and assimilate transport become occluded under anaerobic stress conditions. On the one hand, it was shown that the electrical coupling ratio, which is a measure of plasmodesmatal resistance, between cortical cells of weat 
roots was not affected by the low oxygen treatment, suggesting that solute transport through the cytoplasmic annulus of plasmodesmata was not affected (Zhang and Tyerman, 1997). Moreover, the size exclusion limit (SEL) of the plasmodesmata rises under anaerobiosis (Cleland et al., 1994). On the other hand, there is a hypothesis that the transport through the plasmodesmata does not only involve the cytoplasmic compartment, but also the desmotubule which is part of the endoplasmic reticulum (ER) (Gamalei, 1994). In this context, Davies et al. (1987) have observed that the ER condenses into whorls when the energy charge is reduced by hypoxia. This may well account for the observation that there is a significant increase in molecular SEL, described by Cleland et al. (1994).

\subsubsection{Datisca}

Analysis of the expression levels of sugar transport genes in Datisca showed a very strong induction of hexose transporter gene expression in nodules compared to roots (Figure 3.18). In situ localization of sugar transporter gene expression had been performed previously by Wabnitz (1998). Expression of the hexose transporter gene $D g H T$ was found only in infected cells, while sucrose transporter (DgST) gene expression was detected at very low levels in the pericycle of the nodule vascular system adjacent to the senescence zone of infected cells. Expression levels of DgST in roots, nodules and leaves were below the detection limit for RNA gel blot hybridization. Hence, the sucrose transporter does not seem to play a major role in the Datisca - Frankia symbiosis. However, the hexose transporter gene expression pattern seems to indicate that infected cells take up large amount of hexoses from the apoplast.

In roots of Datisca low expression levels of sugar transporter genes were found, that indicating that here, sugar transport mostly occurs symplastically, which is consistent with the cytological data (4.1.2.).

\subsubsection{Casuarina}

RNA gel blot hybridization analysis of hexose transporter gene $(\mathrm{CgHT})$ expression in Casuarina showed that it was somewhat induced in nodules compared to roots, resembling the situation in Datisca. However, all attempts to determine the expression pattern of $\mathrm{CgHT}$ in situ failed. Since the walls of these cells are lignified (Berg and McDowell, 1987b), which would block apoplastic transport, it is extremely unlikely that 
hexose transporters are responsible for the uptake of hexose from the apoplast into infected cells in Casuarina nodules.

Since up to date, no fragments of Casuarina sucrose transporter genes have been amplified, the expression levels of sucrose transporter genes could not be determined in this plant. Thus, it is impossible to propose a model of sugar transport in Casuarina nodules based on the expression of sugar transport protein genes.

\subsection{Activities and localization of sucrose degrading enzymes in roots and nodules}

Utilization of sucrose as a source of carbon and energy depends on its cleavage into hexoses, and in plants this reaction is catalysed either by sucrose synthase (SuSy) or by one of the several isoforms of invertase (cytosolic, apoplastic or vacuolar). In this study the activities of sucrose-cleaving enzymes in roots and nodules of Medicago, Datisca and Casuarina were compared.

\subsubsection{Invertases}

Different functions have been proposed for the three different types of invertases. Apoplastic invertase is known to participate in phloem unloading by cleaving apoplastic sucrose which allows the subsequent uptake of hexoses into sink cells (Eschrich, 1980). Vacuolar invertase has been proposed to be involved in osmoregulation and cell enlargement and in the control of sugar composition in fruits and storage organs (Sturm and Tang, 1999). The role of cytosolic invertase is unknown, except that it has been proposed to be involved in channelling sucrose into catabolic pathways (Sturm, 1999).

Apoplastic invertase activity is decreased in nodules compared to roots in all three symbiotic systems studied (Figure 3.11). This indicates that in nodules in general, apoplastic sugar transport involving the hydrolysis of sucrose in the apoplast is strongly reduced. Even in Datisca and Casuarina nodules, where hexose transporter expression was found to be induced compared to roots (Figure 3.18), apoplastic invertase activity was reduced more than ten-fold compared to roots in Datisca and almost eight-fold in Casuarina (see Table 4.1). 
Table 4.1. Invertase acitivities in roots and nodules (one representative result of three experiments is shown). These data have been presented graphically in Figure 3.11.

\begin{tabular}{|c|c|c|c|c|c|}
\hline \multirow[t]{2}{*}{ Plant species } & \multirow[t]{2}{*}{ Plant organ } & \multicolumn{4}{|c|}{$\begin{array}{c}\text { INVERTASE activity } \\
\text { [nmol sucrose cleaved } \mathrm{min}^{-1} \mathrm{mg}^{-1} \text { protein] }\end{array}$} \\
\hline & & apoplastic & cytosolic & vacuolar & sum \\
\hline \multirow{2}{*}{$\begin{array}{l}\text { Medicago } \\
\text { truncatula }\end{array}$} & Roots & $0.992 \pm 0.025$ & $0.355 \pm 0.017$ & $0.469 \pm 0.074$ & 1.816 \\
\hline & Nodules & $0.078 \pm 0.008$ & $0.532 \pm 0.069$ & $0.030 \pm 0.006$ & 0.64 \\
\hline \multirow{2}{*}{$\begin{array}{l}\text { Datisca } \\
\text { glomerata }\end{array}$} & Roots & $1.549 \pm 0.227$ & $1.867 \pm 0.367$ & $9.467 \pm 0.967$ & 11.489 \\
\hline & Nodules & $0.136 \pm 0.034$ & $0.133 \pm 0.33$ & $0.733 \pm 0.067$ & 1.002 \\
\hline \multirow{2}{*}{$\begin{array}{l}\text { Casuarina } \\
\text { glauca }\end{array}$} & Roots & $5.326 \pm 0.200$ & $4.083 . \pm 0.04$ & $2.083 \pm 0.104$ & 11.447 \\
\hline & Nodules & $0.706 \pm 0.043$ & $0.571 \pm 0.29$ & $2.143 \pm 0.202$ & 3.42 \\
\hline
\end{tabular}

Localization of acidic, i.e. apoplastic or vacuolar invertase activity in roots by in situ activity staining (Figure 3.13) showed that in Medicago roots, acidic invertase activity is present all over the cortex, which is in agreement with the apoplastic and vacuolar invertase activities and high hexose transporter expression levels in Medicago roots (Figure 3.18; Table 4.1). Thus, high activities of apoplastic sugar transport involving the hydrolysis of sucrose in the apoplast and the uptake of hexoses are present in the root cortex of Medicago.

In Datisca roots, however, all acidic, i.e. vacuolar and apoplastic invertase activity was present in the stele, not in the cortex (Figure 3.13). Since uptake of hexoses from the apoplast is required after the apoplastic hydrolysis of sucrose, it can be presumed that in roots, the weak hexose transporter expression is confined to the stele as well. The very high vacuolar invertase activities determined for Datisca roots (Table 4.1) have also to be confined to the stele.

Slightly increased cytosolic invertase activities were observed in Medicago nodules compared to roots. Elevated cytosolic invertase activities have been found also in potato tubers, where they led to increased carbon flux towards glycolysis and to the accumulation of phosphorylated intermediates (Hajirezaei et al., 2000). In contrast, a strong reduction of cytosolic invertase activities in nodules compared to roots was found in Datisca and Casuarina. Again, the elevated cytosolic invertase activity in Medicago nodules does not exceed the reduced cytosolic invertase activity in Casuarina nodules which comprises only about $14 \%$ of the cytosolic invertase activity in Casuarina roots. 
Vacuolar invertase activity is reduced in Medicago and Datisca nodules compared to roots, but is similar in roots and nodules of Casuarina. It should be pointed out that although vacuolar invertase activity is dramatically reduced in Datisca nodules compared to roots, the remaining activity in Datisca nodules is still about 20 times higher than in Medicago roots (Table 4.1). The high vacuolar invertase activities in Casuarina and Datisca nodules, compared to nodules of Medicago (see Table 4.1) may be related to different requirements for turgor control in actinorhizal versus legume nodules. The mechanism of cell infection is different in actinorhizal nodules than in Medicago. In actinorhizal nodules, no complete endocytotic process takes place but the perisymbiont space remains continuous with the apoplast (Mylona et al., 1995). This aspect might necessitate specific mechanisms for turgor control. However, more symbiotic systems have to be examined before such a conclusion can be drawn.

To summarize the data on invertase activities, Medicago is characterized by comparatively low activities of all three invertase types - apoplastic, cytosolic and vacuolar - compared to Datisca and Casuarina. The reduction of total invertase activities in nodules compared to roots, however, is about three times stronger in Datisca than in the two other systems. The in situ staining results for acidic invertase activity in roots indicate that phloem unloading involves apoplastic transport in Datisca (Figure 3.13B). However, post-phloem transport mechanisms in Medicago and Datisca roots obviously differ, with apoplastic mechanisms dominating in Medicago. This is consistent with the results about sugar transporter gene expression levels.

The roots of the two actinorhizal plants differ in respect to their invertase activity distribution among isoforms. In Datisca roots, vacuolar invertase plays a major role, whereas in Casuarina roots activities of both apoplastic and cytosolic invertases are high, and vacuolar invertase activity is lower $(2.1 \pm 0.1 \mathrm{nmol}$ sucrose cleaved $/ \mathrm{min} / \mathrm{mg}$ protein (vacuolar) in comparison to $4.1 \pm 0.04$ (cytosolic) and $5.3 \pm 0.2$ (apoplastic) activity).

As was mentioned above, the common feature of all systems studied here is a clear reduction of apoplastic invertase activity in nodules compared to roots. This means that the apoplastic transport of sucrose followed by hydrolysis in the apoplast is strongly reduced in nodules compared to roots.

\subsubsection{Sucrose synthase (SuSy)}

SuSy is recognized as an important enzyme of sucrose utilization in plant sink tissues (Ho et al., 1988). SuSy is a globular protein and thus is generally considered to be soluble in the cytosol. However, some percentage of the enzyme is known to be associated with the plasma membrane, perhaps in a specific complex with glucan synthase, producing 
cellulose and/or callose (Amor et al., 1995; Carlson and Chourey, 1996). Part of the soluble fraction of sucrose synthase seems to be associated with the actin cytoskeleton (Winter et al., 1998).

Since in all three types of nodules, invertase activities were reduced in nodules compared to roots, it can be concluded that SuSy has a dominant function in nodule sugar metabolism. This is in agreement with results of Gordon et al. (1999) on a pea mutant with a defect in the SuSy gene expressed in nodules, which caused a dramatic reduction of nitrogenase activity, and thus led to an inefficient symbiosis. SuSy activities are expected to be increased in nodules compared to roots, since a strong increase of sucrose synthase transcription levels in nodules has been reported for the SuSy genes of soybean (Thummler and Verma, 1987), Medicago (Hohnjec et al., 1999) and broad bean (Küster et al., 1993). However, in this study, more or less equal SuSy activities were found in nodules and roots of Medicago and Datisca (see 3.2.2). This is particularly suprising when considering that there is clear transcriptional induction of SuSy in both systems (Figure 3.16) and that in Datisca, a corresponding increase of SuSy protein amounts was found in nodules compared to roots (Figure 3.17). However, there was no increase of SuSy protein in Medicago nodules compared to roots in spite of the transcriptional induction of the SuSy gene (Figures 3.16 and 3.17). A similar situation has already been described for the SuSy gene sh1 in maize roots, where the increase of sh1-mRNA levels under anaerobic conditions was not reflected to the same degree in SS1 protein amounts which showed no detectable increase (McElfresh and Chourey, 1988; Taliercio and Chourey, 1989). In contrast, the transcription levels of the other maize gene coding for sucrose synthase SS2, sus1, decreased during anaerobic stress as indicated by the reduced amounts of sus1 mRNA in root tissue, while SS2 protein levels actually increased in the root tip (McElfresh and Chourey, 1988). In summary, for maize roots it has been shown that the expression of both SuSy genes is regulated at both the transcriptional and the translational level, and that both levels of regulation may act against each other (McElfresh et al., 1988; Taliercio and Chourey, 1989). Thus, translational regulation of SuSy mRNA could also occur in root nodules, particularly in the infected zone where oxygen-limited conditions are established for nitrogenase function (Vance and Heichel, 1991).

Moreover, recently it was shown that pea contains three different isoforms of sucrose synthase (Sus1, Sus2 and Sus3), and that the genes encoding these different isoforms have distinct patterns of expression in different organs of the plant as well as during organ development (Barratt et al., 2001). The presence of at least two SuSy isoforms was detected immunologically in Medicago roots using antibodies raised against SuSy from Vicia faba (Ross and Davies, 1992), while only one immunologically active 
SuSy isoform was found in nodules (see 3.3.2; Figure 3.17). One of the isoforms detected was somewhat larger than the major isoform. This confirms the results of Hohnjec et al. (1999), who found only one SuSy isoform in nodules of eight different legumes, but two isoforms of SuSy in root and stem extracts of Medicago. Studying of the partial cDNA sequences from Medicago truncatula at www.tigr.org shows that Medicago contains at least five different SuSy genes, with DNA homologies to the Vicia faba probe used in this study ranging from $67 \%$ to $91 \%$ (data not shown). Taking into account the existence of multiple SuSy isoforms, one could also propose that discrepancy between the SuSy expression pattern on the mRNA level and on the level of protein amount and enzyme activity is the consequence of incomplete detection of isoformes in Medicago using a cDNA probe from Vicia faba (Küster et al., 1993). To date, only a single isoform of SuSy has been characterized from Vicia faba (Ross and Davies, 1992), whereas for Pisum sativum it has been shown that one of its three SuSy isoforms, Sus2, has less sequence similarity with the two other isoforms than they share among each other (only $70-71 \%$ identity; Barratt et al., 2001). However, Sus3 was found to be only expressed at very low levels. On RNA gel blots containing total RNA, only expression levels in flowers and young testas were high enough for detection, while analysis of Sus3 expression using RNA gel blots with poly $\left(\mathrm{A}^{+}\right) \mathrm{RNA}$ revealed that the transcript was also present in nodules, but not in roots (Barratt et al., 2001). Hence, if Medicago nodules would contain two larger very homologous SuSy isoforms, while roots contained only one of them, an induction of SuSy expression in nodules compared to roots would be apparent in RNA gel blot hybridizations, but not on the protein level. Furthermore, considering the translational regulation of SuSy (Winter and Huber, 2000), it is possible that only one of the mRNAs for the major isoforms is translated, leading to similar protein levels and enzyme activities of SuSy in Medicago roots and nodules in spite of an apparent transcriptional induction.

A study of literature shows that for SuSy a broad analysis of gene expression, protein quantities and presence of isoforms has been performed in different legumes (see e.g. Thummler and Verma, 1987; Buchner et al., 1998; Hohnjec et al., 1999; Küster et al., 1993; Ross and Davies, 1992; Barratt et al., 2001). However, comparisons of SuSy enzyme activities were performed only on nodules grown under different nutrient conditions and stresses, which led to the conclusion that SuSy activity is sufficient for normal nodule function (e.g. González et al., 1995; Gordon et al., 1997). Except for this thesis, SuSy activities in roots and nodules have never been compared so far.

One of the known mechanisms of posttranslational regulation of SuSy activity is the reversible protein phosphorylation (Winter and Huber, 2000). Based on the results for phosphorylation of recombinant SuSy, it has been suggested that phosphorylation specifically activates sucrose cleavage (Nakai et al., 1998). Apart from its effects on SuSy 
activity, phosphorylation/dephosphorylation of SuSy seems to play a role in the distribution of the enzyme between cytosol, plasma membrane, and actin cytoskeleton (Winter et al., 1997; Winter et al., 1998). Taking into account that the $\mathrm{K}_{\mathrm{m}}$ of nonphosphorylated recombinant SuSy protein for sucrose is several folds higher than that of phosphorylated enzyme, it is possible to explain the lack of increase in SuSy activity in Datisca nodules compared to roots by dephosphorylation of part of the total SuSy protein, causing plasma membrane association and a decrease in enzyme activity. It is known that SuSy protein associated with the plasma membrane is involved in cell wall biosynthesis (Amor et al., 1995). The uptake of the microsymbiont into infected cells and its embedding in a polysaccharide-rich cell wall-like matrix necessitates higher activities of synthesis of cell wall-like material in nodules than in roots. Therefore, a change in the distribution of SuSy protein in nodules relative to roots, with an increased fraction of the total SuSy protein being associated with the plasma membrane may reflect the demands of the root nodule symbiosis.

\subsection{The Datisca nodule paradox: hexose transporter expression in the absence of apoplastic invertase activity. Could hexoses be the carbon sources for symbiotic Frankia in Datisca nodules?}

As mentioned above, in nodules of Datisca apoplastic invertase activity was practically absent (Figure 3.11B), indicating that no apoplastic sugar transport occurs that relies on the hydrolysis of sucrose in the apoplast and the uptake of hexoses. However, in spite of the absence of apoplastic invertase activities, a hexose transporter was found to be expressed in nodules at high levels (Figure 3.18), and in situ hybridization showed that it was expressed specifically in the infected cortical cells (Wabnitz, 1998). These data could be interpreted to mean that the hexose transporter is working as an exporter to supply endosymbiotic Frankia with carbon sources.

In analogy to legume nodules, where the bacteria are supposed to be supplied with dicarboxylic acids by the host plant (see e.g. Streeter, 1995), it has been assumed that dicarboxylic acids might also be the carbon source for symbiotic Frankia. While the analysis of enzyme activities in Frankia vesicle clusters isolated from nodules of Alnus and Hippophae yielded results consistent with this hypothesis (Akkermans et al., 1983), experiments on ${ }^{14} \mathrm{CO}_{2}$ uptake of detached Alnus nodules were inconclusive (Huss-Danell, 1990; summarized by Huss-Danell, 1997). Isolated Frankia strains have been divided into two genomic groups based on DNA reassociation kinetics (Lechevalier and Lechevalier, 1990). In the free-living state, Frankia strains of genomic group A tend to grow fairly on 
both sugars and organic acids, while strains of genomic group B grow variably on organic acids and poorly, if at all, on sugars (Lechevalier and Lechevalier, 1990; Benson and Schultz, 1990). The endosymbiont of Datisca, however, has not been isolated yet and based on its 16S rRNA and nifH gene sequences, does not belong to any group of Frankia strains isolated so far (Mirza et al., 1994; Normand et al., 1996; Figure 1.4). Thus, based on the data available, the carbon preferences of the endosymbiont of Datisca cannot be determined, and the strains might be able to grow on hexoses as carbon sources.

In summing up, there is no physiological evidence to contradict the hypothesis that this group of strains in particular, or Frankia strains in general, are fed hexoses during symbiosis. Based on the results presented in this study and in situ hybridisation data of Wabnitz (1998), it is conceivable that in analogy to symbiotic nitrogen-fixing cyanobacteria in Gunnera (R. Parsons, personal communication), endosymbiotic Frankia is supplied with hexoses in nodules of Datisca.

\subsection{Hexose transporters from nodules}

As described above, an unusual function has been suggested for the hexose transporter from Datisca nodules. Preliminary sequence information had also indicated that the hexose transporter from Medicago nodules belongs to a different subfamily than all other hexose transporters published thus far (see sequence alignment in Figure 3.21; Table 3.2). Therefore, the full length cDNA sequences of the hexose transporters MtHT and DgHT were amplified from Medicago and Datisca nodules and sequenced for further analysis.

The amino acid sequences and the predicted secondary structure of DgHT were highly similar to those of other monosaccharide transporters from plants, with the highest homology to AtSTP1 from Arabidopsis (Table 3.2; Sauer et al., 1990). The analysis of the full sequence of MtHT confirmed that this hexose transporter belongs indeed to a different subfamily of transporters than AtSTP1, $-2,-3$ or -4 , but its sequence is less dissimilar to those of other hexose transporters than that of Arabidopsis AtSTP2. AtSTP2 contains two insertions compared to other known hexose transporters from Arabidopsis as well as to MtSTP1, MtHT and DgHT (see sequence alignment in Figure 3.21; Table 3.2).

To analyse the functional characteristics of $\mathrm{DgHT}$, the cDNA was cloned in yeast expression vectors and fused to the strong promoter of the yeast plasmamembrane $\mathrm{H}^{+}$ATPase (PMA1; Serrano et al., 1986) and the 5'-UTR of the sucrose transporter PmSuc2 from Plantago major which has been shown to result in high translation activities in yeast 
(N. Sauer, personal communication). DgHT was shown to represent a hexose transporter with a broad substrate specificity, with the highest affinity to glucose, but also transporting to a less extent D-galactose, D-xylose and D-mannose. DgHT did not transport fructose or L-rhamnose. Regarding substrate specificity, DgHT has more in common with the hexose transporter AtSTP3 from Arabidopsis than with AtSTP1 (Büttner and Sauer, 2000). However, AtSTP3 has a $\mathrm{K}_{\mathrm{m}}$ of $2 \mathrm{mM}$ for glucose, while other hexose transporters have $\mathrm{K}_{\mathrm{m}}$ values for glucose in the micromolar range, like $\mathrm{DgHT}$ with $43 \mu \mathrm{M}$ (Figure 3.25). Hence, regarding substrate affinity DgHT does not resemble AtSTP3 at all. Furthermore, AtSTP3 was the first monosaccharide transporter not to be expressed in sink tissues (Büttner et al., 2000), while DgHT is expressed in at least two types of sink organs, namely at high levels in Datisca nodules and and at low levels in roots, while no DgHT transcripts were detected in leaves by RNA gel blot hybridization (Figure 3.18). At any rate, these comparisons show that hexose transporters of the same sequence group can have different substrate specificities.

The most unusual feature of $\mathrm{DgHT}$ is its $\mathrm{pH}$ optimum which is more acidic (about 4.5; Figure 3.27) than it is known for other monosaccharide transporters with the $\mathrm{pH}$ optima lying in the range of 5.5 (M. Büttner, personal communication). It is known that the peribacteroid space in infected cells of legume nodules is more acidic than the apoplast (Blumwald et al., 1985), which is also the case for the periarbuscular space in infected cells of arbuscular mycorrhizal roots (Guttenberger, 2000). In analogy, it can be assumed that the perisymbiont space in infected cells of actinorhizal nodules is also more acidic than the apoplast. A more acidic $\mathrm{pH}$ optimum of a transporter specific to the perisymbiont membrane (as implied by its supposed function in feeding the bacteria) would correspond with a location in the perisymbiont membrane. This increased $\mathrm{pH}$ gradient between cytosol and perisymbiont space would make the export of sugars in a proton-symport mechanism more difficult, but facilitate the uptake of sugars by the symbiotic bacteria.

Up to now, plant sugar transporters could only be shown to be active in sugar uptake (reviewed by Caspari et al., 1994), although activity in sugar export has been discussed for a sucrose transporter (Truernit and Sauer, 1995) based on its expression pattern and on comparisons of metabolite concentrations in apoplast and cytosol (Lohaus et al., 1995). Interestingly, the only hexose transporter tested in vivo and in vitro (HUP1 from Chlorella kessleri), was found to catalyse strict $\mathrm{H}^{+}$-monosaccharide symport (uptake) when expressed in yeast but was facilitating glucose diffusion in both directions when used in vitro in artificial vesicles (Caspari et al., 1996). Another example that raises questions about the reliability of transport directions determined in yeast is a recently identified zinc transporter from the peribacteroid membrane of soybean nodules, GmZIP1 (Moreau et al., 2002). When expressed in yeast, it only catalyzes zinc uptake, but this 
direction of transport is extremely unlikely in the homologous system where the plant supplies the microsymbiont with micronutrients and not vice versa. Thus, the membrane environment seems to be able to influence a transporter's activity, which might allow the hexose transporter of Datisca to perform glucose export when present in the perisymbiont membrane of infected nodule cortical cells.

\subsection{Nodule and root sugar contents}

The steady state levels of soluble sugars in a plant organ can yield information about metabolism. To complete the analysis of sugar partitioning in nodules, soluble sugars were extracted from nodules and roots of the three model plants and analysed by HPLC (Figures 3.1 - 3.3).

\subsubsection{Sucrose, glucose and fructose in nodules and roots}

A comparison of the amounts of sucrose, glucose and fructose in roots and nodules of the three model plants shows several interesting aspects.

Unusually high sucrose concentrations were found in Casuarina nodules (Figure 3.2; Table 4.2). This phenomenon is probably due to the fact that in contrast with Medicago and Datisca nodules, no starch biosynthesis takes place in Casuarina nodules which means that sucrose may serve as carbon storage form. In other systems, sucrose has been shown to be able to serve as long term carbon storage form, e.g. in sugar beet (Reinefeld et al., 1986) or as transient carbon storage form, e.g. in barley leaves (Riens et al., 1994).

The absence of fructose in extracts of Medicago nodules and roots (Figure 3.1; Table 4.2) is probably caused by high fructokinase (FK) activities, which are often linked with the operation of sucrose syntase (SuSy). A similar situation has been found in potato tubers, where fructokinase has been suggested to reduce cytosolic fructose contents in order to maintain a high SuSy-catalysed net flux of sucrose to phosphorylated hexoses (Renz and Stitt, 1993; Appeldoorn et al., 1997). Both FK and SuSy genes are expressed in similar fashion during the development of sink tissues and both enzymes are inhibited by elevated fructose concentrations (Schaffer and Petreikov, 1997). Therefore, it is likely to be important to effectively remove fructose to maintain high SuSy activities, which are essential for nitrogen fixation in nodules (Gordon et al., 1999). 
In contrast to Medicago, both Datisca and Casuarina nodules contain fructose, but the comparison of the glucose:fructose ratio in roots and nodules reveals differences in the two actinorhizal symbioses. The increase of the glucose:fructose ratio in Datisca nodules compared to roots (Table 4.2) could be a result of increased FK activity, as was shown for stolon tips of potato during tuberization (Davies, 1984). In Casuarina, the glucose:fructose ratio does not change remarkably between roots and nodules (Table 4.2). This is surprising, since the reduction of invertase activities in Casuarina nodules compared to roots, like in Medicago and Datisca, seems to imply that here, SuSy plays the major role in sucrose hydrolysis. Like in potato tubers, the phosphorylated hexoses produced from sucrose by SuSy in Medicago and Datisca nodules could be not only used for the synthesis of cell wall-like material and for nodule metabolism, but also for starch biosynthesis. Both Medicago and Datisca nodules contain large amounts of starch grains while only Casuarina nodules are starch-free (Medicago: Vasse et al., 1990; Datisca: Okubara et al., 1999; Casuarina: E. Duhoux, personal communication). Therefore, these facts may be responsible for the difference in sugar ratios.

Table 4.2. Sugar ratios in roots and nodules of Medicago, Datisca and Casuarina

\begin{tabular}{|l|c|c|c|c|}
\hline \multirow{2}{*}{ Plant } & \multicolumn{2}{|c|}{ Sucrose/Hexoses } & \multicolumn{2}{c|}{ Glucose/Fructose } \\
\cline { 2 - 5 } & root & nodule & root & nodule \\
\hline Medicago & 2.1 & 2.3 & no fructose & no fructose \\
\hline Datisca & 0.9 & 0.4 & 0.32 & 0.55 \\
\hline Casuarina & 1.2 & 2.4 & 0.6 & 0.63 \\
\hline
\end{tabular}

Absolute hexose concentrations in nodules (glucose and fructose) are higher in actinorhizal nodules $(12.5 \mu \mathrm{mol} / \mathrm{g} \mathrm{FW}$ and $7.2 \mu \mathrm{mol} / \mathrm{g} \mathrm{FW}$ in Datisca and Casuarina, respectively) than in Medicago nodules $(4.2 \mu \mathrm{mol} / \mathrm{g} \mathrm{FW})$. These values are also higher in actinorhizal nodules than in the corresponding roots, especially for Datisca, where nodule hexose concentrations exceeded concentrations in roots more than six fold (Figure 3.3). In comparison with Medicago nodules, increased hexose concentrations in actinorhizal nodules might point at an essential difference between rhizobial and actinorhizal symbioses. This difference cannot be connected to starch metabolism, since here Casuarina is different from both Medicago and Datisca. The hexose concentrations might be dependent solely on invertase activities, regardless of the localization of the isoforms, since the interconnection between futile cycles of sucrose/hexose hydrolysis/synthesis enables the interchange of sugars between apoplast, cytosol and vacuole (Nguyen-Quoc 
and Foyer, 2001). The sum of invertase activities is similar in nodules of Datisca and Medicago, but more than five times higher in Casuarina than in Medicago nodules (Table 4.1).

As described in 4.3.1 it is possible that the high hexose contents of actinorhizal nodules are required for the osmoregulation that is needed to allow the infection of cells by branching Frankia hyphae. In Medicago, the uptake of bacteria into infected cells occurs by a complete endocytosis-like process resulting in the formation of symbiosomes. In actinorhizal plants, continuous invagination of the plasma membrane during the infection process requires different turgor control mechanism (Mylona et al., 1995). Interestingly, vacuolar invertase has been implicated in increasing hexose concentrations in source organs during water stress, i.e. particularly in turgor control (Kim et al., 2000). This might be a reason for the high hexose contents of actinorhizal nodules, which contain significantly higher vacuolar invertase activities than Medicago (Figure 3.11). Unfortunately, hexose localization in nodules is not possible since in situ glucose staining does not work on infected cells (see Figures 3.14A and B as well as 3.2.3.1.).

\subsubsection{Datisca contains novel non-structural rhamnosyl saccharides}

\subsubsection{Free rutinose and methylrutinose are found in Datisca sugar extracts}

In extracts of roots and nodules of Medicago, Datisca, and Casuarina, several compounds were present that could not be identified by comparison with the HPLC standards used. The two unknown compounds that were present at high concentrations in Datisca nodules were isolated and named $M$ and $D$. Due to their behaviour in HPLC, M and D were initially assumed to represent a sugar alcohol and a flavone glycoside, respectively. Their structures were determined using NMR, mass spectroscopy, the NMR correlation spectroscopy methods $\mathrm{H}, \mathrm{H}-\mathrm{COSY}$ and $\mathrm{C}, \mathrm{H}-\mathrm{COSY}$ as well as acid and enzyme hydrolysis and HPLC analysis of the hydrolysis products (see 3.1.3.1.). Based on these analyses, $M$ represents a $\alpha$-L-rhamnopyranosid-( $1 \rightarrow 6)-(1-O-\beta$-D-methylglucose (methylrutinose) and $D$ represents $\alpha$-L-rhamnopyranosid-( $1 \rightarrow 6)$-glucose (rutinose) (see Figure 3.6).

The isolation and identification allowed the preparation of concentration standards of methylrutinose and rutinose. Based on the real concentrations of these two sugars in Datisca extracts could be determined (Figure 3.10). The new results showed that rutinose is the sugar with the highest concentration in roots as well as in nodules with concentrations of about 90 and $200 \mu \mathrm{mol} / \mathrm{g} \mathrm{FW}$, respectively. Rutinose was also found in leaves of Datisca, but in much smaller concentrations (about $11 \mu \mathrm{mol} / \mathrm{g} \mathrm{FW}$ ) that are comparable with the concentrations of sucrose in leaves (see 3.1.3.2). Thus, rutinose was not only present in sink organs, but also in source organs. The concentrations of all 
sugars in Datisca extracts except for rutinose are presented in Figure 4.2 to allow a more precise comparison using a smaller scale than necessitated by the high concentrations of rutinose in Figure 3.10. It can be seen that the concentrations of methylrutinose do not differ dramatically from those of the other sugars in the corresponding plant organs, except that leaves contain more sucrose than methylrutinose and nodules vice versa (Figure 3.10).

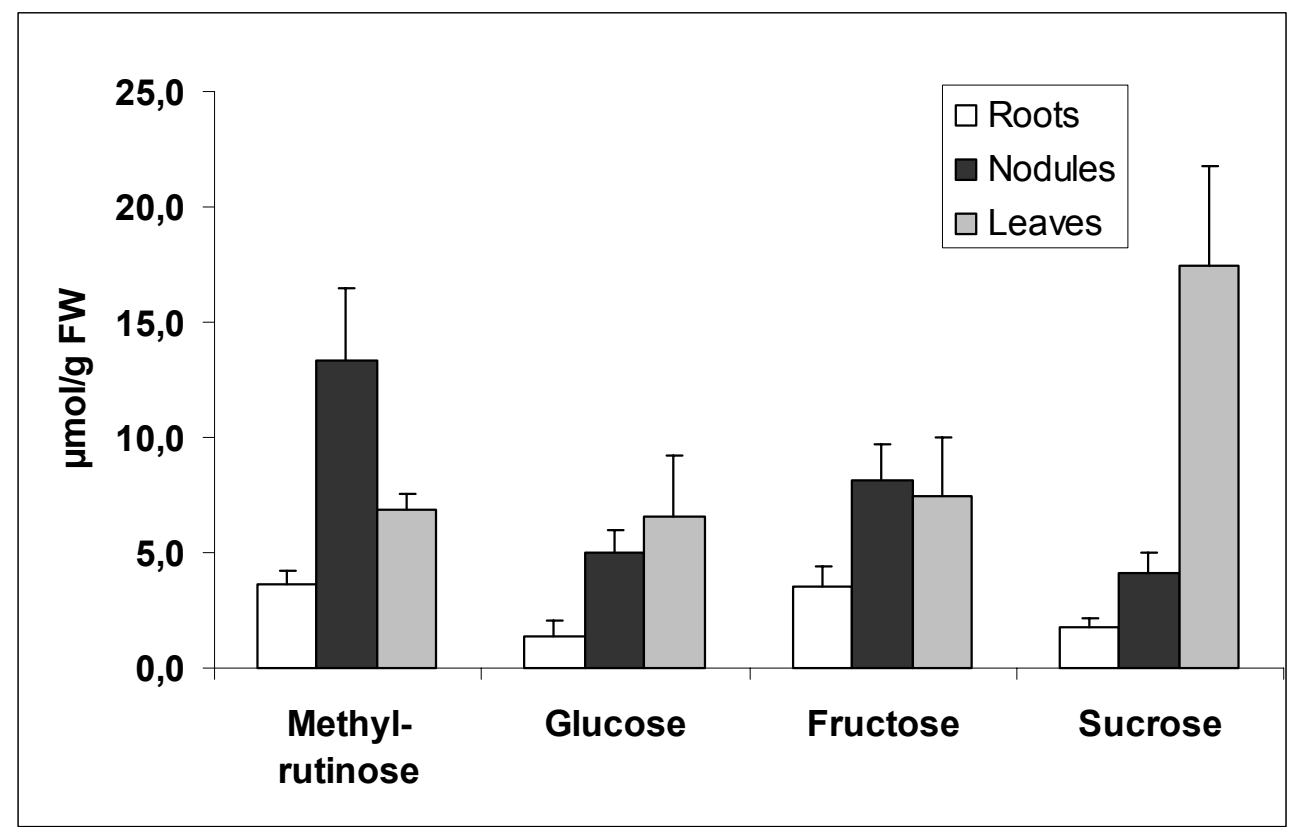

Figure 4.2. Concentrations of methylrutinose, glucose, fructose and sucrose in roots, nodules and leaves of Datisca. Data for rutinose are omitted (see Figure 3.10). Average values of three parallel samples are shown.

\subsubsection{Possible ways of rutinose and methylrutinose synthesis}

A study of the literature on plant glycosides showed that rutinose has not been described as free plant sugar, but only as glycoside part of many flavone glycosides, e.g. rutin, galanginoside, cannabin, datiscin and datinoside, which have been isolated and characterised from the only other Datisca species besides Datisca glomerata, Datisca cannabina (Zapesochnaya and Pangarova, 1976). Datiscin represents 5,7,2'trihydroxyflavone-3-O-rutinose (Zapesochnaya et al., 1982). Methylrutinose is also not known among free plant metabolites.

Many plant glycosides such as flavonoides, cardenolides, phenols, sterols, coumarins and others, contain a disaccharidyl unit and sometimes even a larger oligosaccharide. The synthesis of these glycosides involves stepwise, sequential transglycosylations from the proper sugar nucleotide donors. The degradation of the glycosides is the sequential removal of the monosaccharides by exoglycosidases. 
However, in several cases small amounts of intact disaccharides could be removed from the aglycon by what may be a specific enzymatic "endo"-hydrolysis, catalysed by enzymes called "disaccharidases" or "diglycosidases" (Avigad, 1982). The enzymes degrading a rutinose-containing flavone glycoside, rutin (quercetin-rutinose), were found in seeds of Fagopyrum sp. and of Rhamnus sp., and two different rutin degrading disaccharidases were purified from tartary buckwheat seeds (Fagopyrum tataricum; Yasuda and Nakagawa, 1994; for Rhamnus see Charaux, 1925, cited after Zapesochnaya and Pangarova, 1976). The roots of Datisca cannabina also contain an enzyme hydrolyzing 3-rutinosides of flavones (Favre-Bonvin et al., 1969; cited after Zapesochnaya and Pangarova, 1976). However, the localization, activity, and the role of these enzymes have not yet been studied. The levels of free reducing disaccharides of glycoside origin isolated from plants are usually very small (reviewed by Avigad, 1982). Therefore, the high concentrations of rutinose and methylrutinose in extracts do not support an accidental origin from glycosides. It is, however, possible that the synthesis of rutinose in Datisca proceeds via consecutive glycosylation of Datiscetin (5,7,2'-trihydroxyflavone) and subsequent removal of the rutinose units by a disaccharidase. Nevertheless, it is still unusual to find such high concentrations of a reducing sugar like rutinose. Possibly, the methylation of rutinose to methylrutinose is applied to eliminate this disadvantage. Preliminary results suggest that Datisca seems to contain highly active rutinose demethylases, since a short incubation of ground roots in $\mathrm{H}_{2} \mathrm{O}$ precludes the isolation of methylrutinose, but not of rutinose (data not shown).

\subsubsection{Are rutinose and methylrutinose carbon storage or transport forms?}

Literature studies reveal that all unusual non-structural plant carbohydrates studied thus far represent either polyols or galactosides. The best analysed galactosides are the raffinose oligosaccharides that serve as transport carbohydrates and as carbon storage compounds in leaves, roots and tubers of Cucurbitaceae, Lamiaceae and other plant families (Keller and Pharr, 1996). There is also a biochemical link between the metabolism of raffinose oligosaccharides and that of galactosyl cyclitols (Hoch et al., 1999) which are found in the seeds of many legumes.

As mentioned above, rutinose represents a reducing sugar, and for storage and/or transport purposes the methylation of the anomeric carbon atom might be essential. The following models could be proposed for sugar metabolism in Datisca:

1. Rutinose is an intermediate carbon storage form, additional to transient starch. It accumulates in vacuoles and in case of metabolic demand is introduced into metabolism 
by the action of an $\alpha$-rhamnosidase. Unfortunately, since no plant $\alpha$-rhamnosidases have been cloned yet, it is not possible to analyse their expression pattern and localization.

2. Rutinose is a carbon transport form. Rutinose and sucrose are synthesised in leaves, and rutinose is methylated to methylrutinose. Sucrose and methylrutinose are transported in the phloem to sink organs, where phloem unloading is drawn by immediate demethylation of methylrutinose and hydrolysis of sucrose. At times of carbon excess, rutinose accumulates in sink organs in vacuoles. This assumption begs the question why rutinose and not the non-reducing methylrutinose accumulates in vacuoles, since the rutinose content of roots and nodules is far higher than the methylrutinose content (Figure 3.10). However, storage of reducing sugars has been already reported. For example, tomato fruits are characterized by an accumulation of reducing sugars as the predominant fruit soluble carbohydrates (Garvey and Hewitt, 1991). Glucose was found to accumulate in the fruits of sea buckthorn (Tang, 2002) and of several Rosaceae (e.g. peach; Lo Bianco and Rieger, 2002).

To examine whether rutinose and/or methylrutinose represent carbon transport forms in Datisca, phloem sap samples or exudates from leaf petioles have to be examined. Preliminary results of HPLC analysis of petiole exudates showed the presence of rutinose in high concentrations, whereas methylrutinose levels were low (data not shown). However, instead of high sucrose concentrations, higher levels of glucose and fructose were found, although hexoses are no transport sugars (Heineke et al., 1992). This could be explained by contamination of the petiole exudates with invertase. Similar results have been obtained for transgenic potato plants expressing yeast apoplastic invertase under control of the CaMV 35S-promoter. Petiole exudates of these plants contained sucrose, glucose and fructose (Günther, 1991), while phloem sap won from the same plants by the laser aphid stylet technique as well as petiole exudates of wild type plants contained sucrose, but neither glucose nor fructose (Günther, 1991; Heineke et al., 1992). Thus, it is possible that demethylases as well as invertase were present in the petiole exudates. In analogy to the transgenic potato plants, the demethylases of Datisca should be located in the apoplast. Assuming that the hexoses were hydrolysis products of sucrose, the petiole exudates contained almost 10 times more rutinose/methylrutinose then sucrose. To address the question whether methylrutinose or rutinose is transported, i.e. to avoid the contamination of phloem exudates with sugar-modifying enzymes, it will be necessary to analyse pure phloem sap directly, i.e. to analyse phloem sap isolated using the laser aphid-stylet technique (Barlow and McCully, 1972; Fisher and Frame, 1984).

Since comparisons of petiole exudates and phloem sap are not available from many plants, it is still possible that the invertase/putative demethylase activity in Datisca 
petiole exudates does not come from the apoplast. Rutinose is present in nodules in relatively high concentrations (Figure 3.10), indicating that it is likely to accumulate in vacuoles. That would mean that demethylases could be present in either vacuoles or cytosol, or in both.

In another preliminary experiment, the diurnal rhythm of the concentrations of sucrose, rutinose and methylrutinose was examined in leaves and roots. The concentration changes of both rhamnosyl disaccharides paralleled those of sucrose (data not shown). So, it is possibly to propose that rutinose and/or methylrutinose represent carbon transport forms alternative to sucrose. In principle, the transport of unusual carbohydrates in the phloem is a marker of symplastic phloem loaders which were analysed only on presence of sugar alcohols and raffinose family of oligosaccharides (Zimmermann and Ziegler, 1975). However, symplastic phloem loaders are also characterised by the fact that they transport a variety of carbon compounds in general, while apoplastic phloem loaders have one dominant carbon transport form (Gamalei, 1984). The phloem loading mode of Datisca has not yet been examined. Based on the phylogenetic position of the Datiscaceae, which are closely related to Begoniaceae, Datisca would be expected to represent a primitive apoplastic phloem loader (O. Voitsekhovskaja and Yu. Gamalei, personal communication). It will be very interesting to examine the companion cell differentiation in Datisca leaves in order to find out whether symplastic or apoplastic loading is used for rutinose/methylrutinose. If Datisca were indeed an apoplastic phloem loader, as the presence of about $90 \%$ rutinose/methylrutinose in the petiole exudate and the putative apoplastic location of demethylases (see above) would support, this would imply that either special plasmamembrane rutinose transporters are present in this plant, or, more likely, that the sucrose transporter of Datisca also can transport rutinose/methylrutionose. Plant disaccharide transporters analysed thus far are not strictly specific for sucrose, but also accept, for example, vitamin $\mathrm{H}$ (biotin) as substrate (Ludwig et al., 2000). Of course, rutinose or methylrutinose are not commercially available and therefore were never tested as substrates of disaccharide transporters. Hence, it would be possible that (a) all disaccharide transporters accept rutinose and/or methylrutinose as substrates, or (b) that disaccharide transporters in primitive apoplastic phloem loaders have a broader substrate specificity than those of highly evolved apoplastic phloem loaders. Furthermore, the possibility exists that since rutinose is a reducing sugar, it is recognized by hexose transporters. At least, it has been shown that some transporters of the reducing disaccharide maltose also accept hexoses as substrates (Wieczorke et al., 1999). In this case, membrane penetration of methylrutinose and rutinose could be catalyzed by 
different transporters. Summing up, the identification of novel sugars in Datisca opens very interesting new perspectives on plant carbon partitioning mechanisms in general.

\subsubsection{The implications of the discovery of rutinose (methylrutinose) as major carbohydrate for nodule carbon partitioning in Datisca}

Since the rutinose concentration in nodules is much higher then that of sucrose, it is very important that the analysis of carbon partitioning mechanisms in Datisca involves also the analysis of rutinose-hydrolysing enzymes, namely, $\alpha$-rhamnosidases. Unfortunately, the localization of these enzymes is not possible to examine, since no plant $\alpha$-rhamnosidase has been cloned yet. However, the conclusions on sugar metabolism in Datisca roots and nodules that were based on the assumption that sucrose represents the main transport sugar have to be reconsidered with care. For instance, regarding chapter 4.5. it is possible that rutinose is hydrolysed in the apoplast, followed by the uptake of rhamnose by the microsymbiont Frankia, while glucose is imported into the cytoplasm of host cells via the hexose transporter that is specifically expressed in infected cells. This would mean that Frankia bacteria are fed hexoses in Datisca nodules, but that the hexose transporter is not working as an exporter.

Moreover, the decrease of sucrose synthase activity and strong reduction of invertase activities in nodules compared to roots is no more surprising. Since rutinose and not sucrose is the main transitory storage sugar in Datisca nodules, while both are present at similar concentrations in roots, the higher metabolic activity of nodules should be reflected by the induction of $\alpha$-rhamnosidase and not sucrose synthase expression or activity.

For the future, the identification of rutinose (methylrutinose) as the major sugar in Datisca nodules necessitates the analysis of $\alpha$-rhamnosidase and methylrutinose demethylase activities in roots and nodules of this plant, preferentially including the cloning of the corresponding cDNAs. Furthermore, the presence of rhamnosyl disaccharides in other actinorhizal plants should be examined, considering that the Rhamnaceae, named after their high content of rhamnose-containing flavone glycosides, are one of the eight actinorhizal plant families. There might actually be a link between the presence of rhamnosyl glycosides in a plant species, and the ability to enter a symbiosis with a Frankia strain of clade III (Figure 1.4). 


\section{Summary}

In this thesis sucrose-cleaving enzymes and sugar transport proteins were studied to determine the way of sugar transport and their role in the function of nitrogen-fixing root nodules. Soluble sugar metabolite profile was analysed to reveal dominating sugars, which could be important for the symbiotic function of root nodules. To find out a possible common feature of root nodule symbioses, different model systems, one legume symbiosis (Medicago truncatula - Sinorhizobium meliloti) and two actinorhizal symbioses from different Frankia subclades, Datisca glomerata and Casuarina glauca were chosen. In order to reveal whether sugar partitioning mechanisms represent system-specific adaptations, i.e. resemble sugar partitioning mechanisms established in roots or are common to all nitrogen-fixing root nodules, all experiments included comparisons between roots and nodules.

The main results obtained can be summarized as follows:

- Legume and actinorhizal symbioses differ with respect to sugar transporter (HT) expression: induction of HT expression was found in nodules of actinorhizal plants Datisca and Casuarina, but expression levels of HT in Medicago nodules were strongly reduced.

- Full-size cDNA sequences for hexose transporters were isolated from Medicago $(M t H T)$ and Datisca $(D g H T)$ nodules. Based on their amino acid sequence, the encoded proteins belonged to different classes of sugar transporters. The functional characterization of DgHT in a heterologous system (yeast) demonstrated that $\mathrm{DgHT}$ is a high affinity, energy-dependent monosaccharide transporter, probably a $\mathrm{H}^{+}$-symporter, with broad substrate specificity.

- Expression levels of sucrose transporter (ST) in Medicago nodules were strongly reduced compared to roots.

- The total (sum of apoplastic, cytosolic and vacuolar) invertase activity is strongly reduced in nodules compared to roots of all three symbiotic systems studied.

- Different localizations of acid invertase activity suggest that sugar transport in Medicago roots occurs apoplastically, whereas in Datisca roots it takes place symplastically. There may be apoplastic transport in vascular parenchyma of Datisca roots.

- The major sucrose-cleaving activity in Medicago and Datisca roots and nodules is represented by sucrose synthase (SuSy). Datisca and Casuarina possess a 
single immunoreactive protein for SuSy of about $92 \mathrm{kDa}$, Medicago contains an additional, somewhat larger SuSy protein in roots, but not in nodules. SuSy activities were similar in the soluble protein fractions in both roots and nodules of Medicago. In Datisca nodules they were lower compared to roots.

- Two unknown sugars were isolated from Datisca and identified using biochemical methods, NMR and mass spectroscopy. They were shown to represent rutinose ( $\alpha$-L-rhamnopyranosyl-( $1 \rightarrow 6)$-D-glucose) and methylrutinose ( $\alpha$-L-

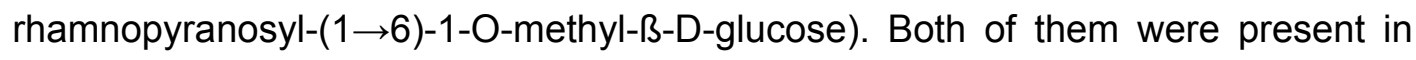
large amounts in roots, nodules and leaves of Datisca.

- Sucrose is the principal sugar of Medicago and Casuarina nodules. The major sugar of Datisca root and nodule extract is rutinose.

The data presented in this thesis show significant differences between carbon partitioning mechanisms in the three symbiotic systems examined. However, some common features were also noted.

In all systems studied there was a decrease of total invertase activity, determined mostly by apoplastic invertase, in nodules compared to roots that could be an evidence for symplastic transport of sugars in nodules. In Medicago, this was underlined by the strong reduction of sugar transporter expression. This implies a shift toward symplastic transport mechanisms in nodules, which is likely to represent a symbiosis-specific adaptation in that symplastic transport allows the plant to control the microsymbiont's access to carbon sources.

Both actinorhizal symbioses showed strong induction of hexose transporter expression in nodules combined with a considerable reduction of apoplastic invertase activity which would be needed to provide these transporters with substrates. The last circumstance allows to propose a special role of the hexose transporter in supplying the microsymbiont with carbon sources in nodules. 


\section{Abbreviations}

\begin{tabular}{|c|c|}
\hline Amp & ampicillin \\
\hline $\mathrm{Amp}^{\mathrm{R}}$ & ampicillin resistance \\
\hline ATP & adenosine $5^{\prime}$ triphosphate \\
\hline bp & base pairs \\
\hline BSA & bovine serum albumin \\
\hline CAA & casamino acids \\
\hline CC & companion cell \\
\hline CCCP & carbonyl cyanide-m-chlorophenylhydrazone \\
\hline cDNA & complementary DNA \\
\hline $\mathrm{CgHT}$ & Casuarina glauca hexose transporter \\
\hline CW & cell wall \\
\hline DAB & diaminobenzidine \\
\hline dCTP & deoxycytosine $5^{\prime}$ triphosphate \\
\hline dd $\mathrm{H}_{2} \mathrm{O}$ & double distilled water \\
\hline $\mathrm{DgHT}$ & Datisca glomerata hexose transporter \\
\hline DMF & dimethylformamide \\
\hline DMSO & dimethylsulfoxide \\
\hline DNA & deoxyribonucleic acid \\
\hline DNase & deoxyribonuclease \\
\hline DNP & 2,4-dinitrophenol \\
\hline dNTP & deoxynucleotide triphosphate \\
\hline dNTPs & deoxyribonucleotides \\
\hline DTT & dithiothreitol \\
\hline ECL & enhanced chemiluminescence \\
\hline EDTA & Ethylenediamine tetraacetic acid \\
\hline EGTA & Ethyleneglycole-bis-(2'-aminoester)-N,N,N',N'-tetraacetate \\
\hline $\mathrm{EtOH}$ & ethanol \\
\hline FW & fresh weight \\
\hline G-6-PDH & glucose-6-phosphate dehydrogenase \\
\hline GWDG & Gesselschaft für wissenschaftliche Datenverarbeitung Göttingen \\
\hline HEPES & hydroxyethyl-piperazinethane sulfonic acid \\
\hline HPLC & high performance liquid chromatography \\
\hline IPTG & isopropyl- $\beta$-D-thiogalactopyranoside \\
\hline kb & kilobase pairs \\
\hline
\end{tabular}




\begin{tabular}{|c|c|}
\hline kDa & kilodalton \\
\hline $\mathrm{Km}$ & kanamycin \\
\hline $\mathrm{K}_{\mathrm{m}}$ & Michaelis-Menten constant \\
\hline $\mathrm{Km}^{\mathrm{R}}$ & kanamycin resistance \\
\hline MEN & MOPS-sodium acetate-EDTA \\
\hline MOPS & morpholinopropane sulfonic acid \\
\hline MtHT & Medicago truncatula hexose transporter \\
\hline MtST & Medicago truncatula sucrose transporter \\
\hline NAD & nicotine adenine dinucleotide (oxidized) \\
\hline $\mathrm{NADH}$ & nicotine adenine dinucleotide (reduced) \\
\hline NADP & nicotine adenine dinucleotide phosphate (oxydized) \\
\hline NADPH & nicotine adenine dinucleotide phosphate (reduced) \\
\hline NMR & nuclear magnetic resonance \\
\hline OD & optical density \\
\hline ORF & open reading frame \\
\hline p.c. & packed cells \\
\hline PAGE & polyacrylamide-gel electrophoresis \\
\hline PCR & polymerase chain reaction \\
\hline PEG & polyethylenglycol \\
\hline PMSF & phenylmethylsulfonylfluoride \\
\hline PVP & polyvinylpyrrolidone \\
\hline PVPP & polyvinylpolypyrrolidone \\
\hline RACE & rapid amplification of cDNA ends \\
\hline RNA & ribonucleic acid \\
\hline RNase & ribonuclease \\
\hline rpm & rounds per minute \\
\hline RT & reverse transcriptase \\
\hline SDS & sodium dodecylsulfate \\
\hline SE & sieve element \\
\hline SE-CC complex & sieve element-companion cell complex \\
\hline ST & sucrose transporter \\
\hline STEL & sucrose-Triton-X-100-Tris-EDTA-lysozyme buffer \\
\hline SuSy & sucrose synthase \\
\hline $\mathrm{T}_{\mathrm{ann}}$ & annealing temperature \\
\hline Taq & Thermus aquqticus \\
\hline TdT & terminal deoxynucleotidyl transferase \\
\hline TEA & triethanolamine \\
\hline
\end{tabular}




\begin{tabular}{|c|c|}
\hline TEMED & N,N,N',N'-tetramethylene diamine \\
\hline $\mathrm{T}_{\mathrm{m}}$ & melting temperature \\
\hline Tris & tris-(hydroxymethyl)-aminomethane \\
\hline U & $\begin{array}{l}\text { enzyme activity unit ( } 1 \text { unit corresponds to the conversion of } 1 \\
\mu \mathrm{mol} \text { substrate } \operatorname{~min}^{-1} \text { ) }\end{array}$ \\
\hline UDP & uridine $5^{\prime}$ diphosphate \\
\hline UDPG- DH & uridine diphosphate glucose dehydrogenase \\
\hline UDP-glucose & uridine diphosphate glucose \\
\hline UTP & uridine $5^{\prime}$ triphosphate \\
\hline UV & ultraviolet light \\
\hline $\mathrm{v} / \mathrm{v}$ & volume/volume \\
\hline$w / v$ & weight/volume \\
\hline X-Gal & 5-bromo-4-chloro-3-indolyl- $\beta$-D-galactopyranoside \\
\hline YNB & yeast nitrogen base \\
\hline
\end{tabular}




\section{References}

Abd-Alla MH, Koyro H-W, Schubert S, Peiter E (2000) Functional structure of the indeterminate Vicia faba L. root nodules: implications for metabolite transport. J Plant Physiol 157: 335-343.

Akkermans ADL, Roelofsen W, Blom J, Huss-Danell K, Harkink R (1983) Utilization of carbon and nitrogen compounds by Frankia in synthetic media and in root nodules of Alnus glutinosa, Hippophae rhamnoides, and Datisca cannabina. Can J Bot 61: 2793-2800.

Altschul SF, Gish W, Miller W, Myers EW, Lipman DJ (1990) Basic local alignment search tool. J Mol Biol 215: 403-410.

Amor Y, Haigler CH, Jonson S, Wainscott M, Delmer DP (1995) A membraneassociated form of sucrose synthase and its potential role in synthesis of cellulose and callose in plants. Proc Natl Acad Sci USA 92: 9353-9357.

Angelini R, Manes F, Federico R (1990) Spatial and functional correlation between diamine-oxydase and peroxidase activities and their dependence upon deetiolation and wounding in chickpea stems. Planta 182: 89-96.

Anthon GE, Emmerich DW (1990) Developmental regulation of enzymes of sucrose and hexose metabolism in effective and ineffective soybean nodules. Plant Physiol 92: 346-351.

Appeldoorn NJG, de Bruijn SM, Koot-Gronsveld EAM, Visser RGF, Vreugdenhil D, van der Plas LHW (1997) Developmental changes of enzymes involved in conversion of sucrose to hexose-phosphate during early tuberisation of potato. Planta 202: 220-226.

Appleby CA (1984) Leghemoglobin and rhizobial respiration. Annu Rev Plant Physiol 35: 443-478.

Arai M, Mori H, Imaseki H (1992) Expression of the gene for sucrose synthase during growth of mung bean seedlings. Plant Cell Physiol 33: 503-506.

Avigad G (1982) Sucrose and disaccharides. In: Encyclopedia of Plant Physiology, Lowus FA and Tanner W, eds. (Berlin: Springer Verlag), pp 217-347.

Ayres PG, Press MC, Spencer-Phillips PTN (1996) Effects of pathogens and parasitic plants on source-sink relationships. In: Photoassimilate Distribution in Plants and Crops, E Zamski and AA Schaffner, eds. (New-York: Marcel Dekker), pp 479-499.

Barker DG, Bianchi S, Blondon F, Datté Y, Duc G, Flament P, Gallusci P, Génier P, Guy P, Muel X, Tourneur J, Dénarié J, Huguet T (1990) Medicago truncatula, a model plant for studying the molecular genetics of the Rhizobium-legume symbiosis. Plant Mol Biol Rep 8:40-49.

Barlow CA, Mc Cully ME (1972) The ruby laser as an instrument for cutting the stylets of feeding aphids. Can J Zool 50: 1497-1498.

Barratt DHP, Barber L, Kruger NJ, Smith AM, Wang TL, Martin C (2001) Multiple, distinct isoforms of sucrose synthase in pea. Plant Physiol 127: 655-664.

Basset B, Goodman RN, Novacky A (1977) Ultrastructure of soybean nodules. I. Release of rhizobia from the infection thread. Can J Microbiol 23: 573-582.

Batut J, Boistard P (1994) Oxygen control in Rhizobium. Anthonie Van Leeuwenhoek 66: 129-150. 
Benson DR, Clawson ML (2000) Evolution of the actinorhizal plant symbiosis. In: Prokaryotic Nitrogen Fixation: A Model System for Analysis of a Biological Process (Symondham: Horizon Scientific Press), pp 207-224.

Benson DR, Schultz NA (1990) Physiology and biology of Frankia in culture. In: The Biology of Frankia and Actinorhizal Plants, Schwintzer CR and Tjepkema JD, eds. (San Diego: Academic Press), pp 107-127.

Benson DR, Silvester WB (1993) Biology of Frankia strains, actinomycete symbionts of actinorhizal plants. Microbiol Rev 57: 293-319.

Berg RH, McDowell L (1987a) Endophyte differentiation in Casuarina actinorhizae. Protoplasma 136: 104-117.

Berg RH, McDowell L (1987b) Cytochemistry of the wall of infected cells in Casuarina actinorhizae. Can J Bot 66: 2038-2047.

Berry AM, Harriot OT, Moreau RA, Osman SF, Benson DR, Jones AD (1993) Hopanoid lipids compose the Frankia vesicle envelope, presumptive barrier of oxygen diffusion to nitrogenase. Proc Natl Acad Sci USA 90: 6091-6094.

Blauenfeldt J, Joshi PA, Gresshoff PM, Caetano-Anollés G (1994) Nodulation of white clover (Trifolium repens) in the absence of Rhizobium. Protoplasma 179: 106-110.

Blumwald E, Fortin MG, Rea PA, Verma DPS, Poole R (1985) Presence of host-plasma membrane type $\mathrm{H}^{+}$-ATPase in the membrane envelope enclosing the bacteroids in soybean root nodules. Plant Physiol 78: 665-672.

Bradford MM (1976) A rapid and sensitive method for the determination of microgramm quantities of protein utilizing the principle of protein-dye binding. Anal Biochem 72:248-254.

Buchner P, Poret M, Rochat C (1998) Cloning and characterization of a cDNA (Accession No. AJ001071) encoding a second sucrose synthase gene in pea (Pisum sativum L.). Plant Physiol 117: 719.

Burgos RC, Chiang VL, Zhang X-H, Campbell ER, Podila GK, Champbell WH (1995) RNA isolation from plant tissues resistant to extraction in guanidine. Bio Techniques 19: 734-737.

Bush DR (1993) Proton-coupled sugar and amino acid transporters in plants. Annu Rev Physiol Plant Mol Biol 44: 513-542.

Büttner M, Sauer N (2000) Monosaccharide transporters in plants: structure, function and physiology. Biochim Biophys Acta 1465: 263-274.

Büttner M, Truernit E, Baier K, Scholz-Starke J, Sontheim M, Lauterbach C, Huss VAR, Sauer N (2000) AtSTP3, a green leaf-specific, low affinity monosaccharide$\mathrm{H}^{+}$symporter of Arabidopsis thaliana. Plant Cell 23: 175-184.

Carlson SJ, Chourey PS (1996) Evidence for plasma membrane-associated forms of sucrose synthase in maize. Mol Gen Genet 252:303-310.

Caspari T, Robl I, Stolz J, Tanner W (1996) Purification of the Chlorella HUP1 hexoseproton symporter to homogeneity and its reconstitution in vitro. Plant $\mathrm{J} 10$ : 10451053.

Caspari T, Will A, Opekarova M, Sauer N, Tanner W (1994) Hexose $/ \mathrm{H}^{+}$symporters in lower and higher plants. J Exp Biol 196: 483-491.

Chandler MR, Date RA, Roughley RJ (1982) Infection and root nodule development in Stilosanthes species by Rhizobium. J Exp Bot 33: 47-57.

Cleland RE, Fujiwara T, Lucas WJ (1994) Plasmodesmal-mediated cell-to-cell transport in weat roots is modulated by anaerobic stress. Protoplasma 178: 81-85. 
Davies DD, Kenworthy P, Mocquot D, Roberts K (1987) The effects of anoxia on the ultrastructure of pea roots. In: Plant Life in Aquatic and Amphibious Habitats, Crawford RMM, ed (Oxford: Blackwell Scientific Publication), pp 265-277.

Davies HV (1984) Sugar metabolism in stolon tips during early tuberization. Z Pflanzenphysiol 113: 377-381.

Day DA, Kaiser BN, Thomson R, Udvardi MK, Moreau S, Puppo A (2001) Nutrient transport across symbiotic membranes from legume nodules. Aust $\mathrm{J}$ Plant Physiol 28: 667-674.

Delmer DP, Amor Y (1995) Cellulose biosynthesis. Plant Cell 7: 987-1000.

Denison RF, Layzell DB (1991) Measurement of legume nodule respiration and $\mathrm{O}_{2}$ permeability by nonivasive spectrophotometry of leghemoglobin. Plant Physiol 96: 137-143.

Doyle JJ (1994) Phylogeny of the legume family: an approach to understanding the origins of nodulation. Annu Rev Ecol Syst 25: 325-349.

Doyle JJ, Doyle JL, Ballenger JA, Dickson EE, Kajita T, Ohashi H (1997) A phylogeny of the chloroplast gene $r b c \mathrm{~L}$ in the Leguminosae - taxonomic correlations and insights into the evolution of nodulation. Amer J Bot 84: 541-554, 1997.

Ehneß R, Roitsch T (1997) Co-ordinated induction of mRNAs for extracellular invertase and glucose transporter in Chenopodium rubrum by cytokinins. Plant $\mathrm{J} 11$ : 539548.

Eschrich W (1980) Free space invertase, its possible role in phloem unloading. Ber Dtsch Bot Ges 93: 363-378.

Fåhraeus G (1957) The infection of clover root hairs by nodule bacteria studied by simple glass technique. J Gen Microbiol 16: 374-381.

Fisher DB, Frame JM (1984) A guide to the use of the exuding-stylet technique in phloem physiology. Planta 161: 385-393.

Fleming Al, Wittenberg JB, Wittenberg BA, Dudman WF, Appleby CA (1987) The purification, characterization and ligand-binding kinetics of hemoglobins from root nodules of the non-leguminous Casuarina glauca - Frankia symbiosis. Biochim Biophys Acta 911: 209-220.

Fontaine MS, Young PH, Torrey JG (1986) Effect of long-term preservation of Frankia strains on infectivity, effectivity and in vitro nitrogenase activity. Appl Environ Microbiol 51: 694-698.

Frohman MA, Dush MK, Martin GR (1988) Rapid production of full-length cDNAs from rare transcripts: Amplification using a single gene-specific oligonucleotide primer. Proc Natl Acad Sci USA 85: 8998-9002.

Gahrtz M, Schmelzer E, Stolz J, Sauer N (1996) Expression of the PmSUC1 sucrose carrier gene from Plantago major $\mathrm{L}$. is induced during seed development. Plant $\mathrm{J}$ 9: 93-100.

Gamalei YV (1984) The structure of leaf minor veins and the types of translocated carbohydrates. Dokl Akad Nauk (in Russ) 277: 1513-1516.

Gamalei YV (1994) The endoplasmic reticulum of plants: its origin, structure and functions. BIN RAN, St-Petersburg.

Gamas P, de Carvalho Niebel F, Lescure N, Cullimore JV (1996) Use of a subtractive hybridization approach to identify new Medicago truncatula genes induced during root nodule development. Mol Plant-Microbe Interact 9: 233-242. 
Garvey TC, Hewitt JD (1991) Starch and sugar accumulation in two accessions of Lycopersicon cheesmanii. J Am Soc Hortic Sci 116:77-79.

Geigenberger P, Langerberger S, Wilke I, Heineke D, Heldt H and Stitt M (1993) Sucrose is metabolised by sucrose synthase and glycolysis within phloem complex of Ricinus communis L. seedlings. Planta 190:446-453.

Geigenberger P, Lerchl J, Stitt M, Sonnewald U (1996) Phloem-specific expression of pyrophosphatase inhibits long distance transport of carbohydrates and amino acids in tobacco plants. Plant Cell Environ 19: 43-45.

Girgis ZMG, Ishac ZI, El-Haddad M, Saleh AE, Diem HG, Dommergues RY (1990) First report on isolation and culture of effective Casuarina- compatible strain of Frankia from Egypt. In: Advance in Casuarina Research and Utilisation, El-Lakany HM, Turnbull WJ and Brewbaker JL, eds. (Kairo: Desert Development Center, A.U.C.), pp156-164.

Godt DE, Roitsch T (1997) Regulation and tissue-specific distribution of mRNAs for three extracellular invertase isoenzymes of tomato suggest an important function in establishing and maintaining sink metabolism. Plant Physiol 115: 273-282.

González EM, Gordon AJ, James CL, Arrese-lgor C (1995) The role of sucrose synthase in the response of soybean nodules to drought. J Exp Bot, 46: 15151523.

Gordon AJ (1991) Enzyme distribution between the cortex and the infected region of soybean nodules. J Exp Bot 42: 961-967.

Gordon AJ, Minchin FR, James CL, Komina O (1999) Sucrose synthase is essential for nitrogen fixation. Plant Physiol 120: 867-877.

Gordon AJ, Minchin FR, Skøt L, James CL (1997) Stress-induced declines in soybean $\mathrm{N}_{2}$ fixation are related to nodule sucrose synthase activity. Plant Physiol 114: 937946.

Greiner S, Rausch T, Sonnewald U, Herbers K (1999) Ectopic expression of a tobacco invertase inhibitor homolog prevents cold-induced sweetening of potato tubers. Nat Biotechnol 17: 708-711.

Greutert H, Keller F (1993) Further evidence for stachyose and sucrose/ $\mathrm{H}^{+}$antiporters on the tonoplast of Japanese artichoke (Stachys sieboldii) tubers. Plant Physiol 101: $1317-1322$.

Günther G (1991) Vergleichende Untersuchungen von Stoffwechselintermediaten in Blättern von transgenen Kartoffelpflanzen. Diplomarbeit, Universität Göttingen.

Guttenberger M (2000) Arbuscules of vesicular-arbuscula mycorrhizal fungi inhabit an acidic compartement within plant roots. Planta 211: 299-304.

Hafeez F, Akkermans ADL, Chaudhary AH (1984) Observations on the ultrastructure of Frankia sp. in root nodules of Datisca cannabina L. Plant Soil 79: 383-402.

Hajirezaei M-R, Takahata Y, Trethewey RN, Willmitzer L, Sonnewald U (2000) Impact of elevated cytosolic and apoplastic invertase activity on carbon metabolism during potato tuber development. J Exp Bot 51: 439-445.

Harrison MJ (1996) A sugar transporter from Medicago truncatula: altered expression pattern in roots during vesicular-arbuscular (VA) mycorrhizal associations. Plant $\mathrm{J}$ 9: 491-503.

Heim U, Weber H, Bäumlein H, Wobus U (1993) A sucrose-synthase gene of Vicia faba L.: Expression pattern in developing seeds in relation to starch synthesis and metabolic regulation. Planta 191: 394-401. 
Heineke D, Sonnewald U, Büssis D, Günther G, Leidreiter K, Wilke I, Raschke K, Willmitzer L, Heldt HW (1992) Apoplastic expression of yeast-derived invertase in potato: effects on photosynthesis, leaf solute composition, water relations, and tuber composition. Plant Physiol 100: 301-308.

Hirsch AM, LaRue TA (1997) Is the legume nodule a modified root or stem or an organ sui generis? CRC Crit Rev Plant Sci 16: 361-392.

Ho LC (1988) Metabolism and compartmentation of imported sugars in sink organs in relation to sink strength. Annu Rev Plant Physiol Plant Mol Biol 39: 355-378.

Hoagland DR, Arnon DT (1938) The water-culture method for growing plants without soil. California Agriculture Experiment Station Circular 347.

Hoch G, Peterbauer T, Richter A (1999) Purification and characterization of stachiose synthase from lentil (Lens cilunaris) seeds. Galactopinitol and stachyose synthesis. Arch Biochem Biophys 366:75-81.

Hohnjec N, Becker JD, Pühler A, Perlick AM, Küster H (1999) Genomic organization and expression properties of the MtSucS1 gene, which encodes a noduleenhanced sucrose synthase in the model legume Medicago truncatula. Mol Gen Genet 261: 514-522.

Huber SC, Huber JL, Liao P-C, Gage DA, McMichael RW, Chourey PS, Hannah LD, Koch K (1996) Phosphorylation of serine-15 of maize leaf sucrose synthase. Occurrence in vivo and possible regulatory significance. Plant Physiol 112: 793802.

Huss-Danell K (1990) The physiology of atinorhizal nodules. In: The biology of Frankia and actinorhizal plants, Schwintzer CR, Tjepkema JD, eds. (San Diego: Acad Press), pp 129-156.

Huss-Danell K (1997) Tansley Review No. 93. Actinorhizal symbioses and their $\mathrm{N}_{2}$ fixation. New Phytol 136, 375-405.

Inoue H, Nojima H, Okayama H (1990) High efficiency transformation of Escherichia coli with plasmids. Gene 96: 23-28.

James EK, Sprent JI, Sutherland JM, McInroy SG, Minchin FR (1992) The structure of nitrogen fixing root nodules on the aquatic mimosoid legume Neptunia plena. Ann Bot (Lond) 69: 173-180.

Jeong J, Suh SJ, Guan C, Tsay Y-F, Moran N, Pawlowski K, Lee Y (2002) A nodulespecific dicarboxylate transporter from Alnus glutinosa. Proc Natl Acad Sci USA, submitted.

Joshi PA, Caetano-Anollés G, Graham ET, Gresshoff PM (1993) Ultrastructure of transfer cells in spontaneous nodules of alfalfa (Medicago sativa). Protoplasma 172: 64-76.

Keller F, Pharr DM (1996) Metabolism of carbohydrates in sinks and sources: galactosylsucrose oligosaccharides. In: Photoassimilate distribution in plants and crops, Zamski E and Schaffer AA, eds. (New York: Marcel Dekker), pp 115-184.

Kijne JW (1992) The Rhizobium infection process. In: Biological Nitrogen Fixation, G Stacey, RH Burris, and HJ Evans, eds. (New York: Chapman and Hall), pp 349398.

Kim J-Y, Mahe A, Brangeon J, Prioul J-L (2000) A maize vacuolar invertase, IVR2, is induced by water stress. Organ/tissue specificity and diurnal modulation of expression. Plant Physiol 124: 71-84.

King SP, Lunn JE, Furbank RT (1997) Carbohydrate content and enzyme metabolism in developing canola siliques. Plant Physiol 114: 153-160. 
Kouchi H, Katsuhiko F, Katagiri H, Minamisawa K, Tajima S (1988) Isolation and enzymological characterization of infected and uninfected cell protoplasts from root nodules of Glycine max. Physiol Plant 73: 327-334.

Krausgrill S, Greiner S, Kröger U, Vogel R, Rausch T (1998) In transformed tobacco cells the apoplasmic invertase inhibitor operates as a regulatory switch of cell wall invertase. Plant J 13: 275-280.

Kühn C, Franceschi VR, Schulz A, Lemoine R, Frommer WB (1997) Macromolecular trafficking indicated by localization and turnover of sucrose transporters in enucleate sieve elements. Science 275: 1298-1300.

Küster H, Frühling M, Perlick AM, Pühler A (1993) The sucrose synthase gene is predominantly expressed in the root nodule tissue of Vicia faba. Mol Plant-Microbe Interact 6: 507-514.

Kutschera U, Heiderich A (2002) Sucrose metabolism and cellulose biosynthesis in sunflower hypocotyls. Physiol Plant 114: 372-379.

Laemmli UK (1970) Cleavage of structural proteins during assembly of the head of bacteriophage T4. Nature 227: 680-685.

Laplaze L, Duhoux E, Franche C, Frutz T, Svistoonoff S, Bisseling T, Bogusz D, Pawlowski K (2000) Casuarina glauca prenodule cells display the same differentiation as the corresponding nodule cells. Mol Plant Microbe Interact 13:107-112.

Lechevalier MP, Lechevalier HA (1990) Systematics, isolation, culture of Frankia. In: The Biology of Frankia and Actinorhizal Plants, Schwintzer CR and Tjepkema JD, eds. (San Diego: Academic Press), pp 35-60.

Lerchl J, Geigenberger P, Stitt M, Sonnewald U (1995) Impaired photoassimilate partitioning caused by phloem-specific removal of pyrophosphate can be complemented by a phloem-specific cytosolic yeast-derived invertase in transgenic plants. Plant Cell 7: 259-270.

Liu Q, and Berry AM (1991) Localization and characterization of pectic polysaccharides in roots and root nodules of Ceanothus spp. during intercellular infection by Frankia. Protoplasma 164: 93-101.

Lo Bianco R, Rieger M (2002) Partitioning of sorbitol and sucrose catabolism within peach fruit. J Amer Soc Hortic Sci127:115-121.

Ludwig A, Stolz J, Sauer N (2000) Plant sucrose-H+ symporters mediate the transport of vitamin H. Plant J 24: 503-509.

Lullien V, Barker DG, Lajudie P, Huguet T (1987) Plant gene expression in effective and ineffective root nodules of alfalfa (Medicago sativa). Plant Mol Biol 9: 469-478.

Marger MD, Saier MH Jr (1993) A major superfamily of transmembrane facilitators that catalyze uniport, symport and antiport. Trends Biochem Sci 18: 13-20.

McElfresh KC, Chourey PS (1988) Anaerobiosis induces transcription but not translation of sucrose synthase in maize. Plant Physiol 87: 542-546.

Meade HM, Long SR, Ruvkun GB, Brown SE, Ansubel FM (1982) Physical and genetic characterization of symbiotic and auxotrophic mutants of Rhizobium meliloti induced by transposon Tn5 mutagenesis. J Bacteriol 149:114-122.

Meesters TM, Genesen ST, Akkermans ADL (1985) Growth, acetylene reduction activity and localization of nitrogenase in relation to vesicle formation in Frankia strains Cc1.17 and Cp1.2. Arch Microbiol 143: 137-142.

Miller IM, Baker DD (1985) The initiation, development and structure of root nodules in Elaeagnus angustifolia L. (Elaeagnaceae). Protoplasma 128: 107-119. 
Minchin FR (1997) Regulation of oxygen diffusion in legume nodules. Soil Biol Biochem 29: 881-888.

Mirza MS, Hahn D, Dobritsa SV, Akkermans ADL (1994) Phylogenetic studies on uncultured Frankia populations in nodules of Datisca cannabina. Can J Microbiol 40: 315-318.

Mullis KB, Faloona FA (1987) Specific synthesis of DNA in vitro via a polymerasecatalysed chain reaction. Methods Enzymol 155: 335-350.

Murry MA, Zhongze Z, Torrey JG (1985) Effect of $\mathrm{O}_{2}$ on vesicle formation, acetylene reduction, and $\mathrm{O}_{2}$-uptake kinetics in Frankia sp. HFPCcl3 isolated from Casuarina cunninghamiana. Can J Microbiol 31: 804-809.

Mylona P, Pawlowski K, Bisseling T (1995) Symbiotic nitrogen fixation. Plant Cell 7: 869-885.

Nakai T, Konishi T, Zhang X-Q, Chollet R, Tonouchi N, Tsuchida T, Yoshinaga F, Mori H, Sakai F, Hayashi T (1998) An increase in apparent affinity for sucrose of mung bean sucrose synthase is caused by in vitro phosphorylation or directed mutagenesis of Ser ${ }^{11}$. Plant Cell Physiol 39: 1337-1341.

Newcomb W (1981) Nodule morphogenesis and differentiation. Int Rev Cytol Suppl 13: S247-S297.

Newcomb W, Wood SM (1987) Morphogenesis and fine structure of Frankia (Actinomycetales): The microsymbiont of nitrogen-fixing actinorhizal root nodules. Int Rev Cytol 109: 1-88.

Nguyen-Quoc B, Foyer CH (2001) A role of "futile cycles" involving invertase and sucrose synthase in sucrose metabolism of tomato fruit. J Exp Bot 52: 881-889.

Nguyen-Quoc B, Krivitzky M, Huber SC, Lecharny A (1990) Sucrose synthase in developing maize leaves. Regulation of activity by protein level during the import to export transition. Plant Physiol 94: 516-523.

Nicholas KB, Nicholas HB Jr, Deerfield DW (1997) GeneDoc: Analysis and Visualization of Genetic Variation. EMBnet.NEWS 4: 14.

Nolte KD, Koch KE (1993) Companion-cell specific localization of sucrose synthase in zones of phloem loading and unloading. Plant Physiol 101: 899-905.

Normand P, Orso S, Cournoyer B, Jeannin P, Chapelon J, Dawson J, Evtushenko L, Misra AK (1996) Molecular phylogeny of the genus Frankia and related genera and emendation of the family Frankiaceae. Int J Syst Bacteriol 46: 1-9.

N'tchobo H, Dali N, Nguyen-Quoc B, Foyer CH, Yelle S (1999) Starch synthesis in tomato remains constant throughout fruit development and is dependent on sucrose supply and sucrose activity. J Exp Bot 50: 1457-1463.

Okubara PA, Pawlowski K, Murphy TM, Berry AM (1999) Symbiotic root nodules of the actinorhizal plant Datisca glomerata express Rubisco activase mRNA. Plant Physiol 120: 411-420.

Parsons R, Silvester WB, Harris S, Gruijters WTM, Bullivant S (1987) Frankia vesicles provide inducible and absolute protection for nitrogenase. Plant Physiol 83: 728731.

Pate JS, Gunning BES, Briarty LG (1969) Ultrastructure and functioning of the transport system of the leguminous root nodule. Planta 85: 11-34.

Patrick JW (1997) Phloem unloading: sieve element unloading and post-sieve element transport. Annu Rev Plant Physiol Plant Mol Biol 48: 191-222. 
Patrick JW, Zhang W, Tyerman SD, Offler CE, Walker NA (2001) Role of membrane transport in phloem translocation of assimilates and water. Aust J Plant Physiol 28: 695-707.

Pawlowski K (2002) Actinorhizal symbioses. In: Nitrogen Fixation at the Millenium; Leigh GJ (ed), Elsevier Science, Pergamon Press, Amsterdam, in press.

Pawlowski K, Bisseling T (1996) Rhizobial and actinorhizal symbioses: What are the shared features? Plant Cell 8: 1899-1913.

Pawlowski K, Swensen SM, Guan C, Hadri A-E, Berry AM, Bisseling T (2002) Distinct patterns of symbiosis-related gene expression and metabolic specialization in actinorhizal nodules from different plant families. Mol Plant-Microbe Interact, submitted.

Pharr DM, Hendrix DL, Robbins NS, Gross KC and Sox HN (1987) Isolation of galactinol from leaves of Cucumis sativus. Plant Sci 50:21-26.

Pradel KS, Ullrich Cl, Santa Cruz S, Oparka KJ (1999) Symplastic continuity in Agrobacterium tumefaciens-induced tumors. J Exp Bot 50: 183-192.

Pueppke SG, Broughton WJ (1999) Rhizobium sp. strain NGR234 and R. fredii USDA257 share exceptionally broad, nested host ranges. Mol Plant Microbe Interact 12: 293-318.

Racette S, Torrey JG (1989) Root nodule initiation in Gymnostoma (Casuarinaceae) and Shepherdia (Elaeagnaceae) induced by Frankia strain HFPGpl1 Can J Bot 67: 2873-2879.

Reinefeld E, Emmerich A, Burba M, Possiel M (1986) Evaluation of sugarbeet quality in terms of corrected sugar content, particularly for evaluation of the importance of classes of involved substances. Zuckerindustrie, 111, 730-738.

Renz A, Stitt M (1993) Substrate specificity and product inhibition of different forms of fructokinases and hexokinases in developing potato tubers. Planta 190: 166-175.

Ribeiro A, Akkermans ADL, van Kammen A, Bisseling T, Pawlowski K (1995) A nodule-specific gene encoding a subtilisin-like protease is expressed in early stages of actinorhizal nodule development. Plant Cell 7: 785-794.

Riens B, Lohaus G, Winter H, Heldt WH (1994) Production and diurnal utilization in leaves of spinach (Spinacia oleracea L.) and barley (Hordeum vulgare L.). Planta 192: 497-501.

Riesmeier JW, Willmitzer L, Frommer WB (1992) Isolation and characterization of a sucrose carrier cDNA from spinach by functional expression in yeast. EMBO $\mathrm{J} 11$ : 4705-4713.

Roitsch T, Bittner M, Godt DE (1995) Induction of apoplastic invertase of Chenopodium rubrum by D-glucose and a glucose analog and tissue-specific expression suggest a role in sink-source regulation. J Plant Physiol 108: 285-294.

Roitsch T, Tanner W (1994) Expression of a sugar transporter gene family in a photoautotrophic suspension culture of Chenopodium rubrum L. Planta 193: 365371.

Romanov VI, Gordon AJ, Minchin FR, Witty JF, Skøt L, James CL, Borisov AY, Tikhonovich IA (1995) Anatomy, physiology and biochemistry of Sprint-2 Fix-a symbiotically defective mutant of pea (Pisum sativum L.) J Exp Bot 46: 1809-1816.

Ross HA, Davies HV (1992) Purification and characterization of sucrose synthase from the cotyledons of Vicia faba L. Plant Physiol 100: 1008-1013.

Rost B, Casadio R, Fariselli P, Sander C (1995) Transmembrane helices predicted at 95\% accuracy. Protein Sci 4: 521-533. 
Rost B, Fariselli P, Casaido R (1996) Topology prediction for helical transmembrane proteins at 86\% accuracy. Protein Science, 5:1704-1718.

Roth LF, Stacey G (1989) Bacterium release into host cells of nitrogen-fixing soybean nodules: the symbiosome membrane comes from three sources. Eur $\mathrm{J}$ Cell Biol 49: 13-23.

Rouhier H, Usuda H (2001) Spatial and temporal distribution of sucrose synthase in the radish hypocotyls in relation to thickening growth. Plant Cell Physiol 42: 583-593.

Roychoudhury R, Jay E, Wu, R (1976) Terminal labelling and addition of homopolymer tracts to duplex DNA fragments by terminal deoxynucleotidyl transferase. Nucleic Acids Res 3: 863-877.

Rozenkranz H, Vogel R, Greiner S, Rausch T (2001) In wounded sugar beet (Beta vulgaris L.) tap-root, hexose accumulation correlates with the induction of a vacuolar invertase isoform. J Exp Bot 52: 2381-2385.

Ruan Y-L, Chourey PS, Delmer DP, Perez-Grau L (1997) The differential expression of sucrose synthase in relation to diverse patterns of carbon partitioning in developing cotton seed. Plant Physiol 115: 375-385.

Ruan Y-L, Patrick JW (1995) The cellular pathway of post-phloem sugar transport in developing tomato fruit. Planta 196: 434-444.

Saftner RA, Daie J, Wyse RE (1983) Sucrose uptake and compartmentation in sugar beet taproot tissue. Plant Physiol 72: 1-6.

Sambrook J, Fritsch EF, Maniatis T (1989) Molecular cloning: A laboratory manual. Second edition (New York: Cold Spring Harbor).

Sander A, Krausgrill S, Greiner S, Weil M, Rausch T (1996) Sucrose protects cell wall invertase but not vacuolar invertase against proteinaceous inhibitors. FEBS Lett 385: 171-175.

Sauer N, Baier K, Gahrtz M, Stadler R, Stolz J, Truernit E (1994) Sugar transport across the plasma membranes of higher plants. Plant Mol Biol 26: 1671-1679.

Sauer N, Friedländer K, Gräml-Wicke U (1990) Primary structure, genomic organization and heterologous expression of a glucose transporter from Arabidopsis thaliana. EMBO J 9: 3045-3050.

Sauer N, Stadler R (1993) A sink-specific $\mathrm{H}^{+} /$monosaccharide co-transporter from Nicotiana tabacum: cloning and heterologous expression in baker's yeast. Plant $\mathrm{J}$ 4: 601-610.

Sauer N, Stolz J (1994) SUC1 and SUC2: two sucrose transporters from Arabidopsis thaliana; expression and characterization in baker's yeast and identification of the histidine-tagged protein. Plant J 6: 67-77.

Sauer N, Stolz J (2000) Expression of foreign transport protein in yeast. In: Membrane transport. A practical approach (Oxford: Oxford University Press), 79-105.

Sauer N, Tanner W (1989) The hexose carrier from Chlorella. cDNA cloning of a eucariotic $\mathrm{H}^{+}$cotransporter. FEBS Lett 258: 43-36.

Sauer N, Tanner W (1993) Molecular biology of sugar transporters in plants. Bot Acta 106: $277-286$.

Schaffer AA, Petreikov M (1997) Inhibition of fructokinase and sucrose synthase by cytological levels of fructose in young tomato fruit undergoing transient accumulation of starch. Physiol Plant 101: 800-806.

Selker JML, Newcomb EH (1985) Spatial relationships between uninfected and infected cells in root nodules of soybean. Planta 165: 446-454. 
Senser M, Kandler O (1967) Vorkommen und verbreitung von galactinol in blättern höherer pflanzen. Phytochemistry 7: 1533-1540.

Serrano R, Kielland-Brandt MC, Fink GR (1986) Yeast plasma membrane ATPase is essential for growth and has homology with $\left(\mathrm{Na}^{+}+\mathrm{K}^{+}\right), \mathrm{K}^{+}-$and $\mathrm{Ca}^{2+}$-ATPases. Nature 319: 689-693.

Shakya R, Sturm A (1997) Characterization of source and sink specific sucrose $/ \mathrm{H}^{+}$ symporters from carrot. Plant Physiol 118: 1473-1480.

Shaw VK, Brill WJ (1977) Isolation of an iron-molybdenum cofactor from nitrogenase. Proc Natl Acad Sci USA 74: 1493-1497.

Silvester WB, Langenstein B, Berg RH (1999) Do mitochondria provide the oxygen diffusion barrier in root nodules of Coriaria and Datisca? Can J Bot 77: 1358-1366.

Skøt L, Egsgaard H (1984) Identification of ononitol and O-methyl-scyllo-inositol in pea root nodules. Planta 161: 32-36.

Smith AE, Phillips DV (1980) Occurrence of pinitol in foliage of several forage legume species. Crop Sci 20: 75-77.

Smith SE, Dickson S, Smith FA (2001) Nutrient transfer in arbuscular mycorrhizas: how are fungal and plant processes integrated? Aust J Plant Physiol 28: 685-696.

Soltis DE, Soltis PS, Morgan DR, Swensen SM, Mullin BC, Dowd JM, Martin PG (1995) Chloroplast gene sequence data suggest a single origin of the predisposition for symbiotic nitrogen fixations in angiosperms. Proc Natl Acad Sci USA 92: 2647-2651.

Sonnewald U, Willmitzer L (1992) Molecular approaches to sink-source interactions. Plant Physiol 99: 1267-1270.

Stadler R, Brandner J, Schulz A, Gahrtz M, Sauer N (1995) Phloem loading by the PmSUC2 sucrose carrier from Plantago major occurs into companion cells. Plant Cell 7: 1545-1554.

Stitt M, Sonnewald U (1995) Regulation of metabolism in transgenic plants. Annu Rev Plant Physiol Plant Mol Biol 46: 341-368.

Stolz J, Stadler R, Opekarová M, Sauer N (1994) Functional reconstitution of the solubilized Arabidopsis thaliana STP1 monosaccharide- $\mathrm{H}^{+}$symporter in lipid vesicles and purification of the histidine tagged protein from transgenic Saccharomyces cerevisiae. Plant Journal 6: 225-233.

Streeter JG (1995) Recent developments in carbon transport and metabolism in symbiotic systems. Symbiosis 19: 175-196.

Sturm A (1996) Molecular characterization and functional analysis of sucrose cleaving enzymes in carrot (Daucus carota L.). J Exp Bot 47: 1187-1192.

Sturm A (1999) Invertases. Primary structures, functions, and roles in plant development and sucrose partitioning. Plant Physiol 121: 1-7.

Sturm A, Chrispeels MJ (1990) cDNA cloning of carrot extracellular $\beta$-fructosidase and its expression in response to wounding and bacterial infection. Plant Cell 2: 11071119.

Sturm A, Šebková V, Lorenz K, Hardegger M, Lienhard S, Unger C (1995) Development- and organ-specific expression of the $\beta$-fructofuranosidase in carrot. Planta 195: 601-610.

Sturm A, Tang GQ (1999) The sucrose-cleaving enzymes of plants are crucial for development, growth and carbon partitioning. Trends in Plant Science 4: 401-407. 
Sung S-JS, Xu D-P, Black CC (1989) Identification of actively filling sucrose sinks. Plant Physiol 89: 1117-1121.

Swensen S (1996) The evolution of actinorhizal symbioses: Evidence for multiple origins of the symbiotic association. Am J Bot 83: 1503-1512.

Taliercio EW, Chourey PS (1989) Posttranscriptional control of sucrose synthase expression in anaerobic seedlings of maize. Plant Physiol 90:1359-1364.

Tang XR (2002) Intrinsic change of physical and chemical properties of sea buckthorn (Hippophae rhamnoides) and implications for berry maturity and quality. J Hortic Sci Biotech 77:177-185.

Tartof KD, Hobbs CA (1987) Improved media for growing plasmid and cosmid clones. Bethesda Res Lab Focus 9: 12.

Thummler F, Verma DPS (1987) Nodulin-100 of soybean ist the subunit of sucrose synthase regulated by the availability of free heme in nodules. J Biol Chem 262: 14730-14736.

Topfer R, Maas C, Horicke-Grandpierre C, Schell J, Steinbiss HH (1993) Expression vectors for high-level gene expression in dicotyledonous and monocotyledonous plants. Methods Enzymol 217:67-78.

Torrey JG (1976) Initiation and development of root nodules of Casuarina (Casuarinaceae). Amer J Bot 63: 335-344.

Truchet G, Barker DG, Calmut S, de Billy F, Vasse J, Huguet T (1989) Alfalfa nodulation in the absence of Rhizobium. Mol Gen Genet 219: 65-68.

Truernit E, Sauer N (1995) The promoter of the Arabidopsis thaliana SUC2 sucrose- $\mathrm{H}^{+}$ symporter gene directs expression of $\beta$-glucuronidase to the phloem: Evidence for phloem loading and unloading by SUC2. Planta 196: 564-570.

Truernit E, Schmid J, Epple P, Illig J, Sauer N (1996) The sink-specific and stressregulated Arabidopsis STP4 gene: enhanced expression of a gene encoding a monosaccharide transporter by wounding, elicitors, and pathogen challenge. Plant Cell 8: 2169-2182.

Truernit E, Stadler R, Baier K, Sauer N (1999) A male gametophyte-specific monosaccharide transporter in Arabidopsis. Plant J 17: 191-201.

Tymowska-Lalanne Z, Kreis M (1998) Expression of the Arabidopsis thaliana invertase gene family. Planta 207: 259-265.

Van Larebeke N, Genetello C, Hernalsteen J, De Picker A, Zaenen I, Messens E, Van Montagu M, Schell J (1977) Transfer of Ti plasmids between Agrobacterium strains by mobilisation with conugative plasmid RP4. Mol Gen Genet 152: 119124.

Vance CP, Heichel GH (1991) Carbon in $\mathrm{N}_{2}$ fixation: limitation or exquisite adaptation. Annual Review of Plant Physiology \& Plant Molecular Biology 42: 329-392.

Vasse J, de Billy F, Camut S, Truchet G (1990) Correlation between ultrastructural differentiation of bacteroids and nitrogen fixation in alfalfa nodules. J Bacteriol 172: 4295-4306.

Verma DPS, Hong ZL (2001) Plant callose synthase complexes. Plant Mol Biol 47: 693701.

Viola R, Roberts AG, Haupt S, Gazzani S, Hancock RD, Marmiroli N, Machray GC, Oparka KJ (2001) Tuberization in potato involves a switch from apoplastic to symplastic phloem unloading. The Plant Cell 13: 385-398. 
Wabnitz P (1998) Untersuchung über die Verteilung von Zuckern in Stickstoff-fixierenden Wurzelknöllchen. Diploma thesis. Georg-August-University, Göttingen, Germany.

Walker NA, Patric JW, Zhang W, Fieuw S (1995) Identification and characterization of a phloem-specific $\beta$-amylase. Plant Physiol 109: 743-750.

Wall LG (2000) The actinorhizal symbiosis. J Plant Growth Regul 19: 167-182.

Weber H, Borisjuk L, Wobus U (1996) Controlling seed development and seed size in Vicia faba: A role for seed coat-associate invertases and carbohydrate state. Plant J 10: 101-112.

Weber H, Borisjuk L, Heim U, Sauer N, Wobus U (1997) A role for sugar transporters during seed development: molecular characterization of a hexose transporter and a sucrose carrier in Vicia faba. Plant Cell 9: 895-908.

Weig A, Franz J, Sauer N, Komor E (1994) Isolation of a family of cDNA clones from Ricinus communis $\mathrm{L}$. with close homology to the hexose carriers. J Plant Physiol 143: 178-183.

Weil M, Krausgrill S, Schuster A, Rausch T (1994) A 17-kDa Nicotiana tabacum cellwall peptide acts as an in-vitro inhibitor of the cell wall isoform of acid invertase. Planta 193: 438-445.

Whitehead LF, Tyermann SD, Salom CL, Day DA (1995) Transport of fixed nitrogen across symbiotic membranes of legume nodules. Symbiosis 19: 141-154.

Wieczorke R, Krampe S, Weierstall T, Freidel K, Hollenberg CP, Boles E (1999) Concurrent knock-out of at least 20 transporter genes is required to block uptake of hexoses in Saccharomyces cerevisiae. FEBS Lett 464:123-128.

Wieczorke R, Krampe S, Weierstall T, Freidel K, Hollenberg CP, Boles E (1999) Concurrent knock-out of at least 20 transporter genes is required to block uptake of hexoses in Saccharomyces cerevisiae. FEBS Lett 464: 123-128.

Williams LE, Lemoine R, Sauer N (2000) Sugar transporters in higher plants - a diversity of roles and complex regulation. Trends Plant Sci 5: 283-290.

Winter H, Huber JL, Huber SC (1997) Membrane association of sucrose synthase: changes during the graviresponse and possible control by protein phosphorylation. FEBS Lett 420:151-155.

Winter H, Huber JL, Huber SC (1998) Identification of sucrose synthase as an actinbinding protein. FEBS Lett 430: 205-208.

Winter H, Huber SC (2000) Regulation of sucrose metabolism in higher plants: Localization and regulation of activity of key enzymes. Crit Rev Plant Sci 19: 3167.

Wisniewski J-P, Rathbun EA, Knox JP, Brewin NJ (2000) Involvement of diamine oxydase and peroxidase in insolubilization of the extracellular matrix: implications for pea nodule initiation by Rhizobium leguminosarum. Mol Plant-Microbe Interact 13: 413-420.

Woodcock DM, Crowther PJ, Doherty J, Jefferson S, Decruz E, Noyer C, Weidner M, Smith SS, Michael MZ, Graham MW (1989) Quantitative evaluation of Escherichia coli host strains for tolerance to cytosine methylation in plasmid and phage recombinants. Nucleic Acids Res 17: 3469-3478.

Xu D-P, Sung S-J, Loboda T, Komarnik PP, Black CC (1989) Characterization of sucrolysis via the uridine diphosphate and pyrophosphate-dependent sucrose synthase pathway. Plant Physiol 90: 635-642. 
Xu J, Avigne WT, McCarty DR, Koch K (1996) A similar dichotomy of sugar modulation and developmental expression affects both path of sucrose metabolism: evidence from a maize invertase gene family. Plant Cell 8: 1209-1220.

Yasuda T, Nakagawa H (1994) Purification and characterization of the rutin-degrading enzymes in tartary buckwheat seeds. Phytochemistry 37: 133-136.

Zamski E, Schaffner AA (1996) Photoassimilates distribution in plants and crops: source-sink relationships (New York: Marcel Decker).

Zapesochnaya GG and Pangarova TT (1976) Structure of flavonoids from Datisca cannabina L. Rastitelnye Resursy (in Russ) 12: 237-241.

Zeng S, Tjepkema JD, Berg RH (1989) Gas diffusion pathway in nodules of Casuarina cunninghamiana. Plant Soil 118: 119-123.

Zhang WH, Tyerman SD (1997) Effect of low oxygen concentration on the electrical properties of cortical cells of weat roots. J Plant Physiol 150: 567-572.

Zimmermann MH, Ziegler H (1975) List of sugars and sugar alcohols in sieve-tube exudates. In: Transport in Plants, Encyclopedia of Plant Physiology, New Series Vol.1 I. Phloem Transport, MH Zimmermann and JA Milburn, eds. (New York: Springer-Verlag), pp 245-271. 


\section{Danksagung}

Frau Dr. Katharina Pawlowski danke ich, dass ich dieses spannende Projekt übernehmen konnte und sie mich bei meiner Dissertation stets unterstützte. Dabei halfen mir ihre umfangreichen praktischen und theoretischen Erfahrungen, meine wissenschaftlichen Kenntnisse zu erweitern.

Prof. Dr. Hans-Walter Heldt danke ich für die Möglichkeit, die Arbeit in seiner Abteilung durchführen zu können und für seine kritischen Kommentare.

Bei Frau PD Dr. Gertrud Lohaus bedanke ich mich für die Unterstützung bei allen HPLCAnalysen.

Frau Prof. Renate Scheibe, Dr. Heike Winter und Daniela Holtgräwe von der Universität Osnabrück bin ich sehr dankbar für die Einführung in die SaccharosesynthaseAktivitätsmessungen.

Prof. Dr. Norbert Sauer und Dr. Michael Büttner danke ich für die Möglichkeit, die HexosenAufnahmetests an der Universität Erlangen durchführen zu können, und ihre Unterstützung bei den Experimenten.

Prof. Dr. Lutz Tietze und Dr. Rocco Fortte vom Institut für Organische Chemie in Göttingen möchte ich danken für die NMR-Analyse und Strukturaufklärung von bis dahin unbekannten Zuckern aus Datisca.

Frau Prof. Dr. Christiane Gatz bin ich sehr dankbar für die Übernahme des Korreferates sowie dafür, dass ich jederzeit die Geräte ihrer Abteilung benutzen durfte. Den Mitarbeitern der Abteilung Gatz danke ich für ihre Hilfsbereitschaft.

Prof. Dr. Dieter Heineke, Frau Dr. Sigrun Reumann, Dr. Christian Knop und Jens Tilsner danke ich für die guten praktischen Ratschläge bei der täglichen Laborarbeit und die kritische Durchsicht meiner Dissertation.

Allen Kollegen aus der Abteilung Biochemie der Pflanze, besonders Anne Brandeck, Andrea Nickel, Monika Raabe, Melanie Hußmann, Dr. Michaela Strauß, Dr. Olga Voitsekhovskaja, Dr. Kirill Demchenko, Dr. Anke Sirrenberg und Anita Stottmeister möchte ich danken für ihre große Hilfsbereitschaft bei allen meinen Fragen und für das angenehme Arbeitsklima. 
Herrn Uwe Wedemeyer danke ich für die sorgfältige Betreuung meiner Pflanzen und Herrn Gerd Mader für die Hilfe bei allen technischen Problemen.

Meinen Eltern möchte ich herzlich danken für ihre große Unterstützung meiner Promotion in Deutschland.

Meinem Mann Marcel danke ich von ganzem Herzen für seine Geduld und für sein freundliches Warten auf den Abschluss meiner Promotion sowie sein Verständnis und seinen Trost in schwierigen Situationen. 


\section{Lebenslauf}

09.01.1975

1982-1992

Juni 1992

1992-1996

Juni 1996

Juni 1996-November 1998

November 1998

Januar-April 1999

Ab Juni 1999 geboren in Leningrad (Russland),

Staatsangehörigkeit: russisch

Mittelschule Nr. 98 St. Petersburg

Abschlußzeugnis

Biologiestudium an der Universität St. Petersburg

Qualifikationsgrad: Bakkalaureus der Biologie mit der Qualifikationsabschlussarbeit zum Thema:

„Benutzung von Baitan für die Selektion von

Tomatenpflanzen mit verändertem

Isoprenoidmetabolismus“ unter Anleitung von

Dr. L.T. Khodjajova

Biologiestudium (Hauptfach: Genetik, Aufbaustudium für Magister-Grad) an der Universität St. Petersburg Magisterarbeit über: „Erzeugung einer Form von Tomaten (Lycopersicon esculentum L.) mit unspezifischer Resistenz gegen den Phitophtoroseerreger Phytophthora infestans" in der Arbeitsgruppe von Prof. Dr. L.A. Lutova

Akademischer Grad: Magister der Biologie

Promotionsstudium an der Universität St. Petersburg (Fortsetzung des Themas der Magisterarbeit)

Promotionsstudium an der Universität Göttingen Abteilung Prof. Dr. H.-W. Heldt, in der Arbeitsgruppe von Dr. K.Pawlowski, Projekt „Zuckerverteilung in Stickstofffixierenden Wurzelknöllchen“ 